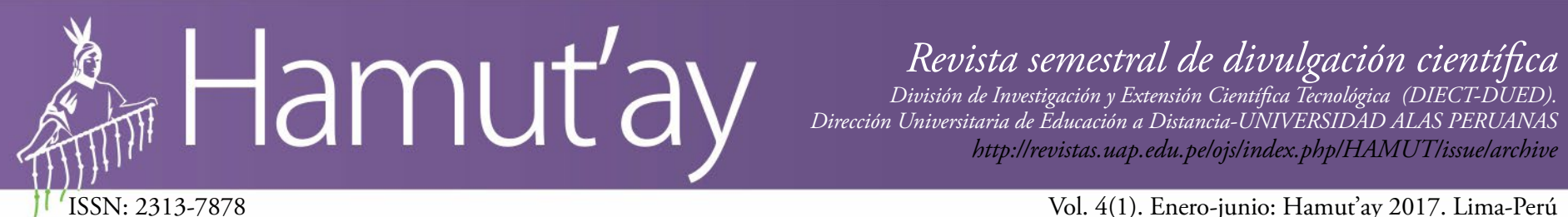
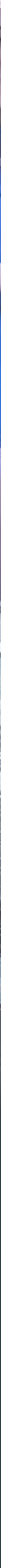


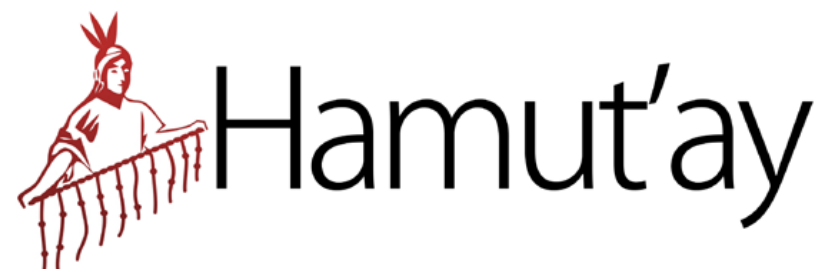

Revista semestral de divulgación científica publicada por la División de Investigación y Extensión Científica Tecnológica (DIECT-DUED) de la Dirección Universitaria de Educación a Distancia. Universidad Alas Peruanas. Lima, Perú.

Título clave: Hamut'ay
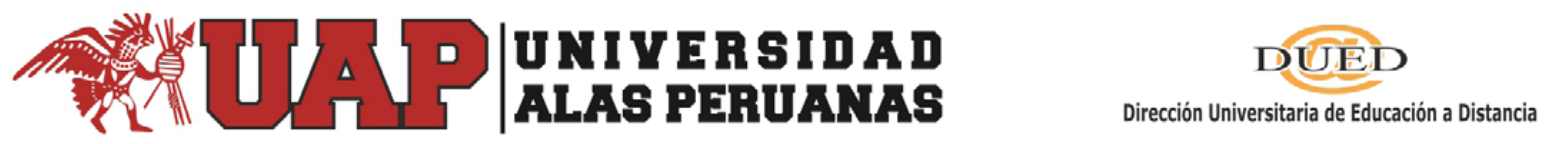

http://revistas.uap.edu.pelojs/index.php/HAMUT/issue/archive correo electrónico: revistahamutay@uap.edu.pe 
UNIVERSIDAD ALAS PERUANAS

Fidel Ramirez Prado Phd. Rector

Dr. Enrique Bedoya Sánchez Vicerrector Académico

Dr. Manuel Coronado Aguilar

Vicerrector Administrativo

Dr. Jorge Lazo Arrasco

Vicerrector de Investigacion e Innovación Tecnológica

Dr. José Soberon Bolaños

Vicerrector de Planificación y Economía

Dra. Rosabel Alarcón Ramírez

Directora, Dirección Universitaria de

Educación a Distancia

EDITOR EN JEFE

Dra. Cleofé Genoveva Alvites Huamaní

Universidad Alas Peruanas, Perú

EDITOR INVITADO

Dra. Esperanza Guarneros Reyes

Universidad Nacional Autónoma de México

CONSEJO EDITORIAL

Dra. Constanza Abadia Garcia

Universidad Nacional Abierta a Distancia, Colombia

Dra. Cynthia Zaira Vega Valero

Universidad Nacional Autónoma de México

Dr. Pere Marqués Graells

Universidad Autónoma de Barcelona, España

Dr. Ramfis Miguelena

Universidad Tecnológica de Panamá

Dr. Jaime Ramírez

Universidad Politécnica de Madrid, Espańa

Dr. José Ernesto Mancera Pineda

Universidad Nacional de Colombia

Dr. Philip Desenne

Harvard University, EE. UU.

Dr. Pedro Agustín Pernías Peco

Universidad de Alicante, España

M.Sc. Plinio Puello Marrugo

Universidad de Cartagena, Colombia

Ing. David Antonio Franco Borré

Universidad de Cartagena, Colombia
Vol. 4(1). Enero-junio: Hamut’ay 2017. Lima-Perú

\section{COMITÉ EDITORIAL}

Dr. Pedro Martínez Geijo

Universidad Nacional de Educación a Distancia, España

Miguel Ángel García-Ruiz, PhD.

Algoma University, Canadá

Adriana P. Herrera. PhD.

Universidad de Cartagena, Colombia

Dr. Arturo Silva Rodríguez

Universidad Nacional Autónoma de México

Dra. Sonia Concari

Universidad Nacional de Rosario, Argentina

Dr. Omar O. López Sinisterra

Universidad de Panamá, Panamá

Maestro Óscar Pérez Mora

Universidad de Guadalajara, México

M.D.C. Martha Amalia Ávalos Medina

Jefa, Educación Superior del Estado de Michoacán, México

Lilian R. Daset, Ph.D.

Universidad Católica del Uruguay, Uruguay

Dr. Miguel Angel Vargas-Lombardo

Universidad Tecnológica de Panamá

Ing. Katia Ruiz

Universidad Alas Peruanas, Perú

Ing. Ana Contreras

Universidad Alas Peruanas, Perú

Mag. Liliana Larrea

Universidad Alas Peruanas, Perú

SOPORTE TÉCNICO

Mg. Jorge Olaya Rodríguez

DIAGRAMACIÓN Y ARTES FINALES

Ing. Víctor Raúl Millán Salazar

CORRECCIÓN DE ESTILO

Dr. Oscar Melanio Dávila Rojas

TRADUCCIÓN

Mg. Magaly Ugarte Sebastián

\section{DIRECCIÓN}

Calle Los Lirios 144 San Isidro, Lima, Perú. Teléfono 422-1808, Anexo 27

http://revistas.uap.edu.pe/ojs/index.php/HAMUT/issue/archive Email: revistahamutay@uap.edu.pe

\section{REVISTA ARBITRADA}

Se permite la copia y distribución por cualquier medio siempre que se mantenga el reconocimiento de los autores y no se realice modificaciones.

Los artículos publicados expresan las opiniones personales de sus autores y no necesariamente las de la Universidad Alas Peruanas. 


\section{Índice}

Editorial

Vol. 4(1). Enero-junio: Hamut’ay 2017. Lima-Perú

Importancia de las tecnologías en los trabajos de investigación: Una experiencia en los estudiantes de Licenciatura, Área EconómicoAdministrativa de la Universidad Veracruzana- México Importance of technologies in research work: An experience in students enrolled in a graduate degree program at the Economics-Administrative Area of the Universidad Veracruzanda, Mexico

Herramientas TIC en el área de Matemática: Caso Escuela PopUp, Piura-Perú

ICT tools in learning in the Mathematics area: Case PopUp School, PiuraPeru

La evaluación de la educación a distancia. Propuesta de una guía para la autoevaluación

Assessment in distance education. A proposal of a guide for self-evaluation

Ambiente virtual de aprendizaje para la capacitación tipo Inducción, sobre contenidos estratégicos y misionales dirigido a colaboradores del ICBF

Virtual learning environment for the induction training on mission and strategic content addressed to collaborators from the Instituto Colombiano de Bienestar Familiar - ICBF

Redes Sociales, Facebook y Blog según los estilos de aprendizaje en Cursos E-Learning Social networking sites, Facebook and Blog according to learning styles in e-learning courses

La práctica supervisada mediada por tecnología como escenario para la Enseñanza de Competencias Clínicas

The supervised practice technology-mediated as a scenario for clinical skills training

Los Recursos tecnológicos como soporte para la enseñanza de las Ciencias Naturales Technological resources as support in natural sciences teaching 


\section{Editorial}

Cita recomendada: Alvites-Huamaní, C. (2017) Las Mujeres en la investigación. Hamut'ay, 4 (1), 6. Recuperado de: http://doi.org/10.21503/hamu.v4i1.1401

\section{Las mujeres en la investigación}

Desde que la mujer inició su participación en la sociedad en el año 1955, permitiéndosele emitir su voto electoral, ha incursionado en diversos campos de la actividad social. Desde entonces ha superado muchos obstáculos hasta ganar protagonismo y el reconocimiento a su innegable capacidad en muchas actividades que antes solo podían considerarse de competencia masculina. Su persistencia, el deseo de superación constante y la lucha permanente contra los prejuicios y las viejas ataduras sociales la han llevado a destacar en distintos campos profesionales: educación, política, economía, ciencia, tecnología e investigación. Su incursión en esta última es muy importante, porque contribuye a la modificación o generación de conocimiento como consecuencia de su interés por la solución de problemas de distinta índole.

En la actualidad, las mujeres se han ganado el reconocimiento de las comunidades académicas de distintas latitudes y ocupan un lugar privilegiado en el desarrollo de la cultura, la ciencia y el conocimiento mundial.

Específicamente, el avance notorio en la apropiación de las tecnologías a nivel global ha incidido también en la divulgación, cada vez mayor, de los aportes de la mujer en la superación de problemas que reclaman soluciones inmediatas, como los de tipo educativo. No es extraño encontrarse en la revisión de la literatura científica con nombres de mujeres valiosas que han conseguido reconocimiento a nivel internacional por haber realizado investigaciones que en otros tiempos hubieran sido consideradas competencia exclusiva de los varones.

Es claro entonces que la mujer de estos tiempos ha vislumbrado que el desarrollo de un país se mide en función de los aportes investigativos de varo-

\section{Women in research}

Since women began their participation in society in 1955 , when it was allowed to them to vote on elections; women have accessed to different fields of social activity. Since then, women have overcome many obstacles to gain prominence and recognition of their undeniable capability in many activities that previously could only be considered of male competence. Their persistence, their desire for constant improvement and the permanent struggle against prejudices and old social ties have led them to stand out in different professional fields: education, politics, economics, science, technology and research. Their incursion into the latter is very important, because it contributes to the modification or generation of knowledge as a consequence of their interest in solving problems of different nature.

Today, women have gained the recognition of academic communities from different latitudes and nowadays they have a prominent place in the development of culture, science and world knowledge.

Specifically, the significant advance in the appropriation of technologies at a global level, has also affected the increasing dissemination of women's contributions in overcoming problems that demand immediate solutions, such as those related to education. When reviewing scientific literature, it is not strange to find names of valuable women who have gained international recognition for having carried out investigations that in other times would have been considered of exclusive competence of men.

It is clear then, that women of these times have noticed that the development of a country is measured in terms of the research contributions of men and women with entrepreneurship capacity 
nes y mujeres con capacidad de emprendimiento y que solo así se puede alcanzar la innovación, el conocimiento y, mediante estos, el desarrollo de la sociedad. Por ello, no se puede dejar de destacar la presencia de la mujer en cada uno de los ámbitos profesionales, empresariales, políticos, en la gestión pública, en la generación de ciencia, el desarrollo de la tecnología, la innovación constante o el emprendimiento de nuevos retos.

Este número de la revista Hamut'ay se propuso destacar la labor de la mujer Latinoamericana en la investigación en ingeniería y tecnología, las ciencias médicas y de la salud, las ciencias agrarias, sociales, naturales y las humanidades. Los artículos incluidos en esta edición se desarrollaron en las diferentes líneas de investigación a las que las mujeres se dedican. De esta manera se da tributo especial a todas las mujeres que, además de madres, esposas, hijas y hermanas, destinan su tiempo a la investigación y la divulgación del conocimiento, como parte de su desarrollo personal, profesional y laboral.

Se espera que el mérito científico de las mujeres incluidas en esta edición sirva como ejemplo y motivación para que las mujeres jóvenes que están en proceso de formación académica se entusiasmen e incursionen también con igual o mayor éxito en el apasionante mundo de la investigación científica. and that only in this way, we can achieve innovation and knowledge and, through them, the development of society. It is therefore undeniable, the presence of women in each of the professional, business and political fields, in the public management sector, in the generation of science, in technology development, in the constant innovation or in the entrepreneurship of new challenges.

This issue of the journal Hamut'ay has the purpose to highlight the work of Latin American women in engineering and technology research, medical and health sciences, agricultural, social and natural sciences and humanities. The articles included in this edition cover the different areas of research to which women dedicate themselves. In this way, special attention is given to all women who, in addition of being mothers, wives, daughters and sisters, spend their time researching and disseminating knowledge as part of their personal, professional and work development.

It is hoped that the scientific merit of the women included in this edition will serve as an example and motivation for young women who are in the process of academic formation, so that they become enthusiastic and get into this fascinating world of scientific research with equal or greater success.

\section{Dra. Cleofé Genoveva Alvites Huamaní Editor Jefe de la revista cientifica Hamut'ay / Editor in Chief of the Hamut'ay journal

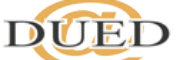 \\ Dirección Universitaria de Educación a Distancia}




\section{EDITORIAL}

Cita recomendada: Guarneros, E. (2017) La mujer en la ciencia Hamut'ay, 4 (1), 8. Recuperado de: http://doi.org/10.21503/hamu.v4i1.1402

\section{La mujer en la ciencia}

Los aportes que brindan la ciencia y la tecnología a nivel internacional para mejorar la calidad de vida y la situación económica, educacional, ambiental y de salud son amplios. Desde esta perspectiva, la mujer ya ha empezado a incursionar en estas líneas desde la vinculación con la investigación.

Si bien todavía existe una brecha considerable en la participación de la mujer en la sociedad, esta ha ido evolucionando y ganándose un lugar especial por los aportes que brinda al campo del conocimiento en la actualidad. Esto es nuevo, ya que la presencia de la mujer estuvo presente desde tiempos antiguos, aunque no se le reconocía el protagonismo que hoy tiene bien ganado. En este siglo XXI, vemos con beneplácito que la mujer juega un rol importante en las diversas esferas del quehacer académico.

Las mujeres que ejercen la docencia universitaria y se dedican a la investigación tienen la oportunidad de aprender y participar en proyectos académicos, de investigación e innovación educativa; trabajan con alumnos, colegas, hacen equipo con sus pares y generan proyectos. Algunas trabajan en laboratorios, dirigen revistas, realizan eventos académicos; varias de ellas dirán simplemente que les apasiona su trabajo. Además, han podido estudiar posgrados, obtener nombramientos en sus universidades que les permitieron alcanzar una mejor calidad de vida, sin asegurar qué tanto ha cambiado sus vidas, puesto que en cada país las condiciones en que se desenvuelven las mujeres científicas pueden variar. Lo cierto es que el trabajo que realizan las coloca en una posibilidad de vida diferente, con mayor esperanza que las niñas y mujeres que no cuentan con la posibilidad de estudiar.

Con la desigualdad entre hombres y mujeres, que aún existente en los países latinos y en todo el mundo, es necesario recordar en todo momento

\section{Women in science}

Contributions produced worldwide by science and technology in order to improve the quality of life as well as the economic, educational, environmental and health situations are significant. From this perspective, women have already begun to get involved in these issues due to their connection with research.

Although there is still a considerable gap in the participation of women in society, they have evolved and gained a special place due to the contributions they provide to the field of knowledge nowadays. This is recent, considering that the presence of women has existed since ancient times, although the prominence that women have today was not recognized at that time. In this twenty-first century, we welcome the fact that women play an important role in the various spheres of academic endeavors.

Women who are involved in university teaching and are dedicated to research, have the opportunity to learn and participate in academic, research and educational innovation projects. They work with students, colleagues, team up with their peers and make projects. Some women work in laboratories, run journals, conduct academic events; many of them will simply say that they are passionate about their work. In addition, they have been able to enroll in postgraduate studies, obtain their appointment at their universities, which provided them a better quality of life, without exactly knowing how much their lives have changed, since in each country conditions in which women scientists operate, can vary. The truth is that their work gives them a different possibility of life, unlike girls and women who do not have the possibility to study.

With the inequality between men and women, still present in Latin American countries and around the world, it is necessary not to forget that there is much to be done to achieve a more fair world in 
que hay mucho por hacer para alcanzar un mundo más justo en oportunidades, como por ejemplo el acceso a la ciencia y la participación activa en esta. La violencia contra las niñas y las mujeres o los techos de cristal del ámbito laboral no son fenómenos de los cuales el mundo universitario y científico esté exento. El mundo científico no es una esfera idealizada ejemplar de equidad de género; por eso, las mujeres y, sobre todo las más jóvenes, que nos dedicamos a la academia, debemos aprovechar nuestra posición para que se escuche nuestra voz, generar proyectos y practicar el trato de igualdad con nuestros estudiantes, compañeros y superiores, pero con mayor intensidad con las colegas. Por tanto, es necesario modelar el respeto, el valor y reconocimiento a la creatividad, originalidad e iniciativa de las estudiantes, docentes, investigadoras, dirigentes académicas mujeres. También se debe propiciar iniciativas que permitan a un mayor número de mujeres estudiar posgrados y formar parte del círculo científico. Esto es indispensable para la calidad de vida de cada una, pero también es un beneficio para todos, para la comprensión, explicación y resolución de problemas, porque las mujeres deben contar con perspectivas que aborden la realidad para estudiarla y encontrar soluciones a los problemas latentes.

Aprovecho el escenario de colaboración que ofrece la revista Hamut'ay, dirigida por una mujer dedicada a la ciencia y la tecnología, para invitar a las mujeres dedicadas al quehacer académico y científico a que, desde nuestras universidades y centros de investigación, recuerden que aún somos pocas las que estamos en este camino y que nuestras actitudes y acciones con nuestras pares y estudiantes pueden abrir o cerrar escenarios de oportunidad.

Más allá de reconocer la desigualdad de oportunidades que aún existe, las mujeres debemos tener en cuenta que somos diferentes sí, pero tenemos las mismas posibilidades de desarrollo profesional que los varones y, como investigadoras, debemos buscar el bien común, que también es nuestra responsabilidad. terms of opportunities, such as the access and the active participation in science. Violence against gir$1 s$ and women or glass ceilings in the workplace are not phenomena of which the university and scientific world is exempt from. The scientific world is not an idealized exemplary sphere of gender equity; that is why women, and especially the younger ones, who dedicate ourselves to the academy, must take advantage of our position so that our voice is heard, bring about projects and practice equality with our students, colleagues and superiors, but with greater intensity with colleagues. Therefore, it is necessary to model the respect, value and recognition to the creativity, originality and initiative of the students, teachers, researchers and female academic leaders. Initiatives should also be encouraged to enable more women to study postgraduate courses and be part of the scientific circle. This is indispensable for the quality of life of each one, but it is also a benefit for everyone, for understanding, explaining and solving problems, because women must have perspectives that address reality to study it and find solutions to latent problems.

I take advantage of the collaborative scenario offered by the journal Hamut'ay, directed by a woman dedicated to science and technology, to invite women dedicated to the academic and scientific work to remember, from our universities and research centers, that we are still a few in this path and our attitudes and actions with our peers and students can open or close opportunity scenarios.

Beyond recognizing the inequality of opportunity that still exists, women must keep in mind that despite our difference, we have the same possibilities of professional development as men, and as researchers, we must seek the common good, which is also our responsibility.

\section{Dra. Esperanza Guarneros Reyes} Editor Invitado

Directora del Laboratorio Digital de Desarrollo Infantil (LDDI) Carrera de Psicologia - FES Iztacala SUAyED. Universidad Nacional Autónoma de México Guest Editor

Director of the Digital Laboratory of Child Development (DLCD). Career in Psychology - FES Iztacala SUAyED Universidad Nacional Autónoma de México

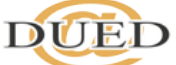

Dirección Universitaria de Educación a Distancia 


\title{
Importancia de las tecnologías en los trabajos de investigación: una experiencia en los estudiantes de licenciatura, área económico-administrativa de la Universidad Veracruzana- México
}

\section{Importance of Technologies in Research Work: An experience in students enrolled in a graduate degree program at the Economics-Administrative Area of the Universidad Veracruzana in Mexico}

\author{
Belinda Izquierdo García ${ }^{1}$ \\ Guadalupe Juárez Gómez ${ }^{2}$ \\ Beatriz Eugenia Salas Parada ${ }^{3}$ \\ Universidad Veracruzana, México
}

Recibido: 27-02 -2017

Aceptado: 29-05-2017

\section{Cita Recomendada}

Izquierdo, B., Juárez, G. y Salas, B. (2017) Importancia de las tecnologías en los trabajos de investigación: Una experiencia en los estudiantes de Licenciatura, Área económico-administrativa de la Universidad Veracruzana-México. Hamut'ay, 4 (1), 9-17. Recuperado de: http://doi.org/10.21503/ hamu.v4i1.1392

\section{RESUMEN}

Este artículo tiene como objetivo divulgar la experiencia relacionada con la utilización de las tecnologías en los procesos de investigación realizados por los estudiantes de Licenciatura. La temática tratada se relaciona con la importancia de las Tecnologías de la Información y la Comunicación (TIC) en los trabajos de investigación y la necesidad de identificar cuáles de ellas son las más utilizadas. Bajo estos términos se llevó a cabo el estudio con el método empírico, descriptivo, analítico y propositivo. La población objetivo estuvo formada por los estudiantes de Licenciatura de la Universidad Veracruzana, de las regiones Xalapa y Puerto de Veracruz, en México. La técnica de recolección de datos utilizadas fueron la encuesta y la entrevista estructurada y los instrumentos el cuestionario y la guía de entrevista, respectivamente. Los resultados dieron lugar a las propuestas referentes a la promoción de la cultura y permitieron facilitar los desempeños en varias áreas, como por ejemplo, el acceso a la información, el procesamiento de datos y la comunicación inmediata (para difundir información de investigación o para contactar autores o establecer redes de colaboración científica en diferentes lugares del mundo).

Palabras Clave: Realidad de las TIC, procesos de investigación, cambios culturales.

\footnotetext{
1 Investigadora de la Universidad Veracruzana- México. Dedicada a las líneas de investigación: El entorno del capital humano y desarrollo organizacional en empresas

2 Docente de la Universidad Veracruzana- México. Dedicada a la línea de investigación: Aplicación de las TIC en la solución de problemas de productividad en las organizaciones.

3 Docente de la Universidad Veracruzana-México. Dedicada a la línea de investigación: Aplicación de las TIC en la solución de problemas de productividad en las organizaciones
} 


\section{Abstract}

This article aims to spread the experience related to the use of the technologies in the research processes carried out by students enrolled in a graduate degree program. The subject matter is related to the importance of Information and Communication Technologies (ICTs) in research work and the need to identify which of them are the most used. Under these terms, the study was carried out with the empirical, descriptive, analytical and propositional method. The target population was made up with students enrolled in the graduate degree program at Universidad Veracruzana, from the Xalapa and Puerto de Veracruz regions in Mexico. The technique of data collection was the survey and the structured interview while the instruments were the questionnaire and the interview guide, respectively. The results allowed us to make proposals regarding the promotion of culture and made it possible to facilitate practices in different areas, such as access to information, data processing and immediate communication (to spread research information, to contact authors or to establish scientific collaboration networks in different parts of the world).

Keywords: ICTs nowadays, research processes, cultural changes

\section{INTRODUCCIÓN}

La investigación, considerada como un proceso riguroso, ordenado, sistemático, lógico, crítico y empírico, ha determinado descubrimientos en las diferentes áreas del conocimiento. Muestra de ello son los métodos administrativos, financieros y el desempeño humano y laboral de los disímiles sectores (educativos, de salud, económicos, culturales y sociales). Su aplicación es invaluable, pues existe una gama de estrategias y postulados en la construcción de métodos para la investigación. Gracias a los antecesores epistemológicos dedicados al descubrimiento de las formas de pensamiento y teorías, hoy se dan diferentes maneras de aplicación del conocimiento, logrando hacer ciencia.

Efectivamente, llevar a cabo el proceso de investigación implica sistematizar lo que se pretende estudiar, de acuerdo a la realidad y no a la abstracción. No se dejan los hechos a la casualidad, término que representa creatividad, dinamismo, cambios evaluables y continuos. El conjunto de estadíos que integran el metódico proceso de la investigación son etapas enlazadas y subsecuentes.

La visión teórica, o sistema lógico integrado por conceptos, proposiciones y definiciones interrelacionados, está presente en cada etapa del proce- so de investigación. Dicha visión, con su sistema lógico, es formulada con base en observaciones, axiomas y postulados, teniendo la finalidad de establecer las condiciones de ejecución de los supuestos. Para ello se toma como referencia una explicación descriptiva o experimental de un fenomeno de estudio o medio de estudio para desarrollar predicciones y poder deducir o postular otros hechos o nuevas hipótesis.

La planeación, proceso y resultados de investigación implican varios recursos, entre ellos los tecnológicos. Aquí es donde se instala la necesidad de analizar a las TIC y su relación con la investigación. Desde este ambito, se ha considerado como objetivo general en este estudio: explicar las diferentes tecnologías de la información y la comunicación, como herramientas en los elementos del proceso de investigación utilizados por los alumnos de Licenciatura en Administración; Administración Turistica y Sistemas Computacionales, de las regiones de Xalapa y Puerto de Veracruz, en México. Como objetivos especificos se planteó: i) conocer en que medida utilizan las herramientas tecnológicas -y cuales- para constituir la base de datos, que apoyen la construcción del sustento de la investigación (marco teórico); ii) escribir en la planeación de la investigación (población, muestra y unidades de medición) la elección de 
las herramientas tecnológicas, ii) describir en la recolección de datos el tipo de herramienta tecnológica utilizada, asi como en la validación de los instrumentos; iii) analizar en la implementación de la investigación el software que utiliza para análisis e interpretación de resultados; iv) explicar el software que utiliza para publicar o difundir los resultados de los reportes de investigación; v) analizar el software que utiliza en caso de participar para establecer, fortalecer o interactuar con colegas (redes de colaboración) y vi) analizar los factores y recursos que inciden en la utilización de las tecnologías en los procesos de investigación.

TIC en el desarrollo del proceso de enseñanza-aprendizaje

Para León y Tapia (2013), las Tecnologías de Información y Comunicación (TIC) son herramientas que han impactado en todo el quehacer humano. Sus efectos en el ámbito organizacional son evidentes al promover la gestión eficiente primero de la información y, posteriormente, del conocimiento. Roblizo y Cózar (2015) definen a las TIC como un fenómeno revolucionario, impactante y cambiante, que abarcan tanto lo técnico como lo social e impregnan todas las actividades humanas, laborales, formativas, académicas, de ocio y consumo. Según Bautista, Martínez e Hiracheta (2014) mencionan que el rápido progreso de las TIC continúa modificando la forma de elaborar, adquirir y transmitir los conocimientos. Es por eso que los sistemas educativos, con sus modelos y estrategias, se han visto en la necesidad de adaptarse a una sociedad que está cada vez más sumergida en las TIC, ya que éstas han brindado posibilidades de renovar el contenido de los cursos y métodos pedagógicos.

Andión (2010), citado por Torres y Valencia (2013), hace hincapié en que la incorporación de las TIC implica de modo necesario un cambio en el paradigma pedagógico. Se requiere pasar de un modelo educativo centrado en la enseńanza a otro que gire en torno al aprendizaje.

Las TIC como elemento ineludible e incuestionable de esta dinámica docente-estudiante y la investigación, como pilar fundamental, son un binomio en el cuál las herramientas tecnológicas permiten, sustentan y facilitan la ejecución de este proceso en todos sus niveles y tipos, también en cada una de las etapas del proceso, como enfatizan León y Tapia (2013), al mencionar que las TIC tienen el potencial de transformar los procesos enseńanza-aprendizaje de manera innovadora para apoyo de las formas tradicionales y no tradicionales.

En la actualidad, las tecnologías están revolucionando de manera muy rápida las formas de enseñar y aprender, proceso que incrementa progresivamente la cantidad de usuarios de las TIC. Los jóvenes de hoy están al día con las nuevas tecnologías; su forma de uso no es una limitante para ellos, es decir, tienen cada vez mayor interacción con ésta (Martínez y Martínez, 2014). Lo anterior ha permitido que los estudiantes universitarios adopten estas herramientas indispensables como recursos y medios didácticos en el desarrollo y construcción de los trabajos escolares e investigaciones académicas. La facilidad de acceso a bibliotecas virtuales, consulta de libros electrónicos, repositorios universitarios, consulta de artículos de investigación especializados, bases de datos estadísticos, hasta el intercambio de correos electrónicos y uso de redes sociales para compartir e intercambiar información de cualquier índole, ha facilitado el trabajo colaborativo en el desarrollo de todas las actividades académicas.

\section{Materiales Y Métodos}

\section{Participantes}

La población estuvo integrada por un grupo de estudiantes de la Universidad Veracruzana, del área económico-administrativa, regiones Xalapa y Veracruz, en México. Se ubican en tres rangos de edad, predominando entre 18 a 21 años, como se muestra en la tabla 3. El estatus socioeconómico que prevalece es de clase media. La mayoría de los estudiantes son de diferentes zonas conurbadas, tanto de Xalapa como de Veracruz.

A continuación, en la tabla 1 se hace notar la distribución de la población objetivo, según carrera y región. 
Importancia de las tecnologías en los trabajos de investigación: una experiencia en los estudiantes de licenciatura, área económico-administrativa de la Universidad Veracruzana- México

Tabla 1

Población objetivo del estudio

\begin{tabular}{llc}
\hline \multicolumn{1}{c}{ Carrera } & \multicolumn{1}{c}{ Región } & No. de estudiantes \\
\hline Administración & Xalapa & 50 \\
\hline Administración & Veracruz & 129 \\
\hline Turismo & Veracruz & 32 \\
\hline Sistemas computacional & Veracruz & 35 \\
\hline & Total & $234^{*}$ \\
\cline { 2 - 3 }
\end{tabular}

Fuente: Elaboración propia (2017).

*De la población total de 234 sujetos, contestaron 214. Los motivos: inasistencias y por no seguir las indicaciones.

El muestreo fue de tipo no probabilístico. Se consideró como sujetos de medición a los estudiantes de las cuatro carreras enunciadas en la tabla 2. Como criterios de inclusión en la muestra se consideró que fueron estudiantes menores de 30 años.

\section{Instrumento}

El instrumento utilizado para recoger la información fue el cuestionario, que incluyó preguntas relativas a las variables enunciadas en la tabla 2 . De estas se desprendieron las preguntas o ítems, en una escala de medición nominal y ordinal, con el propósito de evaluar las respuestas. Las preguntas se elaboraron de manera "cerrada" y presentan categorías o alternativas de respuestas entre las cuales los encuestados debieron elegir una sola. Para la aplicación del instrumento se utilizo la técnica de la entrevista, en la cual se informó a los estudiantes acerca de la intención de la investigación y la importancia de su paricipación en el proceso de este estudio. Con ello se daba cumplimiento al requisito del consentimiento informado.

Tabla 2

Variables del estudio

\begin{tabular}{|c|c|c|}
\hline Variables & Indicadores & Medición \\
\hline $\begin{array}{l}\text { Base de da- } \\
\text { tos del mar- } \\
\text { co teórico }\end{array}$ & $\begin{array}{l}\text { Tiendas electrónicas, recursos de } \\
\text { internet, software de traducción de } \\
\text { idiomas, software para administrar } \\
\text { referencias }\end{array}$ & \\
\hline $\begin{array}{l}\text { Instrumento } \\
\text { recolección } \\
\text { de datos. } \\
\text { Elaboración }\end{array}$ & $\begin{array}{l}\text { Uso de software para creación de los } \\
\text { instrumentos, software para realizar } \\
\text { el piloteo del instrumento, software } \\
\text { para realizar la validación de instru- } \\
\text { mentos }\end{array}$ & \\
\hline
\end{tabular}

\begin{tabular}{lll}
\hline $\begin{array}{l}\text { Aplicación } \\
\text { de instru- } \\
\text { mentos }\end{array}$ & Encuestas en línea & \\
\hline $\begin{array}{l}\text { Análisis e } \\
\text { interpre- }\end{array}$ & spss, excel sphinx, plus, atlas & Nominales \\
tación (de & & Ordinales \\
datos) & & \\
\hline $\begin{array}{l}\text { Presen- } \\
\text { tación de }\end{array}$ & El software que utilizo para publicar / & \\
resultados & \\
difusión de & \\
la investiga- & \\
ción & \\
\hline Trabajo co- & Redes sociales, correo electrónico, & \\
laborativo & chat, video llamadas, foros & \\
\hline
\end{tabular}

Fuente:: Elaboración propia (2017).

La validez del instrumento se verificó en terminos de contenido. Para ello se sometieron los ítems al juicio de diez expecialistas en investigación, utilizándose una escala de ponderación del 1 al 5 . De los diez expertos, solo uno señaló el número 4 , el resto señaló el número cinco. De esta forma el intrumento resultó validado para su aplicación.

Para constrastar la confiabialidad de los instrumentos, estos fueron sometidos a la medición respectiva, que consistió en la aplicación del instrumento en una ocasión a un grupo de 19 estudiantes, equivalente al 10\% del total de los encuestados. Para ello se seleccionó el paquete estadístico Dyane versión 3, el cual reportó un índice alfa de Cronbach de 0.7789 . Este resultado representó una consistencia interna alta, evidencia suficiente para que el instrumento fuera utilizado en el estudio.

\section{Tipo y diseño}

El estudio tiene un alcance descriptivo. Usó el método empírico, analítico y propositivo, porque se fundamentó en la experiencia de las investigadoras. Implicó la observación de los procesos de investigación y la utilización de las herramientas tecnológicas. Para profundizar en el registro de las formas y calidad de las variables de las referidas herramientas se asoció la necesidad de establecer las competencias para el uso de las mismas en un contexto determinado. Tiene un carácter propositivo debido a que estuvo dirigido a la acción para plantear un modelo facilitador de la utilización de las TIC en los diferentes procesos de investi- 
gación, inclusive en las referencias bibliográficas requeridas.

\section{Procedimiento}

Para la recolección de los datos, desde el principio se aludió a los escenarios en donde se realizó el levantamiento de los datos, un espacio exprofeso para el registro de los mismos. Consistió en concentrar a los estudiantes en salas de cómputo donde se ubicaron frente a computadoras para identificar el portal de la aplicación definitiva de los cuestionarios.

Una vez lista y disponible la encuesta a través de la página Encuesta Fácil de Internet, se recuperó el link de acceso y, a continuación, se distribuyó a través de los correos electrónicos, proporcionando las instrucciones necesarias a los grupos de estudiantes en las dos regiones elegidas.

En todo el proceso se consideró el rigor científico, estimándose el tiempo de aplicación en un máximo de 15 minutos. Al termino de este se revisó cada una de las encuestas, con el proposito de verificar que todas las preguntas fueran contestadas.

La codificación de las categorías estuvo a cargo de las personas responsables de la investigación. Se utilizó un programa especial para el tratamiento, en el cual se incluyeron todas las respuestas por grupos, relacionadas con las variables e indicadores del estudio.

Finalmente, se revisaron los cuestionarios que fueran contestados sin tener errores y así facilitar el procesamiento de los datos, representados en tablas y figuras.

\section{Resultados}

Para el procesamiento de los datos y, obedeciendo al estudio de corte descriptivo, los resultados se muestran en tablas y figuras que describen los contenidos de los resultados para el análisis correspondiente, como se señala a continuación en la tabla 3.

Según la tabla 3, el rango de mayor porcentaje se presenta entre 18 y 21 años, prevalenciendo el sexo femenino, ubicados en su gran mayoría en el sexto semestre. Lo relevante de los datos es la frecuencia del número de mujeres a diferencia de los hombres, dato relevante para otro tipo de estudio en relación a la eficiencia terminal.

Tabla 3

Rango de edad según sexo

\begin{tabular}{|c|c|c|c|c|c|c|c|c|c|}
\hline \multirow{2}{*}{$\begin{array}{l}\text { Rango de } \\
\text { edad }\end{array}$} & \multicolumn{2}{|c|}{ Sexo } & \multicolumn{6}{|c|}{ Semestre } & \multirow{2}{*}{$\begin{array}{l}\text { Sub } \\
\text { Total }\end{array}$} \\
\hline & M & $\mathrm{F}$ & $2^{\circ}$ & $4^{\circ}$ & $6^{\circ}$ & $8^{\circ}$ & $10^{\circ}$ & $12^{\circ}$ & \\
\hline $18-21$ & 34 & 108 & 1 & 31 & 97 & 13 & 0 & 0 & 142 \\
\hline $22-25$ & 35 & 31 & 1 & 1 & 30 & 29 & 4 & 1 & 66 \\
\hline $26-29$ & 6 & 0 & 0 & 2 & 2 & 1 & 1 & 0 & 6 \\
\hline TOTAL & 75 & 139 & 2 & 34 & 129 & 43 & 5 & 1 & 214 \\
\hline
\end{tabular}

Fuente: Elaboración propia (2017).

Seguidamente, en los datos generales se preguntó sobre el programa educativo que cursan y fue el de Administración el de mayor porcentaje (70\%), seguido por el de Administración Turística (19\%) y Sistemas Computacionales (10\%).

La población mayormente encuestada fue situada en el puerto de Veracruz, con un $78.5 \%$ y Xalapa representó un $21.5 \%$.

Lo relevante son los datos que proyectan el uso de las bases de datos para la elaboración del marco teórico. Dato que nos lleva a experimentar nuevas hipótesis en relación al adecuado uso de citas en sus tareas de investigación (figura 1).

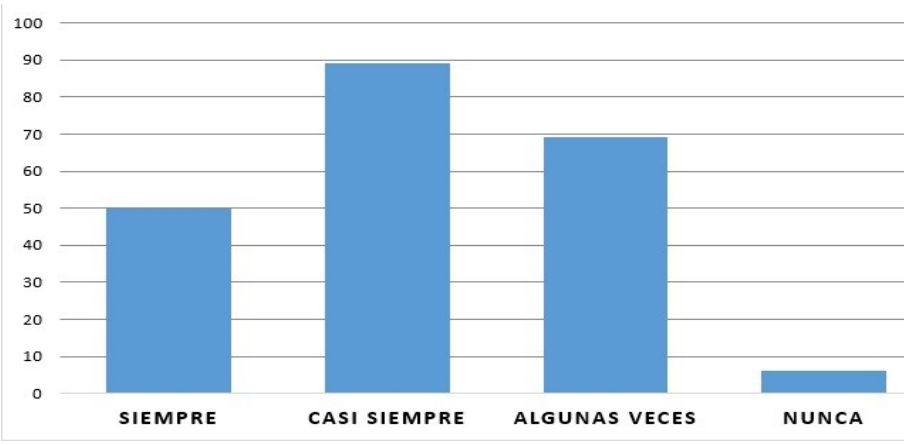

Figura 1. Uso de Bases de datos para la elaboración del marco teórico.

En la figura 2 resalta el uso incipiente "algunas veces" teniendo un mayor porcentaje en cada uno de los conceptos medidos conclusiones 


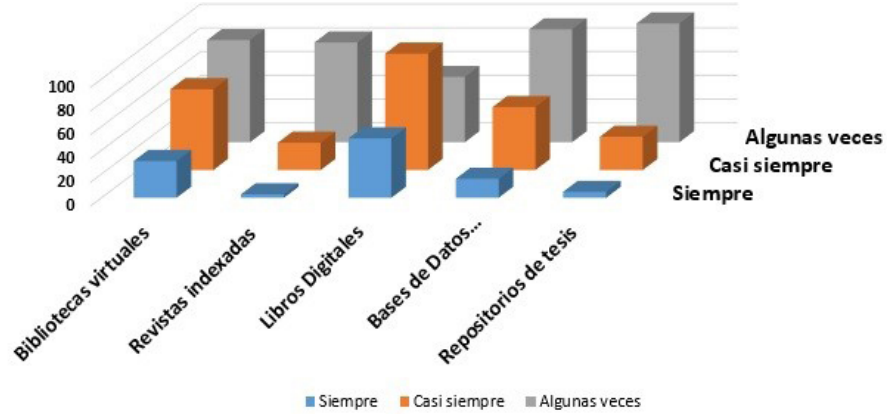

Figura 2. Bases de datos utilizadas. Fuente: Elaboración propia (2017).

Respecto a la pregunta de la utilización de Tiendas electrónicas para adquirir material bibliográfico, se obtuvieron las siguientes respuestas: 78\% para la opción Sí y 21\% para la opción No.

Asimismo, a la pregunta sobre la utilización de recursos de Internet para la prevención del plagio, No obtuvo el 94\% y Sí el 5\%, lo cual refleja otra hipótesis relacionada a la existencia de esta herramienta. Las respuestas referidas a la utilidad del uso de software para administrar referencias en el marco teórico, el $84 \%$ respondió que no la utilizan. Interesantes son los resultados encontrados en la pregunta de uso de software de traducción de idiomas, la cual refleja un porcentaje del $54 \%$ al 44\%. Según estos, las publicaciones en español no son las más utilizadas, sino aquellas elaboradas en otros idiomas. Con relación al software para la creación de instrumentos, los datos indican un $53 \%$ de no uso y un $43 \%$ de uso. Esta diferencia se debe al uso de procesadores de texto.

De acuerdo con la figura 3, lo relevante en el uso del software para realizar el piloteo de instrumentos se halló en la opción "algunas veces", seguida de nunca. Esto indica que hay un mediano uso de las TIC.

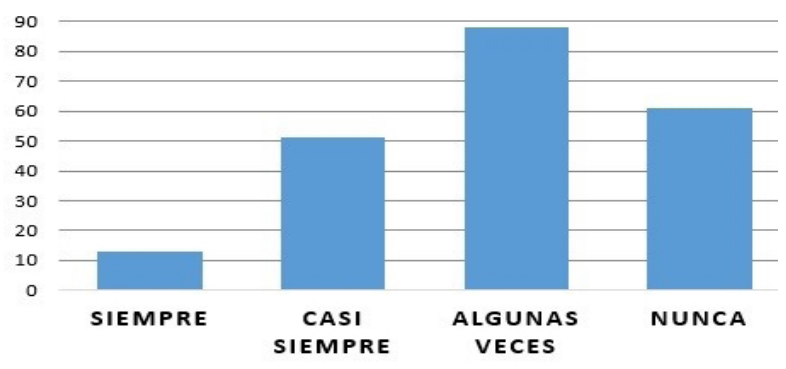

Figura 3. Uso software para el piloteo de los instrumentos de recogida de datos.

Fuente: Elaboración propia (2017).
En la figura 4 se observa la relevancia en el uso de Google Forms, aunque un porcentaje bastate cercano evidenció no usar software.

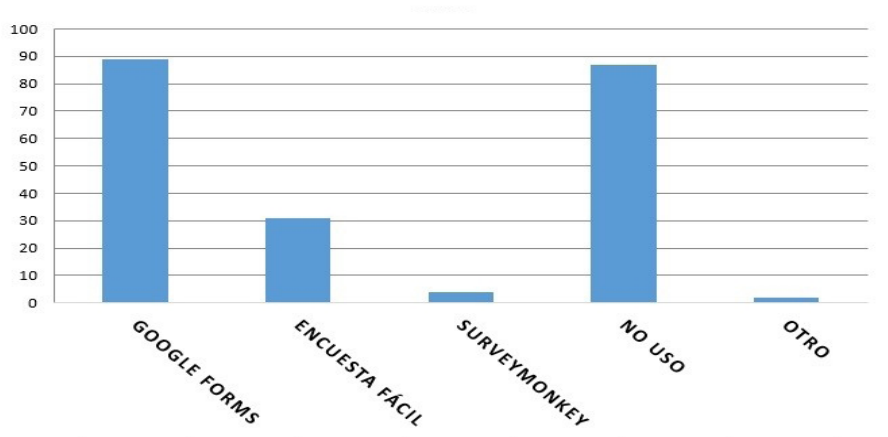

Figura 4. Software utilizado para piloteo de instrumentos de recogida de datos.

Fuente: Elaboración propia (2017).

En el uso del software para la validación de instrumentos es un hecho que el $92 \%$ no los utiliza y el condicionante para ello es la falta de conocimiento de la existencia de programas especializados para el caso, como también la necesidad de licencias de uso de software y un conocimiento especializado para llevar a cabo esta tarea.

La figura 5 muestra la tendencia a la utilización frecuente de redes sociales para la aplicación de instrumentos en sus tareas de investigación.

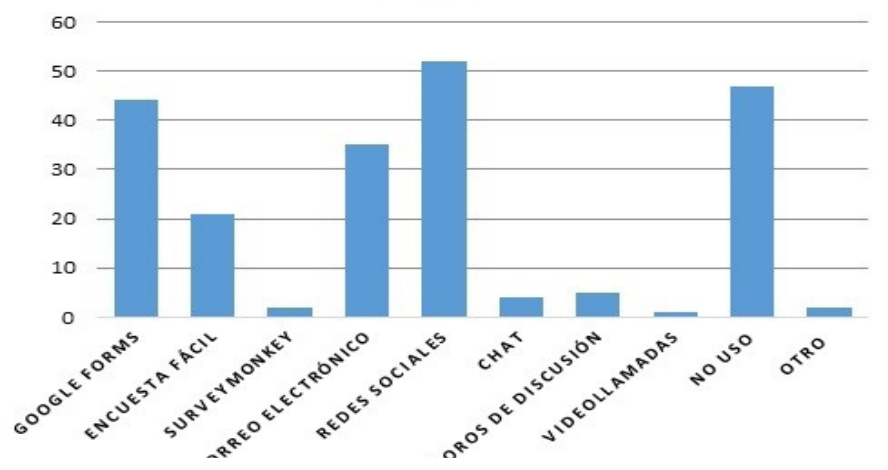

Figura 5. Software utilizado para la aplicación de instrumentos.

Fuente: Elaboración propia (2017).

Se hace relevante el uso de la hoja de cálculo Excel, por la practicidad de su forma de representar datos para el análisis de datos. La relevancia está sobre el uso de portales web (figura 6).

La relevancia de la pregunta sobre el uso del 


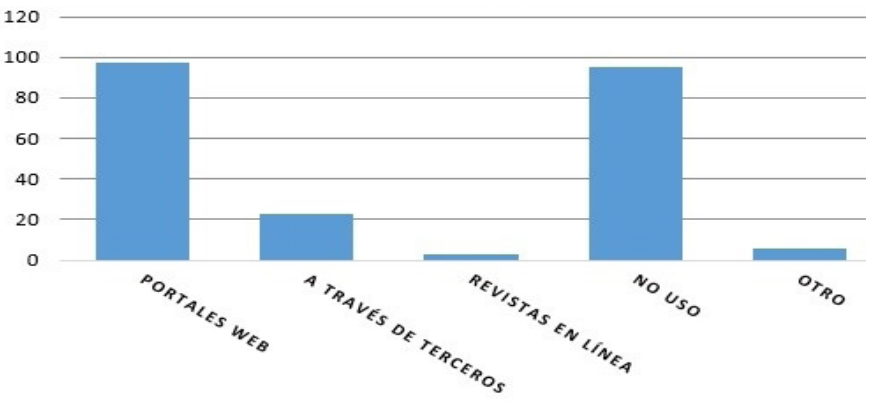

Figura 6. Software usado para difusión / publicación de resultados.

Fuente: Elaboración propia (2017).

software para la creación o interacción con redes de colaboración está en el uso de redes sociales y correo electrónico para la realización de trabajo en red (figura 7).

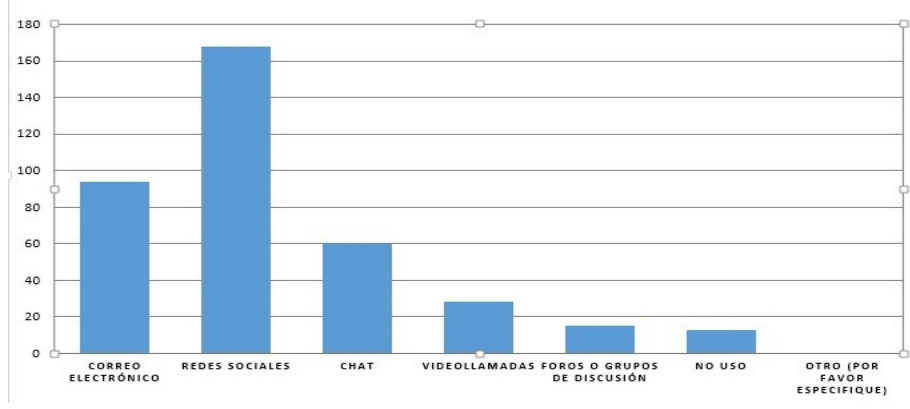

Figura 7. Uso de software para creación o interacción con redes de colaboración.

Fuente: Elaboración propia (2017).

Respecto a las limitaciones en la cantidad de equipos disponibles, los encuestados contestaron en su gran mayoría que hay pocos equipos. De igual manera refieren que las características del hardware de los equipos en sus escuelas dificultan el desarrollo de las tareas de investigación.

Con relación a la infraestructura tecnológica para el acceso a Internet, no es suficiente para realizar las tareas de investigación por el hecho de su insuficiencia.

En la falta de motivación por el docente, llama la atención el resultado, puesto que más del 50\% dice que no lo limita; el resto dice que sí, lo cuál es relevante. El resultado de las habilidades y conocimiento en el uso de las TIC arroja el dato significativo del $57 \%$ que no se les dificulta el uso de las TIC. El resultado de la figura 8 muestra un alto grado de desconfianza en el uso de TIC.

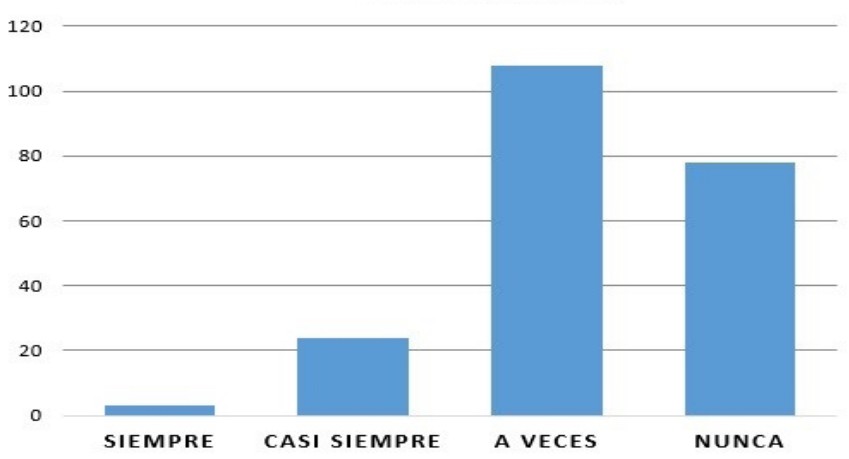

Figura 8. Nivel de confianza en las TIC.

Fuente: Elaboración propia (2017).

\section{Discusión y Conclusiones}

Con base en los hallazgo empíricos, cabe analizar las contradicciones encontradas. El método utilizado para el presente estudio fue el empírico, descriptivo y analítico por tratarse de variables cuantitativas y cualitativas, en escala nominal y ordinal.

Las respuestas en función a las mismas variables evidenciaron que la población elegida fue de 234 estudiantes, pero por factores externos al proceso sólo aplicaron 214. En las dos regiones elegidas predominaron el sexo femenino. En la variable utilización del software para la elaboración del marco teórico fue necesario el uso de la base de datos que tenía el mismo. Sin embargo, conduce a considerar una falta de diversidad del sustento; es decir, no usan otros marcos, esto puede deberse a la estructura utilizada en el planteamiento de la pregunta.

Como afirma Rodríguez (2011), las TIC no son más que medios y recursos que se pueden utilizar en el proceso didáctico. De cómo se las utilice, para qué y en qué contexto, es lo que hace que tengan una incidencia u otra, lo cual se convierte en una observación para la elaboración del instrumento. Otro aspecto importante se relaciona con la equidad del porcentaje en la utilización de tiendas electrónicas, recursos de Internet, software de traducción y software para administración de las referencias, acotándose que la causa puede encontrarse en el ranking de las publicaciones en español. 
En cuanto a la utilización de las TIC en los instrumentos de recolección y análisis de datos y análisis, destaca principalmente que no utilizan las TIC en el piloteo del instrumento, ni mucho menos para realizar la validación ni confiabilidad del mismo. Este hecho se relaciona a la falta de conocimiento en los análisis estadísticos utilizados para ello. En la aplicación de los instrumentos es notorio el uso que se hace de la plataforma Google Forms, lo cual es digno de discutir, principalmente en las academias dirigidas o integradas hacia las tecnologias de información.

Con todo lo anterior se puede afirmar que, por la posición de la marca Google, el acceso y disponibildad de esta se refleja en su alta utilización. Sucede lo mismo en el uso del software Excel para el análisis e interpretación, implicando la tradición y no la innovación en su uso.

Cabe afirmar que la difusión de la investigación se hace a traves de portales web. Asimismo, con referencia a la participación en redes, destaca el uso de las redes sociales y el correo electrónico, no así el uso de software especializado para ello.

En cuanto a las limitantes para el uso de las TIC. En definitiva, la insuficiencia de los equipos, así como su falta de actualización y debilidad en la infraestructura de la red que, sumado a la motivación del docente, son fuertes obstáculos para fortalecer el desarrollo y crecimiento en el conocimiento y la utilización de las TIC.

Con todo lo anterior, se destaca un alto grado de desconfianza en el uso de las tecnologías para la realización de actividades de investigación con fines de aprendizaje, lo que deja como controversia (independientemente de los objetivos) "el supuesto de que las TIC son usadas en un alto porcentaje, destacando que en este estudio no son de uso ni aplicación común para la investigación entre los estudiantes de los tres programas involucrados". Estos resultados deben considerarse al referir al fomento de la cultura en la utilización de las TIC en los procesos de investigación.

Con base en los objetivos planteados, y a través de los resultados, se logró describir, analizar y expli- car las variables en el uso de las TIC. Asimismo, los hallazgos, particularmente del uso de las TIC en la utilidad del software para administrar referencias que fundamentan el marco teórico, queda delimitado por sólo haber sido elegido éste. Se deja de lado el referencial, conceptual, lo que muestra una franca debilidad en el instrumento, ya que hay otras opciones de hacer sustentos para la investigación en la cual cabe también el uso de estas herramientas. Asimismo, se comprobó la falta de conocimiento por parte de los alumnos de las diferentes plataformas para la aplicación e interpretación de instrumentos y los datos obtenidos a través de ellos. Lo anteriormente expuesto puede ser indicativo de una incipiente cultura digital (con propósitos académicos) en el uso de TIC.

Con la presentación de los hechos habría que correlacionar las propuestas por los autores y lo que a la letra dicen. Tal es el caso de Mayer (2000), quien destaca la incorporación de las TIC en el proceso de aprendizaje universitario, deja de ser una mera recepción y memorización de datos. Pasa a la búsqueda, análisis y reelaboración de informaciones ya que, según Mayer, el estudiante deja de ser un procesador activo de información y, de acuerdo a los resultados del presente estudio, sigue siendo un procesador activo de información. Lo cierto es que la tecnologia debería ser parte integral del proceso de aprendizaje-enseńanza de las experiencias educativas de todos los programas educativos; esta situación no fue demostrada en este estudio.

Para concluir, surgen nuevas hipótesis en el interés por explicar el nivel de usabilidad que dan los docentes a las herramientas tecnológicas. Adicionalmente, se debe reflexionar acerca de cómo el docente puede incentivar a sus estudiantes para que usen las TIC en todo el proceso investigativo y sepan cómo valerse de las mismas para generar una cultura digital con la apropiación de estos medios. Por lo tanto, la explicación final encamina la relevancia de la utilización de los diferentes software en cada uno de los elementos del proceso de investigación. La finalidad es contribuir y enriquecer las acciones de colaboración entre grupos. 


\section{REFERENCIAS BIBLIOGRÁFICAS}

Bautista, M., Martínez, A., e Hiracheta, R. (2014). El uso de material didáctico y las tecnologías de información y comunicación (TIC’s) para mejorar el alcance académico. Ciencia y Tecnología, 14, 183 - 194. Recuperado de: https://doi. org/10.18682/cyt.v1i14.217

Cobo, J. (2011). El concepto de tecnologías de la información. Benchmarking sobre las definiciones de las TIC en la sociedad del conocimiento. En Zer-Revista de Estudios de Comunicación, 14(27), 295-318.

García, B. (2005). La Teoría de la educación de Niklas Luhmann. Educación, Pensamiento complejo y Desarrollo institucional integrado. En: Ponencias: I Seminario Nacional - Universidad de la Amazonia, 2005 (pp. 1-20). Florencia, Colombia: Sala del CREDI de la OEI.

Gerardo, E., y Álvarez, A. (2003). La Teoría de Niklas Luhmann. Anthropos, (32), 277-312.

Habermas, J. (2007). La lógica de las ciencias sociales. Madrid: Tecnos.

Hilder, T. (2005). Stafford Beer's The Viable System Model. Recuperado de: http://www.flowmap.com/documents/vsm. pdf

León, J., y Tapia, E. (2013). Educación con TIC para la sociedad del conocimiento. Revista Digital Universitaria, 14(1). Recuperado de: http://www.revista.unam.mx/vol.14/ num2/art16/art16.pdf

Martínez, R. , Martínez, N. (2014). Las TIC en el proceso de aprendizaje de los estudiantes de nivel medio superior en zonas rurales: simulación a través del software VENSIM. Revista de Estudios en Contaduría, Administración e Informática, 3(8). 32 - 66. Recuperado de: http://revistarecai. $\mathrm{mx} /$ index.php/recai/article/download/90/73

Mayer, R. (2000). Diseño educativo para un aprendizaje constructivista”. En Reigeluth, Charles (ed.), Diseño de la Instrucción. Teorías y modelos. Madrid: Aula XXI Santillana, págs. 154- 171.

Muñoz, D. (2006). Anotaciones conceptuales iniciales sobre los aportes sistémicos de Niklas Luhmann a las ciencias sociales: debates en torno a las teorías de la acción y de sistemas. Revista Latinoamericana de Ciencias Sociales. Niñez y Juventud, 4(1), 15.

Roblizo, M., y Cózar, R. (2015). Usos y competencias en TIC en los futuros maestros de educación infantil y primaria: Hacia una alfabetización tecnológica real para docentes. Pixel-Bit, (47), 23-39. Disponible en: https://doi. org/10.12795/pixelbit.2015.i47.02

Rodríguez, R. (2011). Repensar la relación entre las TIC y la enseńanza universitaria: Problemas y Soluciones. Profesorado: Revista de currículum y formación del profesorado, 15(1). Recuperado de: http://www.ugr.es/ recfpro/ rev151ART1.pdf

Torres, C., y Valencia, L. (2013).Uso de las TIC e internet dentro y fuera del aula. Apertura, 5(1), 108 - 119. Recupera- do de: http://www.redalyc.org/articulo.oa?id=68830443010 


\title{
Herramientas TIC en el aprendizaje en el área de matemática: Caso Escuela PopUp, Piura-Perú
}

\section{ICT tools in learning in the Mathematics area: Case PopUp School, Piura-Peru}

\author{
Cleofé Genoveva Alvites-Huamaní ${ }^{1}$
}

Universidad Alas Peruanas, Perú

\section{Cita recomendada}

Alvites-Huamaní, C. (2017) Herramientas TIC en el aprendizaje en el área de Matemática: Caso Escuela PopUp, Piura-Perú. Hamut'ay, 4 (1), 18-30. Recuperado de: http://doi.org/10.21503/hamu.v4i1.1393

\section{RESUMEN}

En la formación de los estudiantes de educación básica se hace necesario implementar recursos innovadores con apropiación de las Tecnologías de la Información y Comunicación (TIC), en todas las áreas curriculares, más aún en aquellas donde se tiene una problemática marcada, como es el caso de las matemáticas. Por ello, en este estudio se tuvo como hipótesis: "el programa desarrollo mis habilidades en matemáticas con TIC mejora significativamente el aprendizaje en el área de matemática en las estudiantes del tercer grado de primaria de la IE San José de Tarbes” de la Escuela Pop Up, Castilla-Piura. Por lo que se realizó un estudio con diseño cuasiexperimental, con preprueba-posprueba y grupo de control. Se desarrollaron 21 sesiones de aprendizajes para la ejecución del programa en el primer y segundo bimestre del 2016. La muestra fue de tipo no probabilística, con 139 estudiantes del tercer grado de primaria de las secciones A, B, C y D. Para la recolección de datos se aplicó la prueba Desarrollo mis habilidades en matemática con TIC, en dos momentos, al inicio y final de la experimentación. Los resultados del contraste de hipótesis indicaron $\mathrm{p}=.000<.05$, por lo que se concluyó que el programa "Desarrollo mis habilidades en matemática con TIC" mejora el nivel de logro en el área de matemática.

Palabras Clave: Tecnologías, matemáticas, software educativo, aprendizaje-enseñanza.

\section{Abstract}

In the instruction of students from basic education it is necessary to implement innovative resources with appropriation of the Information and Communication Technologies (ICT) in all curricular areas, especially in those where there is a major problem, as is the case of mathematics. Therefore, in

\footnotetext{
1 Doctora en psicología, Directora, asesora y revisora de Tesis a nivel nacional e internacional de diversas universidades. Coordinadora de la División de Investigación y Extensión Científica Tecnológica de la Dirección Universitaria de Educación a Distancia de la Universidad Alas Peruanas, adscrita al Directorio Nacional de Investigadores e Innovadores, miembro del programa Mujeres Científicas del Perú y miembro del grupo Ecosistemas de México, Editor en Jefe de la Revista Hamut'ay. cleoalvitesh@gmail.com, c_alvites@uap.edu.pe
} 
this study, the hypothesis was: "the Developing my Skills in Mathematics with ICT program significantly improves learning in the area of mathematics in students of third grade of school San José de Tarbes" at Pop Up School in Castilla-Piura. In order to compare it, a study with a quasi-experimental design was performed, with a pre-test - posttest and a control group. A total of 21 learning sessions were developed for the program, which were implemented during the first and second terms in 2016. The sample was non-probabilistic, with 139 third-grade students in sections A, B, C and D. For the collection of data, the test Developing my skills in mathematics with ICT, was applied in two different moments, at the beginning and at the end of the experimentation. The hypothesis test results indicated $\mathrm{p}=.000<.05$, so it was concluded that the "Developing my skills in mathematics with ICTs" program improves the level of achievement in the area of mathematics.

Keywords: Technologies, mathematics, educational software, teaching-learning

\section{INTRODUCCIÓN}

Uno de los requisitos en la formación de los estudiantes de educación básica y universitaria es el área de matemáticas; pero a pesar de todos los esfuerzos que realizan las instituciones educativas, la enseñanza de esta área todavía sigue siendo un problema mundial. Esto ha conllevado a un déficit en el desarrollo de las competencias que integran el perfil del estudiante en matemáticas, como lo muestran los resultados obtenidos por todos los países del continente, con relación al Informe del Programa Internacional para la Evaluación de Estudiantes, PISA, por sus siglas en inglés. Son los países asiáticos, europeos y Estados Unidos quienes tienen lugares privilegiados; pero en el caso de América Latina los resultados no son tan óptimos como se quisiera. Según la BBC Mundo (2013, diciembre 3), los países latinoamericanos están entre los últimos puestos. Infobae América (2013, diciembre 2) refiere que existe un retroceso en materia educativa en los últimos tres años en esta parte del continente, a pesar de los esfuerzos que han realizado los gobiernos y la implementación de políticas para la mejora de los resultados en esta área. No obstante, aún están por debajo de los estándares estipulados por la Organización para la Cooperación y el Desarrollo Económicos (OCDE), debido a que ningún país de Latinoamérica ha obtenido los 494 puntos para matemáticas. En el caso de Perú, el problema es más álgido, al haber ocupado el último lugar, como lo indica PISA (2015) los puntajes obtenidos están muy por debajo del promedio. En el caso de matemática fue de 387 puntos. Este problema también se ha visto reflejado en la Institución Educativa San José de Tarbes, con mayor énfasis en el nivel primario, de acuerdo a lo indicado en el diagnóstico del Proyecto Educativo Institucional (PEI). Se destaca que en el tercer grado se han presentado dificultades en la interpretación de los enunciados de los problemas; todavía existe dificultad para el cálculo mental, las secuencias numéricas e interpretación de gráficos de barras están entre las más resaltantes. Por tal razón, como la mencionada Institución Educativa tiene a su disposición la Escuela Pop Up, que cuenta con una variedad de herramientas tecnológicas, se ha considerado ejecutar un proyecto utilizando estas. Por lo que se consideró como objetivo general de la investigación fue "determinar la influencia del programa Desarrollo mis habilidades en matemáticas con TIC en el aprendizaje en el área de Matemática en los estudiantes del tercer grado de primaria de la IE San José de Tarbes, Castilla, en Piura.

\section{Herramientas Tecnológicas de la Información y la Comunicación (TIC)}

La apropiación de las TIC como herramienta de apoyo al proceso de aprendizaje-enseñanza, por parte de los docentes de educación básica, se ha hecho más frecuente debido a la facilidad de uso y al permitirles utilizarla como una estrategia de apoyo en sus actividades curriculares. Esto hace 
que los estudiantes tengan una mayor experiencia real e interactiva, así como una fuente inagotable de información, tal como aseveran Chaves et al. (2015), al sostener que las TIC contribuyen a la construcción de conocimiento por facilitar el acceso a información e incrementar la interactividad y conectividad, que permiten la mediación pedagógica en los contenidos de los cursos.

Ello conlleva a la promoción del aprendizaje mediante el uso de una variedad de herramientas tecnológicas, el desarrollo de las inteligencias múltiples y los estilos de aprendizaje. Por su parte, Calderón et al. (2014) enfatizan que las TIC son todas aquellas herramientas que incluyen la computadora, sistemas audiovisuales, Internet, telefonía y los diversos equipos que se integra en la aplicación en la enseñanza con alguno de ellos. Así también lo refieren Farrońay y Ancaya (2016) al mencionar que las TIC son un instrumento indispensable para las instituciones educativas, pues permiten realizar diversas funciones, como fuente de información multimedia, hipermedial, medio de expresión para la creación e instrumento cognitivo. Para Riveros, Mendoza y Castro (2011, p. 113) las TIC son herramientas y materiales que facilitan el desarrollo de distintas habilidades, estilos y ritmos de aprendizaje por parte de los estudiantes y a los docentes le permiten generar propuestas metodológicas innovadoras y creativas para mejorar la cognición y el proceso de aprendizaje. También refiere, como Ausubel, que la aplicación de la TIC apoya la secuencialidad, claridad y dificultad graduada de la exposición de las tareas de aprendizaje, la cual facilita la retroalimentación, la comprensión y disposición hacia la materia; destaca el uso de la PC como herramienta intelectual para incorporar estrategias pedagógicas para la interacción, atención y amplificación de las experiencias de los estudiantes. Esto es posible de una manera textual, visual, sonora y audiovisual, lo cual ayuda a una presentación diferenciada de los contenidos y, a su vez, a realizar simulaciones de los fenómenos abstractos. Desde una perspectiva mucho más específica, en el aprendizaje de las matemáticas, según Mendoza y Castro (2011, p. 119), hay indicios de que las herramientas TIC intervienen como agentes catalizadores del proce- so de cambio en el aprendizaje- enseñanza de la matemática, debido a que ofrecen múltiples posibilidades para manejar dinámicamente los objetos matemáticos de diferentes sistemas de representación dentro de esquemas interactivos. Esto en razón de que la tecnología abre espacios para que los estudiantes vivan las matemáticas de una manera diferente. Las TIC son utilizadas en el aula para el desarrollo de habilidades y procedimientos para la comprensión de las mismas. Según Villarreal (2012), la aplicación de las tecnologías en el campo matemático ha traído transformaciones en la creación de ambientes en os que se puede vivenciar la matemática como una ciencia experimental, como un laboratorio matemático donde es posible realizar "un ensayo y error educado", pudiendo este permitirlo y a la vez visualizarlo, lo cual sirve para la comprensión matemática. Para Parra y Díaz (2014), la incursión de las TIC como nuevas herramientas pedagógicas en el área de matemáticas genera una transformación socio-cultural concerniente a la práctica pedagógica, por la factibilidad en el uso de software y ambientes virtuales. Asimismo, los entornos computarizados evidencian procesos para representar y manipular el quehacer docente en el área de las matemáticas. Aulaplaneta (2015, septiembre 8) enfatiza que las TIC son beneficiosas para presentar conceptos de forma más visual e interactiva; permiten relacionar las matemáticas con otros aspectos de la vida, al vincular estas con un componente lúdico. Presenta 25 herramientas para enseñar matemáticas con TIC, como se muestra en la figura 1.

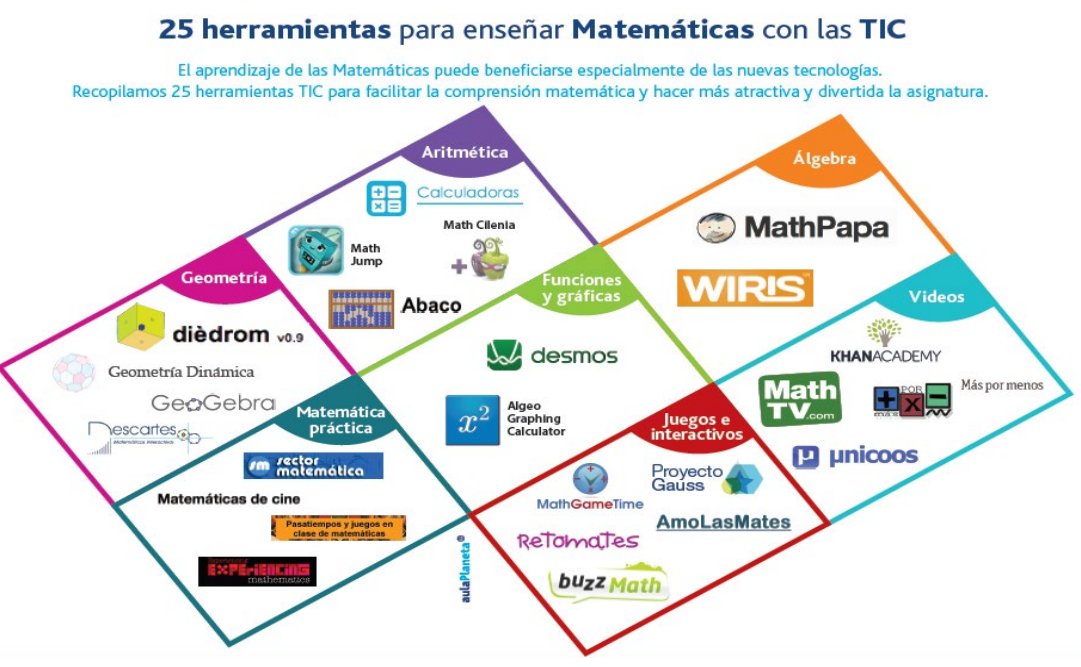

Figura 1. 25 herramientas para enseñar matematicas con TIC.

Fuente: www.aulaplaneta.com 


\section{Aprendizaje en el área de matemáticas}

Según el Ministerio de Educación (2015), el aprendizaje de la matemática debe permitir que los estudiantes desarrollen formas de actuar y pensar matemáticamente en diversas situaciones, que les ayuden a interpretar e intervenir en la realidad a partir de la intuición, el planteamiento de supuestos, formulación de conjeturas e hipótesis para inferir; argumentar para desarrollar métodos $\mathrm{y}$ actitudes útiles para cuantificar ordenar $\mathrm{y}$ medir fenómenos o hechos de la realidad. Márquez y Sánchez (2010) refieren que, de acuerdo a la teoría sociocultural del aprendizaje, se define al aprendizaje como un proceso psicológico de orden superior, el cual se internaliza por las diversas actividades externas que influyen en las estructuras internas, influenciado por instrumentos de orden material denominadas herramientas y de orden psicológico llamados signos. Desde esta perspectiva, el aprendizaje en matemáticas es un proceso donde se sustituyen ideas concretas por otras abstractas; donde los conceptos matemáticos son formales y se aprenden reproduciéndolos, aplicándolos, ejemplificándolos, analizándolos y creando nuevos conceptos; se genera un aprendizaje de procedimientos mediante la construcción progresiva y la puesta en práctica de todo este proceso $y$, en ese sentido, las tecnologías son un medio para afianzar dicho aprendizaje. Por su parte, García (2015) refiere que estos procesos se desarrollan al representar, argumentar, codificar, decodificar, comunicar, calcular, resolver, entre otros; requieren de un tiempo de formación y se van cimentando a lo largo de todo el transcurso de la escolaridad.

Para el Ministerio de Educación (2015, pp.1824), el aprendizaje en el área de matemáticas se da mediante el desarrollo de cuatro competencias.

Competencia 1: Actúa y piensa matemáticamente en situaciones de cantidad. Implica la resolución de problemas de cantidad, en los que se pueda contar y medir para desarrollar el sentido numérico y de magnitud, construir el significado de las operaciones y aplicar las estrategias de cálculo y estimación (figura 2).

Competencia 2: Actúa y piensa matemáticamente en situaciones de regularidad, equivalencia y cambio.

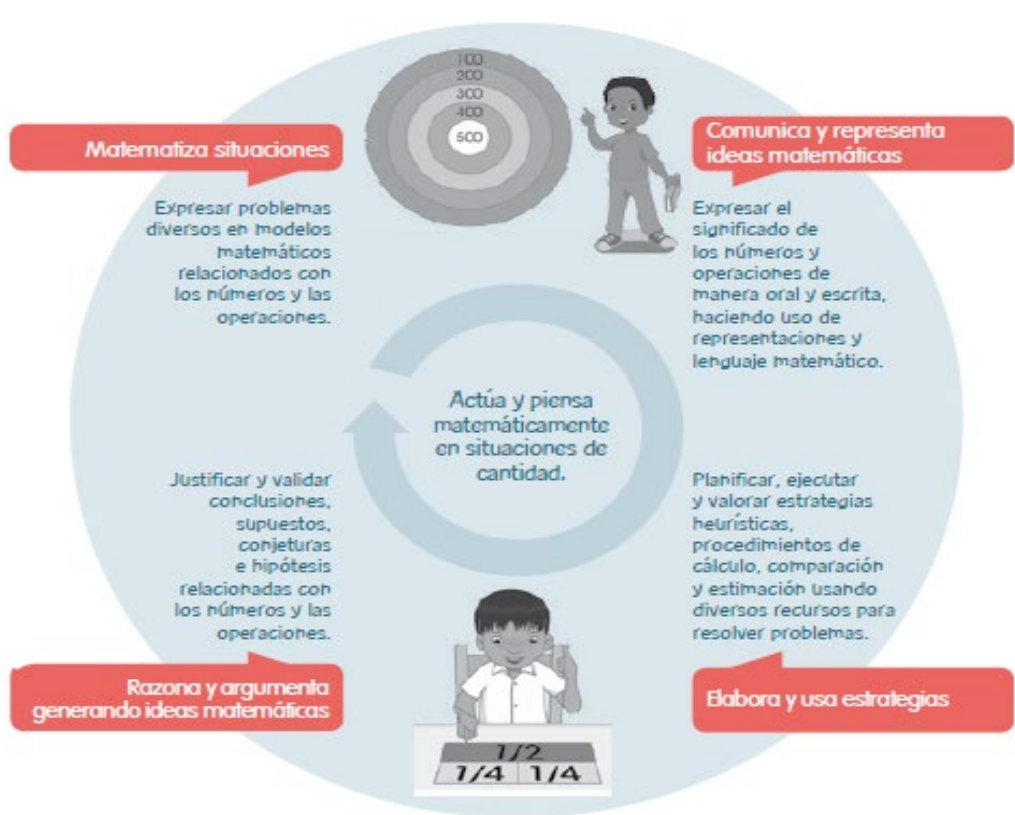

Figura 2. Competencia 1: Actúa y piensa matemáticamente en situaciones de cantidad (Ministerio de Educación, 2015)

Debe desarrollarse progresivamente con la interpretación y generalización de patrones; la comprensión y el uso de igualdades, desigualdades; la comprensión y el uso de relaciones y funciones (figura 3).

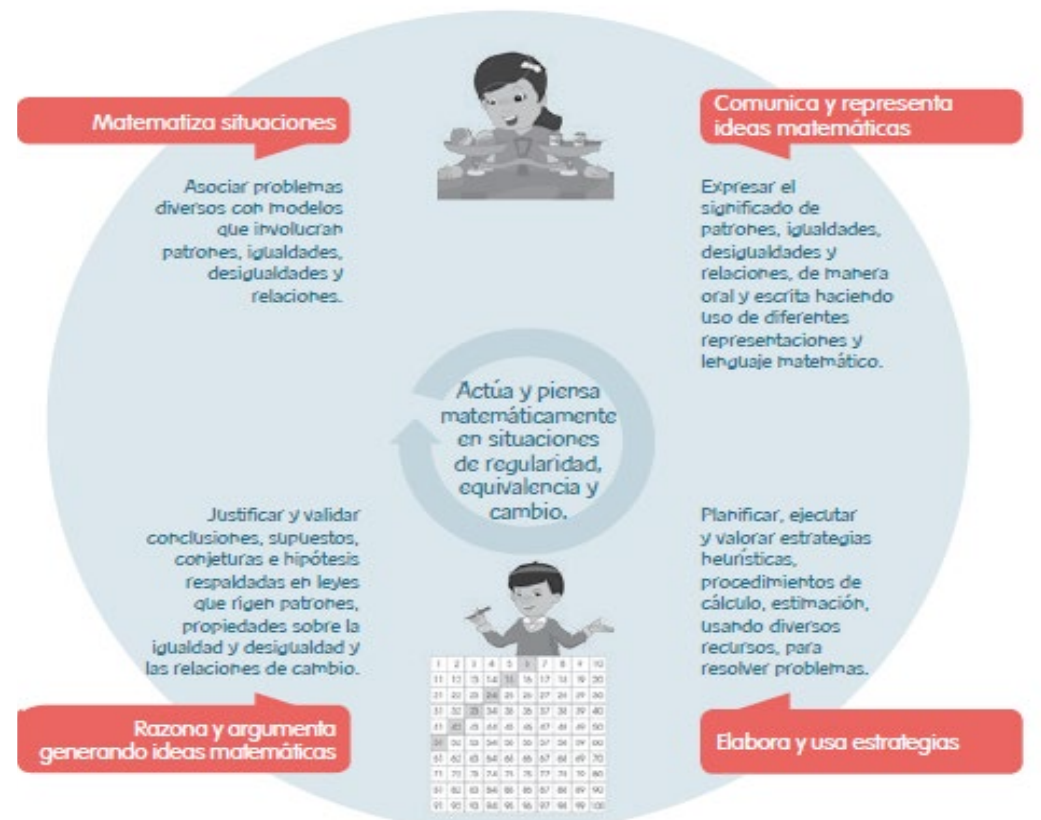

Figura 3. Competencia 2: Actúa y piensa matemáticamente en situaciones de regularidad, equivalencia y cambio (Ministerio de Educación, 2015).

Competencia 3: Actúa y piensa matemáticamente en situaciones de forma, movimiento y localización. Permite desarrollar el sentido de la ubicación en 


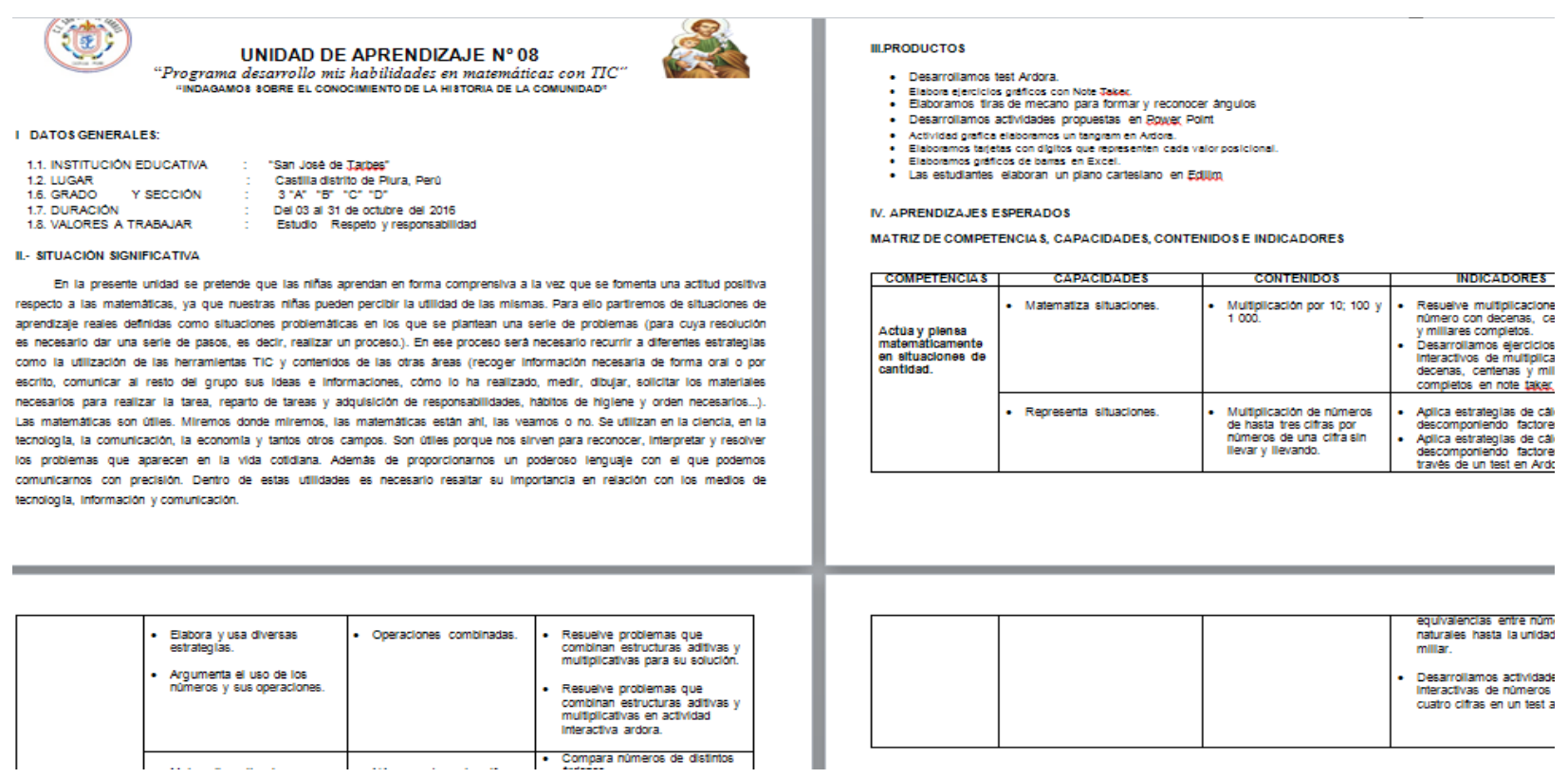

Figura 6. Unidad de aprendizaje elaborada para la investigación.

Fase 3: Elaboración de sesiones de aprendizaje. Las sesiones de aprendizaje constituyen la planificación dosificada y específica de la unidad de aprendizaje e incluyen estrategias y recursos materiales para lograr los aprendizajes propuestos (DCN, 2009, p. 308). El programa experimental estuvo compuesto por 24 sesiones en las cuales se aplicaron las herramientas TIC, como el Software Ardora, note taker, Edilim, Ms Power Point, Excel, entre otros (figura 7).
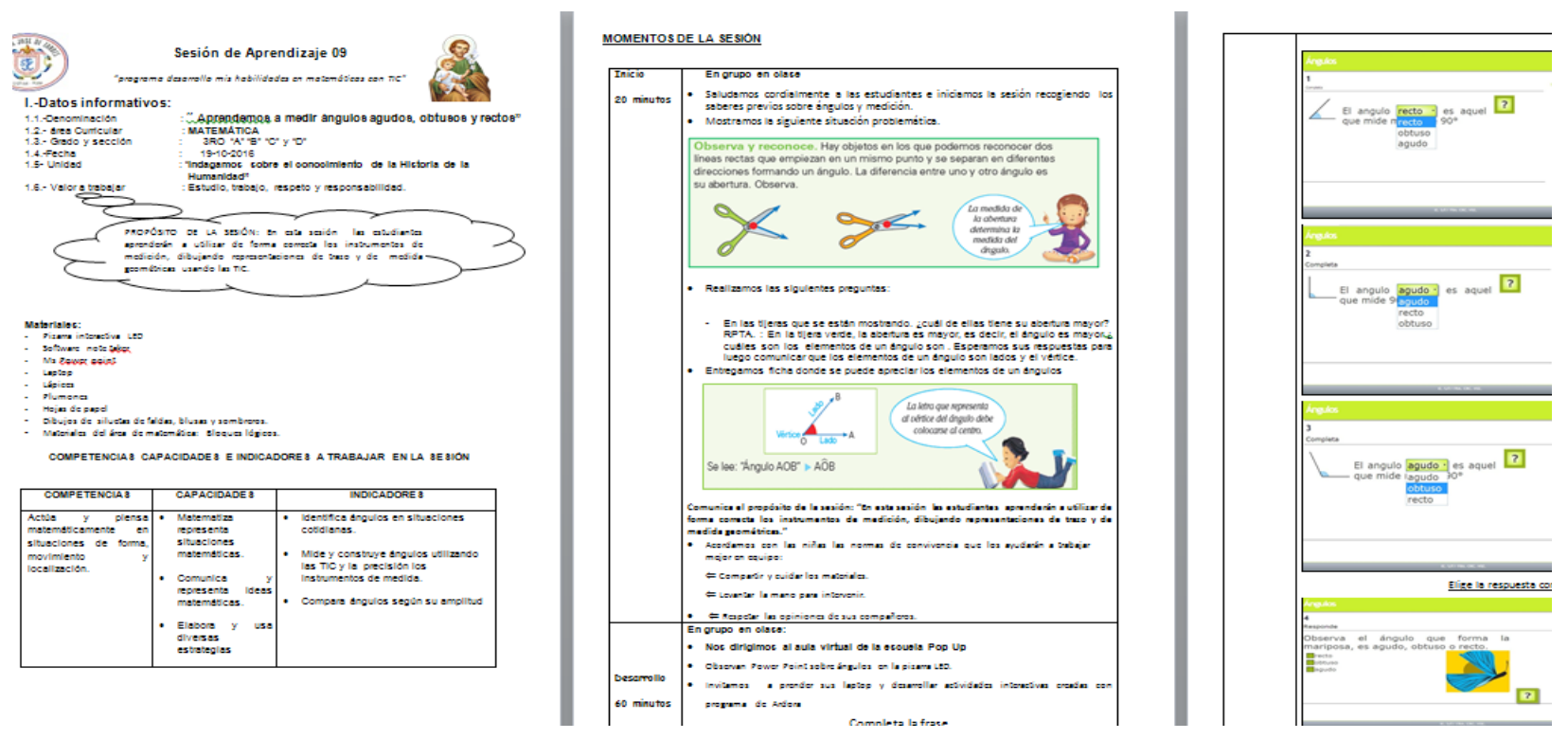

Figura 7. Sesión de aprendizaje elaborada para la investigación, aplicación de Software Ardora. 


\section{Escuelas Pop Up}

La unión de esfuerzos entre el ente público-privado de JP Inspiring Knowledge y Virtual Educa, de manera cooperativa, permitió brindar un nuevo enfoque a las instituciones educativas. Desde su creación, la escuela Pop Up, en Perú, en el año 2015, en el distrito de Castilla, Piura, como parte del plan Ningún niño sin escuela, Ninguna escuela sin conectividad, sirvió para adaptar el aula de clase tradicional a una con características del siglo XXI. De esta manera se acercó a las estudiantes de la educación básica a la apropiación de las TIC, con una infraestructura modular, tecnológica rápida y sencilla, permitiéndose la interacción en múltiples sistemas. Esto permitió incorporar en el proceso de aprendizaje-enseñanza de esta población las herramientas tecnológicas idóneas, contándose con el apoyo de la Fundación Virtual Educa Andina, que propone se siga dando la apropiación continua de estas tecnologías.

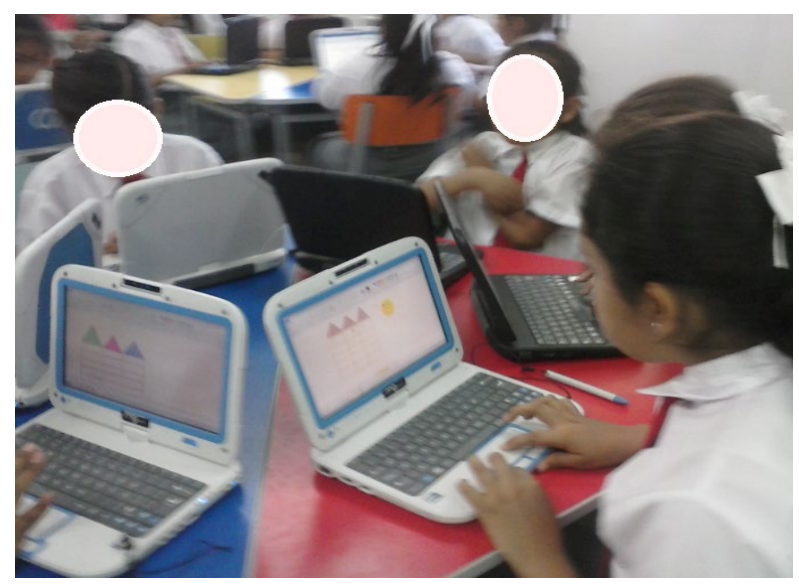

Figura 8. Estudiantes del tercer grado de primaria realizando actividades en la Escuela PopUp. Castilla-Piura.

\section{Materiales y Métodos}

\section{Participantes}

El presente estudio estuvo conformado por una población de 139 estudiantes de cuatro secciones (A, B, C y D) del tercer grado de primaria, que funcionan en la institución educativa San José de Tarbes. Todas las participantes son del sexo femenino, con una edad promedio de entre 8 y 9 años, provenientes de un nivel socioeconómico pobre. La institución educativa está ubicada en la provincia de Castilla, departamento de Piura. La muestra fue de tipo no probabilística. Se trabajó con grupos intactos, ya que en los diseños cuasi-experimentales no se asignan los individuos al azar ni se emparejan los sujetos, grupos están formados antes del experimento (Hernández et al., 2010, p.165.)

Tabla 1

Descripción de la muestra de estudio

\begin{tabular}{lcc}
\hline Grupos & Secciones & Cantidad \\
\hline Control & A y C & 70 \\
\hline Experimental & B y D & 69 \\
\hline & Total & 139 \\
\cline { 2 - 3 }
\end{tabular}

Fuente: I. E. San José de Tarbes.

\section{Instrumento}

Para la recolección de datos se utilizó la prueba Desarrollo mis habilidades en matemática con TIC, descrita en la tabla 2.

La validez del instrumento se determinó mediante juicio de expertos, quienes evaluaron el contenido de la prueba y si esta cumplía con los criterios adecuados para medir las competencias matemáticas. Los especialistas otorgaron una validez promedio de $91 \%$.

La confiabilidad del instrumento se verificó mediante la aplicación de una prueba piloto a un grupo de 20 estudiantes de una institución educativa cercana, la cual tenía características similares a la muestra de estudio. Con los datos de dicha administración piloto se realizó el análisis mediante el coeficiente de confiabilidad de Küder Richardson 20, el mismo que dio un índice de 0.68 , indicando que la prueba era confiable (Me- 
jía, 2005a). También se verificó el grado de dificultad de la prueba, que arrojó 48.79\% (la prueba es relativamente difícil).

Tabla 2

Descripción de la prueba Desarrollo mis habilidades en matemática con TIC

\begin{tabular}{|c|c|}
\hline Dimensiones & Indicadores \\
\hline $\begin{array}{l}\text { Actúa piensa y } \\
\text { matematiza en } \\
\text { situaciones de } \\
\text { cantidad }\end{array}$ & $\begin{array}{l}\text { a. Resuelve multiplicaciones de un número con } \\
\text { decenas, centenas y millares completos. } \\
\text { b. Aplica estrategias de cálculo descompo- } \\
\text { niendo factores. } \\
\text { c. Resuelve problemas que combinan estruc- } \\
\text { turas aditivas y multiplicativas para su solu- } \\
\text { ción. } \\
\text { d. Identifica las equivalencias de números has- } \\
\text { ta cuatro cifras en Unidades de millar, cente- } \\
\text { nas, decenas y unidades. }\end{array}$ \\
\hline $\begin{array}{l}\text { Actúa y piensa } \\
\text { matemáticamen- } \\
\text { te en situaciones } \\
\text { de regularidad, } \\
\text { equivalencia y } \\
\text { cambio }\end{array}$ & $\begin{array}{l}\text { a. Resuelve problemas en los que requiere } \\
\text { realizar el conteo de figuras. } \\
\text { b. Identifica las figuras que completa una se- } \\
\text { cuencia gráfica }\end{array}$ \\
\hline $\begin{array}{l}\text { Actúa y piensa } \\
\text { matemáticamen- } \\
\text { te en situacio- } \\
\text { nes de forma, } \\
\text { movimiento y } \\
\text { localización. }\end{array}$ & $\begin{array}{l}\text { a. Resuelve problemas sobre áreas. } \\
\text { b. Identifica ángulos en situaciones cotidianas } \\
\text { c. Representa mediante pares ordenados la } \\
\text { ubicación de objetos en el plano cartesiano }\end{array}$ \\
\hline $\begin{array}{l}\text { Actúa y piensa } \\
\text { matemáticamen- } \\
\text { te en situaciones } \\
\text { de gestión de } \\
\text { datos e incerti- } \\
\text { dumbre. }\end{array}$ & $\begin{array}{l}\text { a. Emplea tablas y gráficos estadísticos para } \\
\text { analizar e interpretar la información }\end{array}$ \\
\hline
\end{tabular}

Fuente: Fuente: Elaboración propia (2017).

La prueba permite conocer los niveles de logro de los estudiantes en el área de matemática, de acuerdo con cuatro criterios, según lo normado por el Ministerio de Educación (Ministerio de Educación, 2005, p.10; 2009, p. 309), tal como se observa en la tabla 3 .

Tabla 3

Niveles de evaluación de la prueba

\begin{tabular}{lcl}
\hline Nivel & Criterios de evaluación & \multicolumn{1}{c}{ Calificación } \\
\hline 4 & AD & Logro destacado \\
\hline 3 & A & Logro Previsto \\
\hline 2 & B & En Proceso \\
\hline 1 & C & inicio \\
\hline
\end{tabular}

Fuente: Elaboración Propia.

\section{Tipo y diseño}

El estudio es de tipo tecnológico. Los estudios tecnológicos abordan problemas técnicos $\mathrm{y}$, por tanto, pretenden demostrar la utilidad y validez de los recursos tecnológicos en la transformación de la realidad o en la solución de un problema (Sánchez y Reyes, 2006). En tal sentido, el estudio tuvo por finalidad mejorar el aprendizaje de los estudiantes en el área de Matemáticas mediante el uso de las herramientas TIC de la Escuela Pop Up, Piura, Perú (Mejía, 2005a, p. 33). Se utilizó un diseño cuasi-experimental, con preprueba-posprueba y grupo de control. Según Hernández et al. (2010), en este diseño se aplica una preprueba a los grupos de control y experimental, a continuación, se les da estímulo o tratamiento con un programa experimental y, concluido este, se administra la posprueba para, posteriormente, verificar estadísticamente si hay o no diferencias significativas entre ambas mediciones. La tabla 4 describe el modelo del diseño cuasi-experimental.

Tabla 4

Descripción del diseño de estudio

\begin{tabular}{cccc}
\hline \multicolumn{4}{c}{ Diseño cuasi- experimental } \\
\hline$G_{1}$ & $O_{1}$ & $X$ & $O_{2}$ \\
\hline$G$ & $O_{3}$ & - & $O_{4}$ \\
\hline
\end{tabular}

Donde:

$\mathrm{G}_{1}$ : Grupo experimental

$\mathrm{O}_{1}$ : Preprueba

$\mathrm{O}_{2}$ : Posprueba

X: Tratamiento o estímulo con la variable herramientas TIC "Programa desarrollo mis habilidades en matemáticas con TIC”.

G: Grupo de control

$\mathrm{O}_{3}$ : Preprueba

$\mathrm{O}_{4}$ : Posprueba

- : Ausencia de tratamiento o estímulo

Las variables del estudio son:

- Variable independiente (X): Herramientas Tecnológicas de la Información y la Comunicación (TIC).

- Variable dependiente (Y): Aprendizaje en el área de Matemática.

\section{Confidencialidad}

Para garantizar la reserva de la información proporcionada por la muestra, primero se solicitó el consentimiento a la Dirección de la institución 
educativa, la misma que se encargó de solicitar la autorización respectiva a las personas a cargo de las menores. Asimismo, se garantizó la protección de la identidad de la muestra de estudio, en respeto a sus derechos individuales.

\section{Procedimiento}

Para viabilizar el presente estudio, se hizo una serie de coordinaciones con las autoridades de la Institución Educativa San José de Tarbes. Esta institución tiene como parte de su infraestructura a la Escuela PopUp, donde se realizó la investigación y que cuenta con las herramientas tecnológicas idóneas para el desarrollo del trabajo planificado en la forma que se describe a continuación:

Proceso 1. Se solicitó a la Dirección el permiso para que la Fundación Virtual Educa Andina y la Universidad Alas Peruanas puedan ejecutar la investigación en las instalaciones de la Escuela Pop Up. La petición fue aceptada.

Proceso 2. Se coordinó con los docentes responsables de las aulas del tercer grado de primaria, secciones A, B, C y D, para el desarrollo de los contenidos mediante las sesiones de aprendizaje del programa Desarrollo mis habilidades en matemáticas con TIC”. En el trabajo se incluyeron las cuatro secciones.

Proceso 3. Se ejecutó el estudio en el primer y segundo bimestre del 2016. Comprendió la recolección de información mediante la administración de la preprueba a las cuatro secciones y la aplicación del programa solo al grupo experimental, mediante las 24 sesiones de aprendizaje en las que se incluyó el uso de las herramientas tecnológicas.

Proceso 4. Se recolectó datos al concluir la aplicación del programa con la posprueba a las cuatro secciones, para conocer si el programa mejoró el logro de aprendizaje de los estudiantes en el área de matemática.

Proceso 5: Se analizó la información mediante la estadística descriptiva e inferencial. Se utilizó la hoja de cálculo de Excel v.2010 y SPSS v.21.

\section{Resultados}

En el análisis de los resultados se describe en un primer momento los niveles de logro en el área de matemática, de forma general; luego se hace la comparación entre los grupos de control y experimental. En los acápites siguientes se detallan los hallazgos.

\section{Aprendizaje en el área de Matemática}

Según la tabla 5, en el pre test la mayoría de niñas del grupo de control (89.9\%) y del grupo experimental $(92.6 \%)$ se encontraban en inicio. En el post test, la mayoría de estudiantes del grupo de control (50.7\%) se encontraban en proceso, mientras que en el grupo experimental el $44.1 \%$ alcanzó el logro previsto y el $11.8 \%$ el logro destacado.

Tabla 5

Aprendizaje en el área de Matemática según niveles de logro, pre test y post test

\begin{tabular}{llcccc}
\hline & & \multicolumn{2}{c}{$\begin{array}{c}\text { G. de } \\
\text { control }\end{array}$} & \multicolumn{2}{c}{$\begin{array}{c}\text { G. experi- } \\
\text { mental }\end{array}$} \\
\cline { 3 - 6 } Fase & Nivel de logro & $f$ & $\%$ & $F$ & $\%$ \\
\hline Pre test & C (Inicio) & 62 & 89.9 & 63 & 92.6 \\
\hline \multirow{3}{*}{ B (En proceso) } & 7 & 10.1 & 5 & 7.4 \\
\hline & A (Logro previsto) & 0 & .0 & 0 & .0 \\
\hline & AD (Logro destacado) & 0 & .0 & 0 & .0 \\
\hline Post test & C (Inicio & 12 & 17.4 & 3 & 4.4 \\
\hline & B (En proceso) & 35 & 50.7 & 27 & 39.7 \\
\hline & A (Logro previsto) & 22 & 31.9 & 30 & 44.1 \\
\hline & AD (Logro destacado) & 0 & .0 & 8 & 11.8 \\
\hline & TOTAL & 69 & 100.0 & 68 & 100.0 \\
\hline
\end{tabular}

Fuente: Base de datos de los resultados de la prueba de matemática..

\section{Nivel de logro en el área de Matemática por} secciones

De acuerdo con los resultados que se muestran en la tabla 6, en el nivel C (Inicio), el mayor porcentaje de nińas estuvo en tercer grado C (28.6\%); en el nivel B (En proceso), los mayores porcentajes de niñas corresponden a las aulas de tercer grado A (65.7\%) y tercer grado D (44.1\%); en el nivel A (Logro previsto), el mayor porcentaje de niñas 
se registró en tercer grado $\mathrm{B}(42.8 \%)$ y tercer grado $\mathrm{D}(44.1 \%)$ y en el nivel $\mathrm{AD}$ (Logro destacado, el mayor porcentaje de niñas fue en tercer grado $\mathrm{B}$ (14.3\%) y en tercer grado D (11.8\%).

\section{Tabla 6}

Aprendizaje en el área de Matemática, según niveles de logro por secciones

\begin{tabular}{|c|c|c|c|}
\hline Sección & Niveles de logro & $\mathrm{F}$ & $\%$ \\
\hline \multirow{4}{*}{$\begin{array}{l}\text { 3ro. A } \\
n=35\end{array}$} & C (Inicio) & 2 & 5.7 \\
\hline & B (En proceso) & 23 & 65.7 \\
\hline & A ( Logro previsto) & 10 & 28.6 \\
\hline & AD (Logro destacado) & 0 & .0 \\
\hline \multirow{4}{*}{$\begin{array}{l}\text { 3ro. B } \\
n=34\end{array}$} & C (Inicio) & 3 & 8.6 \\
\hline & B (En proceso) & 12 & 34.3 \\
\hline & A ( Logro previsto) & 15 & 42.8 \\
\hline & AD (Logro destacado) & 5 & 14.3 \\
\hline \multirow{4}{*}{$\begin{array}{l}\text { 3ro. C } \\
n=34\end{array}$} & C (Inicio) & 10 & 28.6 \\
\hline & B (En proceso) & 13 & 37.1 \\
\hline & A ( Logro previsto) & 12 & 34.3 \\
\hline & AD (Logro destacado) & 0 & .0 \\
\hline \multirow{4}{*}{$\begin{array}{l}\text { 3ro. } \\
n=34\end{array}$} & C (Inicio) & 0 & .0 \\
\hline & B (En proceso) & 15 & 44.1 \\
\hline & A ( Logro previsto) & 16 & 44.1 \\
\hline & AD (Logro destacado) & 4 & 11.8 \\
\hline Total & & 139 & 100.0 \\
\hline
\end{tabular}

Fuente: Base de datos de los resultados de la prueba de matemática.

La comparación gráfica de los resultados observada en la figura 9, muestra que en tercer grado A es muy evidente que las niñas se hallan en proceso (65.7\%) para desarrollar sus competencias matemáticas; en tercer grado $\mathrm{B}$, un porcentaje acumulado de $57.1 \%$ (la mayoría) están entre el logro previsto y el logro destacado; en tercer grado $\mathrm{C}$ están en transición del proceso $(37.1 \%)$ hacia el logro previsto $(34.3 \%)$ y en tercer grado $\mathrm{D}$, un porcentaje acumulado de $55.9 \%$ están entre los niveles de logro previsto y logro destacado.

Prueba de hipótesis. Para contrastar la hipótesis general, en primer lugar, se determinó si los datos de los grupos de control y experimental cumplían con una distribución normal. Este análisis se realizó a través de la prueba de Shapiro-Wilk, la cual arrojo que todos los datos de ambos grupos, tanto en pre test como en post test, provienen de una distribución normal ( $\mathrm{p}>.05$ ), como se describe en la tabla 7.

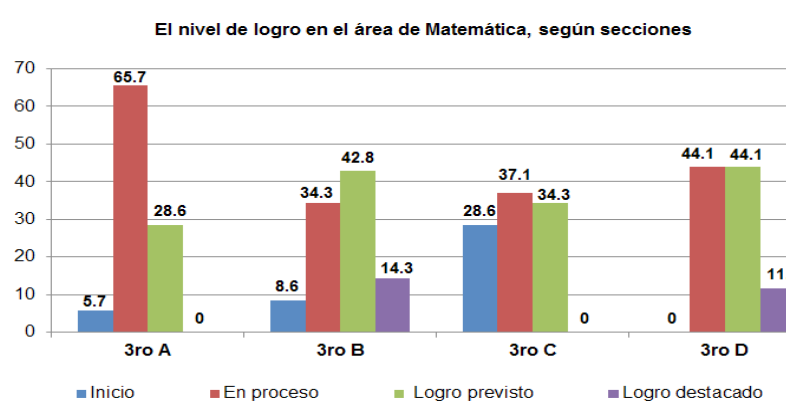

Figura 9. Comparación gráfica del aprendizaje en el área de Matemática, según logro por secciones.

Tabla 7

Prueba de normalidad de los grupos de control y experimental, pre test - post test

\begin{tabular}{llcr}
\hline Fase & Grupos & Shapiro-Wilk & p-valor \\
\hline \multirow{2}{*}{ Pre test } & De Control & .980 & .354 \\
\cline { 2 - 4 } & Experimental & .985 & .565 \\
\hline \multirow{2}{*}{ Post test } & De Control & .974 & .167 \\
\cline { 2 - 4 } & Experimental & .975 & .191 \\
\hline
\end{tabular}

Fuente: Base de datos de los resultados de la prueba de matemática.

\section{Hipótesis general.}

Ha. El programa desarrollo mis habilidades en matemáticas con TIC mejora significativamente el aprendizaje en el área de matemática en los estudiantes del tercer grado de primaria de la IE San José de Tarbes.

H0. El programa desarrollo mis habilidades en matemáticas con TIC no mejora significativamente el aprendizaje en el área de matemática en los estudiantes del tercer grado de primaria de la IE San José de Tarbes.

Para el contraste de la hipótesis general se realizó el análisis inferencial utilizando la prueba $\mathrm{T}$ de Student para muestras independientes, que calculó $\mathrm{p}=.027<.05$ para la diferencia entre los grupos de control y experimental, en el pre test de la prueba de Matemática; es decir, había diferencias significativas entre estos. De igual manera, en el post test, la prueba calculó $\mathrm{p}=.000<.05$, indicando una diferencia significativa entre ambos grupos (tabla 8). 
Tabla 8

Resultado del contraste de hipótesis mediante la prueba de T de Student, pre test-post test

\begin{tabular}{llrrrr}
\hline Fase & Grupos & Media & $\begin{array}{l}\text { Dife- } \\
\text { rencia }\end{array}$ & $\begin{array}{l}\text { T de } \\
\text { Student }\end{array}$ & p-valor \\
\hline Pre test & De Control & 38.65 & 4.43 & 2.243 & .027 \\
\cline { 2 - 6 } & Experimental & 34.22 & & & \\
\hline Post test & De Control & 63.28 & 8.68 & -4.224 & .000 \\
\cline { 2 - 6 } & Experimental & 71.96 & & & \\
\hline
\end{tabular}

Fuente: Base de datos de los resultados de la prueba de matemática.

La influencia de las herramientas TIC en el aprendizaje en el área de Matemática

La figura 10, que se basa en los puntajes totales de la prueba, representa el efecto del programa Desarrollo mis habilidades en matemáticas con TIC. Se observa que, en el pre test, la mediana del grupo de control (39) fue 4 puntos más que la mediana del grupo experimental (35). En cambio, en el post test, como consecuencia del programa, la mediana de los datos del grupo experimental (71) fue 8 puntos más que la mediana del grupo de control (63).

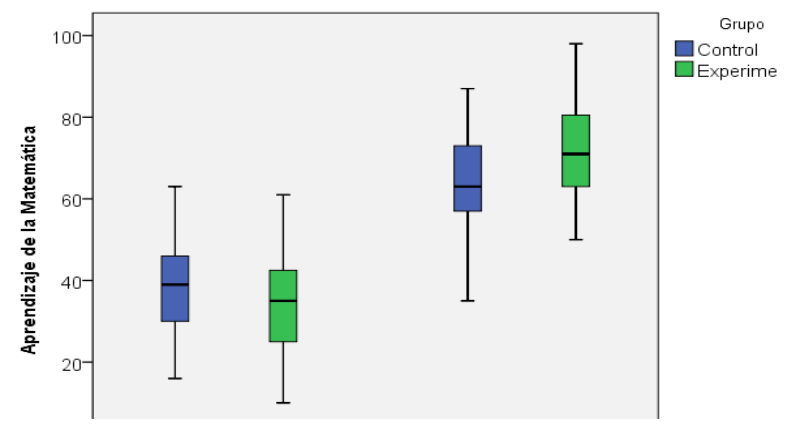

Figura 10. Diagrama de caja y bigotes para la comparación de resultados de los grupos de control y experimental, pre test $\mathrm{y}$ post test.

\section{Discusión y Conclusiones}

El área de Matemáticas es primordial en la educación a nivel mundial; sirve de base para que los estudiantes en formación adquieran y desarrollen competencias idóneas que les permitan continuar desarrollándose académicamente a nivel superior. Pese a su transcendencia, esta todavía sigue siendo un problema para los estudiantes, aun cuando las instituciones de educación básica y superior se han preocupado en buscar estrategias diversas para apalear las dificultades que se presentan en la enseñanza de las mismas; razón por la cual el área de Matemática se tuvo en cuenta en esta investigación.

Los resultados del pre test indicaron que no había diferencias estadísticamente significativas entre el grupo de control $(89.9 \%)$ y el grupo experimental (92.6\%), que se encontraban en el nivel C (Inicio). Sin embargo, después de la experimentación con el programa Desarrollo mis habilidades en matemáticas con TIC, con apoyo de la infraestructura de la Escuela Pop Up, se verificaron resultados diferenciados; un porcentaje acumulado de $57.1 \%$ (la mayoría) de estudiantes del grupo experimental del tercer grado B estuvieron entre el logro previsto y el logro destacado; mientras que un porcentaje acumulado de $55.9 \%$ de estudiantes de tercer grado D estuvieron entre los niveles de logro previsto y logro destacado. Esto indicó la tendencia que las TIC tienen en la actualidad; son relevantes en los estudiantes como herramientas de apoyo en su proceso de aprendizaje. Tales resultados coinciden con los hallazgos de Jame, Zabal y Minguillon (2013), quienes refieren que los estudiantes acogen favorablemente las actividades elaboradas con tecnologías, porque les resulta sencillo el manejo y los contenidos brindados le han sido de gran ayuda en el aprendizaje de matemáticas. En igual sentido se pronuncia Gonzáles (s.f.), al enfatizar que, en el aula, las TIC proporcionan a los estudiantes nuevas formas de aprender las matemáticas. Las utilizan como otro medio para explicar las clases de matemáticas, a través de Paint, software educativo, pizarra digital, lo cual favorece la ampliación de conocimientos y la conexión de ideas y conceptos en la enseñanza de matemáticas en la educación primaria. 
La irrupción de las TIC en el aula ha tenido un avance vertiginoso en todas las áreas y niveles de educación, sobre todo si se tiene en cuenta que los estudiantes de este siglo están habituados a la apropiación de estas, por ser estas herramientas de su generación con las que viven en su vida cotidiana y se interrelacionan con sus pares y su entorno en general.

También se ha podido contrastar en este estudio que el programa Desarrollo mis habilidades en matemáticas con TIC mejora significativamente el nivel de logro en el área de matemática en los estudiantes del tercer grado de primaria de la IE San José de Tarbes, Escuela Pop Up, Piura, Perú $(\mathrm{p}<.05,=.000)$. Estos resultados se relacionan con lo mencionado por González (s.f.) al indicar que las herramientas TIC generan un alto nivel de motivación al aprendizaje de las matemáticas en los estudiantes. Maz-Machado (2012) señala que las matemáticas se han beneficiado de las TIC, al tener una variedad de software que permiten mejorar los procesos de visualización de conceptos; aseguran una adecuada comprensión de ellos al ofrecer variados sistema de representación, como la hoja de cálculo de Excel permite hacer representaciones de diversa índole.

Igualmente, se comprobó en esta investigación que la apropiación de las TIC por medio de la Escuela Pop Up brinda los elementos idóneos para que los estudiantes interactúen con estos nuevos entornos. Hubo una diferencia significativa entre ambos grupos; la mayoría de estudiantes del grupo de control (50.7\%) se encontraban en proceso, mientras que en el grupo experimental el $44.1 \%$ alcanzó el logro previsto y el $11.8 \%$ el logro destacado. Tal resultado coincide con los hallazgos de Vidaurre y Vallejos (2015), quienes refieren que el aprendizaje de la matemática después de la aplicación del software EdiLIM genera en los estudiantes un nivel de logro significativo. Los estudiantes con quienes realizaron el estudio estuvieron en el nivel deficiente y al final del experimento migraron a las categorías regular, bueno y muy bueno, con porcentajes de 10\%, $86.7 \%$ y $3.3 \%$, respectivamente.

\section{Agradecimiento}

De manera especial se agradece a la Hna. Carla Rosales Díaz, Directora de la IE San José de Tarbes; a las docentes María Antonieta Vegas Timoteo, Catherine Paola Rodríguez Coronado, Clara Soledad del Valle Cerna, Heidy Lourdes Sinche Espinoza, Edita Urbina Barreto y Fiorella Rosillo, al haber ejecutado las sesiones de aprendizaje del presente estudio con sus estudiantes del tercer grado de primaria, y a todo el personal técnico que brindó su apoyo en la Escuela Pop Up.

El agradecimiento también a la Fundación Virtual Educa Andina, que ha financiado el presente estudio en aras de una mejora en las competencias de las estudiantes del nivel primario en el área de matemáticas de la Escuela Pop Up, en Piura, Perú.

\section{REFERENCIAS Bibliográficas}

Aulaplaneta. (2015, septiembre 8). 25 herramientas para enseñar Matemáticas con las TIC. Recuperado de: http:// www.aulaplaneta.com/2015/09/08/recursos-tic/25-herramientas-para-ensenar-matematicas-con-las-ticl

BBC Mundo. (2013, diciembre 3). ¿Cómo les fue a los países de América Latina en la Prueba Pisa? Recuperado de http://www.bbc.com/mundo/noticias/2013/12/131203_ pisa_resultados_am

Benavidez, V. (2010). Las evaluaciones de logros educativos y su relación con la calidad de la educación. Revista Iberoamericana de educación, 53, 83-96.

Caro, L., Vargas, T. y Campo, J. (2015). Estudio preliminar sobre el uso de tecnologías de información y comunicación en instituciones de educación superior de la Red Ilumno. Revista Hamut'ay, 2 (1) 49-62. Recuperado de https://doi. org/10.21503/hamu.v2i1.829

Canós-Ruis, N. y Guitert-Cateses, M. (2014). Uso de las TIC en la interacción profesor-alumno: un estudio de caso en una Escuela de Arte y Superior de Diseño. Revista Latinoamericana de Tecnología Educativa, 13 (1) 63-74.

Chaves, O., Chaves, L. y Rojas, D. (2015). La realidad del uso de las TIC y su mediación pedagógica para enriquecer las clases de inglés. Revista Ensayos Pedagógicos, 10 (1), 159-183.

Calderon, S., Nuñez, P. Di Laccio, J. Iannelli, L. y Gil, S. (2014). Aulas-laboratorios de bajo costo, usando TIC. Revista Eureka sobre enseñanza y divulgación de las Ciencias, 12 (1) 212-226.

Ministerio de Educación. (2009). DCN-Diseño Curricular Nacional. Recuperado de: www.minedu.gob.pe/DeInteres/ 
xtras/download.php?link=dcn_2009.pdf

PISA (2015) PISA: Resultados clave. OCDE. Recuperado de: http://www.oecd.org/pisa/pisa-2015-results-in-focusESP.pdf

Farroñay, P. y Ancaya, M. (2016). Gestión administrativa y conocimiento de las TIC en docentes de educación primaria de las instituciones educativas Innova Schools de San Juan de Lurigacho y Ate. Revista Hamut'ay, 3 (1) 35-45. Recuperado de: https://doi.org/10.21503/hamu.v3i1.998

González, L. (s.f.). El conocimiento y uso de estrategias metodológicas apoyadas en las TIC para mejorar el proceso de enseñanza-aprendizaje del área de matemáticas en la educación primaria.

García, B. (2015). Competencias matemáticas, expectativas de aprendizaje y enculturación matemática. Escenarios, 13 (1), 22-33. Recuperado de: https://doi.org/10.15665/esc. v13i1.549

Hernández, R., Fernández, C. y Baptista, P. (2010). Metodología de la investigación (5ta. Ed.) México, D.F.: Mc. Graw-Hill

Infobae América. (2013, diciembre 2). Informe PISA: América Latina retrocede en comprensión de lectura, matemática y ciencias. Recuperado de http://www.infobae. com/2013/12/02/1527987-informe-pisa-america-latina-retrocede-comprension-lectura-matematica-y-ciencias/

Jame, G., Zabal, M. y Minguillon, E. (2013). Autoaprendizaje de las matemáticas con nuevas tecnologías en los grados de carácter económico. Revista electrónica sobre la enseńanza de la Economía Pública, 13, 1-22. Recuperado de: http://e-publica.unizar.es//wp-content/uploads/2015/09/ 131JARNE.pdf

Maz-Machado, A. (2012). TIC y matemáticas: una integración en continuo progreso. Revista de Educación Mediatica yTIC, 1 (2), 4-6. Recuperado de: https://doi.org/10.21071/ edmetic.v1i2.2848

Márquez, G. y Sánchez, M. (2010). Motivación al logro, uso de tecnología y aprendizaje estudiantil en matemática del primer ańo de educación superior. Revista Iberoamericana de Educación, 52 (4), 1-11.

Mejía, E. (2005a). Metodología de la investigación científica. Lima: Ediciones de la Universidad Nacional Mayor de San Marcos.

Mejía, E. (2005b). Técnicas e instrumentos de investigación. Lima: Ediciones de la Universidad Nacional Mayor de San Marcos.

Ministerio de Educación. (2005). Evaluación de los aprendizajes de los estudiantes en la educación básica regular. (Directiva No. 004-VMGP-2005, aprobado por R.M. No. 0234-2005-ED) Recuperado de:

http://www.minedu.gob.pe/normatividad/directivas/DIR004-2005-VMGP.pdf

Ministerio de Educación. (2009). Diseño curricular nacional de educación básica regular. Recuperado de: http://www. minedu.gob.pe/DeInteres/xtras/dcn_2009.pdf
Ministerio de Educación. (2015). Rutas del aprendizaje. Versión 2015, ¿Qué y cómo aprenden nuestros niños y niñas? IV Ciclo, Área curricular Matemática. Recuperado de: http://www.minedu.gob.pe/rutas-del-aprendizaje/documentos/Primaria/Matematica-III.pdf

Parra, O. y Díaz, V. (2014). Didáctica de las matemáticas y tecnologías de la información y la comunicación. Revista Educación y Desarrollo Social, 8 (2), 60-81.

Riveros, V., Mendoza, M. y Castro, R. (2011). Las tecnologías de la información y la comunicación en el proceso de instrucción de la matemática. Quórum Académico, 8 (15) 11-130.

Sánchez, H. y Reyes, C. (2006). Metodología y diseños en la Investigación Científica. Lima: Visión Universitaria.

Sarmiento, M. (2007). La enseñanza de las matemáticas y las NTIC. Una estrategia de formación permanente. (Tesis doctoral inédita, Universitat Rovira I Virgili). Recuperada de http://www.tdx.cat/bitstream/handle/10803/8927/C-TESIS_CAPITULO_1.pdf; jsessionid=AC50110E7C3A35E48A72D3B03E0AFA79? sequence=3

UNESCO. (2013). Enfoques estratégicos sobre las TICs en educación en América Latina y el Caribe.

Vidaurre, W. y Vallejos, L. (2015). Software educativo para lograr aprendizajes significativos en el área de matemática. UCV-HACER, 4 (2) 38-45.

Villarreal, M. (2012). Tecnologías y educación matemática: necesidad de nuevos abordajes para la enseñanza. Innovación y Experiencias, 3(5), 73-94. 


\title{
La evaluación de la educación a distancia. Propuesta de una guía para la autoevaluación
}

\author{
Assessment in distance education. A proposal of a guide for self-evaluation
}

\author{
Ana María Bañuelos Márquez ${ }^{1}$ \\ Gabriela Montero Montiel² \\ Universidad Nacional Autónoma de México
}

Recibido: 27-03-2017

Aceptado: 03-06-2017

\section{Cita Recomendada}

Bañuelos, A. y Montero, G. (2017) La evaluación de la educación a distancia. Propuesta de una guía para la autoevaluación. Hamut'ay, 4 (1), 31-44. Recuperado de: http://doi.org/10.21503/hamu.v4i1.1394

\section{RESUMEN}

La educación a distancia comienza a generalizarse y no es extraordinario identificar en esta modalidad programas académicos que adolecen de calidad. Por ello es necesario examinar sus características y la manera en que operan. Al realizar la evaluación de un programa educativo de esta naturaleza, se puede determinar la forma en que se están desarrollando sus procesos, en busca de una mejora de la calidad educativa o con fines de acreditación. Sin embargo, es recomendable que cualquier valoración de este tipo comience con un ejercicio de autoevaluación, donde los propios actores del proceso educativo sean los responsables de la valoración. La autoevaluación es el primer paso para recoger, sistematizar y globalizar la información acerca del objeto de análisis, al considerar los objetivos, procesos, procedimientos y resultados del modelo educativo que ejecutan, con la finalidad de que la institución tome conciencia de sus fortalezas y debilidades, así como sus áreas de oportunidad. El objetivo de este estudio fue estructurar un instrumento para la autoevaluación de programas educativos a distancia. Después de aproximadamente cuatro meses de trabajo analítico documental y la depuración de propuestas se desarrolló la Guía de autoevaluación para programas educativos a distancia, instrumento que integra cinco ejes, 17 categorías y 30 indicadores para autoevaluar programas educativos a distancia. Su construcción y validación se encuentran sustentadas por su aplicación a un programa académico a distancia, para la formación profesional en la Universidad Nacional Autónoma de México, la misma que atiende aproximadamente a 2,800 estudiantes con una planta académica de 500 profesores.

Palabras Clave: Educación a distancia, evaluación, autoevaluación

\footnotetext{
1 Doctora en Pedagogía por la Universidad Nacional Autónoma de México (UNAM), especialista en educación a distancia, evaluación de la docencia y de programas educativos no presenciales. Profesora del Sistema Universidad Abierta de la Facultad de Psicología y Subdirectora de Evaluación Educativa de la Secretaría Académica de la Coordinación de Universidad Abierta y Educación a Distancia de la UNAM.

2 Maestra en Administración de Organizaciones por la Facultad de Contaduría y Administración de la Universidad Nacional Autónoma de México (UNAM), Master Universitario Internacional en Enseñanza Abierta y a Distancia, en la Universidad Nacional de Educación a Distancia (UNED) de España, Especialidad en Entornos Virtuales de Aprendizaje.
} 


\section{Abstract}

Distance education has started to expand dramatically. It's not surprising, however, identifying academic programs in this modality, which lack of quality. It is therefore necessary to examine their characteristics and the way in which they operate. When evaluating an educational program of this nature, it is possible to determine the way in which its processes are being developed, in search of an improvement of the educational quality or for accreditation purposes. However, it is advisable that any appraisal of this type begins with a self-assessment exercise, where the parties involved in the educational process are themselves responsible for the evaluation. Self-evaluation is the first step to collect, systematize and globalize information about the object of analysis, since it considers the objectives, processes, procedures and results of the educational model they execute, in order to make the institution aware of its strengths and weaknesses, as well as their areas of opportunity. The objective of this study was to develop an instrument for self-evaluation in distance education programs. After approximately four months of documentary analytical work and the dismissal of proposals, the Self-Evaluation Guide for distance education programs was developed, an instrument that integrates five areas, 17 categories and 30 indicators to self-evaluate distance education programs. Its development and validation are supported by its application to a distance academic program for professional training at the National Autonomous University Mexico, which handles approximately 2,800 students with an academic staff of 500 teachers.

Keywords: Distance education, assessment, self-evaluation

\section{INTRODUCCIÓN}

La evaluación de la calidad de la educación a distancia es un tema muy importante y de amplio recorrido en la literatura. Una búsqueda en cualquier base de datos especializada arroja una cantidad impresionante de referencias bibliográficas relacionadas con el tema. Esto denota la relevancia de la temática, entre otros motivos, debido a los procesos de acreditación a los que las universidades deben responder ante organismos nacionales e internacionales en este campo. Asimismo, la cantidad de documentos sobre el tema refleja el dinamismo y evolución de los indicadores de evaluación de la modalidad a distancia, lo que ha dado como resultado una diversidad de propuestas, experiencias, reportes de buenas prácticas, análisis críticos, entre otros.

En México, de acuerdo al análisis hecho por López, Chávez y Bautista (2011, pp. 309-310), el aseguramiento de la calidad de la educación superior está regulado por el Sistema de Evaluación y Acreditación que involucra distintos propósitos evaluativos y a diferentes organismos. Los Comités Interinstitucionales para la Evaluación de la Educación Superior (CIEES), pueden participar en una evaluación diagnóstica institucional. El Consejo para la Acreditación de la Educación Superior (COPAES) evalúa la calidad de los programas educativos con miras a la acreditación, siendo la única instancia reconocida por el Ministerio de Educación Pública del país. Para cumplir con su objetivo, el Consejo agrupa alrededor de 30 organismos acreditadores, así se asegura de cubrir todas las áreas de conocimiento. A nivel de posgrado, el Programa Nacional de Posgrados de Calidad (PNPC), junto con el Consejo Nacional de Ciencia y Tecnología (CONACyT) es el responsable de reconocer la calidad de los programas académicos de especialización, maestría y doctorado (López, Chávez y Bautista, 2011). En todos los casos, las valoraciones se integran por una autoevaluación, evaluación externa (pares académicos) y el seguimiento para la mejora continua, situación que se ilustra en la figura 1 .

Si bien en todos los casos anteriores el autodiagnóstico inicial tiene el propósito de establecer una línea base para el mejoramiento, ya sea per se o con fines de acreditación, en esta investigación se perfila una guía de autoevaluación que aplica 
exclusivamente para la educación a distancia. Se considera componentes de orden psicopedagógico, tecnológico, de gestión y a los actores del proceso educativo con un único propósito: trabajar en la mejora continua.

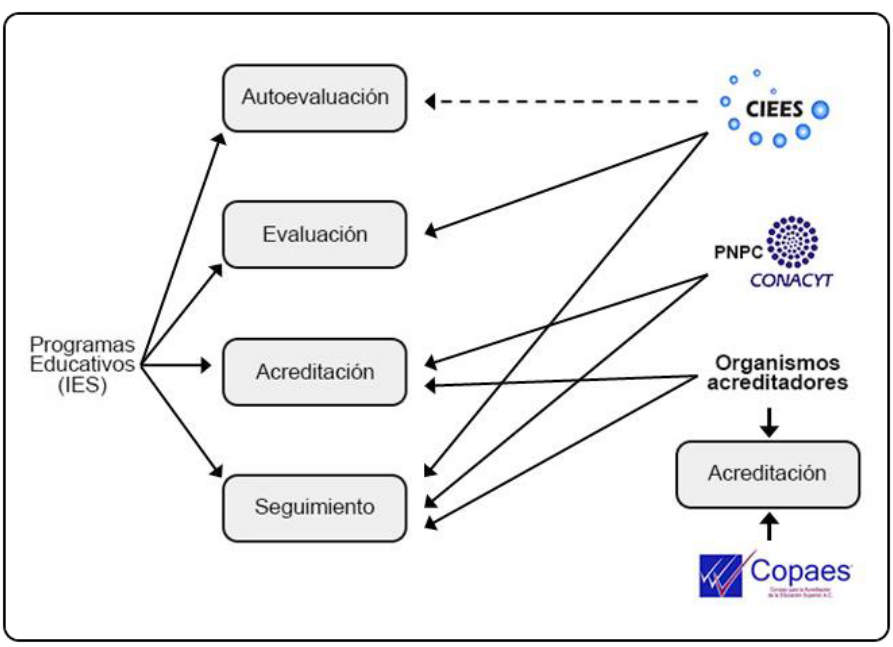

Figura 1. Evaluación y acreditación de programas educativos.

Fuente: López, Chávez y Bautista (2011).

Es así que se coincide con González et al. (2011) en el sentido de que la autoevaluación es un proceso de autoconocimiento y re-conocimiento; los evaluadores son los actores de la propia institución educativa. La intención de la autoevaluación tiene tres momentos: (i) la realización de un autoestudio en el que se concentre y sistematice la información necesaria para llevar a cabo el proceso, (ii) un autoanálisis de los resultados obtenidos, cuyo producto es un diagnóstico de cómo se está en relación a cómo se debería estar, y (iii) una autorregulación poniendo en práctica un plan de mejora en el que se planee la consolidación de las fortalezas y se atienden las fallas detectadas o se planeen nuevas metas.

La investigación que se presenta constituye la primera fase de un estudio de largo alcance cuyo objetivo es la validación de una Guía de autoevaluación para programas educativos a distancia. En este documento se describe el proceso de construcción de dicha guía y la primera evaluación a través de su aplicación a un programa a distancia de la Universidad Nacional Autónoma de México (UNAM), en la Ciudad de México. Para una segunda etapa posterior, se desarrollará la validación con la totalidad de programas a distancia que ofrece la Universidad.

El razonamiento detrás de la presente propuesta fue la determinación del modelo educativo de educación a distancia: es decir, de la concepción de enseñanza en esta modalidad y su consecuente evaluación. Entre otras, surgen las siguientes incógnitas a despejar: ¿Qué elementos tienen mayor peso? ¿El tecnológico? ¿El educativo? La respuesta la encontrará el lector a lo largo de la exposición. De esta manera, el objetivo del estudio es validar una Guía de autoevaluación para programas educativos a distancia, que permita a las instituciones de educación superior identificar las fortalezas y áreas de oportunidad para iniciar planes de mejora que consoliden los programas educativos.

\section{Calidad de la educación a distancia}

La calidad educativa es la mejora continua o el refuerzo constante de la coherencia entre aquello que se pretende del alumnado cuando acaba su formación (finalidades educativas), lo que se hace en las aulas para garantizar que se cumpla (procesos educativos) y, finalmente, los resultados de aprendizaje obtenidos (Malpica, 2012, p. 56). Sin embargo, hablar de calidad conduce a la reflexión de ¿̨respecto de quién o de qué?, tal y como lo señala el Instituto Nacional para la Evaluación de la Educación (INEE, 2005, p. 4) de México. Dependiendo de la postura y el propósito de quien estudia la calidad, y del sujeto o la realidad sobre la que se reflexiona, se encuentran diferencias en torno al concepto.

De acuerdo a la Red Iberoamericana para la Acreditación de la Calidad de la Educación Superior (RIACES, 2004), la calidad es el grado en el que un conjunto de rasgos diferenciadores inherentes a la educación superior cumple con una necesidad o expectativa establecida. Silvio (2006, p. 2) menciona que la calidad se refiere a la conformación de las características de un objeto, material o inmaterial, con una norma, criterio o patrón. Ello permite evaluar los programas, proyectos y actividades de educación a distancia con diversos criterios que contienen indicadores acerca del grado en el que el programa se ajusta a las normas de calidad en varios aspectos significativos para su desempeño como programa. Dos son los aspectos 
esenciales de acuerdo a este autor: la formación de las personas que terminan el programa y la capacidad de la institución para producir cambios (Silvio, 2006, p. 2).

No hay duda de que para las instituciones de educación superior el tema de la calidad se ha convertido en una cuestión de vital importancia, especialmente para aquellas que ofrecen educación a distancia. Por lo tanto, la creciente preocupación por la calidad ha llevado a las universidades a buscar maneras de gestionar los procesos de ésta, permitiendo mejorar los programas, la práctica educativa y concentrar esfuerzos y recursos (Pitsoe y Maila, 2014). En la elaboración de parámetros, estándares e indicadores para la educación a distancia tendrán que incluirse necesariamente aquellos que le son propios, sin olvidar que otros serán comunes con la educación presencial, ya que hablamos de formar al ser humano desde modelos diferentes, pero con objetivos comunes (Rubio, 2015).

Si bien el aseguramiento de la calidad es preocupación de todo sistema educativo, pareciera que para la modalidad a distancia esta propiedad es más importante cuando no hay necesidad de ello, toda vez que la misma preocupación aplica a cualquier tipo de oferta educativa (Cervantes et al., 2015). Se coincide con Moreno (2007), quien señala que responder a la pregunta ¿qué es la calidad? puede tener una gran variedad de respuestas, según las diversas expectativas que se tengan en relación con los distintos procesos, productos y servicios de los que se espera una satisfacción a las necesidades o aspiraciones. Un elemento importante que remarca este autor es que la excelencia de la educación institucionalizada no depende de la modalidad educativa, sino de la calidad de los procesos que se viven y aprenden, la cual está condicionada fundamentalmente por el personal académico, el currículo, el apoyo a los estudiantes, los recursos de información y conocimiento, y su accesibilidad y procedimientos de evaluación válidos y confiables para la institución, la sociedad y el propio estudiante.

Rama (2015, p. 14) menciona que la educación a distancia implica una lógica educativa que se centra en el aprendizaje autónomo, que no sólo otorga necesariamente una mayor intensidad en la evaluación de los resultados frente a la evaluación de insumos y de los procesos de enseñanza, sino que integra a un nuevo elemento cada vez más importante en los aprendizajes, como son los recursos pedagógicos, las tecnologías interactivas, las infraestructuras donde se asientan las comunidades de aprendizaje como componentes crecientemente más importantes en la educación y en el aprendizaje y por ende, en la evaluación.

La calidad educativa como estándar de excelencia es un proceso en constante evolución, dinámico y permanente, cuyo propósito es la promoción de la mejora continua. Como señala Bañuelos (2011), existen cuatro elementos que caracterizan la modalidad a distancia: la separación espacio-temporal, la interacción sincrónica y asincrónica, el empleo de materiales didácticos elaborados ex profeso y el soporte en las Tecnologías de Información y Comunicación (TIC).

La separación espacio-temporal parece ser una preocupación válida, ya que el contacto personal cara a cara no se presenta; sin embargo, en los programas a distancia la cercanía no se pierde, incluso llega a ser en algunas ocasiones más cercana a la modalidad presencial (Bañuelos, 2011). Una bondad de la separación temporal es que las aportaciones pueden ser más profundas o de mayor elaboración cognitiva, ya que los actores (profesores y alumnos) tienen tiempo para reflexionar los conceptos y consultar otros materiales o discutir con otros compañeros. La interacción se lleva a cabo con apoyo de recursos telemáticos donde la comunicación puede ser tanto asincrónica como sincrónica.

Un valor agregado de esta modalidad es la creación de materiales didácticos elaborados por los propios docentes que, en el mejor de los casos, atenderán los cursos. Una estrategia para la elaboración de dichos materiales es hacerlo por academias; es decir, se congrega a un grupo de los mejores docentes quienes se encargan de dicha elaboración, apoyados con especialistas didácticos en diseño gráfico y en programación para la elaboración de materiales más complejos; por ejemplo, simuladores.

Las dudas sobre la calidad de la oferta educativa 
en este tipo de programas no son gratuitas, es necesario cuidarse de no caer en una oferta que signifique una enseñanza de "segunda", un aprendizaje en soledad, aprendizaje por Internet, donde la labor del docente se circunscribe a la mera resolución de dudas, a la digitalización de los apuntes que se emplean en el salón de clases o, al contrario, a una antología de ligas de sitios de Internet o un método de enseńanza que no aprovecha las posibilidades que ofrecen las TIC, para lo cual es preciso considerar componentes de base para el aseguramiento de la calidad.

\section{Evaluación de la educación a distancia}

Así como al inicio se mencionó la diversidad de posturas en torno a la calidad educativa, el mismo fenómeno se presenta alrededor de los criterios y lineamientos de evaluación de la educación a distancia. Al respecto se presentan a continuación los ejes y criterios de cuatro documentos que se consideraron esenciales en la elaboración de la presente propuesta y como los más representativos de medición de la calidad de la educación a distancia en la UNAM, en México y en el extranjero.

El primero de ellos, "Lineamientos y criterios para la presentación de Planes de Estudio de Licenciatura en el Sistema Universidad Abierta y Educación a Distancia de la UNAM" (CUAED, 2014 , p. 3), es el documento que las escuelas y facultades de la Universidad deben presentar ante el Consejo Asesor del Sistema Universidad Abierta y Educación a Distancia para contar con la opinión favorable del programa, requisito indispensable para el registro e implantación de planes y programas de estudio en las modalidades abierta y a distancia de la UNAM. La propuesta se compone de cuatro dimensiones:

i. Dimensión curricular

- Presentación general del Plan de Estudios

- Ficha de identificación curricular

- Síntesis del Plan de estudios

ii. Dimensión psicopedagógica: el enfoque teórico-metodológico que sustenta las prácticas educativas

- Las características de la modalidad en la dependencia
- El enfoque teórico sobre la concepción del proceso de aprendizaje

- El desarrollo metodológico de la propuesta

iii. Dimensión comunicativa y tecnológica: las herramientas y recursos que apoyan el proceso educativo

- Para los planes de estudio en la modalidad abierta

- Para los planes de estudio en la modalidad a distancia

iv. Dimensión administrativa y de gestión: organización, gestión, evaluación y seguimiento relacionados con la implantación y operación del Plan de estudios

- La organización institucional donde se impartirá la propuesta

- La gestión académico-administrativa

- La evaluación integral

- El seguimiento de la implantación

El segundo documento es el de los Comités Interinstitucionales para la Evaluación de la Educación Superior, A.C. (CIEES, 2016), con el texto Ejes, categorías e indicadores para la evaluación de programas de educación superior. La tabla 1 muestra la propuesta que comprende cuatro ejes y doce categorías. Los CIEES son un organismo de carácter no gubernamental cuya función específica es la evaluación diagnóstica interinstitucional de programas académicos y formular recomendaciones puntuales para su mejoramiento.

Tabla 1

Ejes y categorías de los CIEES

\begin{tabular}{|c|c|}
\hline Eje & Categoría \\
\hline \multirow{2}{*}{$\begin{array}{l}\text { i. Fundamentos y } \\
\text { condiciones de } \\
\text { operación }\end{array}$} & 1. Propósitos del programa \\
\hline & 2. Condiciones generales de operación \\
\hline \multirow{2}{*}{$\begin{array}{l}\text { iii. Currículo específico } \\
\text { y genérico }\end{array}$} & 1. Modelo educativo y plan de estudio \\
\hline & 2. Actividades para la formación integral \\
\hline \multirow{4}{*}{$\begin{array}{l}\text { iii. Tránsito de los } \\
\text { estudiantes por el } \\
\text { programa }\end{array}$} & 1. Proceso de ingreso al programa \\
\hline & 2. Trayectoria escolar \\
\hline & 3. Egreso del programa \\
\hline & 4. Resultados de los estudiantes \\
\hline \multirow{4}{*}{$\begin{array}{l}\text { v. Personal } \\
\text { académico, } \\
\text { infraestructura y } \\
\text { servicios }\end{array}$} & 1. Personal académico \\
\hline & 2. Infraestructura académica \\
\hline & 3. Infraestructura física \\
\hline & 4. Servicios de apoyo \\
\hline
\end{tabular}


El siguiente es el Marco de referencia para la evaluación y seguimiento de programas de posgrado en la modalidad no escolarizada, del Consejo Nacional de Ciencia y Tecnología de México (CONACyT, 2016). En el contexto del Programa Nacional de Posgrados de Calidad, el Consejo tiene el propósito de reconocer la calidad y pertinencia de los programas a nivel posgrado (con orientación profesionalizadora, a fin de estimular la vinculación con los sectores de la sociedad. El marco de referencia incorpora cinco categorías y dieciséis criterios (Ver la tabla 2).

Tabla 2

Marco de referencia del CONACyT

\begin{tabular}{|c|c|}
\hline Categoría & Criterio \\
\hline \multirow{2}{*}{$\begin{array}{l}\text { i. Responsabilidad } \\
\text { social de la } \\
\text { institución }\end{array}$} & 1. Compromiso institucional \\
\hline & $\begin{array}{l}\text { 2. Sistema interno de aseguramiento de } \\
\text { la calidad }\end{array}$ \\
\hline \multirow{4}{*}{$\begin{array}{l}\text { iii. Estructura y } \\
\text { personal académico } \\
\text { del programa }\end{array}$} & 1. Plan de estudios \\
\hline & $\begin{array}{l}\text { 2. Proceso de enseñanza- apren- } \\
\text { dizaje }\end{array}$ \\
\hline & 3. Núcleo académico básico \\
\hline & $\begin{array}{l}\text { 4. Líneas de generación y/o aplicación } \\
\text { del conocimiento }\end{array}$ \\
\hline \multirow[t]{2}{*}{ v. Estudiantes } & 1. Ingreso de estudiantes \\
\hline & $\begin{array}{l}\text { 2. Seguimiento de la trayectoria acadé- } \\
\text { mica de los estudiantes }\end{array}$ \\
\hline \multirow[t]{3}{*}{$\begin{array}{l}\text { iii. Infraestructura y } \\
\text { servicios }\end{array}$} & $\begin{array}{l}\text { 1. Tecnologías para el aprendizaje y } \\
\text { servicios administrativos a distancia }\end{array}$ \\
\hline & $\begin{array}{l}\text { 2. Espacios, equipamiento, laboratorios } \\
\text { y talleres }\end{array}$ \\
\hline & 3. Información y documentación \\
\hline \multirow[t]{5}{*}{$\begin{array}{l}\text { iv. Resultados y } \\
\text { vinculación }\end{array}$} & $\begin{array}{l}\text { 1. Trascendencia, cobertura y evolución } \\
\text { del programa }\end{array}$ \\
\hline & 2. Efectividad del posgrado \\
\hline & 3. Contribución al conocimiento \\
\hline & 4. Vinculación \\
\hline & 5. Financiamiento \\
\hline
\end{tabular}

Fuente: Elaboración propia.

Finalmente, se menciona el documento $\mathrm{E}$ l proceso de garantía de calidad para la educación en línea y a distancia, del Instituto Latinoamericano y del Caribe de Calidad en Educación Superior a Distancia, de Ecuador y del Online Learning Consortium (CALED, 2015, p. 13). Esta propuesta es el resultado de un trabajo conjunto de dichas entidades muy reconocidas y dedicadas a asesorar a instituciones e individuos en mejoramiento de la calidad en el continente americano. Se compone de nueve categorías con noventa y uno indicadores (Ver la tabla 3).

Tabla 3

Categorías e indicadores del CALED-OLC

\begin{tabular}{llc}
\hline \multicolumn{2}{l}{ Categoría } & Indicadores \\
\hline i. & Apoyo institucional & 8 \\
\hline ii. & Apoyo tecnológico & 8 \\
\hline iii. & $\begin{array}{l}\text { Desarrollo y diseño instruccional de los } \\
\text { cursos en línea }\end{array}$ & 20 \\
\hline iv. & Estructura de los cursos en línea & 9 \\
\hline v. & Enseñanza y aprendizaje & 6 \\
\hline vi. & Participación social y estudiantil & 1 \\
\hline vii. & Apoyo a los docentes & 6 \\
\hline viii. & Apoyo a los alumnos & 20 \\
\hline ix. & Evaluación y valoración & 13 \\
\hline
\end{tabular}

Los elementos comunes a los cuatro instrumentos arriba descritos son: plan de estudios o equivalente, el proceso enseńanza aprendizaje, el papel y/o funciones del alumno, del docente y el empleo de las tecnologías de información y comunicación. Sin duda, componentes esenciales en una modalidad no presencial.

\section{Materiales y Métodos}

\section{Participantes}

Para la validación de la guía, participó una de las facultades de la UNAM en México, que ofrece tres licenciaturas en modalidad a distancia. La entidad cuenta con una matrícula activa de 2,800 alumnos y una planta de 500 profesores. Este estudio carece de una muestra de participantes como tal, debido a que la Guía de autoevaluación fue validada con los responsables del programa educativo.

\section{Instrumento}

Un proceso de autoevaluación requiere distintas fuentes de datos; una muy importante es la opinión de los responsables de los programas. Para obtener dicha información, se utilizó el instru- 
mento que se presenta (Guía de autoevaluación para programas educativos a distancia) elaborado con base en los 4 documentos antes descritos, los cuales sirvieron para la redacción de los 5 Ejes, 17 Categorías y 36 Indicadores con sus respectivas descripciones. La tabla 4 resume la propuesta original.

Esta Guía de autoevaluación está respaldada con una visión de la educación a distancia que retoma algunos de los postulados mencionados al inicio de este documento; esto es, el énfasis está puesto en los elementos didáctico-pedagógicos que se anteponen ante los elementos de orden tecnológicos. Además, se insiste en que la autoevaluación se lleva a cabo para identificar las fortalezas (para consolidarlas) y las áreas de oportunidad con la finalidad de mejorar de manera continua.

Por la naturaleza del instrumento, se decidió omitir una prueba de confiabilidad toda vez que no aplica. La validez llevada a cabo fue de constructo, a través del juicio de expertos con la finalidad de obtener certeza en los ejes, categorías e indicadores propuestos.

La validación por jueces consistió en consultar a quince especialistas en la materia, a quienes se les solicitó valorar el grado de congruencia entre los ejes, categorías e indicadores, en una escala que abarcó los criterios de pertinencia de la categoría-indicador, la relevancia y la claridad de los indicadores. Los expertos que participaron en esta etapa del instrumento son responsables de licenciaturas a distancia de otras entidades académicas de la propia UNAM.

Los resultados confirmaron la propuesta inicial, es decir, no se excluyó ningún indicador, todos fueron considerados pertinentes, relevantes y claros, sólo se aceptaron algunas sugerencias en la redacción. Esto se logró conservando los indicadores con un rango de 80 a 100\% de coincidencia favorable entre los expertos.
Tabla 4

Indicadores originales de autoevaluación para programas educativos a distancia

\begin{tabular}{|c|c|c|c|}
\hline Eje & Categoría & Indicadores & Ponderación \\
\hline \multirow{4}{*}{$\begin{array}{l}\text { i. Plan de } \\
\text { estudios }\end{array}$} & 1. Plan de estudios & 5 & \multirow[t]{4}{*}{$35 \%$} \\
\hline & $\begin{array}{l}\text { 2. Diseño } \\
\text { educativo }\end{array}$ & 5 & \\
\hline & $\begin{array}{l}\text { 3. Materiales } \\
\text { didácticos }\end{array}$ & 2 & \\
\hline & Subtotal & 12 & \\
\hline \multirow[t]{4}{*}{ ii. Docentes } & 1. Perfil docente & 2 & \multirow[t]{4}{*}{$14 \%$} \\
\hline & 2. Enseñanza & 2 & \\
\hline & 3. Tutoría & 1 & \\
\hline & Subtotal & 5 & \\
\hline \multirow[t]{5}{*}{ iii. Alumnos } & 1. Perfil del alumno & 2 & \multirow[t]{4}{*}{$28 \%$} \\
\hline & 2. Ingreso & 4 & \\
\hline & 3. Trayectoria & 2 & \\
\hline & 4. Egreso & 2 & \\
\hline & & 10 & \\
\hline \multirow[t]{4}{*}{ iv. Tecnologías } & 1. Calidad de servicio & 2 & \multirow[t]{4}{*}{$11 \%$} \\
\hline & 2. Seguridad & 1 & \\
\hline & 3. Infraestructura & 1 & \\
\hline & Subtotal & 4 & \\
\hline \multirow[t]{6}{*}{ v. Gestión } & $\begin{array}{l}\text { 1. Administración } \\
\text { escolar }\end{array}$ & 1 & \multirow[t]{5}{*}{$14 \%$} \\
\hline & $\begin{array}{l}\text { 2. Administración } \\
\text { académica }\end{array}$ & 1 & \\
\hline & 3. Evaluación & 2 & \\
\hline & 4. Cobertura & 1 & \\
\hline & Subtotal & 5 & \\
\hline & Total & 36 & 100 \\
\hline
\end{tabular}

En concordancia con lo anterior, las categorías con mayor número de indicadores $\mathrm{y}$, por tanto, mayor peso ponderado son Plan de estudios, Diseño educativo y Materiales didácticos ya que concentran las descripciones de la metodología de enseñanza a distancia donde lo importante es el diseño de los ambientes que favorezcan la construcción significativa de los aprendizajes. En este sentido, se coincide con Rama (2015), quien retoma como centro el aprendizaje en la evaluación de las modalidades no presenciales.

\section{Tipo y diseño}

El tipo de estudio empleado en esta investigación 
es descriptivo, debido al interés de los autores por determinar los indicadores de evaluación pertinentes a la educación a distancia, a fin de validar una guía de autoevaluación.

El diseño utilizado es no experimental transeccional exploratorio (García, 2009), en tanto se trata de una exploración inicial a una comunidad, en un contexto específico.

\section{Procedimiento}

Para validar la propuesta se siguieron una serie de etapas, las mismas que se describen a continuación:

- Etapa 1. Se solicitó la autorización de la responsable de las carreras de una Facultad de la UNAM, que ofrece tres licenciaturas en la modalidad a distancia.

- Etapa 2. Teniendo la autorización, se procedió a capacitar en varias sesiones de trabajo al personal involucrado de la Facultad; entre ellos, los coordinadores del área académica, de orientación educativa, de servicios extracurriculares, de estadística y evaluación, de material didáctico y con el responsable del departamento de educación a distancia. En las sesiones se explicó el fundamento de la guía, cada uno de los 36 indicadores y las evidencias que dan sustento al indicador. Se decidió emplear el software libre Alfresco como repositorio de las evidencias y para el llenado de la guía.

- Etapa 3. La elaboración de la autoevaluación tomó alrededor de 4 meses de trabajo con asesoría permanente de especialistas en el tema. Concluida esa etapa, se procedió al análisis del documento de autoevaluación y de las evidencias probatorias. Lo anterior permitió identificar aquellos indicadores y descripciones con redacción confusa; empero, el análisis más importante versó en la pertinencia del indicador en función de las características de la educación a distancia que ofrece la Universidad y del aporte a los parámetros de calidad del programa educativo en cuestión.

- Etapa 4. Se presentron los resultados de la validación para proceder a describir el ajuste que tuvo la propuesta original y presentar el instrumento final.

\section{Resultados}

El análisis de los resultados se hizo de manera cualitativa, esto es, con base en la aplicación, se examinó de manera crítica cada uno de los indicadores en términos de la pertinencia de estos en el contexto universitario. Los hallazgos posibilitaron la eliminación de seis indicadores, a continuación se justifica la razón de esto:

\section{Primer eje: Plan de estudios}

Categoría: Plan de estudios.

Indicador: Registro oficial de la modalidad ante las instancias correspondientes

Justificación: El registro de los programas educativos que las entidades académicas de la UNAM deben realizar ante el Ministerio de Educación Pública es una situación ajena o independiente de la modalidad a distancia. Los responsables académicos deben llevar a cabo dicho registro de los programas tanto presenciales como abiertos o a distancia.

\section{Segundo eje: Plan de estudios.}

Categoría: Plan de estudios.

Indicador: Flexibilidad curricular.

Justificación: La flexibilidad curricular de un plan de estudios hoy día es una tendencia y sinónimo de una mayor oportunidad para cursar los estudios universitarios, incluso llega a ser reflejo de innovación educativa. Bajo esta lógica, la flexibilidad en el currículo debería estar presente en cualquier plan, con independencia de la modalidad educativa en cuestión. El alumno debe tener la posibilidad de elegir su trayectoria formativa, acceder a los distintos esquemas de movilidad (física o virtual), revalidación de saberes previos, entre otros.

\section{Tercer Eje: Docentes}

Categoria: Perfil docente.

Indicador: Certificación de la planta docente.

Justificación: En tanto que en la Universidad existen distintas instancias que apoyan la formación 
de la planta docente sin distingo de la modalidad, al mismo tiempo que cada facultad organiza sus propios programas de capacitación, se decidió eliminar el indicador, ya que no aportaba información relevante para la operación del programa educativo en la modalidad.

\section{Cuarto eje: Alumnos}

Categoria: Perfil del alumno.

Indicador: Competencias del alumno.

Justificación: Con base en el análisis de lo reportado por la facultad participante en esta investigación, este indicador no parece aportar nada a la valoración de la calidad de un programa a distancia, debido a que se caía en el "deber ser" de las competencias que corresponden a un alumno en la modalidad a distancia, por ejemplo, ser autogestivo.

\section{Quinto eje: Alumnos}

Categoría: Ingreso.

Indicador: Carga académica por ciclo escolar.

Justificación: Debido a que la carga de asignaturas en cada ciclo escolar es una decisión personal y esto refiere a los elementos de flexibilidad para operar el programa académico, el indicador se agrupó en el Eje Plan de estudios, específicamente en lo correspondiente a la Operación del programa, por la importancia de considerar esta alternativa a los estudiantes.

\section{Sexto eje: Gestión}

Categoría: Evaluación.

Indicador: Procesos académico-administrativos.

Justificación: De acuerdo a la respuesta ofrecida por la entidad académica en cuestión y con base en un análisis de los procesos de evaluación académico-administrativa de la Universidad, este indicador no es exclusivo de la modalidad a distancia, es decir, las facultades que llegan a realizar evaluaciones de este tipo lo hacen a nivel central, sin distinción de la metodología de enseñanza.

Los resultados arrojados muestran que el Eje Tecnologías es el único que no sufrió cambios. En el Eje Plan de estudios se eliminaron dos indicadores que aplican tanto a la modalidad presencial como a la de distancia. Lo mismo ocurre en el Eje Docentes, donde lo planteado originalmente no es exclusivo de la modalidad a distancia. Por lo que toca al Eje Alumnos, uno de sus elementos no recuperaba lo originalmente planeado (competencias del alumno) y el segundo fue reagrupado en otro Eje. Finalmente, en el Eje Gestión, la evaluación de los procesos académico-administrativos aplica a toda la facultad sin distingo de la modalidad educativa.

De acuerdo a lo anterior, la Guía de autoevaluación para programas educativos a distancia que se propone como resultado de esta investigación, responde a un modelo de enseńanza a distancia centrada en el aspecto psicopedagógico. El mayor número de indicadores que corresponden a un 33\% del total da cuenta de la importancia de primar el elemento educativo sobre los tecnológicos o de gestión.

En concordancia con lo anterior, el segundo componente de relevancia con un peso del $27 \%$ (y ocho indicadores) lo tiene el Eje Alumnos, lo cual se explica por la consideración de valorar la trayectoria completa de los estudiantes, desde su perfil de ingreso hasta la culminación de sus estudios. $\mathrm{Al}$ resto de los tres Ejes les corresponde un porcentaje o peso ponderado de un $13 \%$, lo que equivale a cuatro indicadores para cada uno.

\section{Instrumento final}

Después del análisis de los resultados, la versión final de la Guía validada y ofrecida en este espacio académico quedó conformada por 30 indicadores que aplican a la autoevaluación de programas educativos a distancia. Cabe mencionar que el instrumento final, al término de cada Eje, contempla un espacio para la descripción de las fortalezas y áreas de oportunidad.

Con el análisis de las fortalezas y las áreas de oportunidad se elaboró un plan de mejora que permitirá consolidar la oferta educativa ofrecida en la modalidad en cuestión.

En la tabla 5 se resume la propuesta final y en el anexo de este artículo se presentan los 30 indicadores validados. 
Tabla 5

Indicadores finales de autoevaluación para programas educativos a distancia

\begin{tabular}{|c|c|c|c|}
\hline Eje & Categoría & Indicadores & Ponderación \\
\hline \multirow{4}{*}{$\begin{array}{l}\text { i. Plan de } \\
\text { estudios }\end{array}$} & 1. Plan de estudios & 3 & \multirow[t]{4}{*}{$33 \%$} \\
\hline & $\begin{array}{l}\text { 2. Diseño } \\
\text { educativo }\end{array}$ & 5 & \\
\hline & $\begin{array}{l}\text { 3. Materiales } \\
\text { didácticos }\end{array}$ & 2 & \\
\hline & Subtotal & 10 & \\
\hline \multirow[t]{4}{*}{ ii. Docentes } & $\begin{array}{l}\text { 1. Competencias } \\
\text { docentes }\end{array}$ & 1 & \multirow[t]{4}{*}{$13 \%$} \\
\hline & 2. Enseñanza & 2 & \\
\hline & 3. Tutoría & 1 & \\
\hline & Subtotal & 4 & \\
\hline \multirow[t]{5}{*}{ iii. Alumnos } & 1. Perfil del alumno & 1 & \multirow[t]{5}{*}{$27 \%$} \\
\hline & 2. Ingreso & 3 & \\
\hline & 3. Trayectoria & 2 & \\
\hline & 4. Egreso & 2 & \\
\hline & Subtotal & 8 & \\
\hline \multirow[t]{4}{*}{ iv. Tecnologías } & 1. Calidad de servicio & 2 & \multirow[t]{4}{*}{$13 \%$} \\
\hline & 2. Seguridad & 1 & \\
\hline & 3. Infraestructura & 1 & \\
\hline & Subtotal & 4 & \\
\hline \multirow[t]{6}{*}{ v. Gestión } & $\begin{array}{l}\text { 1. Administración } \\
\text { escolar }\end{array}$ & 1 & \multirow[t]{5}{*}{$13 \%$} \\
\hline & $\begin{array}{l}\text { 2. Administración } \\
\text { académica }\end{array}$ & 1 & \\
\hline & 3. Evaluación & 1 & \\
\hline & 4. Cobertura & 1 & \\
\hline & Subtotal & 4 & \\
\hline & Total & 30 & $100 \%$ \\
\hline
\end{tabular}

Fuente: Elaboración propia.

\section{Discusión y Conclusiones}

El término educación a distancia comienza a generalizarse con mucha frecuencia hoy en día, sobre todo en universidades públicas y privadas; pero en la misma medida que esta modalidad educativa va creciendo, existe una preocupación constante por conocer la calidad con la que se imparten los cursos. Por ello, la evaluación de la calidad en modelos educativos a distancia es fundamental. En países como México, el aseguramiento de la calidad educativa a nivel superior, se encuentra regulado por el Sistema de Evaluación y Acreditación, a través de diferentes organismos, cuya participación depende del propósito y tipo de evaluación que se persiga (diagnóstica, acreditación etc.).

Al llevar a cabo la evaluación de un programa educativo, se puede determinar el nivel de eficiencia y eficacia con que opera, con miras a tomar mejores decisiones a través del fortalecimiento, adecuación o cambios significativos en dicho programa educativo. Sin embargo, todo proceso de evaluación debe comenzar con un ejercicio de autoevaluación que permita establecer las bases o líneas de acción para asegurar justamente ese mejoramiento. Pero, tratándose de modelos educativos a distancia, existe una diversidad de indicadores para cumplir con esta tarea, resultando difícil establecer con claridad cuáles son los parámetros que aporten la información para aplicar una valoración objetiva en relación al cómo se está y el cómo se debería estar.

La presente investigación hace un aporte valioso en la medida en que presenta como resultado una propuesta de Guía de autoevaluación para programas educativos a distancia. Si bien la literatura especializada ofrece una variedad de estándares e indicadores de evaluación de las modalidades no presenciales, la iniciativa presentada aquí coindice con las ideas de autores como Silvio (2006), Rubio (2015), Moreno (2007) y Rama (2015), en tanto se ofrece como parámetro para garantizar la calidad, en primer lugar, de un programa educativo de nivel superior, y en segundo lugar, de la metodología de enseñanza a distancia.

Cabe resaltar que, realizar el análisis de las fortalezas, debilidades y las áreas de oportunidad a partir de la metodología propuesta, permitirá elaborar un plan de mejora que permita consolidar la oferta educativa para este tipo de programas. Como se planteará al inicio del trabajo, éste constituye la primera fase de un estudio de largo aliento. En este sentido, la recomendación central es ampliar la validación de la Guía a otras facultades de la Universidad para consolidar la propuesta. Una vez que el instrumento sea analizado a la luz de otros contextos, será dado a conocer para beneficio de quienes invierten esfuerzos en la educación a distancia. 


\section{REFERENCIAS BibLIOGRÁficAS}

Bañuelos, M. (2011). La evaluación de los programas a distancia. En: Escalona, L. La calidad de la educación superior en América Latina: los desafíos para la educación bibliotecológica. (pp. 1-16). México: UNAM.

Cervantes, P., Bañuelos, M., Chávez, M. y Rocha, R. (2015). La evaluación de la calidad de la educación superior a distancia en México. En: M. Morocho y C. Rama. Los problemas de la evaluación de la educación a distancia en América Latina y el Caribe. (pp. 102-130). Ecuador: Virtual Educa. CALED. UTPL.

Comités Interinstitucionales para la Evaluación de a Educación Superior, A.C. CIEES. (2016). Ejes, categorías e indicadores para la evaluación de programas de educación superior. (p. 6). México: CIEES. Recuperado de https://goo. $\mathrm{gl} / \mathrm{t} 4 \mathrm{ADCV}$

Consejo Nacional de Ciencia y Tecnología. CONACyT. (2016). Marco de referencia para la evaluación y seguimiento de programas de posgrado en la modalidad no escolarizada. México: SEP. Recuperado de https://goo.gl/s9NZPi

Coordinación de Universidad Abierta y Educación a Distancia. CUAED. (2014). Lineamientos y criterios para la presentación de Planes de Estudio de Licenciatura en el Sistema Universidad Abierta y Educación a Distancia de la UNAM (p.3). México: UNAM. Recuperado de http://www.cuaed. unam. $\mathrm{mx} /$ consejo/interiores/Lineamientos.pdf

García, C. (2009). Manual de métodos de investigación para las ciencias sociales. Un enfoque de enseñanza basado en proyectos. (p. 37). México: Manual Moderno.

González, G., Gold, M., Santamaría, A., Yáñez, O. y Masjuán, P. (2011). Análisis estructural integrativo de organizaciones universitarias. El modelo $\mathrm{V}$ de evaluación-planeación como instrumento para el mejoramiento permanente de la educación superior. (p.55). México: Red Internacional de Evaluadores, A.C.

Instituto Latinoamericano y del Caribe de Calidad en Educación Superior a Distancia. CALED. (2015). El proceso de garantía de calidad para la educación en línea y a distancia. (p. 13). Ecuador: UTPL.

Instituto Nacional para la Evaluación de la Educación. INEE. (2005). ¿Qué es la calidad educativa? Los Temas de la Evaluación. Colección de folletos $\mathrm{N}^{\circ} 3$. Recuperado de https://goo.gl/jxwSZA

López, L., Chávez, M., Bautista, A. (2011). Evaluación y Acreditación de la Educación a Distancia en México. En: C. Rama y J. Domínguez. El aseguramiento de la calidad de la educación virtual. (pp. 305-330). Perú: Virtual Educa. ULADECH.

Malpica, F. (2012). 8 ideas clave. Calidad de la práctica educativa. Referentes, indicadores y condiciones para mejorar la enseñanza-aprendizaje. (p. 56). Barcelona: Graó.

Moreno, C. (2007). La calidad de la educación a distancia en ambientes virtuales. Apertura, 7 (7), 19-31.

Pitsoe, V. y Maila, M. (2014). Quality and quality assuran- ce in open distance learning (ODL) discourse: Trends, challenges and perspectives. Anthropologist, 18 (1): 251-258.

Rama, C. (2015). Las complejidades de evaluar y acreditar la educación a distancia. En: M. Morocho y C. Rama. Los problemas de la evaluación de la educación a distancia en América Latina y el Caribe. (pp. 11-17). Ecuador: Virtual Educa. CALED. UTPL.

Red Iberoamericana para la Acreditación de la Calidad de la Educación Superior. RIACES. (2004). Glosario internacional de evaluación de la calidad y acreditación. Madrid: RIACES. (Citado el 25 de enero de 2017). Recuperado de https://goo.gl/uzdHjr

Rubio, G. (2015). Indicadores, experiencias y problemas en la evaluación de la educación a distancia. En: M. Morocho y C. Rama. Los problemas de la evaluación de la educación a distancia en América Latina y el Caribe. (pp. 87-102). Ecuador: Virtual Educa. CALED. UTPL.

Silvio, J. (2006). Hacia una educación virtual de calidad, pero con equidad y pertinencia. Revista Universidad y Sociedad del Conocimiento. Recuperado el 13 de febrero de $2017 \mathrm{de} \mathrm{http://www.uoc.edu/rusc/3/1/dt/esp/silvio.html}$ 
Anexo

\section{EJE 1: PLAN DE ESTUDIOS}

\begin{tabular}{|c|c|c|}
\hline CATEGORÍAS & INDICADORES & GUÍA \\
\hline \multirow[t]{3}{*}{ 1. Plan de estudios } & $\begin{array}{l}\text { 1. Plan de Estudios en la modalidad a } \\
\text { distancia. }\end{array}$ & $\begin{array}{l}\text { Describir la propuesta del diseño curricular acorde a la } \\
\text { modalidad a distancia. }\end{array}$ \\
\hline & 2. Modelo educativo & $\begin{array}{l}\text { Explicar el modelo educativo que da soporte a la modalidad } \\
\text { a distancia. }\end{array}$ \\
\hline & 3. Operación del programa. & $\begin{array}{l}\text { Indicar los mecanismos de flexibilidad en la operación del } \\
\text { programa académico de acuerdo al modelo educativo esta- } \\
\text { blecido, por ejemplo, carga académica semestral. }\end{array}$ \\
\hline \multirow[t]{5}{*}{ 2. Diseño educativo } & $\begin{array}{l}\text { 1. Ambientes de enseñanza y de apren- } \\
\text { dizaje en la modalidad a distancia }\end{array}$ & $\begin{array}{l}\text { Especificar los principios de la planeación didáctica de las } \\
\text { asignaturas, tomando en cuenta la metodología de enseñan- } \\
\text { za en la modalidad a distancia. }\end{array}$ \\
\hline & $\begin{array}{l}\text { 2. Actividades de enseñanza y de } \\
\text { aprendizaje. }\end{array}$ & $\begin{array}{l}\text { Detallar las características de las actividades de enseñanza } \\
\text { y de aprendizaje de acuerdo al modelo y a la naturaleza de } \\
\text { las asignaturas. Si el trabajo es individual o colaborativo y los } \\
\text { recursos Web donde se apoya. }\end{array}$ \\
\hline & $\begin{array}{l}\text { 3. Actividades de evaluación de los } \\
\text { aprendizajes }\end{array}$ & $\begin{array}{l}\text { Precisar cómo se lleva a cabo la evaluación y si se em- } \\
\text { plean herramientas tecnológicas, señalar cuáles son. }\end{array}$ \\
\hline & $\begin{array}{l}\text { 4. Comunicación sincrónica y } \\
\text { asincrónica. }\end{array}$ & $\begin{array}{l}\text { Describir las herramientas de comunicación sincrónica y } \\
\text { asincrónica que permiten la interacción docente-alumno, } \\
\text { alumno-alumno, alumno-institución. Señalar si éstas } \\
\text { se ubican en la plataforma tecnológica o se apoyan en } \\
\text { recursos de las TIC (videoconferencia, aula virtual, chat, } \\
\text { Facebook, blog, etc.). }\end{array}$ \\
\hline & 5. Comunicación visual & $\begin{array}{l}\text { Explicar la comunicación visual del ambiente virtual, consi- } \\
\text { derando el tipo de usuario, la presentación del contenido, los } \\
\text { elementos gráficos de interacción, comunicación y navega- } \\
\text { ción. }\end{array}$ \\
\hline \multirow[t]{4}{*}{ 3. Materiales didácticos } & 1. Metodología de desarrollo & $\begin{array}{l}\text { Mencionar la metodología de desarrollo y las características } \\
\text { de los materiales didácticos que dan soporte a los conteni- } \\
\text { dos. Indicar cuál es la política de protección intelectual en } \\
\text { torno a los materiales elaborados. }\end{array}$ \\
\hline & \multirow[t]{3}{*}{ 2. Materiales didácticos empleados } & $\begin{array}{l}\text { Referir los tipos y características de los materiales em- } \\
\text { pleados y/o desarrollados; por ejemplo: textos originales, } \\
\text { documentos o videos recuperados de la Web, objetos de } \\
\text { aprendizaje, tutoriales, blogs, videos originales, interactivos, } \\
\text { audiolibros, e-books, materiales multimedia. Tener presente } \\
\text { la descarga de los materiales tanto en computadora personal } \\
\text { como en dispositivos móviles. }\end{array}$ \\
\hline & & $\begin{array}{l}\text { Señalar los criterios de accesibilidad empleados para } \\
\text { personas con algún tipo de discapacidad (auditiva, } \\
\text { motora o visual) o de edad avanzada; por ejemplo, lector } \\
\text { de pantalla, navegador de voz, ampliación de tamańo de } \\
\text { letra, contraste de color de texto y fondo. }\end{array}$ \\
\hline & & $\begin{array}{l}\text { Mencionar los criterios de usabilidad (facilidad de uso) } \\
\text { empleados, por ejemplo, páginas con navegación intuiti- } \\
\text { va, imprimibles, rápidas para cargar, sin sobrecarga visual. }\end{array}$ \\
\hline
\end{tabular}




\section{EJE 2: DOCENTES}

\begin{tabular}{lll}
\hline CATEGORÍAS & \multicolumn{1}{c}{ INDICADORES } & \multicolumn{1}{c}{ GUíA } \\
\hline 1. Perfil docente & 1. Formación y actuallización & $\begin{array}{l}\text { Reseñar la formación y actualización de los docentes para } \\
\text { desempeñarse como asesores en la modalidad a distancia. } \\
\text { Señalar las competencias docentes que poseen los asesores } \\
\text { en la modalidad a distancia. }\end{array}$ \\
\hline 2. Enseñanza & $\begin{array}{l}\text { Describir el modelo de docencia en consonancia con la } \\
\text { modalidad a distancia. Indicar las funciones del docente. }\end{array}$ \\
\cline { 2 - 3 } & 2. Modelo de docencia & $\begin{array}{l}\text { Explicar el seguimiento que se lleva del desempeño del } \\
\text { docente en cuanto al tiempo y a la forma de retroalimenta- } \\
\text { ción, así como su actuación en los espacios de asesoría; es } \\
\text { decir, si propicia relaciones sociales en el grupo (presencia } \\
\text { social), domina el contenido y la comunicación didáctica (pre- } \\
\text { sencia didáctica) y fomenta el pensamiento crítico y reflexivo } \\
\text { (presencia cognitiva). }\end{array}$ \\
\hline 3. Tutoría & $\begin{array}{l}\text { Señalar el programa de tutoría que se lleva a cabo, las fun- } \\
\text { ciones, el tipo (individual, grupal,) y la manera en que opera } \\
\text { de acuerdo al modelo educativo de la modalidad a distancia. }\end{array}$ \\
& 1. Figura de tutor & \\
&
\end{tabular}

\section{EJE 3: ALUMNOS}

\begin{tabular}{|c|c|c|}
\hline CATEGORÍAS & INDICADORES & GUÍA \\
\hline 1. Perfil del alumno & $\begin{array}{l}\text { 1. Formación propedéutica a la } \\
\text { modalidad }\end{array}$ & $\begin{array}{l}\text { Describir el programa de formación propedéutica que se } \\
\text { ofrece a los alumnos de la modalidad a distancia para garan- } \\
\text { tizar un buen desempeño. }\end{array}$ \\
\hline \multirow[t]{3}{*}{ 2. Ingreso } & 1. Requerimientos tecnológicos. & $\begin{array}{l}\text { Especificar los requisitos tecnológicos que el alumno } \\
\text { necesita para iniciar sus actividades académicas. Señalar el } \\
\text { medio de difusión donde se encuentra el listado de requisitos } \\
\text { tecnológicos para operar. }\end{array}$ \\
\hline & 2. Método de estudio. & $\begin{array}{l}\text { Indicar la manera en que se da a conocer el método de } \\
\text { estudio de acuerdo al modelo educativo a distancia. }\end{array}$ \\
\hline & 3. Identidad institucional. & $\begin{array}{l}\text { Explicar los mecanismos para promover la identidad con la } \\
\text { institución, por ejemplo, sesiones de bienvenida. }\end{array}$ \\
\hline \multirow[t]{2}{*}{ 4. Trayectoria } & 1. Trayectoria escolar & $\begin{array}{l}\text { Identificar la trayectoria de los alumnos regulares y en } \\
\text { situación de rezago, de acuerdo al tiempo curricular y al } \\
\text { reglamentario. }\end{array}$ \\
\hline & 2. Recuperación académica & $\begin{array}{l}\text { Reseñar las estrategias o programa de actividades orientado } \\
\text { a la recuperación académica de alumnos en rezago escolar. }\end{array}$ \\
\hline \multirow[t]{2}{*}{ 4. Trayectoria } & 1. Servicio Social. & $\begin{array}{l}\text { Precisar las características de los programas de Servicio } \\
\text { Social, en concordancia con la modalidad a distancia; por } \\
\text { ejemplo, la posibilidad de cubrir el programa los fines de } \\
\text { semana o en línea. }\end{array}$ \\
\hline & 2. Idioma & $\begin{array}{l}\text { Describir las opciones que tienen los alumnos para cumplir } \\
\text { con el requisito del idioma. }\end{array}$ \\
\hline
\end{tabular}




\section{EJE 4: TECNOLOGÍAS}

\begin{tabular}{lll}
\hline CATEGORÍAS & \multicolumn{1}{c}{ INDICADORES } & \multicolumn{1}{c}{ GUÍA } \\
\hline 1. Calidad de servicio & 1. Servicio permanente & $\begin{array}{l}\text { Describir el servicio para la atención de las actividades } \\
\text { académicas y administrativas programadas y la manera en } \\
\text { que se garantiza su operación. }\end{array}$ \\
& 2. Asesoría tecnológica & $\begin{array}{l}\text { Explicar los mecanismos implementados para ofrecer aseso- } \\
\text { ría tecnológica a docentes y alumnos; por ejemplo, tutoriales, } \\
\text { manuales, servicio de call center. }\end{array}$ \\
\hline 1. Medidas de seguridad & $\begin{array}{l}\text { Referir los manuales o procesos que garanticen resolver } \\
\text { posibles contingencias y recuperar los servicios tecnológicos } \\
\text { de inmediato. }\end{array}$ \\
\hline 3. Infraestructura & $\begin{array}{l}\text { Especificar la infraestructura tecnológica que tiene la entidad } \\
\text { académica para operar el programa; por ejemplo, servidores, } \\
\text { computadoras para los profesores, salas de videoconferen- } \\
\text { cias. }\end{array}$ \\
\hline
\end{tabular}

\section{EJE 5: GESTIÓN}

\begin{tabular}{lll}
\hline CATEGORÍAS & \multicolumn{1}{c}{ INDICADORES } & \multicolumn{1}{c}{ GUÍA } \\
\hline 1. Administración escolar & 1. Trámites escolares & $\begin{array}{l}\text { Indicar los trámites escolares virtuales que la entidad aca- } \\
\text { démica ofrece a los alumnos de la modalidad. Por ejemplo, } \\
\text { constancias de estudio, historial académico, pagos de } \\
\text { servicios. }\end{array}$ \\
\hline 2. Administración académica & 1. Estructura organizativa & $\begin{array}{l}\text { Mencionar la estructura organizativa con la que cuenta la } \\
\text { entidad académica y las funciones correspondientes. }\end{array}$ \\
\hline 3. Evaluación & 1. Evaluación académica semestral & $\begin{array}{l}\text { Describir las evaluaciones que se aplican al término del ciclo } \\
\text { escolar; por ejemplo, el desempeño docente, el ambiente } \\
\text { virtual de aprendizaje, los contenidos académicos, los mate- } \\
\text { riales didácticos, las actividades de aprendizaje y evaluación. }\end{array}$ \\
\hline 4. Cobertura & $\begin{array}{l}\text { Referir la cobertura nacional o internacional del programa } \\
\text { académico. }\end{array}$
\end{tabular}




\title{
Ambiente virtual de aprendizaje para la capacitación tipo inducción, sobre contenidos estratégicos y misionales dirigido a colaboradores del Instituto Colombiano de Bienestar Familiar (ICBF)
}

\section{Virtual learning environment for the induction training on mission and strategic content addressed to collaborators from the Instituto Colombiano de Bienestar Familiar (ICBF)}

\author{
Nancy Olarte López ${ }^{1}$ \\ Universidad Militar Nueva Granada, Colombia \\ Jennifer González Castillo² \\ Instituto Colombiano de Bienestar Familiar
}

Recibido: 10-03-2017

Aceptado: 16-06-2017

\section{Cita recomendada}

Olarte, N. y González, J. (2017) Ambiente Virtual de Aprendizaje para la Capacitación Tipo Inducción, Sobre Contenidos Estratégicos y Misionales Dirigido a Colaboradores del Instituto Colombiano de Bienestar Familiar - ICBF. Hamut'ay, 4 (1), 45-59. Recuperado de: https://doi.org/10.21503/ hamu.v4i1.1400

\section{RESUMEN}

Se desarrolló un Ambiente Virtual de Aprendizaje (AVA) para la capacitación tipo Inducción a los colaboradores ICBF, mediante contenidos estratégicos y misionales a través de la implementación de diferentes herramientas multimedia para la apropiación de conocimientos que anteriormente sólo se transmitían de forma presencial en las diferentes regionales del ICBF.

El diseño de un AVA mediante espacios Web 2.0 involucró la participación de colaboradores del Instituto. Estos espacios permitieron escenarios colaborativos para gestionar conocimiento e información relevante hacia la capacitación de procesos donde se involucran poblaciones vulnerables de niños, niñas y adolescentes, reduciendo de manera significativa la inversión de recursos económicos logísticos en desplazamiento, capital humano y tiempos invertidos en capacitaciones en sitios presenciales. Asimismo, el AVA, como instrumento para la capacitación tipo inducción, aportó ampliamente al fortalecimiento del desempeño y competencias de los colaboradores ICBF como entidad pública, desde un modelo cooperativo.

En primer lugar, se lleva a cabo una descripción detallada del modelo de aprendizaje apropiado al AVA, introducción al ICBF desarrollado, luego se indican las fases del diseńo del AVA, junto con el Objeto Virtual de Aprendizaje - OVA - Misional Estratégico. Por otro lado, se indica detalladamente la arquitectura del diseño y la construcción del AVA. En seguida se describen las herramientas tenidas en cuenta para las pruebas hacia los colaboradores ICBF, junto con sus resultados. Mediante

1 Docente de Planta Universidad Militar Nueva Granada, Magister en Tecnologías de la Información Aplicadas a la Educación - ETIAE Universidad Pedagógica Nacional - UPN, Especialista en Tecnologías de la Información Aplicadas a la Educación - ETIAE Universidad Pedagógica Nacional - UPN Ingeniero en Telecomunicaciones Universidad Militar Nueva Granada, nancy.olarte@unimilitar.edu.co. 2 Integradora Virtual Administradora Escuela Instituto Colombiano de Bienestar Familiar - ICBF, Especialista en Tecnologías de la Información Aplicadas a la Educación - ETIAE Universidad Pedagógica Nacional - UPN, Ingeniero de Sistemas Universidad Distrital Francisco José de Caldas, Jennifer.GonzalezC@icbf.gov.co. 
estrategias tecnológicas basadas en una capacitación tipo inducción se formó a colaboradores en lo estratégico y misional del instituto, incursionando de una manera semipresencial, con acogida de la herramienta diseñada.

Palabras Clave: AVA, capacitación, contenido, estratégico, inducción, misional, tecnologías.

\section{Abstract}

A Virtual Learning Environment (VLE) was developed as part of an induction training addressed to $I C B F$ collaborators. It combined strategic and mission content through the implementation of different multimedia tools, provided that it facilitates the appropriation of knowledge that was previously transmitted only through face- to- face interaction in the different regions of the ICBF. The design of an VLE through Web 2.0 spaces, involved the participation of collaborators from the Institute. These spaces allowed collaborative scenarios to manage knowledge and information relevant to the training, in processes involving vulnerable population of children and adolescents, significantly reducing in this way, the investment of economic resources in logistics, travel expenses, human capital and time invested in on-site training. In the same way, the VLE, as an instrument for induction training, greatly contributed to the strengthening of the practices and competences of the $I C B F$ collaborators as a public entity, deriving out of a cooperative model.

Firstly, we deal with a detailed description of the learning model pertinent to the VLE, an explained introduction to the $I C B F$, then we state the phases of the VLE design, along with the Virtual Learning Object - VLO - Strategic and Mission related content. On the other hand, the architecture of the VLE design and its construction is carefully detailed. Next, the tools used to test the ICBF collaborators are described, along with their results. Through technological strategies based on an induction training, collaborators were trained in relation to strategic and mission content of the institute, accessing in a blended way, with a pleasing acceptance of the designed tool.

Keywords: VLE, training, content, strategic, induction, mission, technologies

\section{INTRODUCCIÓN}

Desarrollo del Ambiente Virtual de Aprendizaje - AVA

El Instituto Colombiano de Bienestar Familiar ICBF, en la actualidad brinda de manera presencial y de cubrimiento parcial, inducción a todos sus colaboradores que hacen parte de una amplia diversidad de población, entre ellos, los vinculados como servidores públicos, contratistas, pasantes, madres comunitarias y profesionales que trabajan día a día para cumplir la misión del instituto que, en otras palabras, es fomentar el desarrollo y la protección integral de la primera infan- cia, la niñez, la adolescencia y el bienestar de las familias de nuestro país.

Llevar a cabo la inducción es un requisito necesario para facilitar la identificación de los colaboradores con la institución (ICBF, 2013). No obstante, capacitarlos en su totalidad se convierte en un reto, ya que se debe considerar que el alcance del instituto es a nivel nacional; es decir, está dirigido hacia 33 regionales y alrededor de 206 centros zonales que hasta el día de hoy se tienen; el trabajo se realiza de manera conjunta en la construcción de una sociedad próspera y equitativa a partir del desarrollo integral de las nuevas generaciones y sus familias (ICBF, 2014). 
Hoy en día, el cubrimiento en capacitación no se logra en su totalidad; por un lado existen zonas apartadas de nuestro territorio nacional con acceso limitado, en las cuales se evidencia dificultad en el desplazamiento del personal y que representa costos logísticos altos para la institución en cuanto a traslados entre y hacia diferentes lugares; por otro, se evidencia el incremento en el número de colaboradores del instituto $\mathrm{y}$, por último, el número de capacitadores con los que cuenta no es suficiente. Aunque se pretende completar el tipo de inducción hacia cada uno de ellos, al ser ésta una tarea ambiciosa pero gratificante, se puede llegar a afirmar que una de las maneras para alcanzar este propósito podría ser mediante la ayuda de las Tecnologías de la Información y Comunicaciones (TIC).

Por otro lado, el instituto tiene sus orígenes en 1968. A partir de allí y, a través de más de cuatro décadas, ha brindado atención a niños y niñas, adolescentes y familias. De manera especial, a aquellos en condiciones de amenaza, insolvencia o vulneración de sus derechos (ICBF, 2011). Uno de los aspectos fuertes a destacar dentro de los recursos de protección ha sido acoger a la población víctima de la violencia, población que al ser analizada aumentó de 23 a 82 por cada 100.000 habitantes durante los años 1980 a 1985 . Esta cifra angustiante evidenciada a causa de tendencias como, por ejemplo, el predominio de la fuerza para consecución de fines, tanto en los espacios de la vida privada como en los de la vida pública, e igualmente en las interacciones políticas y en las familiares, y aún en las laborales (ICBF, 2013).

Al retomar el tema de la inducción, surge una pregunta: ¿Capacitar a los colaboradores ICBF mediante las tecnologías de la información en lo misional del instituto, tendrá la misma relevancia que en la forma presencial? Rebatir esta pregunta lleva a comprender hasta el momento dos variables a abarcar: Funcionalidad y Suficiencia.

Para comenzar, algo es "funcional" si logra satisfacer las necesidades de sus usuarios. Al relacionar este término hacia el aspecto de una capacitación (variable dependiente), de manera particular, se tienen dos tipos de usuarios: los iniciales colaboradores ICBF -quienes recibirán la inducción misional con fines estratégicos para el desarrollo y fortalecimiento de la capacidad organizacional del instituto-y la población vulnerable, quienes recibirán el apoyo y atención de los primeros. Pensar ante todo en garantizar una excelente inducción llevaría a los colaboradores no sólo a tener alto nivel de pertenencia al instituto, o potenciar su excelencia y desarrollo humano, sino también un incremento en el desempeño de sus funciones, al satisfacer las necesidades de los segundos.

Por otro lado, se piensa en "suficiencia", es necesario plantear si las tecnologías de la información serán adecuadas como apoyo a una óptima capacitación, inclusive si a través de varias décadas se ha manejado por modalidad presencial. Reflexionar en este paradigma permite relacionar factores como la capacidad informática y ofimática de las regionales y si sus colaboradores tienen o no conocimiento en su manejo; además de aspectos como su ubicación geográfica dentro del territorio nacional, que en ocasiones es limitante para el alcance tecnológico.

Pero, si se tuviesen las condiciones ideales o pertinentes, sería más que significativo cumplir con el objeto de capacitar a todos los funcionarios, incluso en términos de optimización de las funciones de la entidad, más aún cuando de por medio se tengan las herramientas de información y tecnología necesarios. No obstante, se debe resaltar que el trabajo colaborativo que ha tenido relevancia a nivel presencial puede tener una transición a su vez, al ser de manera interactiva. No sólo el hecho de aprender nuevas herramientas e interactuar con ellas aumenta la curiosidad, sino que la motivación al estar frente a aplicaciones atractivas permite incrementar el conocimiento y satisfacción personal.

Sin embargo, no se pretende que el acceso por parte de la población a las TIC y el desarrollo social del país ocasionen un distanciamiento, sino que, al contrario, vayan soportadas una con la otra, de manera cooperativa. De forma singular, en el caso del ICBF, no sólo se pretende informar, comprender y fomentar la actualidad tecnológica, sino también que, a través de un ambiente colaborativo y accesible, se lleve a cabo procesos de capacitación en inducción. 
Ambiente Virtual de Aprendizaje para la Capacitación Tipo Inducción, Sobre Contenidos Estratégicos y Misionales Dirigido a Colaboradores del Instituto Colombiano de Bienestar Familiar (ICBF)

\section{Diseño y desarrollo del Ambiente Virtual de Aprendizaje - AVA}

En primer lugar, se ideó que el AVA (variable independiente) estuviera conformada por módulos didácticos, uno de generalidades del ICBF y el otro misional, ambos diseńados para abordar procesos de formación permanente que se implementan actualmente en el instituto (ver figura 1), desde los cuales el sentido de atención hacia los colaboradores sea mejorado (Medina, 2016) a través de los contenidos, recursos y actividades a implementar; además de que a tiempo futuro se incremente el número de los módulos de este ambiente inicial.

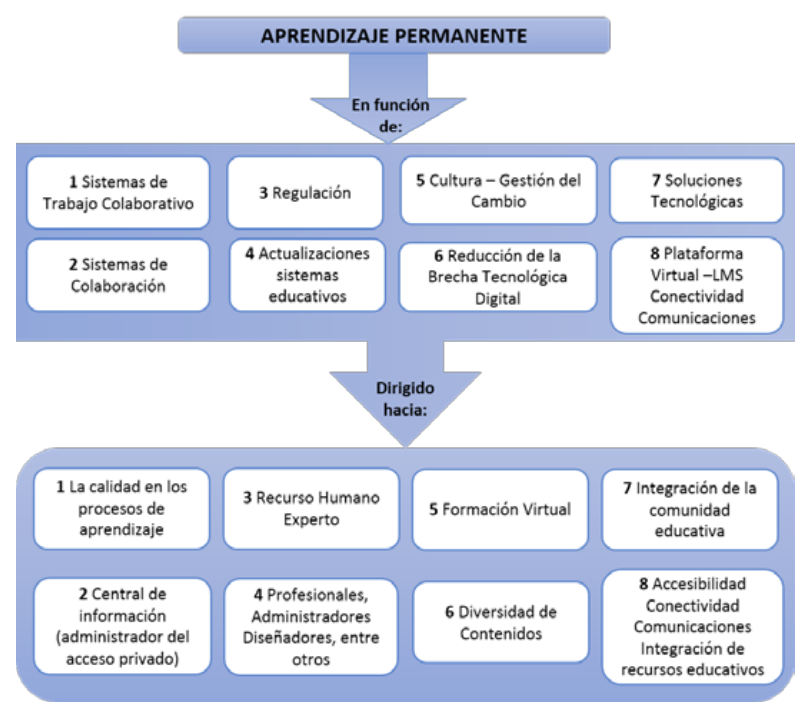

Figura 1. Situación deseada: aprendizaje permanente en el ICBF.

Fuente: Elaboración propia.

Luego de que el estudiante navegue por los contenidos multimedia y lleve a cabo actividades de aprendizaje y evaluaciones de ambos módulos, al cumplir con los requisitos establecidos podrá descargar, de manera automática, el certificado de la Escuela ICBF.

Asimismo, dentro de los aspectos operativos para el levantamiento de información inicial, se llevaron a cabo entrevistas a 10 colaboradores aleatorios, identificados como líderes de cada área de los procesos institucionales y programas del Instituto.

Por otro lado, dentro del diseño del AVA, se tuvieron en cuenta las fases cuyas actividades se describen en la tabla 1.
Tabla 1

Fases del proyecto

\begin{tabular}{|c|c|}
\hline Fase & Actividad \\
\hline \multirow[t]{2}{*}{$\begin{array}{l}\text { Levantamiento } \\
\text { de información }\end{array}$} & $\begin{array}{l}\text { Selección y definición de los contenidos por } \\
\text { cada una de las temáticas a desarrollar. }\end{array}$ \\
\hline & Establecimiento del cronograma de actividades. \\
\hline \multirow[t]{9}{*}{ Análisis } & Revisión de materiales entregados \\
\hline & Definición de la población objetivo. \\
\hline & $\begin{array}{l}\text { Descripción de temáticas de los objetos de } \\
\text { aprendizaje. }\end{array}$ \\
\hline & Definición de modelo pedagógico. \\
\hline & $\begin{array}{l}\text { Definición de objetivos de aprendizaje y alcance } \\
\text { temático del curso. }\end{array}$ \\
\hline & Definición de la estructura general del curso. \\
\hline & $\begin{array}{l}\text { Escritura de contenidos, diseño de actividades } \\
\text { de aprendizaje, evaluaciones y selección de } \\
\text { contenidos de estudio. }\end{array}$ \\
\hline & Módulo: Eje Institucional. \\
\hline & Módulo: Eje Misional \\
\hline \multirow[t]{5}{*}{ Diseño } & Construcción y revisión de maqueta (Prototipo). \\
\hline & Definición de línea gráfica. \\
\hline & $\begin{array}{l}\text { Propuesta de diagramación de los objetos } \\
\text { virtuales de aprendizaje. }\end{array}$ \\
\hline & Elaboración del manual de usuario. \\
\hline & Alistamiento del ambiente virtual de aprendizaje. \\
\hline Desarrollo & $\begin{array}{l}\text { Producción de los módulos eje institucional, eje } \\
\text { misional. }\end{array}$ \\
\hline \multirow[t]{4}{*}{ Implementación } & Montaje en plataforma de la Escuela ICBF. \\
\hline & Pruebas técnicas de los objetos de aprendizaje. \\
\hline & Diseño de manual de usuario. \\
\hline & Prueba piloto con colaboradores del ICBF. \\
\hline
\end{tabular}

Fuente: Elaboración propia.

Por otro lado, cabe resaltar que dentro de la estructura del desarrollo del AVA no solo era necesario tener un diseño instruccional, sino que era indispensable contar con un modelo pedagógico. El ICBF, dentro de sus capacitaciones institucionales siempre ha implementado el cognitivismo, el mismo que fue también implementado al AVA. Este modelo cuenta con características como: (i) énfasis en el conocimiento significativo, (ii) la participación activa del estudiante en el proceso de aprendizaje, (iii) creación de ambientes de aprendizaje que permitan y estimulen a los estudiantes a hacer conexiones mentales con material previamente aprendido, (iv) la estructuración, organización y secuencia de la información para facilitar su óptimo procesamiento (Casas, 2016). 
Asimismo, este modelo se encuentra basado en procesos de razonamiento y asimilación de información que todo individuo tiene durante su vida, sea durante su proceso educativo dentro de la escuela o fuera del entorno escolar, a temprana edad o en educación superior (Beltrán, 2016).

Debido al énfasis en las estructuras mentales, se considera a las teorías cognitivas más apropiadas para explicar las formas complejas de aprendizaje (razonamiento, solución de problemas, procesamiento de información).

Por otro lado, en cuanto a la integración de contenidos, mediante la siguiente gráfica (figura 2) se describen las teorías que se aplicarán mediante las Tecnologías de la Información y Comunicación (TIC), en el AVA de Inducción al ICBF:

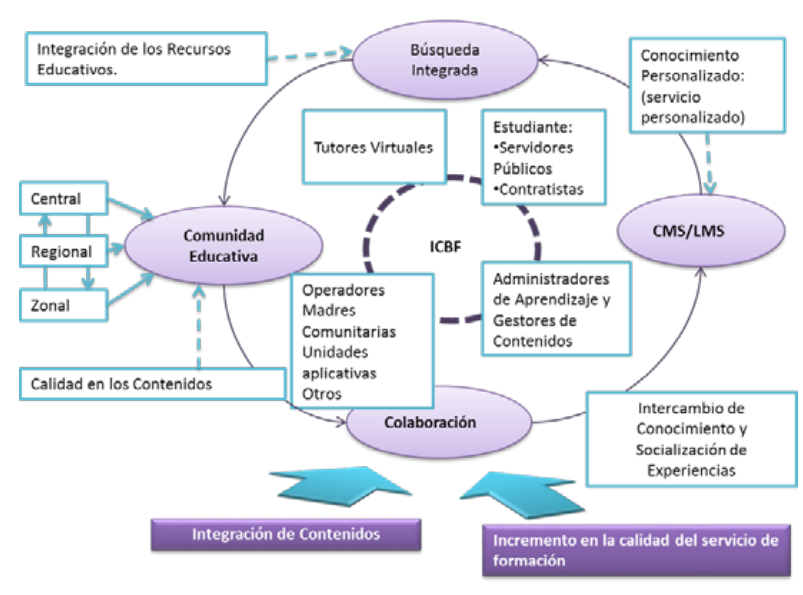

Figura 2. Integración contenidos ICBF.

Fuente: ICBF.

A partir de estas condiciones, el curso de Inducción al ICBF utilizó la plataforma virtual de la Universidad Pedagógica Nacional - UPN, llamada Kenta, la cual permitió que no sólo se subieran los contenidos, sino también que se desarrollaran varias pruebas, como, por ejemplo: de navegabilidad entre la población estudio y su posterior descripción detallada. La tabla 2 describe las restricciones o pseudorequerimientos a tener en cuenta a nivel tecnológico para el óptimo desarrollo y navegación del AVA dentro de la plataforma Kenta.
Tabla 2

Pseudorequerimientos

\begin{tabular}{|c|c|}
\hline Identificador & Características \\
\hline RN1: Red - Internet & $\begin{array}{l}\text { Computadores con conexión a internet. } \\
\text { Desde y hacia los recursos propios del } \\
\text { ICBF. }\end{array}$ \\
\hline RN2: Plataforma & LMS Moodle. \\
\hline Tecnológica & $\begin{array}{l}\text { Identificación de usuarios de estudiantes } \\
\text { con sus respectivas contraseñas (con } \\
\text { parámetros de seguridad con políticas } \\
\text { de acceso local y remoto) }\end{array}$ \\
\hline $\begin{array}{l}\text { RN3: Sistema } \\
\text { Operativo }\end{array}$ & Preferiblemente Windows XP - 8 . \\
\hline RN4: Navegador Web & $\begin{array}{l}\text { Preferiblemente Chrome deshabilitando } \\
\text { elementos emergentes. }\end{array}$ \\
\hline RN5: Software & $\begin{array}{l}\text { De tipo aplicación hacia usuario final } \\
\text { como Flash y sus complementos (Ver- } \\
\text { sión CS3 o superior). }\end{array}$ \\
\hline $\begin{array}{l}\text { RN6: Tamaño de } \\
\text { archivos }\end{array}$ & $\begin{array}{l}\text { Entre } 7 \mathrm{MB} \text { y } 15 \mathrm{MB} \text {, dependiendo de la } \\
\text { actividad propuesta por el docente. }\end{array}$ \\
\hline
\end{tabular}

Fuente: Elaboración propia.

Dentro de las estrategias para cada meta de aprendizaje y contenido se pueden tener varias estrategias pedagógicas. Cada una de estas ha descrito los criterios a seguir (tabla 3).

Tabla 3

Estrategias pedagógicas

\begin{tabular}{ll}
\hline Meta de & Al ingresar el colaborador a la institución, se le \\
Aprendizaje & $\begin{array}{l}\text { aportará conocimientos e información básica de } \\
\text { la entidad, creándose pertenencia en procesos y } \\
\text { actividades misionales. }\end{array}$ \\
\hline Contenido & Indicación del contenido específico. \\
& - Módulo \\
& - Introducción \\
& - Objetivos estratégicos. \\
& - Contexto histórico. \\
& - Misión y visión. \\
& - Principios institucionales. \\
& - Mapares institucionales. \\
& - Estructura organizacional. \\
\hline Estrategia & Se realiza una estrategia: \\
& - Fase de motivación: \\
& - Fase de comprensión \\
- Fase de adquisición. \\
- Fase de retención. \\
- Fase de recuerdo. \\
- Fase de generalización. \\
- Fase de ejecución.
\end{tabular}


Ambiente Virtual de Aprendizaje para la Capacitación Tipo Inducción, Sobre Contenidos Estratégicos y Misionales Dirigido a Colaboradores del Instituto Colombiano de Bienestar Familiar (ICBF)

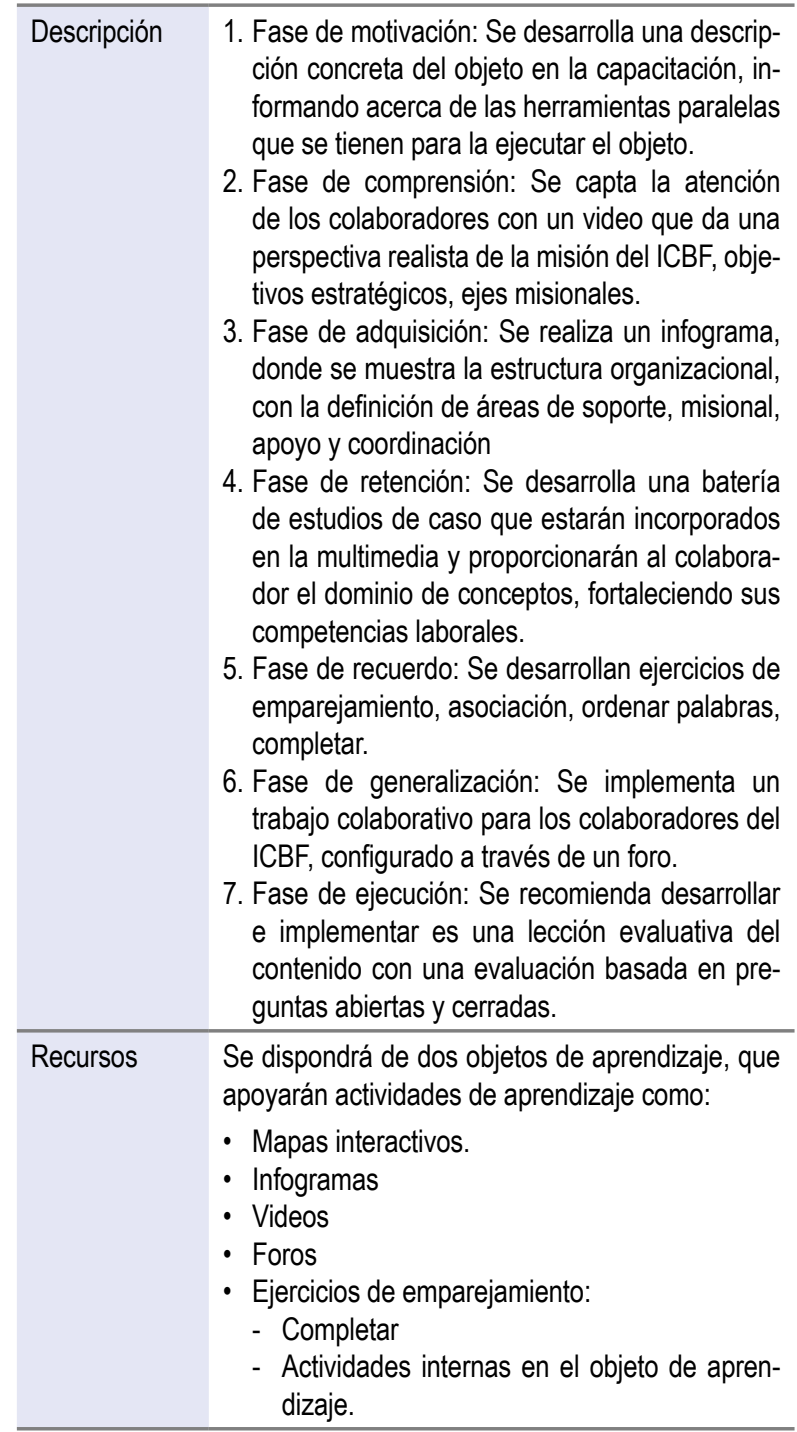

Fuente: Elaboración propia.

En la tabla 4 se describe los contenidos del AVA involucrados.

Tabla 4

Contenidos involucrados en el ambiente

\begin{tabular}{|c|c|c|}
\hline Contenido & Descripción & Metodología \\
\hline $\begin{array}{l}\text { Foro de } \\
\text { Presentación }\end{array}$ & $\begin{array}{l}\text { Diseñado para } \\
\text { el colaborador } \\
\text { del ICBF. }\end{array}$ & $\begin{array}{l}\text { El colaborador realiza una breve } \\
\text { presentación (nombres, apelli- } \\
\text { dos, profesión, cargo, ciudad, ex- } \\
\text { periencia las expectativas frente } \\
\text { al Curso). }\end{array}$ \\
\hline \multirow{3}{*}{$\begin{array}{l}\text { Fase ¿Qué } \\
\text { tanto } \\
\text { sabemos? }\end{array}$} & \multirow{3}{*}{$\begin{array}{l}\text { Se busca que } \\
\text { el participante } \\
\text { identifique los } \\
\text { conocimientos } \\
\text { previos frente } \\
\text { a las temá- } \\
\text { ticas que se } \\
\text { abordarán en el } \\
\text { módulo. }\end{array}$} & ACTIVIDAD 1 \\
\hline & & $\begin{array}{l}\text { Conocer los conceptos previos } \\
\text { que tienen los participantes } \\
\text { frente al Instituto Colombiano de } \\
\text { Bienestar Familiar. }\end{array}$ \\
\hline & & $\begin{array}{l}\text { Metodología: Los participantes } \\
\text { deberán responder la pregunta } \\
\text { del foro: ¿Qué es el Bienestar } \\
\text { Familiar para ti? }\end{array}$ \\
\hline
\end{tabular}

Criterios de evaluación: Esta actividad no será evaluada; se utiliza como diagnóstico y es requisito para generar el certificado al final del recorrido multimedia.

\begin{tabular}{ll}
\hline $\begin{array}{l}\text { Fase ¿Qué } \\
\text { debemos }\end{array}$ & Plantea la infor- \\
saber? & mación y fun- \\
& damentación \\
& conceptual, \\
& metodológica \\
& y normativa \\
& que se requiere \\
& para ser parte \\
& del ICBF.
\end{tabular}

ACTIVIDAD 2

Conocer o el Instituto Colombiano de Bienestar Familiar.

Propósito: Conocer las generalidades de ICBF.

Metodología: El participante observará el contenido del video Somos Instituto colombiano de Bienestar Familiar, disponible en https://www.youtube.com/watch?v=MSJBX6Uxh31

ACTIVIDAD 3

Conociendo las generalidades del Instituto colombiano de Bienestar Familiar

Propósito: Conocer las generalidades del Instituto colombiano de Bienestar Familiar por parte de los participantes.

Metodología: El participante observará y navegará por el OVA Estratégico - Misional que explica los antecedentes, misión, visión, objetivos estratégicos, líneas estratégicas, fases, etcétera.

\begin{tabular}{lll}
\hline $\begin{array}{l}\text { Fase ¿Qué } \\
\text { hemos }\end{array}$ & $\begin{array}{l}\text { Los participan- } \\
\text { tes pondrán }\end{array}$ & ACTIVIDAD 4 \\
aprendido? & $\begin{array}{l}\text { a prueba sus tanto sabes del Instituto } \\
\text { conocimientos } \\
\text { adquiridos en el } \\
\text { módulo }\end{array}$ & $\begin{array}{l}\text { Colombiano de Bienestar Fami- } \\
\text { liar? }\end{array}$ \\
& $\begin{array}{l}\text { Propósito: Identificar la apropia- } \\
\text { ción de las generalidades del } \\
\text { instituto colombiano de Bienestar } \\
\text { Familiar a través de una evalua- } \\
\text { ción. }\end{array}$
\end{tabular}

Metodología: El participante deberá realizar la evaluación final y contara con 3 intentos.

Criterios de evaluación: Preguntas para la evaluación final (la evaluación contará con 10 preguntas aleatorias de una batería de 50). De estas se deben responder correctamente como mínimo 8 de 10 preguntas.

Porcentaje de Evaluación: 0-100, donde 100 es la nota más alta y 60 es el mínimo aprobatorio.

\begin{tabular}{ll}
\hline Fase ¿Qué & Se espera que \\
Propongo? & los participan- \\
& tes puedan \\
& proponer las \\
& estrategias o \\
& las acciones
\end{tabular}

Actividad 5

EVALUACIÓN

Propósito: Hacer una aproximación general al Instituto Colombiano de Bienestar Familiar, de sus propósitos, estrategias, principios institucionales, etcétera. 
Metodología: Diseñe un slogan para el instituto Colombiano de Bienestar Familiar teniendo en cuenta los contenidos vistos en este.

Criterios de evaluación: Esta actividad será evaluada a partir del nivel de apropiación conceptual y metodológica del participante frente a las generalidades del ICBF, el cual tendrá la opción de realizar el slogan durante la permanencia en el Módulo.

Fuente: Elaboración propia.

Las dinámicas de interacción que se pueden llevar a cabo entre estudiantes, estudiante-maestro y la navegación del ambiente, se diagraman mediante la figura 3 .

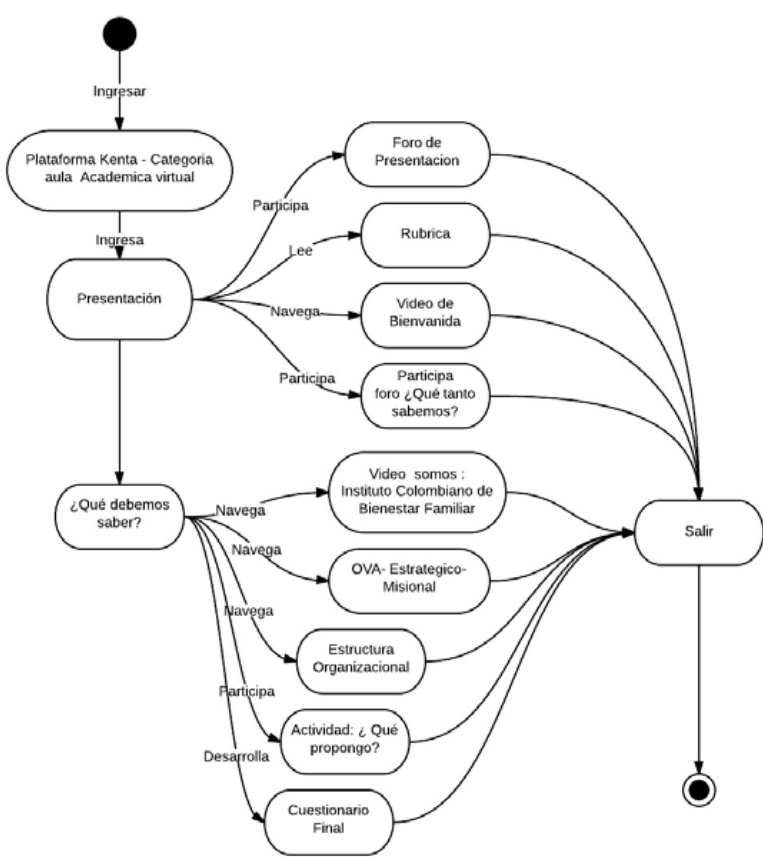

Figura 3. Modelo dinámico navegación AVA. Fuente: Elaboración propia.

Además, dentro de la construcción del Ambiente Virtual de Aprendizaje, la Inducción al ICBF está diseñada para ser un complemento de la capacitación presencial, que se lleva a cabo en cada una de las regionales y centros zonales del ICBF a nivel nacional, hacia los colaboradores ICBF.

Su implementación, incluye también un Objeto Virtual de Aprendizaje, el cual incluye contenidos estratégicos y misionales del instituto, que contribuirán a la formación y compromiso en el tiempo de los nuevos colaboradores ICBF.

Para la estructura del AVA fueron diseñados diferentes espacios de formación y navegación en leguaje HTML, bajo la herramienta Macromedia Dreamveawer CS6. Por otro lado, los botones y algunos escenarios fueron llevados a cabo de manera personalizada, dibujados a mano y luego tratados de forma especial bajo el programa Macromedia Flash.

Para el diseño se tuvieron en cuenta los colores institucionales del ICBF, también conceptos como la usabilidad y la aplicación del uso de color a través de pruebas realizadas según los tipos de aprendizaje e inteligencias múltiples que tienen los colaboradores valorados. Desde el principio se buscó aplicar un sentido motivacional del AVA, con un toque personalizado, que emergió de esquemas verticales o rígidos para la navegación de todos los recursos.

En la figura 4 se tiene la pantalla de inicio del AVA: Inducción al ICBF.

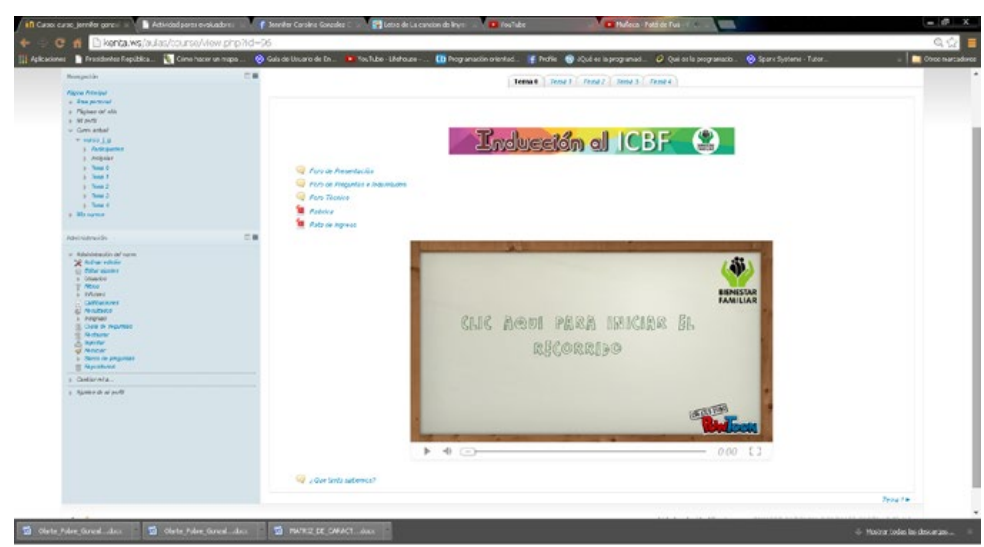

Figura 4. Pantalla de inicio AVA.

Fuente: Elaboración propia.

Por otro lado, en la pantalla de inicio del OVA Estratégico - Misional se tienen los elementos que se muestran en la figura 5 . 

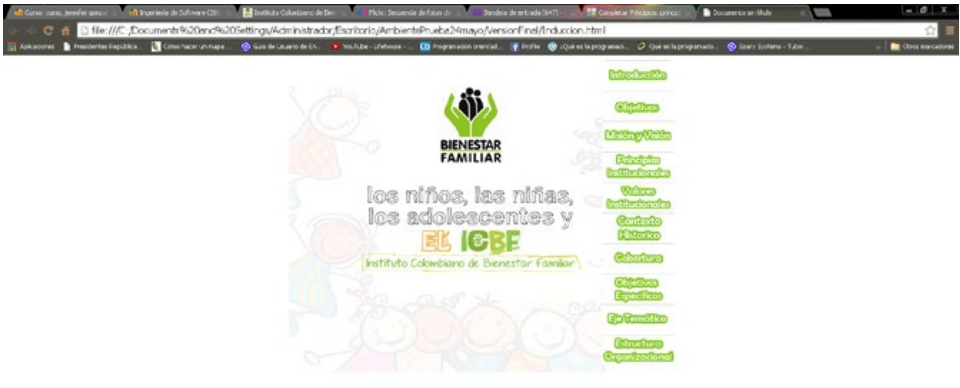

Figura 5. Pantalla de inicio OVA. Fuente: Elaboración propia.

\section{Materiales y Métodos}

\section{Participantes}

El grupo piloto evaluado estuvo conformado por seis (6) hombres y cuatro (4) mujeres, para un total de 10 colaboradores elegidos en forma aleatoria. Estos recibieron una capacitación de inducción en lo misional y estratégico. Sus edades oscilaban entre los 25 y 45 ańos. Cada uno de los sujetos eran servidores públicos que se desempeñaban como contratistas, operadores del sistema, pasantes, madre comunitaria y o profesionales que formaban parte de la misión del ICBF en la ciudad de Bogotá. Pertenecían a niveles socioeconómicos ubicados entre los estratos 2 y 4.

Cada uno de estos colaboradores tuvo previamente una inducción en el modelo basado en poblaciones beneficiadas, incluyendo primera infancia, niñez y adolescencia, familia y comunidad con protección integral y coordinación regional. A su vez, tuvieron una capacitación en valores institucionales, como don de servicio, sentido de pertenencia, innovación, tolerancia, credibilidad, enfoque a resultados, amabilidad y honestidad.

Cabe resaltar que las pruebas realizadas tenían como propósito caracterizar el tipo de aprendizaje de la población de estudio y, ya a nivel del curso, verificar pruebas de navegabilidad.

\section{Instrumentos}

Los instrumentos que se describen a continuación fueron aplicados a colaboradores del ICBF entre enero a mayo de 2014. Fueron de gran ayuda para el desarrollo y valoración tanto de AVA en Inducción al ICBF, como del OVA Estratégico - Misional. Los resultados que se presentan mediante tablas y gráficos se explican en la sección siguiente de este artículo.

Cada instrumento tiene un objetivo específico.

Test de KOLB. El objetivo es caracterizar los tipos de aprendizaje predominantes y luego identificar si las decisiones de color basadas en las inteligencias múltiples fueron o no acertadas. Éste test, cuenta con un total de 9 preguntas, cada una de ellas ofrece 4 opciones de respuesta, a las cuales se les debe asignar un puntaje (en el rango 4-1), considerando que el cuatro (4) es lo que mejor describe al individuo y uno (1) lo que peor lo describe. Este test se realizó en formato Excel y fue aplicado desde 1985.

Encuesta 1 de satisfacción del curso. Su objetivo es identificar si los objetivos del curso se ajustan a los contenidos estratégicos y misionales del ICBF. Consta de 24 preguntas de elaboración propia, enfocadas hacia temas como el desarrollo de contenido, evaluación del curso, respecto a contenidos actividades y evaluación e interacción gráfica. Se realizó mediante la herramienta formularios de Google.

Encuesta 2 Evaluación del ambiente virtual de aprendizaje. En este instrumento se incluyeron 26 preguntas de elaboración propia, distribuidas en cuatro dimensiones: relevancia, pensamiento reflexivo, interactividad, apoyo del tutor, apoyo de compañeros e interpretación. Se realizó mediante la herramienta formularios de Google.

Los tres instrumentos para la valoración del AVA en sus diferentes fases fueron aplicados a colaboradores del ICBF, específicamente en la Sede Dirección General ubicada en la ciudad de Bogotá (Av. Cra. 68 No. 64C-75), Barrio Bosque Popular de la localidad de Engativá (figura 6). 


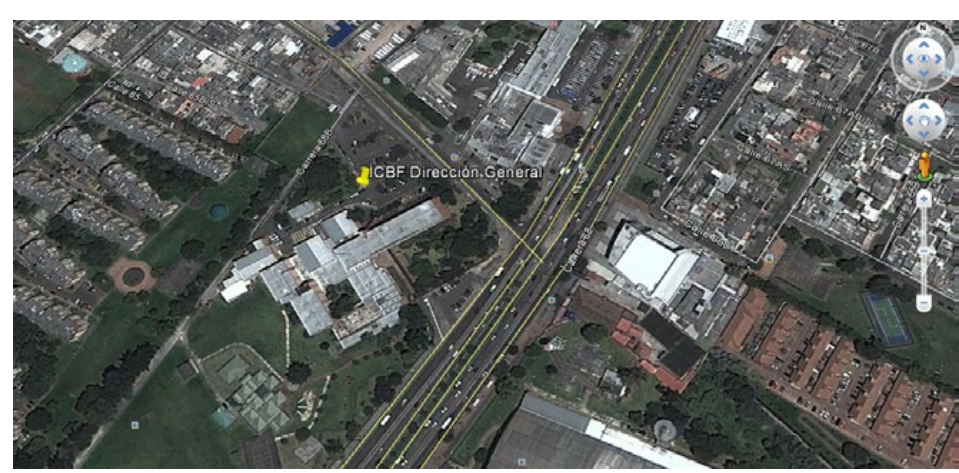

Figura 6. Sede Dirección General ICBF. Fuente: Herramienta Google Earth.

\section{Tipo y diseño}

Aunque se ha realizado un análisis cualitativo de la información, debido a la implementación de un modelo pedagógico cognitivista en los diferentes momentos del AVA, también se obtuvieron resultados cuantitativos, pues se valoraron 10 individuos colaboradores del ICBF, para caracterizar su estilo de aprendizaje, además de su valoración hacia la navegabilidad del curso desarrollado.

Se trata de una investigación no experimental de tipo exploratoria que, además, buscó establecer la confiabilidad del AVA hacia colaboradores ICBF, identificar el estilo de aprendizaje predominante entre los encuestados y las particularidades de favorabilidad o desacuerdo con los contenidos implementados bajo mediación de TIC en el AVA.

El estudio tuvo un alcance exploratorio para conocer la importancia de la capacitación tipo inducción, realizada en forma virtual a colaboradores ICBF. El diseño de investigación es no experimental transeccional, pues las mediciones se realizaron en un solo momento, entre enero a mayo de 2014.

\section{Variables:}

- Variable independiente: Ambiente Virtual de Aprendizaje.

- Variable dependiente: Capacitación tipo inducción.

\section{Resultados}

En este acápite se detallan los resultados de los 3 primeros instrumentos, ya que el último se administró de manera personal a cada colaborador y su grado de subjetividad depende por un lado del manejo eficiente de herramientas informáticas y ofimáticas.

La tabla 5 resume los resultados del Test de Kolb.

Tabla 5

Matriz resultados Test de Kolb

\begin{tabular}{|c|c|c|c|c|}
\hline \multicolumn{5}{|c|}{ Resultados Test de Kolb dirigido a colaboradores ICBF } \\
\hline \multirow[b]{2}{*}{ Colaborador } & \multicolumn{4}{|c|}{ Estilo de aprendizaje } \\
\hline & $\begin{array}{l}\text { Conver- } \\
\text { gente }\end{array}$ & $\begin{array}{l}\text { Diver- } \\
\text { gente }\end{array}$ & $\begin{array}{c}\text { Asimila- } \\
\text { dor }\end{array}$ & $\begin{array}{c}\text { Acomoda- } \\
\text { dor }\end{array}$ \\
\hline 1 & & & & $x$ \\
\hline 2 & & $\mathrm{X}$ & & \\
\hline 3 & & & $\mathrm{x}$ & \\
\hline 4 & & $\mathrm{X}$ & & \\
\hline 5 & & & & $\mathrm{x}$ \\
\hline 6 & & & $\mathrm{X}$ & \\
\hline 7 & & $\mathrm{X}$ & & \\
\hline 8 & & $\mathrm{X}$ & & \\
\hline 9 & & $\mathrm{X}$ & & \\
\hline 10 & & $\mathrm{x}$ & & \\
\hline Total & 0 & 6 & 2 & 2 \\
\hline Porcentajes & $0 \%$ & $60 \%$ & $20 \%$ & $20 \%$ \\
\hline
\end{tabular}

Fuente: Elaboración propia.

La distribución de los porcentajes, según los estilos de aprendizaje obtenidos, se aprecian en la figura 7.

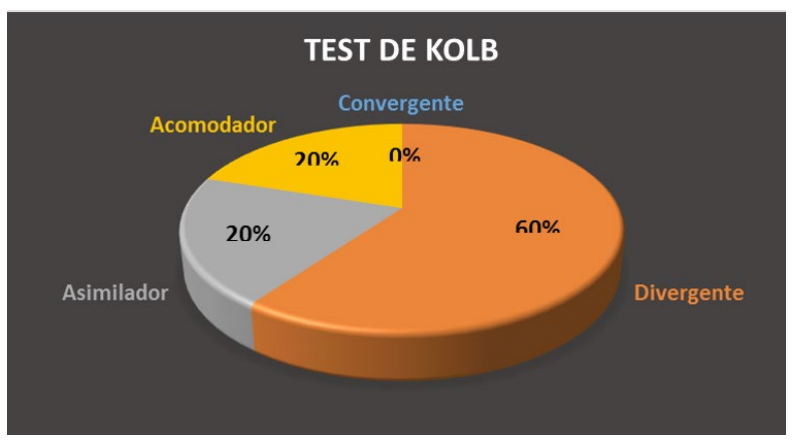

Figura 7. Resultados Test de Kolb. Fuente: Elaboración propia. 
Ambiente Virtual de Aprendizaje para la Capacitación Tipo Inducción, Sobre Contenidos Estratégicos y Misionales Dirigido a Colaboradores del Instituto Colombiano de Bienestar Familiar (ICBF)

A partir de los porcentajes calculados, se obtuvieron las características por estilo de aprendizaje (CCA, 2012), que se describen en la tabla 6 .

Tabla 6

Características y dominio de cada estilo de aprendizaje

\begin{tabular}{|c|c|c|}
\hline $\begin{array}{l}\text { Estilo de } \\
\text { aprendizaje }\end{array}$ & Dominio & Caracterizado porque \\
\hline \multirow[t]{2}{*}{ Divergente } & $60 \%$ & $\begin{array}{l}\text { Se basan en experiencias concretas } \\
\text { (EC), aunque su punto fuerte es la ca- } \\
\text { pacidad imaginativa. Por lo tanto, son } \\
\text { excelentes productores de diferentes } \\
\text { ideas. También poseen una observación } \\
\text { reflexiva (OR), proporcionando herra- } \\
\text { mientas para el pensamiento y planea- } \\
\text { ción. }\end{array}$ \\
\hline & & $\begin{array}{l}\text { Características: Sensorial o kinestési- } \\
\text { cos (toman decisiones en función de lo } \\
\text { que sienten), experimentales, flexibles, } \\
\text { creativos y tienen iniciativa. }\end{array}$ \\
\hline \multirow[t]{2}{*}{ Asimilador } & $20 \%$ & $\begin{array}{l}\text { Son lógicos al organizar información, } \\
\text { combinando la conceptualización abs- } \\
\text { tracta (CA) y la observación reflexiva } \\
\text { (OR). Se encuentran más interesados } \\
\text { en las ideas abstractas y conceptos, } \\
\text { prevaleciendo lo lógico frente a lo prác- } \\
\text { tico. }\end{array}$ \\
\hline & & $\begin{array}{l}\text { Características: En ellos predominan } \\
\text { las carreras de tipo científico o analíti- } \\
\text { co. Son metódicos, lógicos, racionales y } \\
\text { sistemáticos. }\end{array}$ \\
\hline
\end{tabular}

Acomodador $20 \% \quad$ Aprenden de la experiencia concreta (EC), con iniciativa para participar en cosas nuevas y la combinan con la experiencia activa (EA) para la ejecución de planes. Son fácilmente adaptables a nuevas circunstancias específicas.

Características: Arriesgados, poco pacientes, emocionales, intuitivos, imaginativos y observadores de detalles específicos.

Convergente \% Aprenden a través de la solución de problemas, buscan la práctica a través de las ideas. Toman decisiones a través de los resultados encontrados para encontrar o definir una sola rama o resultado como conclusión.

Características del convergente: Hábiles para interpretar la teoría a la práctica, excelentes para los puestos técnicos.

Fuente: CCA (2012).

De acuerdo a la clasificación anterior, se deduce que, dentro de la caracterización del estilo de aprendizaje aplicado a 10 colaboradores aleatorios del ICBF, predomina el tipo divergente a comparación del convergente, que no obtuvo resultados.
Se encontró que el $60 \%$ de la población estudiada (6 de 10 personas), se inclinan hacia el aprendizaje divergente, caracterizándose por aprender a partir de sensaciones, ser experimentales, flexibles y creativos. Dentro de esta caracterización, los individuos evidencian habilidades en consejería, administración del personal y como especialistas en desarrollo organizacional (Córdova, 2015). Estos resultados son importantes porque contar con colaboradores de estas características contribuye todavía más al crecimiento visional y misional del Instituto (García, 2016). Ahora bien, para determinar qué tipo de inteligencia poseen, fue necesario tener en cuenta el modelo de cuatro cuadrantes de Kolb (CCA, 2012), que se describe en la figura 8.

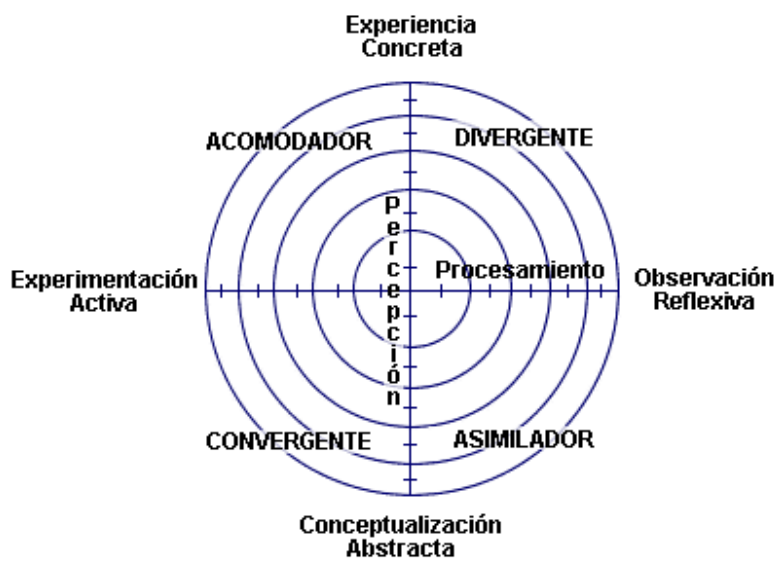

Figura 8. Modelo de cuatro cuadrantes de Kolb (CCA, 2012).

Como el estilo de aprendizaje divergente se ubica en medio de los cuadrantes Observación Reflexiva (OR) y Experiencia Concreta (EC), identificamos una combinación entre el tipo de aprendizaje reflexivo y el activo.

A partir de los resultados, para el estilo reflexivo se utilizan colores rosa, marrón y verde, mientras que para el estilo activo se emplean tonos amarillo, rojo y naranja. Esto obedece a que los colores predominantes coinciden dentro de los usados tanto en el AVA Introducción al ICBF, como para el OVA Misional Estratégico. A continuación, en la siguiente figura 9 se evidencia la aplicación de estos colores. 


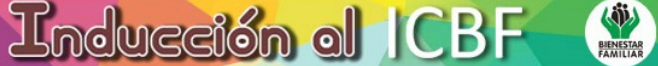

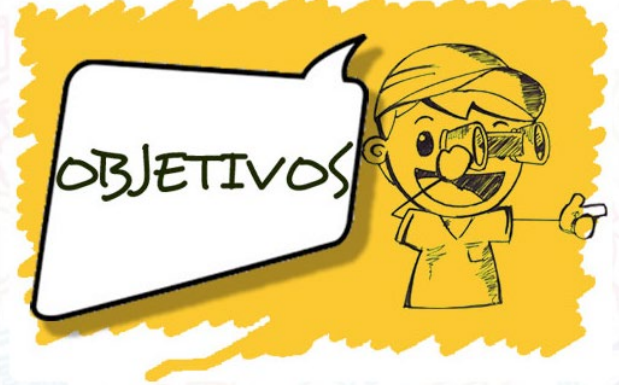

Figura 9. Aplicación tipo de colores según inteligencias múltiples.

Por otro lado, se tiene en cuenta la distribución de resultados de la encuesta de satisfacción 1 , mediante diagramas de torta, de manera inicial a las preguntas relacionadas con el desarrollo de contenido (figura 10), donde el $80 \%$ de los colaboradores opinaron que los contenidos están lógicamente organizados; el 90\% indicó que el lenguaje de los temas y módulos fue el adecuado y el 90\% indicó que la información es clara y precisa.

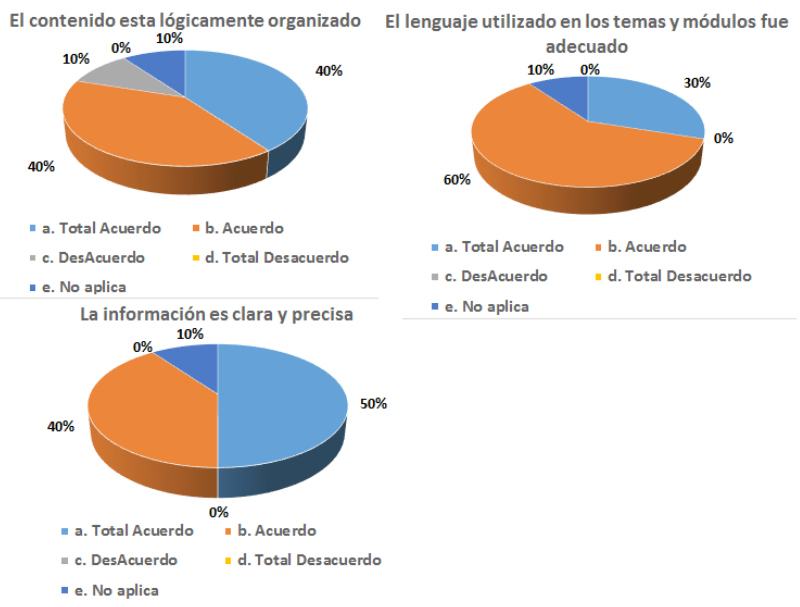

Figura 10. Resultados para las preguntas desarrollo de contenido.

De manera similar, más del 70\% de la población opinó que se cumplieron con los objetivos de las actividades, se verificaron los temas propuestos y que el manejo de la plataforma fue sencillo (figura 11).

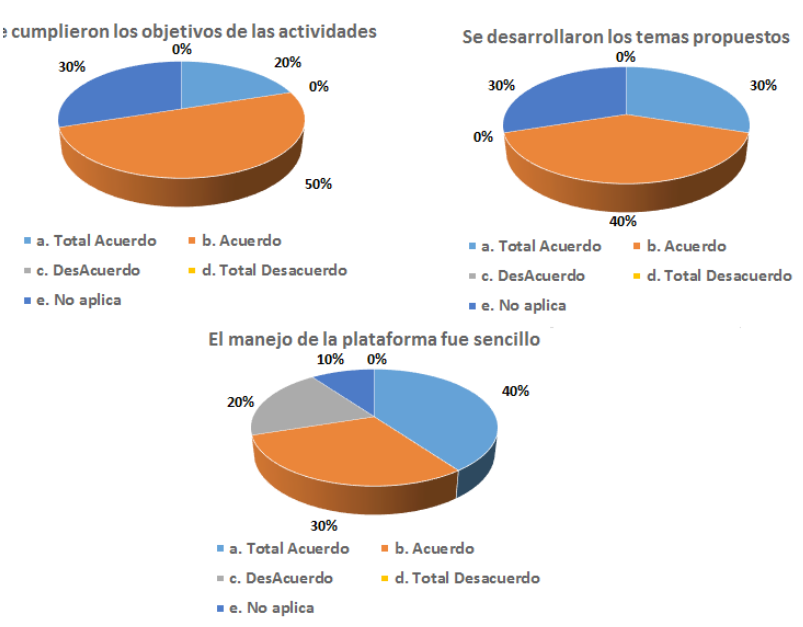

Figura 11. Resultados para las preguntas objetivos del curso

Para preguntas relacionadas con la resolución de inconvenientes durante el curso y el tiempo de respuesta frente a ellos (figura 12), prevaleció la respuesta no aplica, ya que la prueba era solo de navegabilidad más no de certificación de los contenidos. Por otro lado tan sólo el $10 \%$ opino que las inquietudes planteadas no fueron resueltas satisfactoriamente y el $80 \%$ de los colaboradores ICBF opinaron que el curso cumplió con sus expectativas.

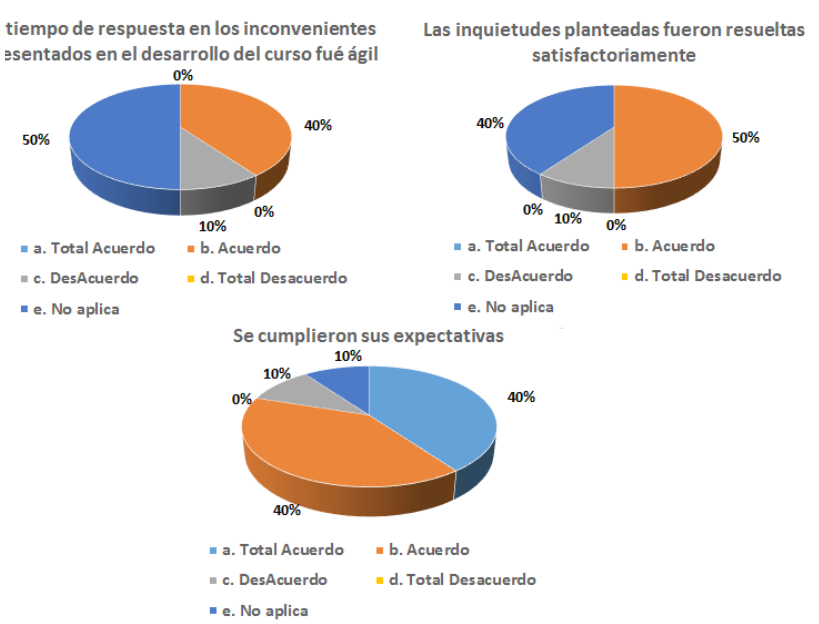

Figura 12. Resultados para las preguntas tiempo de respuesta.

Respecto a los contenidos, actividades y evaluación (figura 13), el 90\% opinó que el apoyo tecnológico fue pertinente en el aprendizaje de contenidos, transferible a la práctica profesional y coherente, pertinente y actual con los objetivos propuestos. 
Ambiente Virtual de Aprendizaje para la Capacitación Tipo Inducción, Sobre Contenidos Estratégicos y Misionales Dirigido a Colaboradores del Instituto Colombiano de Bienestar Familiar (ICBF)

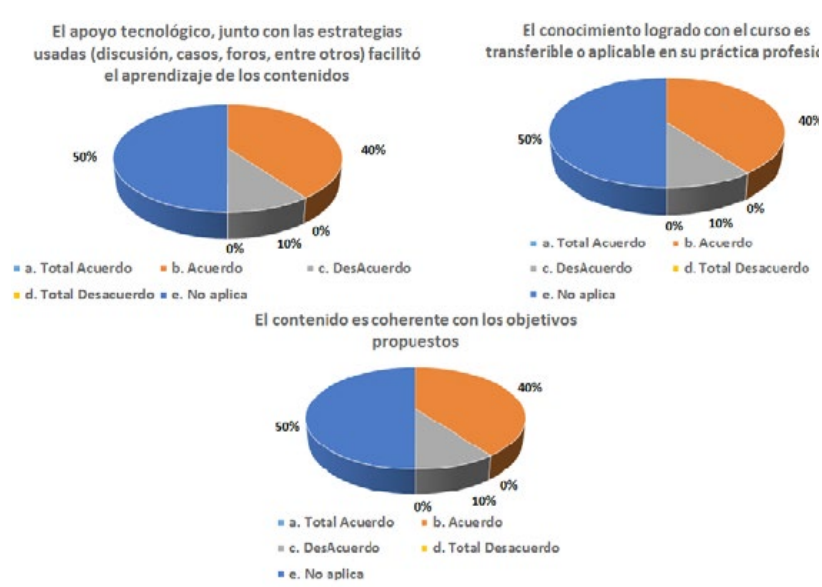

Figura 13. Resultados para las preguntas referidas a contenidos, actividades y evaluación.

En cuanto a las fechas de entrega de las actividades (figura 14), más del 70\% indicó que estas fueron claras y el $90 \%$ estuvo de acuerdo que se informó con claridad los objetivos.

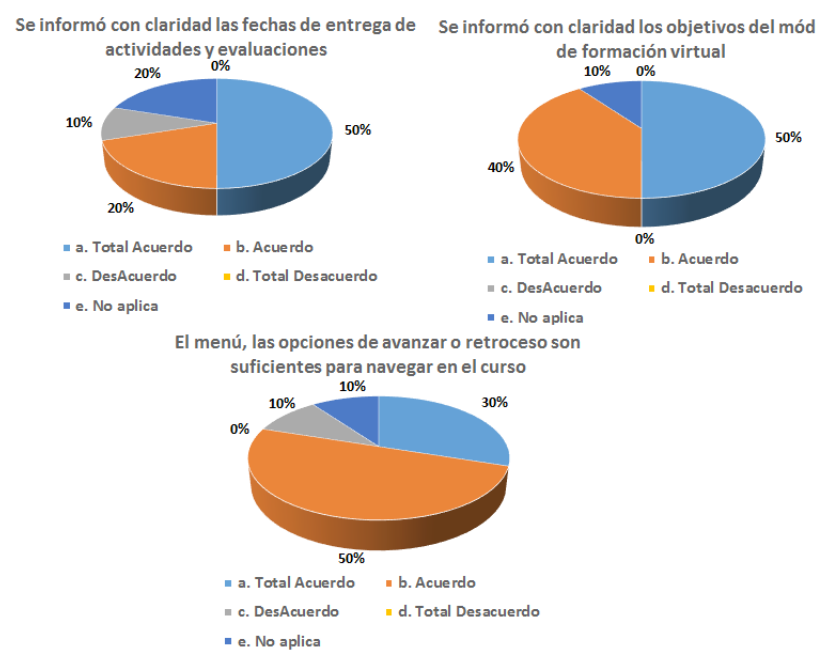

Figura 14. Resultados para las preguntas tiempo de entrega e interacción gráfica.

Por otro lado, para la interacción gráfica (figura 15 ) el $80 \%$ de los usuarios opinaron que las ilustraciones fueron apropiadas, al igual que las interacciones.

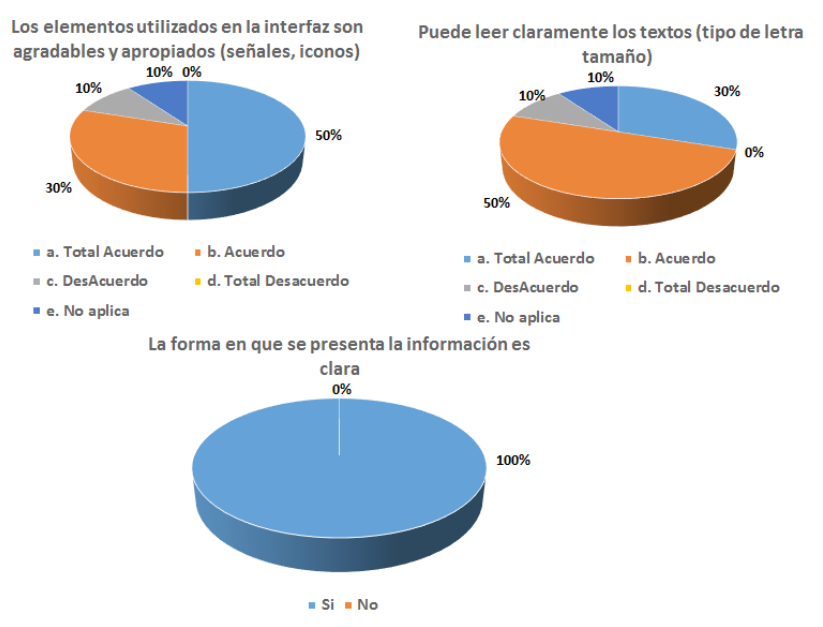

Figura 15. Resultados para las preguntas representación gráfica (parte 2).

Para la Encuesta 2: Evaluación ambiente virtual de aprendizaje, que tiene en cuenta la relevancia del AVA (figura 16), los usuarios indicaron que casi siempre los temas fueron interesantes, importantes y estaban relacionados con su práctica.

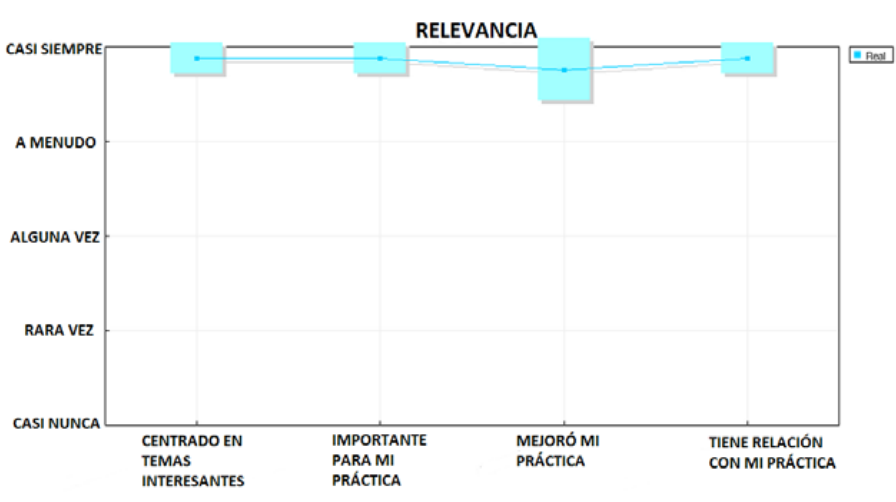

Figura 16. Resultados para la relevancia del AVA.

Por otro lado, en el pensamiento reflexivo (figura 17), los colaboradores a menudo fueron críticos en el aprendizaje, con sus ideas, con otros estudiantes y con lo que leen.

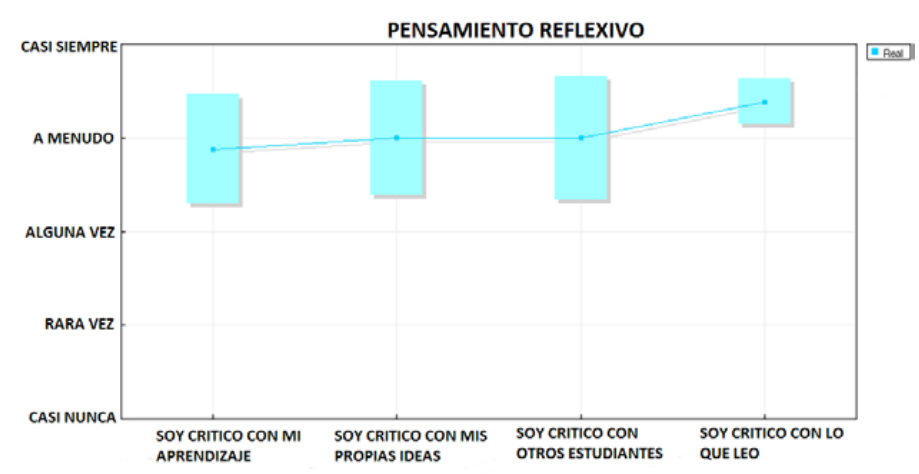

Figura 17. Resultados para el pensamiento reflexivo. 
Dentro de las relaciones con el tutor (figura 18), cabe resaltar, según ellos ,que a menudo su tutor estimuló la reflexión, lo animó, casi siempre ejemplificó sus disertaciones y ejemplificó la autoreflexión.

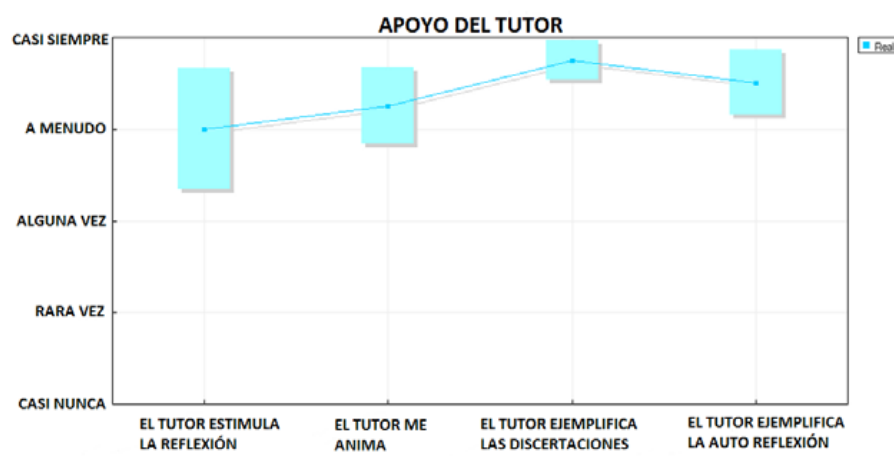

Figura 18. Resultados relaciones con el tutor.

Además, se evidenció que, a menudo, los estudiantes se animan con el apoyo de los compañeros, se elogian entre ellos, los valoran y empatizan (figura 19).

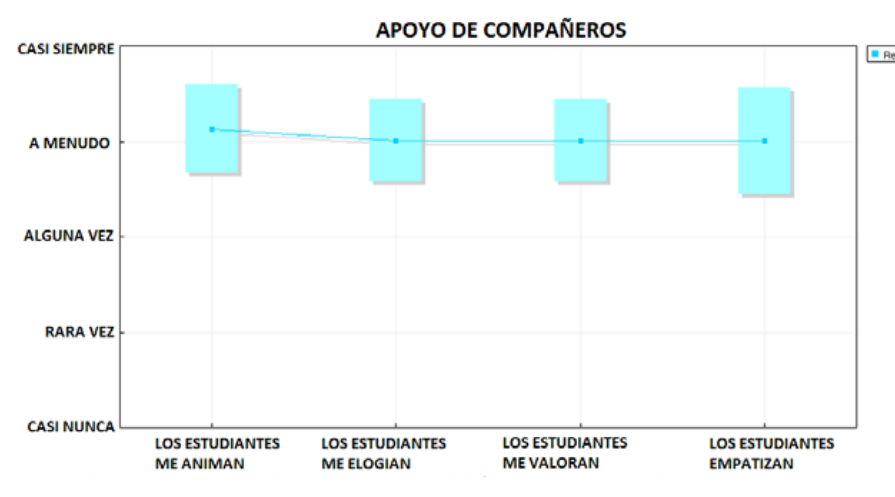

Figura 19. Resultado apoyo de compañeros.

En cuanto a la interpretación (figura 20), los colaboradores ICBF evaluados, a menudo entienden a otros estudiantes; otros estudiantes los entienden y casi siempre entienden al tutor y, a su vez, el tutor los comprende.

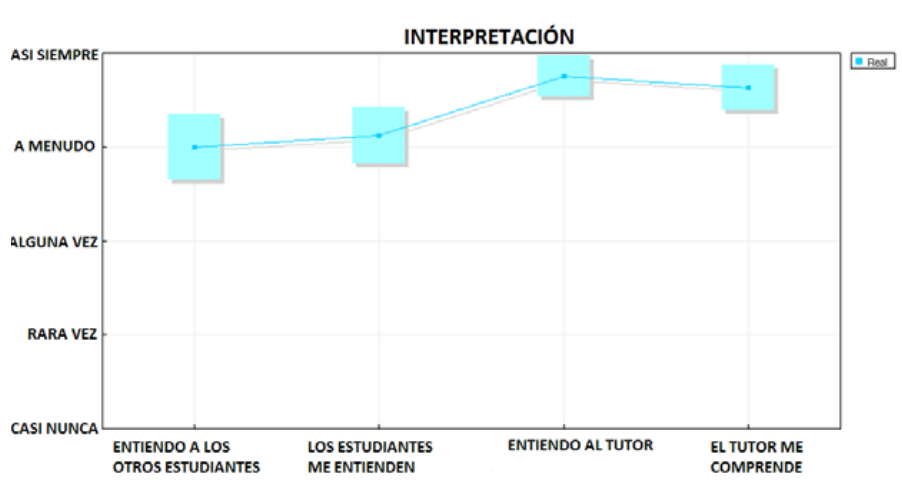

Figura 20. Resultados para la interpretación.

\section{Discusión, Conclusiones Y RECOMENDACIONES}

Las estrategias planteadas en la investigación de Huertas en Colombia indican la necesidad de plantear contenidos o enunciados expresados en lenguaje natural o simbólico, imágenes, dibujos, expresiones y gráficos (Huertas, 2015). Ese hallazgo fue también relevante en la presente investigación, ya que no sólo incrementó el nivel motivacional de los colaboradores por su interacción con el ambiente de aprendizaje mediante animaciones, sino que también ayudó a conocer cualitativamente su opinión acerca de los contenidos y el diseño del ambiente.

En consecuencia, se puede concluir que:

1. El diseño de un AVA permitió consolidar una cultura enfocada en el desarrollo de un trabajo sistémico. Generó impacto social y actuó de manera coherente con los objetivos y valores institucionales del ICBF; asimismo, favorece el cumplimiento de la misión institucional.

2. Mediante estrategias tecnológicas, constantemente, en el instituto se busca fortalecer la capacidad organizacional mediante intervenciones focalizadas (Nacional - Regional - Zonal) que permitan potenciar la excelencia y el desarrollo humano de los colaboradores para el logro de cada uno de los objetivos estratégicos, formándose colaboradores competentes, cualificados y alineados con la estrategia organizacional e integrando modalidades de 
aprendizaje (presencial, virtual y semipresencial).

3. Con el tiempo, si bajo la misma AVA se ingresan más contenidos para los módulos, con el objeto de capacitar al colaborador ICBF, será necesario documentar no sólo su construcción (Guion técnico), sino también buscar que los estudiantes se certifiquen en los diferentes módulos, fuera del estratégico y misional.

4. A su vez, es importante que, mientras se incremente el número de temas, estos se vean con el tiempo reflejados en la rúbrica, contenidos y ruta de ingreso para una óptima navegabilidad del AVA y OVA's. Así se acomodarán los recursos en una plataforma propia del ICBF y no bajo la administración de otra institución.

5. Por otro lado, debe existir una navegabilidad intuitiva, adicional a textos legibles, y recursos digitales apropiados para temas misionales y estratégicos del ICBF.

Sin duda, la incorporación de ambientes de aprendizaje web en las dinámicas corporativas sociales promueve el interés de los colaboradores mediante actividades de capacitación misional y visional.

De lo anterior se desprenden las siguientes recomendaciones:

1. Una de las recomendaciones a tener en cuenta es la necesidad de contar con mecanismos de soporte técnico para los roles de maestro y usuario, en cuanto a políticas de acceso a la plataforma y, también, de reserva de los contenidos, en caso de que la plataforma llegue a fallar; es decir, mediante algún ataque informático que implique la pérdida de la información.

2. Otro aspecto a resaltar es que los colaboradores que reciban la capacitación estratégica y misional bajo la modalidad virtual, conozcan de antemano el uso y manejo de herramientas ofimáticas e informáticas.

Entre las limitaciones a superar está la disponibilidad de herramientas computacionales en cada regional, pues resulta relevante considerar que la plataforma a utilizar (en este estudio la plataforma Kenta de prueba bajo Moodle LMS) no debe presentar problemas para activar y matricular usuarios en el ambiente virtual. Al poner al servicio del público este tipo de ambientes virtuales, es necesario que existan herramientas computacionales en cada regional con soporte de internet para el ingreso y la continuidad del curso.

\section{AGRADECIMIENTOS}

A la Universidad Pedagógica Nacional - UPN y su grupo de investigación KENTA de la Facultad de Ciencia y Tecnología, por permitir la orientación de tesis de posgrado en la Especialización en Tecnologías de la Información Aplicadas a la Educación y en la Maestría en Tecnologías de la Información Aplicadas a la Educación.

\section{REFERENCIAS BibliográficAs}

Córdova, F., Díaz, M., Cifuentes, F., Cañete, L., \& Palominos, F. (2015). Identifying problem solving strategies for learning styles in engineering students subjected to intelligence test and EEG monitoring. Procedia Computer Science, 55, 18-27. Recuperado de: https://doi.org/10.1016/j. procs.2015.07.003

Beltrán, J. (2016). La educación virtual en Colombia: la implementación de las TIC en la educación superior. Academia y Virtualidad, 4(1), 6-21. Recuperado de: https:/doi. org/10.1016/j.procs.2015.07.003

Casas, L. (2016). Tecnologías de comunicación e información en educación: Referentes para el análisis de entornos virtuales de enseñanza y aprendizaje. Revistas de Investigación, 33 (68).

Centros Comunitarios de Aprendizaje CCA (2012). Modelo de David Kolb, aprendizaje basado en experiencias.

García, M. (2016). Correlación inherente de los estilos del aprendizaje y las estrategias de enseńanza-aprendizaje. Revista Iberoamericana de Producción Académica y Gestión Educativa.

Huertas, O. (2015). Una interpretación semántica de la lectura y comprensión de los problemas de matemáticas en las pruebas externas nacionales en el grado quinto. Tesis de maestría inédita). Universidad Nacional de Colombia. Recuperado a partir de http://www.bdigital.unal.edu.co/48880/

Instituto Colombiano de Bienestar Familiar, De la Fuente, C. (2011). Contexto. Plan y objetivos estratégicos. Bogotá D.C. 
ICBF. (2013). Asistencia Técnica, Divulgación y Capacitación a Servidores Públicos para la Administración del Estado. DAPS, 2.

ICBF. (2014) ¿Qué es el ICBF?. Recuperado de: http:// www.icbf.gov.co/portal/page/portal/PortalICBF/EiInstituto

Medina, J., Martín, Y. y Beltrán, J. (2016). La responsabilidad social empresarial (RSE) en las organizaciones públicas: estudio de caso "Ecopetrol". Academia y Virtualidad, 6(1), 92-113. 


\title{
Redes Sociales, Facebook y Blog según los Estilos de Aprendizaje en Cursos E-Learning
}

\author{
Social Networking Sites, Facebook And Blog According to Learning Styles in \\ E-Learning Courses
}

\author{
Ilse Astrid Porras Nieto ${ }^{1}$ \\ Universidad Minuto de Dios - Uniminuto UVD, Colombia
}

Recibido: 08-03 -2017

Aceptado: 15-06-2017

\section{Cita Recomendada}

Porras, I. (2017) Redes Sociales, Facebook y Blog según los Estilos de Aprendizaje en Cursos E-Learning. Hamut'ay, 4 (1), 60-74. Recuperado de: http://doi.org/10.21503/hamu.v4i1.1395

\section{RESUMEN}

Pese a las distintas etapas de desarrollo que se ha tenido en educación, aún persiste la baja calidad de los productos de aprendizaje generados por parte de los estudiantes. Estos continúan con dificultades para leer, analizar, comprender y estructurar un aporte académico destinado, por ejemplo, a un foro en el aula virtual o a la producción de un escrito propio de calidad en lo referido a la presentación del contenido y su estructura gramatical, por lo que este estudio tuvo como objetivo determinar cómo se relacionan las características de la red social Facebook y el blog con las tendencias en los estilos de aprendizaje. La finalidad es usarlas como estrategia para lograr una mejora en el producto de aprendizaje de los estudiantes del curso virtual Teoría Psicoanalítica, del Programa de Psicología UVD, en la Universidad Minuto de Dios, en Bogotá - Colombia. El estudio se realizó con un enfoque cuantitativo y diseño no experimental transversal descriptivo, mediante la caracterización de los estudiantes de un curso en el periodo 2016-3 determinando las tendencias en su estilo de aprendizaje según el modelo de Felder y Silverman y valorando el producto con rúbrica diseñada para tal fin. Se encontró la marcada tendencia a ser Visual, Activo, Secuencial y Sensitivo, logrando con la aplicación de las estrategias en Facebook y en blog colaborativo que la frecuencia en los resultados, en el rango de calificación 80 a 100, se incrementara del 45,7\% al 74,30\%, y encontrando que en esta categoría se destacan quiénes cuentan con la combinación Activo-Visual-Secuencial.

Palabras Clave: AVA, Red social, blog colaborativo, estilos de aprendizaje, e-Learning.

\section{Abstract}

Despite the different stages of development in education, the low quality of the learning products generated by students persists. They still have difficulties in reading, analyzing, understanding and structuring an academic contribution, for example, for a forum in a virtual classroom or in the pro-

1 Psicóloga de la Universidad Nacional de Colombia, con formación y especialización clínica, Maestría en Psicoanálisis de la Universidad de León (España) y Maestría en e-Learning y redes sociales de la Universidad de la Rioja - UNIR. Investigadora en temas de la subjetividad y la cultura. Por su interés en la docencia virtual se ha especializado y desempeñado como tutor AVA en Universidad Minuto de Dios (UVD) y, actualmente, en Psimática Editorial. E-mail ilse.porras@icloud.com 
duction of a high-quality piece of writing on their own, regarding the presentation of the content and its grammatical structure. The objective of the study is to determine how the characteristics of the social networking site Facebook and the collaborative blog relate to the trends in learning styles. The purpose is to use them as a strategy to achieve an improvement in the learning product of the students enrolled in the virtual course Psychoanalytic Theory of the UVD Psychology Program at the Minuto de Dios University in Bogota, Colombia. The study was carried out with a quantitative approach and a descriptive non-experimental cross-sectional design, through the characterization of the students from a course in the period 2016-3. The trends in their learning style were determined according to Felder and Silverman's model and the product assessed with a rubric designed for that purpose. It was found a noticeable tendency to be Visual, Active, Sequential and Sensitive. Through the implementation of the strategies in Facebook and in collaborative blog, we managed that the frequency in the results increase from $45.7 \%$ to $74.30 \%$, in the 80 to 100 rating scale. We also found out that in this category people who have the Active-Visual-Sequential combination are the ones who stand out.

Keywords: Social networking site, collaborative blog, learning styles, e-Learning.

\section{INTRODUCCIÓN}

Con el auge en el uso de tecnologías en la educación y, en el marco de una sociedad del conocimiento, se plantea como reto, tanto para docentes como para estudiantes, contar con procesos y estrategias pedagógicas que optimicen y faciliten el proceso de aprendizaje-enseńanza. A su vez, se trata de saber gestionar el conocimiento, entendido como un "conjunto de procedimientos, reglas y sistemas destinados a captar, tratar, recuperar, presentar y transmitir datos, informaciones y conocimientos de una organización" FUCN (2005). La gestión del conocimiento evoluciona como respuesta necesaria a las condiciones de producción en la exigente competición global, tanto para estudiantes como docentes y para los profesionales en general. Por ello resulta indispensable la publicación de sus trabajos de estudio y los productos de la investigación. Lo mencionado implica, desde una perspectiva construccionista, que las personas aprendan a aprender de forma autónoma y colaborativa. Por tanto, conocer las tendencias en los estilos de aprendizaje se convierte en una herramienta que facilita dicho proceso. Dentro de todo este proceso no están exentas las nuevas tendencias del uso de redes sociales. Ese es el caso específico de Facebook, que es utiliza- da por los estudiantes para comunicarse de manera síncrona y asíncrona con sus compañeros. Facebook se ha convertido también en un medio para compartir contenidos, interactuar y discutir sobre los mismos y también para elaborar tareas. Algo similar ocurre con el blog. Buxarrais (2015) plantea que el uso de las redes sociales en la educación promueve el aprendizaje colaborativo, la interconectividad y la autonomía, lo que se traduce en cambios en la forma de enseñar, aprender e investigar. De Haro (2010), explica los tipos de servicios de redes que existen y se enfoca en el uso del microblogging; destaca la organización de redes y sub-redes y su aplicación en el aula como estrategia para la enseñanza.

En este estudio se trató de aprovechar las características propias de la Web 2.0, y específicamente, de las redes sociales que facilitan la participación y la colaboración y cuentan con estructuras de uso gratuito para ser utilizadas en forma de chat, foro, blog colaborativo, procurando la comunicación y difusión de los productos de aprendizaje e investigación. En este contexto, el objetivo fue implementar estrategias de enseñanza en redes sociales como lo es Facebook y en el blog, guiado por la pregunta: ¡efectivamente se logra con dichas estrategias, favorecer las tendencias en el estilo de 
aprendizaje y mejorar el producto de aprendizaje en estudiantes del curso virtual Teoría Psicoanalítica, del Programa de Psicología UVD en la Universidad Minuto de Dios, en Bogotá, Colombia?

Las redes sociales como mediadoras de aprendizaje

Una de las herramientas más representativas de la Web 2.0 son las redes sociales o comunidades virtuales, las cuales brindan la posibilidad de poder utilizarlas para diversos fines, dado el notorio uso por parte de los estudiantes, en especial para establecer contactos, compartir información, jugar, ejecutar actividades de colaboración, chatear, compartir aficiones, comprar y vender productos. Se constituye así en un ciberespacio muy adecuado para comunicarse y, por tanto, también pueden ser una buena estrategia para la educación, facilitar y permite el aprendizaje colaborativo y el intercambio de información en comunidades de aprendizaje y cooperación. Al respecto, Garrigos et al. (2015) señala que las redes sociales son esenciales para la creación, el aprendizaje y el intercambio de conocimiento. También refieren que las redes sociales permiten acortar el ciclo de aprendizaje para que cada individuo aproveche las experiencias de otros y amplíe así las propias. Esto coincide con el concepto de Zona de Desarrollo Próximo (ZDP) de Vygotsky, quien indicara que existe una diferencia entre la ejecución del estudiante frente a la tarea pedagógica cuando actúa por sí solo y el desempeño que puede lograr gracias a la ayuda de otra persona más competente (como el profesor o algún compañero que sabe más), teniendo lugar el aprendizaje colaborativo.

Para remarcar la importancia que puede tener el uso de las redes sociales, aunque se consideran varias definiciones, la UNIR (2016) precisa que estas son consideradas como cualquier grupo de usuarios que se establecen en torno a una temática o actividad inicial concreta y que desarrolla una comunicación fundamentalmente asíncrona, pero también síncrona para compartir información, opiniones y recursos a través de una plataforma o entorno online. Ahora bien, si se enfocan en el incremento de la calidad en los procesos educativos, se requiere que el profesor desarrolle nue- vos materiales instruccionales que tengan como objetivo la motivación y la satisfacción de las necesidades individuales de aprendizaje mediante el empleo adecuado de las estrategias de enseñanza planificada, debiendo tenerse en cuenta las tendencias en los estilos de aprendizaje. Cornejo (2013), en su investigación sobre el desarrollo de las competencias cognitivas básicas en estudiantes de sexto grado a través del uso del Facebook como herramienta mediadora del proceso de aprendizaje, concluyó que los estudiantes, además de lograr textos con coherencia, conexión, puntuación, intencionalidad, progresión temática y ortografía, desarrollan repetidas actividades en Facebook, sin aburrirse, motivándose a la lectura y análisis de los textos. De la misma manera, Pino (2015), en su investigación sobre Las redes sociales como herramientas didácticas para la producción de textos argumentativos en estudiantes del cuarto grado de secundaria del centro experimental de aplicación de la Universidad Nacional de Educación Enrique Guzmán y Valle, hizo un análisis exhaustivo y concluyó que, siempre y cuando se cuente con acceso a un computador con conexión a internet, se puede afirmar, con un $95 \%$ de confiabilidad, que las redes sociales, como herramienta didáctica, influyen significativamente en la producción de textos argumentativos en estudiantes de cuarto grado de secundaria. Además, este autor refiere que las redes sociales ayudan a desarrollar competencias y habilidades para la identificación de las características de los textos argumentativos, mediante el trabajo colaborativo y el pensamiento crítico, incidiendo con ello en su vida social y académica.

Por su parte Molina y Briones-Véliz (2016), en el estudio realizado sobre Redes Sociales en la Educación aseguran que las Redes Sociales en la Educación Superior brindan la posibilidad de intercambiar conocimientos y experiencias a nivel académico y promueven la reflexión o la posibilidad de análisis en torno a temas específicos. Guzman-Duque (2013), en su trabajo sobre el uso de Twitter, confirma que las redes sociales posibilitan la creación de conocimiento a través de la cooperación entre sus miembros. Se llega a considerarlas como acumuladoras de Capital Social. En el trabajo se exponen las formas cómo las universidades utilizan estas herramientas para facilitar y 
dinamizar las comunicaciones con la comunidad educativa mediante las redes sociales.

La red social Facebook ha sido utilizada en distintas experiencias educativas como estrategia participativa. Nuria (2015), en su estudio sobre Metodologías participativas y Facebook en el ámbito universitario destaca la potencialidad de esta red social como generador y dinamizador de conocimiento. Por su parte, López, Flores y Espinoza (2015), en el estudio Diversidad de usos de Facebook en la educación superior. Análisis desde un caso de estudio, plantean su utilidad para la comunicación entre docentes y alumnos con fines de asesorías, tutorías, circulación de materiales y documentos varios, para actividades de formación y actualización, concluyendo que Facebook tiene el potencial para enriquecer los procesos educativos, siempre y cuando los docentes, alumnos y administrativos hagan un uso consciente y dirigido. Por su parte, Pérez, Ortiz, y Flórez (2015) conceptualizan las redes sociales y las comunidades educativas en su investigación Redes sociales en educación y propuestas metodológicas para su estudio, remarcan su importancia y presentan algunas estrategias metodológicas; hacen énfasis en la comunicación, en sus fortalezas de tipo didáctico y las formas de interacción para lograr los objetivos de aprendizaje. Por su parte, Rodríguez (2013) indica que las universidades, desde diversos lugares del mundo, incursionan cada vez más en el uso de la Web 2.0 como herramienta de formación, como lo han realizado en México el Centro Universitario de los Altos (CuAltos) y en la Universidad Veracruzana, donde se promueven espacios colaborativos como Youtube, Facebook, Twitter, Myspace, entre otros. Además, en interacción con los canales instituciones, se promueve como idea educativa "aprovechar el potencial de las redes para organizar tareas, proyectos o actividades conjuntas con equipos cooperativos de aprendizaje".

Teniendo en cuenta que cada persona cuenta con un estilo de aprendizaje particular y que la modalidad e-Learning favorece el auto-aprendizaje, esta investigación se propuso tener en cuenta los estilos de aprendizaje-enseñanza para generar estrategias mediante el uso de redes sociales. La finalidad es favorecer la experiencia y el aprendizaje cola- borativo en la apuesta por el aprendizaje significativo, promoviéndose competencias cognitivas, metodológicas, tecnológicas y lingüísticas, con una perspectiva constructivista. Al incorporar las aplicaciones Web 2.0 en los procesos formativos, se debe adoptar nuevos estilos de comunicación, roles, formas de intervención, escenarios que deben cumplir con nuevos desafíos educativos para lo cual se plantea la utilidad de incorporar estrategias pedagógicas acordes con los estilos de aprendizaje, como una manera más de motivar y de estructurar el aprovechamiento de estos espacios de acceso gratuito y de manejo conocido por la mayoría.

\section{Uso del Facebook en educación}

Esta red, creada por Mark Zuckerberg cuando era estudiante de la Universidad de Harvard con el fin de compartir contenidos de forma sencilla e intercambiar comunicación a través de internet, es hoy en día una de las redes sociales más utilizadas y populares. Cuenta en la actualidad con 2.000 millones de usuarios en todo el mundo (Campoamor, 2017) y es ya valorada como un tipo de comunidad metrópolis cuyos fines principales son conversar, compartir y conectar. Además, por contar con dicha popularidad, puede ser aprovechada para desarrollar nuevas habilidades digitales y niveles más complejos de participación gracias a que su potencial ha permitido la alfabetización de los usuarios independientemente de ser o no nativos digitales. Según Islas (2010), Facebook se ha convertido, sin proponérselo, en una plataforma que alfabetiza a todos por igual en el uso de herramientas y aplicaciones propias de la Web Social; ayuda a desarrollar destrezas en términos cognitivos, propiciando prácticas que permiten disminuir barreras para el aprendizaje. Muchos autores coinciden en que es un reto para los docentes encontrar y aplicar nuevas formas de aprendizaje-enseñanza en las redes, tal como sostiene Meso (2010) al afirmar que la educación es uno de los ámbitos en los cuáles se puede desarrollar el potencial de las redes sociales. Facebook, a pesar de no haber sido concebida como un entorno para construir y gestionar experiencias de aprendizaje, representa un espacio colaborativo por excelencia, ya que ofrece muchos recursos 
para ilustrar aplicaciones, proponer ejercicios de aplicación, optimizar la dinámica de la clase, entre otros. Brinda la posibilidad de conectar estudiantes entre sí, de manera que cada estudiante o cada comunidad de aprendizaje funcionen como un nodo en la red. Para tal fin se aprovecha el hecho de que ofrece la posibilidad de crear grupos y administrarlos contando con seguridad y privacidad, para configurar las condiciones con el fin de compartir contenidos e incluso crear encuestas. Facebook brinda la alternativa para generar estas comunidades de aprendizaje y espacios de colaboración con el fin de compartir contenidos y para la discusión a manera de foros, sirviendo de apoyo a la plataforma educativa. De Haro (2010), afirma que las aplicaciones de las redes son tan amplias como profesores las usen, pues cada uno de ellos identificará situaciones específicas considerando las necesidades de sus estudiantes.

\section{Uso del blog en educación}

Otra de las aplicaciones propias de la Web 2.0, que comparte características de participación y colaboración con las redes sociales y, también, ha tenido una amplia acogida y uso es el blog, el cual en un principio fue utilizado y nombrado por Jorn Barger en 1997 como "weblog” y, más tarde, en 1999, Peter Merholz acortó el término utilizando la denominación blog. Para García (2014), el blog ha tenido auge desde 2003, gracias a la distribución de software gratuito y a la existencia de herramientas para la creación y publicación de páginas web mucho más sencillas que las diseñadas en formato HTML. Así se convierte en una de las herramientas más democráticas para compartir contenidos e información en la web.

Tal como afirma García (2014), un blog utilizado en ambientes educativos de forma colaborativa puede convertirse en un instrumento ideal para motivar a los alumnos como participantes en su proceso de formación, para que expresen lo mejor de sí de forma escrita. El hecho de convertirse en autor y editor de un producto que tendrá destinos inimaginables puede animar a potenciar la reflexión, el pensamiento y la construcción de saber que se comparte, de manera que aprende haciendo y siendo autor y dueño de su proceso de aprendizaje.

Así, los blogs educativos y colaborativos se han convertido en espacios en los cuáles los docentes comparten sus reflexiones y gestionan su conocimiento, facilitándose la comunicación entre docentes, con sus estudiantes y para que los estudiantes lo hagan entre ellos. Siendo esta una de las herramientas más representativas de la web 2.0, y siguiendo los lineamientos del Espacio Europeo de Educación Superior (EEES), Marín-Díaz y Gómez-Parra (2015) presentan un diseño innovador aplicado en estudiantes del plan de estudios de Educación Primaria de la Universidad de Córdoba. La finalidad del blog, como se enuncia, es fomentar el trabajo colaborativo y en grupo, y apoyar el aprendizaje de una materia de contenido de tres subáreas diferentes. Después de 4 meses de trabajo con este recurso, lograron que el estudiante se desempeñe de forma eficiente mediante el trabajo en grupo y adquiera habilidades en la reflexión, la búsqueda y la selección de la información, Concluyeron que es una herramienta fundamental para contar con la evaluación positiva de la experiencia de los estudiantes.

Symsek (2010), ante las dificultades en el aprendizaje de la escritura de sus setenta estudiantes de primaria, realiza una experiencia aplicando el weblog como un medio para la enseñanza de la escritura. Concluye que éste mejora tal aprendizaje en los estudiantes. Por su parte Zaini, Kenboya y Supyan (2011) refieren que los blogs se han convertido en una de las formas más populares de discurso en línea, utilizan el Blogging como una plataforma de aprendizaje en la provisión de oportunidades para el aprendizaje del idioma inglés, con el fin de mejorar el conocimiento de los estudiantes sobre su desempeño a través del lenguaje escrito y maximizar la colaboración de la escritura. Afirman que los estudiantes se aprecian como autores y es por tal percepción que la estrategia contribuye a desarrollar y mejorar el desempeño en la escritura de la lengua extranjera.

\section{Estilos de aprendizaje: Modelo Felder y} Silverman

Aunque resulte evidente que no existe una sola forma de aprender, que cada persona cuenta con 
su estilo particular de establecer su relación con el mundo, con la información y el conocimiento, mediante investigaciones en el campo de la neurofisiología y en la psicología se han definido enfoques y paradigmas con el fin de explicar y comprender cómo aprendemos los seres humanos, lo que ha llevado a reconocer que cada persona cuenta con una forma de recibir, procesar y trabajar con la información, base fundamental para pensar el aprendizaje como un proceso personal y para el diseño de estrategias que lo faciliten a cada estudiante, máxime cuando el aprender se constituye en la actitud que favorece la participación y procura elementos para la construcción en el mundo actual.

A partir de la década de los setenta, se han propuesto y estudiado modelos para determinar las tendencias en el estilo de aprendizaje. Unos desde el enfoque más comportamental de la psicología, otros a partir del paradigma cognitivo y, algunos, con una visión que incluye lo afectivo y fisiológico, como se puede apreciar en la tabla 1.

Tabla 1

Instrumentos de diagnóstico de los estilos de aprendizaje

\begin{tabular}{|c|c|}
\hline Autores & Instrumento \\
\hline David Kolb (1976) & $\begin{array}{l}\text { Inventario de Estilos de Aprendizaje } \\
\text { (Learning Style Inventory) }\end{array}$ \\
\hline $\begin{array}{l}\text { Rita Dunn y Kennet } \\
\text { Dunn (1978) }\end{array}$ & $\begin{array}{l}\text { Inventario de Estilos de Aprendizaje } \\
\text { (Learning Style Inventory). }\end{array}$ \\
\hline James Keefe, (1979) & $\begin{array}{l}\text { Perfil de Estilos de Aprendizaje (Lear- } \\
\text { ning Style Profile) }\end{array}$ \\
\hline Juch (1987) & $\begin{array}{l}\text { Ejercicio de Perfil de Aprendizaje (Lear- } \\
\text { ning Profile Exercise) }\end{array}$ \\
\hline $\begin{array}{l}\text { Bernice McCarthy } \\
\text { (1987) }\end{array}$ & 4MAT System \\
\hline $\begin{array}{l}\text { Richard M. Felder y } \\
\text { Linda K. Silverman } \\
\text { (1988) }\end{array}$ & $\begin{array}{l}\text { Cuestionario Indice de Estilo de Aprendi- } \\
\text { zaje (Index of Learning Styles) }\end{array}$ \\
\hline $\begin{array}{l}\text { Honey y Mumford } \\
\text { (1988) }\end{array}$ & $\begin{array}{l}\text { Cuestionario de Estilos de Aprendizaje } \\
\text { (Learning Styles Questionnaire) }\end{array}$ \\
\hline $\begin{array}{l}\text { Alonso, Gallego y } \\
\text { Honey }(1992,1994)\end{array}$ & $\begin{array}{l}\text { Cuestionario Honey-Alonso de Estilos de } \\
\text { Aprendizaje (CHAEA) }\end{array}$ \\
\hline $\begin{array}{l}\text { Robert Sternberg } \\
\text { (1997) }\end{array}$ & $\begin{array}{l}\text { Inventario de Estilos de Pensamiento } \\
\text { (Thinking Styles Inventory) }\end{array}$ \\
\hline $\begin{array}{l}\text { Catherine Jester } \\
\text { (1999) }\end{array}$ & $\begin{array}{l}\text { Encuesta sobre Estilos de Aprendizaje } \\
\text { para la Universidad (Learning Style } \\
\text { Survey for College) }\end{array}$ \\
\hline $\begin{array}{l}\text { S. Whiteley y K. White- } \\
\text { ley (2003) }\end{array}$ & $\begin{array}{l}\text { Inventario de Estilos de Aprendizaje } \\
\text { del proyecto Memletics (The Memletics } \\
\text { Learning Styles Inventory) }\end{array}$ \\
\hline
\end{tabular}

Fuente: García (2012).
Como se ha podido apreciar en la tabla 1, son muchos los autores que han investigado sobre este tema y han plasmado sus teorías. Por ello, en el presente estudio se ha considerado la propuesta Felder y Silverman (1988), quienes consideran el aprendizaje en el entorno educativo como un proceso en dos etapas y cuatro dimensiones. La primera, como etapa de recepción que se lleva a cabo por los sentidos, de forma visual o auditiva; luego la segunda etapa, que es el procesamiento de la información, en la cual los estudiantes seleccionan el tipo de información que prefieren procesar para luego darle un tratamiento, bien sea la simple memorización o procurando el razonamiento, la reflexión o la acción, la introspección o la interacción. Es así como proponen cuatro dimensiones, cada una con dos polos, visual o verbal, activo o reflexivo, secuencial o global, sensorial o intuitivo, para conocer el estilo de aprendizaje. Si bien comparten algunas de estas dimensiones con otros modelos de estilos de aprendizaje, las combinaciones y la manera de operar en el aprendizaje son únicas para este modelo.

\section{Estilos de aprendizaje y tecnologías}

Por considerar que el centro de interés de la formación universitaria debe ser el estudiante y porque los objetivos se circunscriben al desarrollo profesional del docente universitario, debe cambiar la óptica. La Declaración de Bolonia (1999) y el Comunicado de Bergen (2005) insisten en la necesidad de cambiar los estilos tradicionales de enseñanza para hacer uso de las nuevas Tecnología de Información y Comunicación (TIC) para la mejora de la docencia y con la finalidad de lograr las competencias impuestas por el Espacio Europeo de Educación Superior (EEES). En este sentido, experiencias como la llevada a cabo en la universidad CEU de San Pablo, llevada a cabo por Gómez et al (2012), a la hora de pensar en elaborar estrategias e implementar metodologías docentes, han considerado que tal innovación implica tener en cuenta los estilos de aprendizaje de sus estudiantes. En la investigación realizada por Acosta (2016), sobre La relación entre los estilos de aprendizaje y el uso de las tecnologías de información y comunicación en educación de personas adultas, se plantea el impacto que las TIC 
han tenido en la educación y cómo los estilos de aprendizaje son una guía para la implementación de estrategias que faciliten el aprendizaje. Ese es el caso de personas adultas que acceden a la educación, incluso cuando se les enseña la utilización de la tecnología. Amaya y Cuellar (2016), en el estudio realizado sobre Estilos de Aprendizaje de los estudiantes de posgrado a distancia de la Universidad Autónoma de Tamaulipas, se obtuvo el perfil del estudiante a partir del modelo de Bandler y Grinder, que permitió realizar recomendaciones a los contenidos, recursos y actividades de aprendizajes acordes con cada estilo de aprendizaje que poseían.

\section{Materiales y Métodos}

\section{Participantes}

La población estuvo formada por 70 estudiantes que cursaban el cuarto periodo del programa de Psicología de Uniminuto UVD, matriculados en el curso de Teoría Psicoanalítica para el periodo 2016-3. Se dividía en dos secciones de 35 estudiantes cada una, a cargo de un tutor responsable.

Para realizar el presente estudio, el autor seleccionó una muestra no probabilística por conveniencia, con la sección del curso Teoría Psicoanalítica NRC1079-16 del periodo 2016-3 a su cargo. Fueron en total 35 estudiantes, de los cuáles solo participaron en la investigación 31; uno se retiró del curso y tres no participaron en las actividades propuestas. A continuación, en la tabla 2 se describen las características relevantes en cuando a la edad, el género y la situación socioeconómica de los participantes.

Tabla 2

Caracterización de los estudiantes del curso Teoría Psicoanalítica NRC1079-16

\begin{tabular}{ll} 
Edad & $\begin{array}{l}\text { El } 45,16 \% \text { de los estudiantes se ubican } \\
\text { en el rango de } 25-43 \text { años. }\end{array}$ \\
\hline Género & $\begin{array}{l}27 \text { mujeres, } 88,58 \% \\
4 \text { hombres, } 11,42 \%\end{array}$ \\
$\begin{array}{ll}\text { Situación socio-eco- } \\
\text { nómica }\end{array}$ & $\begin{array}{l}\text { Son estudiantes de estratos socioeconó- } \\
\text { micos 1, 2, y 3, principalmente. }\end{array}$
\end{tabular}

Fuente: Elaboración propia.

\section{Consentimiento informado}

Luego de obtener autorización por parte de la Dirección del Programa de Psicología UVD, al iniciar el curso, mediante documento e indicaciones subidos en el aula virtual correspondiente, se les comunicó a los estudiantes inscritos la finalidad y las razones por las cuales se usaría las redes sociales. Al participar en las actividades propuestas en el Facebook y en el blogger y responder el cuestionario de estilos de aprendizaje de Felder y Silverman, cuyas respuestas se subieron al aula virtual durante la primera semana del curso, los estudiantes aceptaron y otorgaron su consentimiento para utilizar la información contenida en el mismo.

\section{Instrumento}

Para la recolección de datos se utilizaron dos instrumentos: uno relacionado a las redes sociales para recopilar datos sobre el uso del Facebook y el blog, el otro para las tendencias en los estilos de aprendizaje.

Se aplicó el Inventario de Estilos de Aprendizaje de Felder y Silverman, el cual sirvió para determinar los estilos de aprendizaje, compuesto por 44 preguntas que permiten determinar cuatro dimensiones del proceso. El tipo de información que se prefiere recibir (sensitiva/intuitiva), la modalidad sensorial utilizada (visual/verbal), forma de organizar y comprender la información (secuencial/global) y forma como se trabaja con la información recibida (activa/reflexiva), cada una de las dimensiones está compuesta por 11 preguntas, con dos alternativas de respuesta (Ver Figura 1).

En cuanto a la validez y confiabilidad del inventario, este está estandarizado a nivel internacional, es de uso libre. En el caso de la población colombiana esta es utilizada por la Universidad Nacional Abierta y a Distancia (UNAD) y en la investigación realizada por Martínez (2011) en 353 estudiantes de diversos programas de la Universidad Nacional de Colombia. La confiabilidad es aceptable para las cuatro dimensiones del inventario, entre 0.7 y 0.9 . 


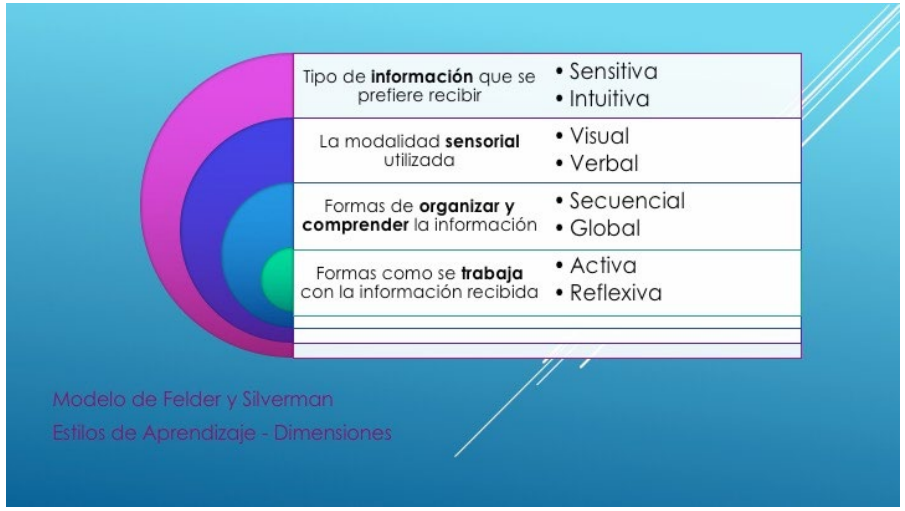

Figura 1. Dimensiones del Inventario de Estilos de aprendizaje de Felder y Silverman.

El otro instrumento utilizado fue la rúbrica, que permite describir, mediante un conjunto amplio de indicadores, el grado en el cual un estudiante está ejecutando un proceso o producto. El instrumento mide los niveles progresivos de competencia o pericia que obtendrá (rango de desempeños posibles) el estudiante y cómo este transita de un nivel básico a uno avanzado, especialmente en temas complejos, imprecisos o subjetivos. Díaz-Barriga y Hernández (2010) señalan que esta debe cumplir con las siguientes características:

- Son instrumentos de evaluación auténtica.

- Facilitan la evaluación de competencias complejas.

- Están basadas en criterios de desempeño claro y coherente.

- Describen lo que será aprendido.

- Son esencialmente descriptivas y enfatizan una evaluación cualitativa, aunque no se excluye lo cuantitativo.

- Ayudan a los alumnos a supervisar el progreso de su aprendizaje y valorar su propio desempeño.

En esta investigación la rúbrica ha sido el otro instrumento utilizado para recopilar información en la valoración de los productos de aprendizaje, la participación de los estudiantes, según premisa en el foro, en grupo cerrado en Facebook y en el blog colaborativo creado en Blogger. Para su diseño y uso se siguieron los siguientes pasos:

1. Seleccionar la competencia o capacidad o producto a evaluar, el procedimiento o producto de aprendizaje que interesa evaluar. En este trabajo los dos productos a evaluar han sido el Foro en Facebook y la participación en el Blog.

2. Luego se enfatizó en cuatro categorías que permitían la valoración de la participación e interacción, en la calidad del aporte en cuanto a la expresión escrita y en su contenido, en la elaboración y claridad del aporte realizado.

3. En cada categoría se asignó un porcentaje-peso de valoración sobre el cien por ciento de la calificación, tal como se describe en la tabla 3.

4. Se elige el número de niveles de clasificación para esta rúbrica, siendo 4, asignados como sobresaliente, satisfactorio, necesita mejorar e insuficiente. Estos niveles se valoran en términos de puntuación, según el grado que alcance en cada categoría establecida (Ver tabla 3).

La validación de la rúbrica se realizó en base al criterio de juicio de expertos, siendo evaluada por tres docentes investigadores de reconocida trayectoria, a quiénes se les entregó la matriz de la rúbrica para su valoración. Se determinó la correspondencia de los criterios, de las categorías y su valoración. Después de revisarla, indicaron algunas pequeñas modificaciones a la misma, las cuales fueron consideradas y realizadas antes de la aplicación de la rúbrica.

\section{Tipo y diseño}

El estudio se realizó con un enfoque cuantitativo y diseño no experimental transversal descriptivo (Hernández, Fernández y Baptista 2010), porque se pretendió especificar características y tendencias en los estudiantes en cuanto a su estilo de aprendizaje y la estrategia de enseñanza propuesta en las redes sociales Facebook y Blog para valorar el impacto en el producto de aprendizaje. Es decir, la finalidad fue caracterizar a los estudiantes del curso Teoría Psicoanalítica del Programa de Psicología UVD de la Universidad Minuto de Dios con sede en Bogotá, en relación con su edad, género y las tendencias en su estilo de aprendizaje.

\section{Procedimiento}

El estudio se desarrolló en cuatro (4) fases que se detallan a continuación: 
Tabla 3

Rubrica para evaluar productos de Facebook y el blog

\begin{tabular}{|c|c|c|c|c|}
\hline CATEGORIA & SOBRESALIENTE & SATISFACTORIO & NECESITA MEJORAR & INSUFICIENTE \\
\hline $\begin{array}{l}\text { CONTENIDO } \\
\text { Investiga-Aporta }\end{array}$ & $\begin{array}{l}\text { El aporte del estudiante } \\
\text { da cuenta de la lectura } \\
\text { y análisis del material } \\
\text { indicado. } \\
\text { Elabora su aporte y con } \\
\text { sus propias palabras. } \\
\text { De ser necesario, indica el } \\
\text { autor y fuente utilizados. }\end{array}$ & $\begin{array}{l}\text { El aporte del estudiante } \\
\text { es un parafraseo. dando } \\
\text { cuenta de la lectura y } \\
\text { análisis del material. Indica } \\
\text { el autor y fuente utilizados. }\end{array}$ & $\begin{array}{l}\text { El aporte del estudiante } \\
\text { es un parafraseo sin dar } \\
\text { cuenta de análisis propio. } \\
\text { Indica el autor y las fuen- } \\
\text { tes utilizadas. }\end{array}$ & $\begin{array}{l}\text { El aporte del estudiante es } \\
\text { copia textual del material, no } \\
\text { da cuenta de análisis propio. } \\
0 \text { hay parafraseo sin citar el } \\
\text { autor o fuente del material. }\end{array}$ \\
\hline $30 \%$ & ENTRE 22,5 - 30 PUNTOS & 15,1 -22,5 PUNTOS & 7,6-15 PUNTOS & 0-7,5 PUNTOS \\
\hline Argumenta-Aplica & $\begin{array}{l}\text { El estudiante presenta } \\
\text { argumentos e ideas claras } \\
\text { y protundas. }\end{array}$ & $\begin{array}{l}\text { El estudiante presenta } \\
\text { argumentos e ideas, con } \\
\text { poca claridad y/o profun- } \\
\text { didad. }\end{array}$ & $\begin{array}{l}\text { El estudiante presenta } \\
\text { argumentos e ideas } \\
\text { con escasa claridad y/o } \\
\text { profundidad. }\end{array}$ & $\begin{array}{l}\text { El estudiante presenta ideas } \\
\text { o argumentos confusos. }\end{array}$ \\
\hline $30 \%$ & ENTRE 22,5 - 30 PUNTOS & 15,1-22,5 PUNTOS & 7,6-15 PUNTOS & 0-7,5 PUNTOS \\
\hline $\begin{array}{l}\text { REDACCION Y } \\
\text { ORTOGRAFIA } \\
\text { Expresa }\end{array}$ & $\begin{array}{l}\text { Las aportaciones del } \\
\text { estudiante cumplen con la } \\
\text { estructura del texto: clari- } \\
\text { dad. Sencillez y precisión. } \\
\text { Y no presenta errores } \\
\text { ortográficos (puntuación, } \\
\text { acentuación y gramática). }\end{array}$ & $\begin{array}{l}\text { Las aportaciones se } \\
\text { encuentran bien estructu- } \\
\text { radas en mínimo } 75 \% \text {. } \\
\text { Cuenta con claridad, pero } \\
\text { denota ambigüedad. } \\
\text { Y tiene menos de } 3 \text { errores } \\
\text { ortográficos (puntuación, } \\
\text { acentuación y gramática) }\end{array}$ & $\begin{array}{l}\text { Las aportaciones se en- } \\
\text { cuentran bien estructura- } \\
\text { das en un } 50 \% \text { pero falta } \\
\text { claridad y precisión. } \\
\text { Y tiene entre } 4 \text { y } 6 \text { errores } \\
\text { ortográficos (puntuación, } \\
\text { acentuación y gramática). }\end{array}$ & $\begin{array}{l}\text { Las aportaciones no cum- } \\
\text { plen con los requisitos de } \\
\text { una buena redacción. } \\
\text { Y tiene más de } 6 \text { errores } \\
\text { ortográficos }\end{array}$ \\
\hline $20 \%$ & ENTRE 15,1-20 PUNTOS & 10,1 -15 PUNTOS & 5,1-10 PUNTOS & 0-5 PUNTOS \\
\hline $\begin{array}{l}\text { INTERACCION } \\
\text { Participa-Colabora }\end{array}$ & $\begin{array}{l}\text { El estudiante establece. } \\
\text { en la red social, un dialogo } \\
\text { con los compañeros con el } \\
\text { tutor, debatiendo y defen- } \\
\text { diendo ideas, y colaboran- } \\
\text { do con sus aportes en la } \\
\text { construcción del tema. }\end{array}$ & $\begin{array}{l}\text { El estudiante establece un } \\
\text { dialogo con sus compañe- } \\
\text { ros y con el tutor sin deba- } \\
\text { tir ni defender ideas que } \\
\text { aporten en la construcción } \\
\text { del tema y sus conclusio- } \\
\text { nes en la red social. }\end{array}$ & $\begin{array}{l}\text { El estudiante establece } \\
\text { un dialogo mínimo con los } \\
\text { compañeros y } \\
\text { el tutor, sin un aporte } \\
\text { personal en la construc- } \\
\text { ción del tema y posibles } \\
\text { conclusiones en la red } \\
\text { social. }\end{array}$ & $\begin{array}{l}\text { El estudiante participa sin } \\
\text { establecer un dialogo con los } \\
\text { compañeros y el tutor en la } \\
\text { red social. }\end{array}$ \\
\hline $20 \%$ & ENTRE 15,1-20 PUNTOS & 10,1 -15 PUNTOS & $5,1-10$ PUNTOS & 0-5 PUNTOS \\
\hline
\end{tabular}

Fuente: Elaboración propia.

- Fase de identificación del problema y contextualización. Comprendió la identificación de una de las problemáticas propias de los estudiantes que estudian en modalidad virtual y se propuso a la Dirección del Programa de Psicología UVD en la Universidad Minuto de Dios realizar un piloto con el fin de impactar favorablemente los productos del aprendizaje en el curso Teoría Psicoanalítica del período 2016-3. En esta fase se eligió el instrumento para definir las tendencias en el estilo de aprendizaje para el caso de los estudiantes del curso elegido.

- Fase de aplicación y caracterización. Haciendo uso del aula virtual creada en el Learning Managment System (LMS) Moodle, se informó a los estudiantes del curso elegido acerca del piloto y se les envió el cuestionario de Fel- der y Silverman. Para ello se creó una actividad en la plataforma Moodle y se subió tanto el Inventario de Estilos de aprendizaje como la hoja de respuestas correspondientes. Se pidió a los estudiantes responder y devolver la hoja de respuestas vía la Tarea creada en la misma plataforma. También incluir datos de nombre y edad. Con el envío de su respuesta se obtuvo el consentimiento informado para el tratamiento de la información. Recibidas las respuestas de 31 de los 35 estudiantes, en el plazo establecido, durante la primera semana del curso se calificó el cuestionario para determinar las tendencias en el estilo de aprendizaje de cada estudiante, relacionándolas con la edad y el género, y se informó a cada uno indicando sugerencias para lograr un mejor desempeño según el perfil identificado. 
- Fase de implementación, de acuerdo con las tendencias encontradas: visual, secuencial, activo y sensitivo. Se eligieron dos redes sociales para implementar dos actividades que permitieran valorar los resultados en el producto de aprendizaje: un foro en Facebook y la participación en un blog colaborativo en Blogger. Se diseñó la rúbrica específica para va-

\begin{tabular}{lllllllll} 
& \multicolumn{2}{c}{ Recepción } & \multicolumn{2}{c}{ Organización } & \multicolumn{2}{c}{ Experiencia } & \multicolumn{2}{c}{ Procesamiento } \\
\cline { 2 - 9 } & Visual & Verbal & Secuencial & Global & Sensitivo & Intuitivo & Activo & Reflexivo \\
\hline Mujeres & 26 & 2 & 24 & 4 & 18 & 10 & 20 & 8 \\
\hline Hombres & 3 & 0 & 2 & 1 & 2 & 1 & 2 & 1 \\
\hline Total & 29 & 2 & 26 & 5 & 20 & 11 & 22 & 9 \\
\hline$\%$ & 93,5 & 6,5 & 83,87 & 16,13 & 64,51 & 35,49 & 70,97 & 20,03 \\
\hline
\end{tabular}
lorar los productos de aprendizaje y la participación en redes sociales. El instrumento tiene cuatro categorías y cuatro criterios de valoración. Se solicitó el apoyo de tres expertos para la validación.

- Fase de resultados. Se compararon los resultados obtenidos por cada estudiante, entre la primera actividad del curso (foro en Facebook) y última actividad llevada a cabo en la octava semana (participación en el Blog). Luego se compararon los resultados en el producto de aprendizaje, con las tendencias en el perfil de aprendizaje coincidentes con las características favorecidas por las redes sociales: visual, activo, secuencial y sensitivo.

\section{Resultados}

A continuación se presentan los resultados del estudio, cuyo objetivo ha sido implementar estrategias de enseñanza en la red social Facebook y en el blog colaborativo, guiado por la pregunta: ¿se logra con dichas estrategias, favorecer las tendencias en el estilo de aprendizaje y mejorar el producto de aprendizaje en estudiantes del curso virtual Teoría Psicoanalítica, del Programa de Psicología UVD en la Universidad Minuto de Dios, en Bogotá, Colombia?

Según la tabla 4 y figura 3, la mayoría de estudiantes $(93,5 \%)$ se concentró en la recepción visual (26 mujeres y 3 varones); en la organización secuencial, el $83,87 \%$ (24 mujeres y 2 varones); en la experiencia sensitiva, el 64,51\% (18 mujeres y 2 varones) y en el procesamiento activo, el $70,97 \%$ (20 mujeres y 2 varones).
Tabla 4

Tendencias encontradas en el estilo de aprendizaje en los estudiantes del curso Teoría Psicoanalítica NRC 1079-16

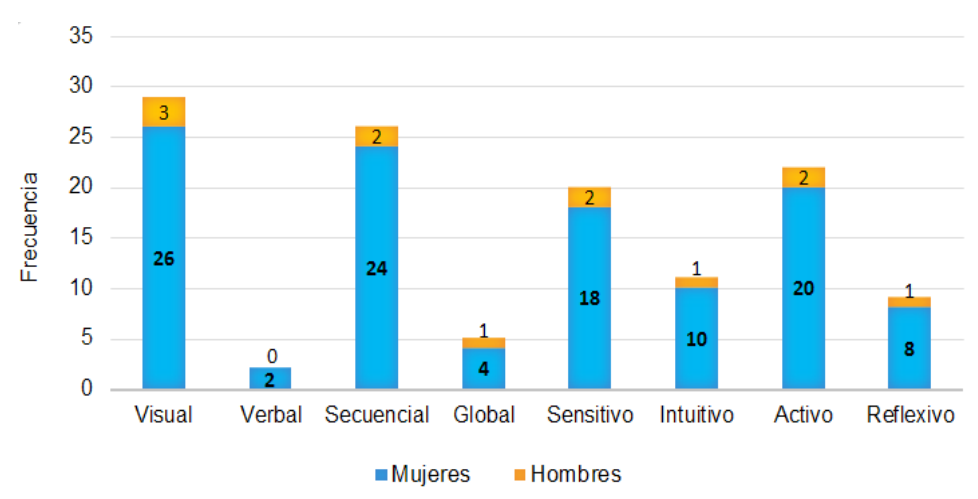

Figura 3. Tendencias encontradas en el estilo de aprendizaje en los estudiantes del curso Teoría Psicoanalítica NRC 1079-16.

Puesto que la mayoría de los estudiantes tienen perfiles en los que predomina lo: visual, sensitivo, secuencial y activo, las actividades propuestas buscaron favorecer la recepción por el canal visual, la organización de manera secuencial y el trabajar con la información de manera activa. Así se creó un grupo en Facebook y se propuso un foro, indicando mediante la rúbrica creada para valorar su aporte el marco para llevar a cabo la actividad en ese espacio de la red social. Los resultados del foro en Facebook se presentan en la tabla 5.

Tabla 5

Resultados Foro en Facebook (frecuencia y porcentaje)

\begin{tabular}{cccccc}
\hline Calificación & $\begin{array}{c}\text { Marca } \\
\text { de clase } \\
(\mathrm{x})\end{array}$ & $\begin{array}{l}\text { Frecuencia } \\
\text { Absoluta } \\
(\mathrm{f})\end{array}$ & $\begin{array}{l}\text { Porcen- } \\
\text { taje } \\
\%\end{array}$ & $\begin{array}{l}\text { Frecuen- } \\
\text { cia Relativa } \\
(\mathrm{fr})\end{array}$ & $\begin{array}{l}\text { Frecuencia } \\
\text { Absoluta } \\
\text { Acumulada } \\
(\mathrm{F})\end{array}$ \\
\hline 0 & 0 & 6 & 17,14 & 0,170 & 6 \\
\hline $050-060$ & 3,14 & 1 & 2,85 & 0,028 & 7 \\
\hline $060-070$ & 3,71 & 1 & 2,85 & 0,028 & 8 \\
\hline $070-080$ & 4,28 & 11 & 31,40 & 0,310 & 19 \\
\hline $080-090$ & 4,85 & 9 & 25,70 & 0,250 & 28 \\
\hline $090-100$ & 5,42 & 7 & 20,00 & 0,200 & 35 \\
\hline Total & & 35 & 100,00 & 0,99 & \\
\hline
\end{tabular}


Se observa que 6 estudiantes no participaron y el 31,4\% (la mayoría de ellos) obtuvieron calificaciones entre 70 y 80 sobre 100 , mientras que el $25,7 \%$ entre 80 y 90 sobre 100 ; solo el $20 \%$ entre 90 y 100 , sobre 100 puntos.

En la semana octava se propuso la participación en un blog creado para tal fin en la red social Blogger y se indicó que en esta actividad se valorarían los mismos aspectos de la primera actividad; es decir, el Foro en Facebook.

Los resultados de valoración del aporte de los estudiantes en Blogger se presentan en la tabla 6 , según la cual, 5 estudiantes no participaron en la actividad; el 74,3\% de los estudiantes logró calificaciones superiores a 80 sobre 100 , el $34,3 \%$, entre 80 y 90 , y el $40 \%$ entre 90 y 100 , sobre la base de 100 puntos.

Tabla 6

Resultados Blog Colaborativo (frecuencia y porcentaje)

\begin{tabular}{cccccc}
\hline Calificación & $\begin{array}{c}\text { Marca } \\
\text { de clase } \\
(\mathrm{x})\end{array}$ & $\begin{array}{l}\text { Frecuencia } \\
\text { Absoluta } \\
(\mathrm{f})\end{array}$ & $\begin{array}{l}\text { Porcen- } \\
\text { taje } \\
\%\end{array}$ & $\begin{array}{l}\text { Frecuen- } \\
\text { cia Relativa } \\
(\mathrm{fr})\end{array}$ & $\begin{array}{l}\text { Frecuencia } \\
\text { Absoluta } \\
\text { Acumulada } \\
(\mathrm{F})\end{array}$ \\
\hline 0 & 0,00 & 5 & 14,20 & 0,140 & 5 \\
\hline $050-060$ & 3,14 & 1 & 2,85 & 0,028 & 6 \\
\hline $060-070$ & 3,71 & 0 & 0,00 & 0,000 & 6 \\
\hline $070-080$ & 4,28 & 3 & 8,57 & 0,085 & 9 \\
\hline $080-090$ & 4,85 & 14 & 40,00 & 0,400 & 23 \\
\hline $090-100$ & 5,42 & 12 & 34,30 & 0,340 & 35 \\
\hline Total & & 35 & 100,00 & 0,99 & \\
\hline
\end{tabular}

De lo anterior, se concluye que los resultados obtenidos por los estudiantes mejoraron entre la primera (foro en Facebook) y la última actividad (participación en Blogger), realizada en dichas redes sociales considerando las tendencias en el estilo de aprendizaje de los estudiantes (tabla 7).

El intervalo 0 corresponde a los estudiantes que, de la muestra de 35, no participaron en las actividades. Uno de ellos se retiró del curso y otro no participó en ninguna de las actividades propuestas en redes sociales, aunque sí en las demás desarrolladas en el aula virtual.
Tabla 7

Comparación resultados entre actividad en Facebook y en Blog

\begin{tabular}{ccc}
\hline Calificación & $\begin{array}{c}\text { Foro Facebook } \\
\text { Frecuencia } \\
\text { Absoluta }(\mathrm{f})\end{array}$ & $\begin{array}{c}\text { Aporte Blog } \\
\text { Frecuencia } \\
\text { Absoluta }(\mathrm{f})\end{array}$ \\
\hline 0 & 6 & 5 \\
\hline $050-060$ & 1 & 1 \\
\hline $060-070$ & 1 & 0 \\
\hline $070-080$ & 11 & 3 \\
\hline $080-090$ & 9 & 14 \\
\hline $090-100$ & 7 & 12 \\
\hline Total & 35 & 35 \\
\hline
\end{tabular}

La mejora o desmejora en el producto de aprendizaje relacionado con las tendencias en el estilo de aprendizaje se evidencia en la tabla 8. En esta se observa que la combinación Activo-Intuitivo-Visual- Secuencial (AIVS) es la que presenta el mayor porcentaje de estudiantes que mejoran su producto $(17,1 \%)$ y la combinación Activo-Sensitivo-Visual-Secuencial (ASVS) es la que presenta un mayor porcentaje de estudiantes que desmejoran $(17,1 \%)$; esta última es también una de las que mejoran en mayor porcentaje (14,2\%).

La combinación Activo-Visual-Secuencial está presente en las categorías que presentan un porcentaje mayor de mejora (AsVS y AIVS). En el sumatorio general, en el $42,7 \%$ de los estudiantes que logran mejorar se presenta la combinación Activo-Visual (AsVS, AIVS, AsVG), mientras que las combinaciones que contienen la característica Reflexivo no se destacan; y el único estudiante que cuenta en su perfil con la combinación Reflexivo-Verbal (RIBG) desmejora en su producto. 
Tabla 8

Mejora o desmejora del producto de aprendizaje según las tendencias en el estilo de aprendizaje

\begin{tabular}{ccccccc}
\hline $\begin{array}{c}\text { Combinación } \\
\text { estilo }\end{array}$ & $\begin{array}{c}\text { Frecuencia } \\
\text { mejora }\end{array}$ & $\%$ & $\begin{array}{c}\text { Frecuencia } \\
\text { desmejora }\end{array}$ & $\% 2$ & $\begin{array}{c}\text { No } \\
\text { participa }\end{array}$ & $\% 3$ \\
\hline RIVG & 1 & 2,85 & 0 & 0 & 0 & 0 \\
\hline RsVS & 2 & 5,71 & 2 & 5,71 & 0 & 0 \\
\hline AsVS & 5 & 14,2 & 6 & 17,1 & 0 & 0 \\
\hline AIVS & 6 & 17,1 & 1 & 2,85 & 0 & 0 \\
\hline AsVG & 4 & 11,4 & 0 & 0 & 0 & 0 \\
\hline RIVS & 2 & 5,71 & 0 & 0 & 0 & 0 \\
\hline RIBG & 0 & 0 & 1 & 2,85 & 0 & 0 \\
\hline NR & 1 & 2,85 & 2 & 5,71 & 2 & 5,71 \\
\hline Total & 21 & & 12 & & 2 & \\
\hline
\end{tabular}

Nota: Las combinaciones corresponden a $\mathrm{R}=$ Reflexivo, $s=$ Sensitivo, I=Intuitivo, V=Visual, $B=$ Verbal, G=Global, $\mathrm{S}=$ Secuencial.

\section{Discusión y Conclusiones}

En la administración piloto llevada a cabo para valorar los productos de aprendizaje de los estudiantes del curso de Teoría Psicoanalítica perteneciente al cuarto periodo del programa de Psicología UVD se aplicaron estrategias en las Redes Sociales Facebook y Blog, considerando las tendencias en el estilo de aprendizaje de los alumnos. Los resultados de este trabajo, que se muestran en las tablas 7 y 8 , permiten afirmar que, utilizando las redes sociales como estrategias para llevar a cabo actividades diseñadas para favorecer las tendencias en el estilo de aprendizaje de los estudiantes, se logra mejorar la calidad de los productos de aprendizaje. Esto es coherente con lo expuesto por Garrigos et al. (2015), quien señala que las redes sociales son muy importantes para fomentar y desarrollar la creación, el aprendizaje y el intercambio de conocimiento. Tanto Facebook como el blog son herramientas bastante usadas por los estudiantes fuera de las aulas y que los docentes deben incorporar en el proceso de aprendizaje para desarrollar las competencias comunicativas y el análisis de información. En estos medios, los estudiantes intercambian abundante información durante gran parte del día. Por eso mismo, sería bueno que en las aulas de clase aprendieran a crear y difundir por ellos productos de calidad.
Es necesario prestar más atención a los estilos de aprendizaje de los estudiantes y el contacto que estos tienen con la Tecnología de Información y Comunicación (TIC). La innovación pedagógica debe ser una de las mayores fortalezas de los docentes, quienes en estos tiempos se ven obligados a usarlas para conseguir que sus estudiantes desarrollen sus competencias en cada una de las áreas curriculares (La Declaración de Bolonia, 1999; Comunicado de Bergen; 2005).

Los resultados sirvieron para verificar que la tendencia predominante (Activo-Visual-Secuencial) está presente en las categorías que tienen un porcentaje mayor de mejora (AsVS y AIVS). En el sumatorio general, el $42,7 \%$ de los estudiantes que logran mejorar presentan la combinación Activo-Visual (AsVS, AIVS, AsVG), mientras que las combinaciones que contienen la característica Reflexivo no se destacan. El único estudiante que cuenta en su perfil con la combinación Reflexivo-Verbal (RIBG) desmejora en su producto.

Para futuras investigaciones deben implementarse actividades que permitan, en distintos momentos del curso, evaluar de forma puntual el aprendizaje, pero considerando las tendencias que no predominan, como ocurrió en este estudio con el perfil Reflexivo-Verbal. También se debe contrastar con aquellos resultados en los que suelen predominar: Activo-Visual, pero variándose el tipo de material aportado por el docente. De esta forma se permitirá reconocer qué ocurre en relación con las tendencias en el estilo de aprendizaje, como también valorar si la facilidad y mejora presentada en la actividad final se debe, de manera exclusiva, al espacio elegido, a su facilidad de manejo y a la experiencia ganada durante el curso.

\section{REFERENCIAS BibliográficAS}

Acosta-Castillo, L. (2016). La relación entre los estilos de aprendizaje y el uso de las tecnologías de información y comunicación en educación de personas adultas. Revista Electrónica Educare, 20 (3). Recuperado de: https://doi. org/10.15359/ree.20-3.10

Alducin-Ochoa, J. y Vázques-Martínez, A. (2017). Estilos de aprendizaje, variables sociodemográficas y rendimiento académico en estudiantes de Ingeniería de Edificación. Revista Electrónica Educare, 21(1), 350-380. Recuperado de: 
http://www.scielo.sa.cr/scielo.php?script=sci_arttext\&pi$\mathrm{d}=$ S1409-42582017000100350\&lng=en\&tlng=en

Amaya, A. y Cuellar, A. (2016). Estilos de Aprendizaje de los alumnos de posgrado a distancia de la Universidad Autónoma de Tamaulipas. Apertura, 8 (2), 8-21 (2016) Recuperado de: https://doaj.org/article/72dddebcae014220ac48467317b653dd

Buxarrais, M. Redes sociales y educación. Education in the Knowledge Society (EKS), 17(2), 15-20. Recuperado de: https://doi.org/10.14201/eks20161721520

Buxarrais, M. (2016). Redes sociales y educación. Teoría de la Educación. Educación y Cultura en la Sociedad de la Información. 15-20. Recuperado de: http://www.redalyc.org/ pdf/2010/201046521002.pdf

Cabero-Almenara, J., y Marín-Díaz, V. (2014). Posibilidades educativas de las redes sociales y el trabajo en grupo. Percepciones de los alumnos universitarios. Comunicar, (42), 165. Recuperado de: https://doi.org/10.3916/C42-2014-16

Campoamor, J. (4 de mayo, 2017). 2.000 millones de usuarios en todo el mundo: el impresionante récord de Facebook y cómo se compara con otras cifras globales. BBC Mundo. Recuperado de: http://www.bbc.com/mundo/noticias-39806985

Coll, C., Engel, A. y Bustos, A. (2008). Los entornos virtuales de aprendizaje basados en la representación visual del conocimiento. Cap. XI EN: Psicología de la Educación Virtual. Aprender y enseñar con las Tecnologías de la Información. Madrid: Morata. Libro Electrónico.

Colvin, R. y Mayer, R. (2011). E-Learning and the Science of Instruction. Pfeiffer. Libro electrónico. Recuperado de: www.wiley.com/college/clark

Cornejo, E. (2013). El desarrollo de las competencias cognitivas básicas en estudiantes de sexto grado a través del uso de Facebook como herramienta mediadora del proceso de aprendizaje. Fundación Universitaria Andaluza Inca Garcilaso para Eumed.net. Recuperado de: http://www.eumed. net/libros-gratis/2014/1375/

Chávez, I., y Gutiérrez, M. del C. (2016). Redes sociales como facilitadoras del aprendizaje de ciencias exactas en la educación superior. Apert. (Guadalaj., Jal.) vol.7 n.2 Guadalajara Mar. 2016. On-line versión ISSN 2007-1094. Recuperado de: http://www.scielo.org.mx/scielo.php?script=sci_arttext $\&$ pid $=$ S1665-61802016000100049\&ln$\mathrm{g}=\mathrm{en} \& \mathrm{t} \operatorname{lng}=\mathrm{en}$

De Haro, J. (2010). Redes sociales en educación. Educar para la comunicación y la cooperación social, 27, 203-216. Recuperado de: http://jjdeharo.blogspot.com.co/2010/05/ redes-sociales-en-educacion.html

De Moya, M., Hernández, J. y Cózar, R. (2011). Análisis de los estilos de aprendizaje y las TIC en la formación personal del alumnado universitario a través del cuestionario REATIC. Revista de Investigación Educativa, 29 (1), $137-$ 156. Recuperado de: http://revistas.um.es/rie/article/viewFile/110481/126972

Díaz Barriga, F. y Hernández, G. (2010). Estrategias do- centes para un aprendizaje significativo. Una interpretación constructivista. México, McGrawHill Editores.

Felder, R., y Silverman, L. (1988). Learning and teaching styles in engineering education. Engineering education, 78(7), 674-681. Recuperado de: http://www4.ncsu.edu/ unity/lockers/users/f/felder/public/Papers/LS-1988.pdf

Felder, R. y Brent, R. (2005). Understanding student differences. Journal of Enginneering Education, 94 (1). Recuperado de: https://doi.org/10.1002/j.2168-9830.2005. tb00829.x

Felder, R., Felder, G. y Dietz, E. (2002). The effects of personality type on enginnering student performance and attitudes. Journal of Enginneering Education, 91(1), 3-17. Recuperado de: https://doi.org/10.1002/j.2168-9830.2002. tb00667.x

Fundación Universitaria Católica del Norte-FUNC (Comp.) (2005) Educación virtual: Reflexiones y experiencias. Medellín. ISBN: 958-33-7872-0. Recuperado de: http://www. ucn.edu.co/institucion/sala-prensa/Documents/educacion-virtual-reflexiones-experiencias.pdf

García, J., Santizo, J., y Alonso, C. (2008), Identificación del uso de la tecnología computacional de profesores y alumnos de acuerdo a sus estilos de aprendizaje. Recuperado de: http://learningstyles.uvu.edu/index.php/jls/article/ view/84 y https://dialnet.unirioja.es/servlet/articulo?codigo $=2957421$

García, L. (2014). Bases, mediaciones y futuro de la educación a distancia en la sociedad digital. Madrid: Síntesis. ISBN 978- 84- 995886-3-6. Libro electrónico.

García, M. (2007). Construcción social del conocimiento. Comunicación y pedagogía: Nuevas tecnologías y recursos didácticos. ISSN 1136-7733, No. 223, 2007, págs. 34-37. Recuperado de: https://dialnet.unirioja.es/ejemplar/180271

Garrigós, F., Oltra, J., Montesa, J., Narangajavana, Y. y Estelles-Miguel, S. (2015). The use of Facebook and Social Networks to improve Education. Recuperado en: Dirección y organización: Revista de dirección, organización y administración de empresas, ISSN 1132-175X, No 55, 2015, págs. 4-10. Recuperado de: https://www.researchgate.net/ publication/281959517_The_use_of_Facebook_and_social_networks_to_improve_education

Garrigós, F., Oltra, J., Montesa, J., Narangajavana, Y. y Estelles-Miguel, S. (2016) Measuring the Use of Twitter in Education. The Asian Conference on Society, Education \& Technology 2016 Official Conference proceedings. Recuperado de: http://papers.iafor.org/papers/acset2016/ACSET2016_33044.pdf

Gewerc, A., Montero, L. y Lama, M. (2014). Colaboración y redes sociales en la enseńanza universitaria. Comunicar 42: ¿La revolución de la enseńanza? Vol. XXI, no 42, $1^{\circ}$ semestre, 1 enero 2014 E-ISSN: 1988-3293 / ISSN: 1134-3478. Recuperado de: https://doi.org/10.3916/C42-2014-05

González, C., y Muñoz, L. (2016). Redes Sociales, su impacto en la educación superior: Caso de estudio Universidad Tecnológica de Panamá. Campus Virtuales Vol. 5, Num. 1, 
pp 84-90. Consultado el 12-05-2017 en www.revistacampusvirtuales.es

Gómez, S., Garcia, E., Masa, C. y Villar, N. (2012). El uso de las TIC en los estilos de aprendizaje para la consecución de las competencias del EEES - Su aplicación en la CEU - USP. En: Estilos de aprendizaje: investigaciones y experiencias: [V Congreso Mundial de Estilos de Aprendizaje], Santander, 27, 28 y 29 de junio de 2012 / coordinado por Fernando Guerra López, Rosa García-Ruiz, Natalia González Fernández, Paula Renés Arellano, Ana Castro Zubizarreta, 2012, ISBN 978-84-695-3454-0. Recuperado de: https://dialnet.unirioja.es/descarga/articulo/4658390.pdf

Guzmán, A. (2013). Factores Críticos de Éxito en el Uso de las Redes Sociales en el Ámbito Universitario: Aplicación A Twitter. (Tesis doctoral). Editorial Universitat Politècnica de València. Recuperado de: https://doi.org/10.4995/Thesis/10251/28212

Hernández, R., Fernández, C. y Baptista, P. (2010). Metodología de la Investigación. México: McGrawHill.

Iglesias, M., y González-Díaz, C. (2013). El uso de Facebook como herramienta para la interacción en el proceso de enseñanza-aprendizaje. Recuperado de: https://web.ua.es/ es/ice/jornadas-redes-2013/documentos/2013-comunicaciones-orales/335221.pdf

Islas, C. y Carranza, M. (2011).Uso de las redes sociales como estrategias de aprendizaje. ¿Transformación educativa? Revista Universidad de Guadalajara. 3 (2). Recuperado de http://www.udgvirtual.udg.mx/apertura/index.php/apertura/article/view/198/213

König, M. (2013). Theory of learning styles and practical applications. Gring Verlag GmbH. Libro electrónico.

Llanos, R. A., y Orozco, C. M. (1999). Las redes sociales ¿Para Qué?; Social Networks, for what purpose? Psicología desde el Caribe, (2-3). Recuperado de: http://ciruelo. uninorte.edu.co/pdf/psicologia_caribe/2-3/7\%20Las\%20 redes\%20sociales.pdf

López, C. (2014) La interrelación entre las redes sociales específicas de la comunicación científica y las redes sociales de uso general. Vivat Academia, 127, 103-116. Recuperado de: https://dialnet.unirioja.es/descarga/articulo/4899545.pdf

López, M., Flores, K., y Espinoza, A. (2015). Diversidad de usos de Facebook en la educación superior. Análisis desde un caso de estudio. Innoeduca. International Journal of Technology and Educational Innovation, 1(2), 106-114. Recuperado de: https://doi.org/10.20548/innoeduca.2015. v1i2.1040

López, R. (2010) Facebook la reina de las redes sociales. Revista Mexicana de Comunicación, 23 (123) 12-18. Recuperado de: https://dialnet.unirioja.es/servlet/articulo?codigo $=5670260$

UNIR. (2016). Modelos y estrategias de participación en redes sociales. (Tesis de maestría inédita). Universidad de la Rioja. Recuperado de: https://campusingenieria.unir.net/ access/lessonbuilder/item/2830995/group/rep-mel/mel14_ modelos_estrategias_redes/web/tema1/ideasclave.html?vir- tualpage $=1$

Marín-Díaz, V. y Gómez-Parra, E. (2017). Edublogs in the development of the European higher education area: an initiative in the Primary Education Degree course at the University of Cordoba (Spain). 7th World Conference on Educational Sciences, (WCES-2015), 05-07, February 2015, Novotel Athens Convention Center, Athens, Greece. Recuperado de: https://doi.org/10.1016/j.sbspro.2015.07.329

Martinez, J. (2011). La minería de datos en educación matemática relación entre estilos de aprendizaje y desempeño académico. (Tesis de maestría inédita). Universidad Nacional de Colombia. Recuperado de:

Mesa-López, L., Torres-Velandía, S. y Lara-Ruiz, J. (2016). Estrategias de aprendizaje emergentes en la modalidad E-learning. RED-Revista de Educación a Distancia, 48 (5). Recuperado de: https://doi.org/10.6018/red/48/5

Molina, L. y Briones, I. (2016). Redes Sociales en la Educación. Dominio de las Ciencias, 2 (4), 570-578. Recuperado de: https://dialnet.unirioja.es/servlet/articulo?codigo $=5802872$

Molina, W. y Valenzuela, M. J. (2011). Por qué fascinan las redes sociales a los jóvenes. Recuperado de: http://repositorio.puce.edu.ec/handle/22000/5191

Morales, R. E. y Pereida, M. A. (2017). Inclusión de estilos de aprendizaje como estrategia didáctica en un AVA. Campus Virtuales, 6(1), 67-75.

Muñoz, M., Fragueiro, M. y Ayuso, M. (2013). La importancia de las redes sociales en el ámbito educativo. Escuela abierta, 16, 91-104. Recuperado de: http://www.docfoc. $\mathrm{com} /$ dialnet-laimportanciadelasredessocialesenelambitoeducativo-4425349

Nuria, S. (2015). Metodologías participativas y Facebook en el ámbito universitario. Innoeduca: International journal of technology and educational innovation, ISSN-e 2444-2925, Vol. 1, No. 1, 2015, pp. 25-32. Recuperado de: http://www. revistas.uma.es/index.php/innoeduca/article/view/104/496

Onrubia, J., Colomna, R. y Engel, A. (2008). Los entornos virtuales de aprendizaje basados en el trabajo en grupo y el aprendizaje colaborativo. Cap. XI EN: Psicología de la Educación Virtual. Aprender y enseñar con las Tecnologías de la Información. Madrid: Morata. Libro Electrónico.

Orellana, N., Bo, R., Belloch, C. y Aliaga, F. (2010). Estilos de Aprendizaje y Utilización de las Tic en la Enseńanza Superior. Recuperado de: reposital.cuaed.unam.mx:8080/ jspui/bitstream/123456789/2563/1/117.pdf

Pantoja, M., Duque, L., y Correa, J. (2013). Modelos de estilos de aprendizaje: una actualización para su revisión y análisis. Revista Colombiana de Educación, 0(64), 79-105. Recuperado de: https://doi.org/10.17227/01203916.64rce79.105

Pérez, N. (2015). Facebook como plataforma de aprendizaje. Revista científica electrónica de Educación y Comunicación en la Sociedad del Conocimiento. Publicación en línea (Semestral), Granada (España), Época II, Año XV, Número 15, Vol. II, Julio-Diciembre de 2015. ISSN 1695-324X. 
Recuperado de: https://dialnet.unirioja.es/servlet/articulo?codigo $=5476878$

Pérez, M. del S., Ortiz, M. G. y Florez, M. M. (2015). Redes sociales en Educación y propuestas metodológicas para su estudio. Ciencia, docencia y tecnología, No. 50. On-line versión ISSN 1851-1716. Recuperado de: http://www.scielo.org.ar/scielo.php?script=sci_arttext\&pi$\mathrm{d}=$ S1851-17162015000100008\&lng=en\&tlng=en

Pino, R. y Soto, T. (2015). Las redes sociales como herramientas didácticas para la producción de textos argumentativos en estudiantes del cuarto grado de secundaria del centro experimental de aplicación de la Universidad Nacional de Educación Enrique Guzmán y Valle. (Tesis de licenciatura inédita). Lima, Chosica: Universidad Nacional Enrique Guzmán y Valle. Recuperado de: http://repositorio.une.edu. pe/bitstream/handle/UNE/558/005.pdf?sequence $=1$

Rivero, C., Chávez, A., Vásquez, A., y Blumen, Sh. (2016). Las TIC en la formación universitaria: logros y desafíos para la formación en psicología y educación. Recuperado de: http://www.scielo.org.pe/scielo.php?script=sci_arttext\&pi$\mathrm{d}=$ S0254-92472016000100008\&lng=en\&tlng=en

Ríos, A. (2015). Tecnologías de la Información y Comunicación (TIC's) en la educación superior a distancia en México: estudios de derecho, retos y oportunidades. En: Enl@ ce: Revista Venezolana de Información, Tecnología y Conocimiento, 12. Universidad del Zulia. Recuperado de www. redalyc.org/pdf/823/82343214007.pdf

Rodríguez, A. (2013). Uso de las redes sociales como estrategia de aprendizaje. Revista AKADEMOS. 2 (19). 59-76. Recuperado de: https://web20upelcuam.files.wordpress. com/2015/07/alrodriguez-uso-de-redes-sociales-como-estrategia-de-aprendizaje.pdf

Rojas-Jara, C., Díaz- Larenas, C., Vergara-Morales, J., Alarcón-Hernández, P., y Ortíz-Navarrete, M., (2016). Estilos de enseńanza y estilos de aprendizaje en educación superior: Análisis de las preferencias de estudiantes de pedagogía en inglés en tres universidades chilenas. Recuperado de: https://doi.org/10.15359/ree.20-3.7

Salazar, V. (2014). Propuesta conceptual sobre el uso didáctico de las redes sociales en el contexto educativo formal. Recuperado de: http://repositorio.uc.cl/xmlui/handle/123456789/4942

Symsek, O. (2010). The Effect of Weblog (blog) students' writing performance. Procedia Social and Behavioral Sciences 2 (2010) 953-958 A. Recuperado de: https://doi.org/10.1016/j.sbspro.2010.03.133

Tenorio, L. y Taquez, H. (2016). Ambientes de aprendizaje mediados por TIC, hallando sentidos en la escuela. Recuperado de: http://eduteka.icesi.edu.co/articulos/aprendizaje-mediado-por-tic

Torres, J. (2016). Aspectos básicos para una enseñanza e-Learning de calidad en la educación superior. En: 3 c TIC: cuadernos de desarrollo aplicados a las TIC, ISSN-e 22546529, Vol. 5, No. 3, 2016, pp. 8-32. Recuperado de: http:// ojs.3ciencias.com/index.php/3c-tic/article/view/299
Zaini A. Ismail, Kemboja, I. y Supyan, H. (2010). Blogs in Language Learning: Maximizing Students' Collaborative Writing. Procedia - Social and Behavioral Sciences, Volume 18, 2011, pp. 537-543. Recuperado de: https://doi. org/10.1016/j.sbspro.2011.05.079 


\title{
La Práctica Supervisada Mediada por Tecnología como Escenario para la Enseñanza de Competencias Clínicas
}

\section{The Supervised Practice Technology-Mediated as a Scenario for Clinical Skills Training}

\author{
De la Rosa-Gómez, Anabel ${ }^{1}$ \\ González-Pérez, Marco Antonio ${ }^{2}$ \\ Rueda-Trejo, Jesús Alberto ${ }^{3} \mathrm{y}$ \\ Rivera-Baños, Judith ${ }^{4}$ \\ Facultad de Estudios Superiores Iztacala, SUAyED Psicología. \\ Universidad Nacional Autónoma de México
}

Recibido: 02-04-2017

Aceptado: 18-06-2017

\section{Cita Recomendada}

De la Rosa-Gómez, A., González-Pérez, M., Rueda-Trejo, J. y Rivera-Baños, J. (2017). La Práctica Supervisada Mediada por Tecnología como Escenario para la Enseñanza de Competencias Clínicas. Hamut'ay, 4 (1), 75-84. Recuperado de: http://doi.org/10.21503/hamu.v4i1.1396

\section{RESUMEN}

Los estudiantes de Psicología a distancia tienen actualmente la necesidad de contar con una formación profesional que les garantice mayor eficiencia y competencia para incidir en la solución de problemas de salud emocional. En ese sentido, el objetivo principal de esta investigación fue conocer la eficacia de un programa de práctica supervisada y mediada por tecnología, para garantizar el desarrollo de competencias clínicas en los estudiantes de psicología a distancia. El programa de formación tuvo una duración de cinco meses y se basó en un modelo de competencias profesionales. Se implementó un estudio piloto con diez estudiantes de los últimos semestres de la licenciatura en Psicología. Los datos obtenidos mediante la administración de la Escala de terapia cognitiva (ETC), de Beck y Young (1980), evidenciaron que los practicantes mejoraron sus habilidades clínicas después de terminar el programa de entrenamiento. Asimismo, los resultados de la prueba estadística no paramétrica rangos de Wilcoxon, se obtuvieron diferencias significativas entre las evaluaciones anterior y posterior al entrenamiento $(z=2,20 ; \mathrm{p}=, 027)$. En cuanto a la satisfacción de los participantes con el programa de formación, los estudiantes consideraron que es un escenario de formación innovador para el desarrollo de sus habilidades clínicas. Es así que resulta pertinente proponer una alternativa prometedora ante la carencia de escenarios de práctica profesional y, de ese modo, lograr que los estudiantes se involucren en escenarios reales vinculados a sus intereses o a la propia estructura curricular. En este sentido, nuevas perspectivas de investigación y desarrollo tecnológico se abren para la enseñanza práctica.

Palabras Clave: enseñanza virtual, competencias clínicas, consejería a distancia.

1 Coordinadora del Centro de Apoyo Psicológico y Educativo a Distancia (CAPED). UNAM, México. anabel.delarosa@ired.unam.mx 2 Coordinador del Observatorio de Educación a Distancia. UNAM, México. marco.gonzalez@ired.unam.mx

3 Responsable operativo del Centro de Apoyo Psicológico y Educativo a Distancia (CAPED). UNAM, México. alberto.trejo@ired.unam.mx 4 Responsable de evaluación del Centro de Apoyo Psicológico y Educativo a Distancia (CAPED). UNAM, México. judith.rivera@ired.unam. $\mathrm{mx}$ 


\section{Abstract}

Psychology students enrolled in a distance program, currently need to have a professional training that guarantees them a greater efficiency and competence in order to impact in the solution of emotional health problems. In this sense, the main objective of this research was to know the effectiveness of a supervised and technology-mediated practice program, to guarantee the development of clinical competences in psychology students at a distance learning program. The training program lasted five months and it was based on a model of professional competences. A pilot study was implemented with ten students of the last semesters of the degree program in Psychology. Data obtained through the administration of the Beck and Young's (1980) Cognitive Therapy Scale (CTS) showed that practitioners improved their clinical skills after completing the training program. Likewise, the results of the Wilcoxon nonparametric statistical signed-rank test, showed significant differences between the pre- and post-training evaluations $(\mathrm{z}=2.20 ; \mathrm{p}=, 027)$. Regarding the participants' satisfaction with the training program, the students considered it as an innovative training scenario for the development of their clinical skills. It is therefore pertinent to propose a promising alternative considering the lack of professional practice scenarios. In this way, we can get students involved in real scenarios related to their interests or to the curriculum structure itself. In this sense, new perspectives of research and technological development are opened up for practical teaching.

Keywords: Virtual teaching, clinical competences, distance counseling.

\section{INTRODUCCIÓN}

Una de las metas de la educación universitaria es graduar a profesionales que posean conocimientos, habilidades y actitudes adecuadas para contribuir al desarrollo sostenible y el mejoramiento de la sociedad en su conjunto (UNESCO, 2017). En el caso del sector salud, para responder a tales situaciones, se requiere de recursos humanos que cuenten con competencias profesionales para la evaluación e intervención en los servicios psicológicos en los que puedan ensayar y aplicar lo aprendido. Estas capacidades se generan por medio de una formación que incluya el dominio de técnicas y procedimientos de intervención eficaces (Cárdenas, De la Rosa y Jurado, 2012).

Los escenarios de práctica adquieren relevancia en sistemas educativos diseñados para contextos virtuales, debido a que éstos deben estar estructurados de tal manera que respondan a las necesidades formativas de la población estudiantil, para favorecer así en el estudiante la correcta utilización de los recursos disponibles (personales, talentos, habilidades), institucionales (infraestructura, ma- teriales, entre otros) y curriculares (aprendizajes, métodos, técnicas). De este modo se fomenta la mejora continua de los procesos internos entre todos los miembros de la comunidad, quienes enriquecen su conocimiento y experiencias en el área mediante la interacción continua y conjunta. Es así que los estudiantes se convierten en los beneficiarios primarios de los escenarios de práctica y, a su vez, con su desempeño profesional demostrarán las competencias adquiridas para atender las necesidades de la sociedad, razón por la cual se formaron en dichos escenarios (Araujo, Larreal y Alonso, 2014; Francisco, 2012).

Adicionalmente al proceso de formación de los futuros profesionistas, existen factores individuales que deben ser considerados dentro de ese mismo perfil, como son la carga de trabajo, las demandas académicas, los estresores sociales, los problemas económicos y el ajuste inherente al ambiente universitario, entre otros; y que pudieran tener efectos negativos sobre su salud mental y reflejarse en su desempeño académico (Álvarez y Cáceres, 2010). 
En este sentido, con la finalidad de solventar las necesidades detectadas en este ámbito y aprovechando la infraestructura en el acceso a los medios tecnológicos, la Coordinación de Educación a Distancia de la Facultad de Estudios Superiores Iztacala de la Universidad Nacional Autónoma de México (UNAM), ha detectado y atendido las necesidades de mayor frecuencia en la población del alumnado del Sistema de Universidad Abierta y Educación a Distancia (SUAyED), informó, coincidentemente con la literatura científica, que los estresores de mayor incidencia son causados por problemas emocionales de la vida personal, o bien aquellas derivadas del momento socio-ambiental por el que atraviesa el país, tomándose en cuenta las regiones donde residen, o las generadas por las vicisitudes que presenta el reto de estudiar una carrera a distancia (González, 2014). Dichos estresores de vida aumentan la probabilidad de abandono de estudios o impactan negativamente en el rendimiento académico. Por lo que, evaluar y brindar orientación psico-emocional y educativa se convierte en una necesidad de salud integral para la población estudiantil.

Debido a las condiciones de comunicación asincrónica de los alumnos, el apoyo psicológico y la orientación educativa es brindada a través de aplicativos virtuales que permiten tanto la evaluación, como la consejería en modalidad a distancia, donde son los propios alumnos y futuros profesionales competentes quienes atienden las necesidades de la comunidad estudiantil y desarrollan habilidades propias de su profesión durante el proceso. De esta forma se creó el Centro de Apoyo Psicológico y Educativo a Distancia (CAPED), que permite: (1) un escenario de práctica para el desarrolo de competencias clínicas y psico-educativas en estudiantes de psicología SUAyED en las áreas de profundización de clínica y educativa y (2) brindar apoyo psicológico y orientación educativa a estudiantes en modalidad a distancia. Igualmente, permite dar respuesta al Plan de estudios de la carrera de Psicología a distancia (Silva, 2005), en donde se plantea como imperativo el desarrollo de estancias de práctica en escenarios reales, como eje sustantivo de la formación profesional.
Importancia de la inclusión de práctica profesional supervisada en la formación del psicólogo

Las prácticas curriculares son un aspecto clave de este proceso de formación, pues en ellas se adquiere el conocimiento y aprendizaje del "ethos" profesional en los entornos específicos en que se encuentran los estudiantes; es decir, el sistema de valores, normas y patrones de comportamiento, así como su técnica y las tecnologías que de ella se derivan y que son propios de su profesión, para orientar una práctica ética y profesional en su disciplina (Romero y Yurén, 2007).

Sin embargo, los escenarios de práctica deben considerar lo que Castells (2000) describe como el surgimiento de la "sociedad red", la trascendencia de la cultura material a una cultura digital, donde la información deja de ser impresa y comienza a difundirse por diversos medios digitales, tomándose en cuenta además los cambios significativos en la estructura de la cultura y la conducta social que esto implica. La construcción de una sociedad sostenida en torno a redes personales y corporativas, operadas por redes digitales coordinadas vía Internet que requieren a su vez de nuevas habilidades y ofrecen nichos que deben ser llenados por los profesionistas. Aterrizando lo anterior en la educación a distancia, se puede decir que estas prácticas requieren de nuevos escenarios de encuentro, que aludan a su vez a nuevas formas de interrelaciones entre profesores y alumnos, aprovechándose el amplio potencial de las tecnologías de la información y la comunicación (TIC), e implican extender la interacción más allá de los límites físicos de las instituciones. En este último punto se puede ver que, por sí misma, la virtualidad ofrece la infraestructura que consigue dicho objetivo, pues reúne a los participantes en el mismo lugar, en medio de la virtualidad, con los mismos objetivos y las mismas metas, pero facilitando la comunicación y el trabajo colaborativo a través de las diversas herramientas y formas de contacto disponibles.

La práctica virtual supera los límites de la presencialidad y ofrece acceso constante a un espacio común, a la información y los materiales educativos, de estudio, de capacitación; encuestas, estadísticas, seguimiento de secuencias de apren- 
dizajes, entre otras opciones. Permite además un acceso permanente mediante diversos medios y plataformas tecnológicas que proporcionan servicios web para facilitar el acceso por medio de computadoras, tabletas, smartphones, entre otros dispositivos móviles (Filippi, Pérez y Aguirre, 2011).

En tanto las comunidades de práctica y aprendizaje pueden ser definidas como organizaciones que mantienen una continuidad temporal, donde se comparta una práctica y organización entre sus diferentes miembros. En ella también se comparten experiencias y aprendizajes de forma que la práctica cotidiana y el aprendizaje quedan completamente unidos en su interior. En el caso de las comunidades virtuales, como escenario de práctica mediado por las tecnologías, éstas últimas conllevan un papel primordial que enlazan las actividades de cada miembro mediante servicios de mensajería, redes sociales, aulas virtuales, administradores de archivos, páginas Web, entre otras herramientas y aplicaciones (Wayne, 2012).

Las comunidades de práctica virtual se han convertido en un medio importante para el desarrollo profesional. Además, el impacto de la virtualidad en las diversas esferas sociales da cuenta de un nuevo proceso educativo que rompe con los esquemas preconcebidos y estandarizados de forma mecánica y lineal, donde el estudiante recibe y hace notas de un pizarrón (Castell, 2012). Si bien algunos autores (Rodríguez, 2007; Sangrà, 2001) consideran que la virtualidad conlleva la pérdida de algunos de los componentes interactivos que se consideraban más significativos en las interacciones de una comunidad de práctica presencial, como la contigüidad y temporalidad de las interacciones, el uso de tecnologías y herramientas web gana en versatilidad y el amplio abanico de recursos disponibles. La atemporalidad, la disposición al contacto entre sus miembros, su alcance y las capacidades comunicativas aplicados a la formación práctica han enriquecido las posibilidades de acción, lo que también implica un proyecto común de desarrollo y aprendizaje aplicado en casos y funciones reales que ponen a prueba a los alumnos y su formación personal (Tirado, Marín y Lojo, 2008).

Finalmente, en esta misma línea el informe de la
Asociación Nacional de Universidades e Instituciones de Educación Superior, (ANUIES, 2000; en Rodríguez y Leyva, 2007) indica que el promedio nacional de eficiencia terminal en México hacia el año 2000, se ubicaba en el 39\% de la población estudiantil universitaria y, para el año 2007, por cada 100 alumnos inscritos, lograron concluir 64 en las escuelas públicas y 71 en las privadas. Si bien en lo que respecta a la eficiencia terminal hay una cierta tendencia a su reducción en las casi dos últimas décadas, la eficiencia terminal comparada al número de estudiantes que ingresan revela que continúan existiendo problemas en la conclusión de los estudios universitarios, provocados sobre todo por las dificultades escolares, así como por las dificultades emocionales y afectivas. Lo anterior deja de manifiesto que, además de la necesidad de desarrollar programas académicos y estímulos que combatan el rezago y abandono escolar, es imprescindible diseñar proyectos de atención a las necesidades clínicas y psicoeducativas de la población estudiantil.

Es así que el presente proyecto pretendió comprobar la eficacia de la estancia de práctica supervisada mediada por tecnología para la adquisición de competencias clínicas en estudiantes de psicología a distancia, con lo cual se espera apoyar y fortalecer la formación práctica de los estudiantes de la licenciatura bajo supervisión de especialistas y, también, permitir que las intervenciones cuenten con bases teóricas y metodológicas que se pretende fomentar en el alumnado y que incida en la calidad de los servicios que ofrezca a la comunidad.

\section{Materiales y Métodos}

\section{Participantes}

La muestra estuvo conformada por diez estudiantes de los últimos semestres de la licenciatura en Psicología (7mo. a 9no.), inscritos al Sistema de Universidad Abierta y a Educación a distancia (SUAyED), 7 mujeres y 3 hombres, de entre 27 y 50 ańos $(M=38$, D.E. $=7)$, que brindaron consejería psicológica a estudiantes de la misma carrera de 1 ro a 9 no. semestre. 


\section{Instrumento}

Se utilizó la Escala de terapia cognitiva-ETC de Beck y Young (1980). Esta mide las competencias clínicas deseables que un terapeuta cognitivo-conductual desplegaría en una sesión de intervención. La ETC cuenta con 12 ítems que se califican con base en un escalamiento tipo Likert de 7 grados $(0=$ Pobre o ausencia de competencia a $6=$ Excelente desempeño o competencia). Los ítems restantes (ítem 13 a 18) tienen como objetivo explorar las condiciones en las que transcurrió la sesión, asignar una calificación general del desempeño del terapeuta evaluado y ofrecer comentarios finales para la mejora de las competencias del psicólogo evaluado. Asimismo, la ETC ha demostrado poseer una muy buena consistencia interna, $\alpha=, 95$ (Blackburn, James, Milne y Reichelt, 2000). También se reportaron puntuaciones de intercorrelación ítem-total e ítem-ítem, que oscilan de 0,94 a 0,77 y un coeficiente de fiabilidad de 0,60 (Blackburn et al., 2000). La escala fue empleada por psicólogos supervisores de psicoterapia cognitivo-conductual, con el propósito de valorar las competencias clínicas que un psicólogo clínico en formación muestra para ejecutar una sesión psicoterapéutica.

\section{Material}

Se usaron los siguientes materiales:

- El Manual de entrenamiento para asesores psicológicos a distancia (De la Rosa, 2016), que fue realizado con el objetivo de brindar la información básica para el entrenamiento del asesor psicológico para dirigir una intervención de consejería emocional a distancia.

- El Sistema de Evaluación Inteligente e Interfaz para videoconferencia y Chat en plataforma Moodle, que constituye un escenario virtual de interacción entre usuario-asesor a lo largo del proceso de atención psicológica y orientación educativa. Por sí mismo es un espacio en el que se llevan a cabo los procesos de evaluación e intervención psicológica, pues alberga los recursos y medios disponibles, entre materiales y recursos audiovisuales, formatos de registro y actividades, calendarización de citas, recursos de apoyo e instrumentos de evaluación, así como alberga el acceso al servicio de chat $y$ videoconferencia, medio esencial para llevar a cabo la sesión en línea.

El entrenamiento se realizó en un aula multimedia equipada con 27 computadoras personales, acceso a Internet, micrófonos, auriculares y cámaras de videoconferencia. Esta sala cuenta con un sistema de monitoreo a través del cual se puede realizar la supervisión en tiempo real.

\section{Tipo y diseño}

La investigación se realizó siguiendo un diseño cuasi-experimental, modelo preprueba-posprueba y un grupo. Se realizaron mediciones repetidas antes y después del entrenamiento y estancia de práctica supervisada (Montero y León, 2007).

\section{Procedimiento}

El programa de prácticas supervisadas contempló que los alumnos realicen una estancia de práctica clínica o educativa de cinco meses. Antes de la estancia de práctica supervisada, el alumno ya contaba con fundamentos y antecedentes de los diferentes procedimientos y técnicas propios de formación académica; también conocía los criterios de prescripción y las actividades terapéuticas relacionadas con los diversos procedimientos de cambio conductual.

Dado que el objetivo de la estancia era lograr que el estudiante lleve a la práctica las diferentes técnicas y procedimientos en ambientes virtuales propios de la modalidad a distancia, los alumnos seleccionados cursaron un entrenamiento intensivo e inducción a la práctica por un total de 25 horas, durante una semana, donde recibió los fundamentos referentes a los antecedentes de las intervenciones psicológicas mediadas por tecnologías y consejería psicológica vía Internet.

Al término de la capacitación, el estudiante fue sometido a una evaluación de competencias clínicas a través de una sesión virtual (a través de videoconferencia) con un usuario simulado. En dicha sesión, un voluntario simuló una problemática estandarizada, que el asesor desconocía y 
que debía evaluar para el análisis de caso y aplicar alguna técnica de intervención de corte cognitivo conductual. Todas las sesiones virtuales de evaluación fueron videograbadas y se aleatorizaron para el envío a los supervisores, en su calidad de evaluadores ciegos, quienes calificaron la ejecución del estudiante mediante la Escala de terapia cognitiva (ETC) de Beck y Young (1980).

Durante la estancia de práctica, los estudiantes recibieron supervisión en modalidad individual y grupal por profesores con amplia experiencia en el campo, quienes atendieron sus dudas y les asistieron en la formulación de sus tratamientos e intervenciones mediante: (1) supervisión "in situ", es decir que los asesores se encontraron acompañados por un supervisor de guardia que les asistió en caso de emergencias, así como les orientó en la intervención de cada uno de sus usuarios, y (2) supervisión plenaria semanal, donde se compartieron aprendizajes y se intercambiaron opiniones sobre casos clínicos. Al finalizar la estancia, se realizó nuevamente la evaluación simulada aplicando el mismo procedimiento descrito anteriormente.

\section{Consejería a distancia: tratamiento}

Se realizó la difusión del servicio en medios de comunicación institucionales, con el objetivo de que éste sea conocido por los usuarios meta y puedan solicitar y recibir atención psicológica y orientación educativa. Los candidatos enviaron una solicitud de servicio vía formulario del sitio web. El coordinador operativo del programa asignó un consejero u orientador a distancia, que desde el centro de apoyo psicológico le brindó la intervención. El terapeuta realizó una primera sesión por videoconferencia para conocer el motivo de consulta del usuario, así como para explicar el servicio y el tipo de intervención. Después de la primera sesión por videoconferencia, el consejero realizó las evaluaciones pertinentes vía Internet y estableció junto con el usuario fecha y horario para realizar las sesiones de consejería u orientación. La intervención podía ir desde una a ocho sesiones, una vez por semana, en modalidad a distancia y dependiendo del tipo de intervención: consejería (2-5 sesiones) y terapia breve (3-8 sesiones), con una duración de 60 minutos, las cua- les se llevaron a cabo vía Internet empleando una aplicación para videoconferencia o chat desde el sitio web del CAPED (www.caped.iztacala.unam. $\mathrm{mx}$ ), vinculado a la plataforma Moodle. Durante la intervención clínica se utilizaron técnicas cognitivo-conductuales con las cuales los usuarios adquieren las herramientas necesarias para resolver su problemática. Una vez finalizadas las sesiones de tratamiento se programaron las evaluaciones post-tratamiento.

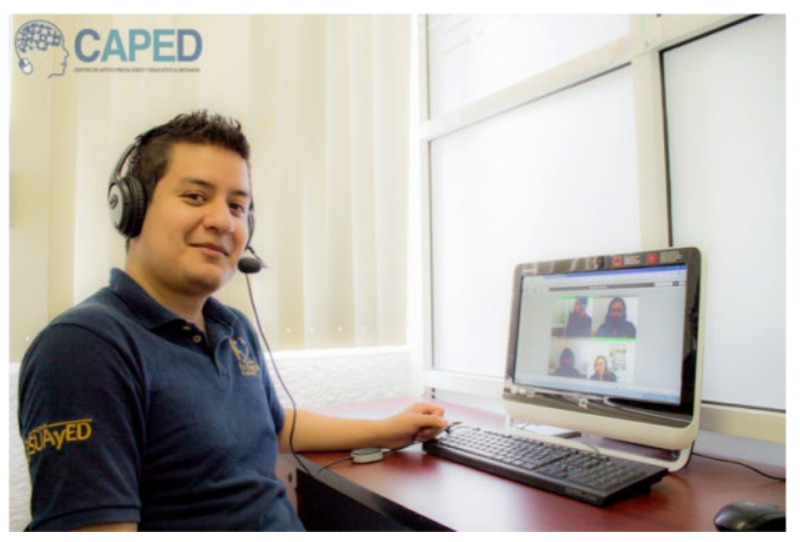

Figura 1. Escenario de práctica supervisada. Fuente: http://caped.iztacala.unam.mx/

\section{Resultados}

Los resultados iniciales, obtenidos del estudio piloto basado en las evaluaciones de adquisición de competencias clínicas en estudiantes de psicología en modalidad a distancia, señalan que la mayoría de los estudiantes (60\%) cubrieron el segundo nivel de competencia (principiante avanzado) al mostrar conocimientos específicos, buen manejo de técnica con algunos problemas al conducir la sesión de intervención. Ningún alumno había tenido contacto con usuarios reales bajo supervisión (ver tabla 1). En la figura 2 se muestran la puntuación y nivel de competencia medido antes y después de la estancia de práctica supervisada. 
Tabla 1

Nivel de competencia evaluado antes y después de la estancia de práctica supervisada

\begin{tabular}{lcccl}
\hline Consejero & \multicolumn{2}{c}{ Pre-evaluación } & \multicolumn{2}{c}{ Post-evaluación } \\
\hline Calificación & $\begin{array}{c}\text { Puntua- } \\
\text { ción }\end{array}$ & $\begin{array}{c}\text { Nivel de } \\
\text { competencia }\end{array}$ & $\begin{array}{c}\text { Puntua- } \\
\text { ción }\end{array}$ & $\begin{array}{c}\text { Nivel de } \\
\text { competencia }\end{array}$ \\
\hline 1 & 17 & Novato & 21 & Novato \\
\hline 2 & 32 & $\begin{array}{l}\text { Principiante } \\
\text { avanzado }\end{array}$ & 35 & $\begin{array}{l}\text { Principiante } \\
\text { avanzado }\end{array}$ \\
\hline 3 & 29 & $\begin{array}{l}\text { Principiante } \\
\text { avanzado }\end{array}$ & 35 & $\begin{array}{l}\text { Principiante } \\
\text { avanzado }\end{array}$ \\
\hline 4 & 32 & $\begin{array}{l}\text { Principiante } \\
\text { avanzado }\end{array}$ & 35 & $\begin{array}{l}\text { Principiante } \\
\text { avanzado }\end{array}$ \\
\hline 5 & 42 & Competente & 52 & $\begin{array}{l}\text { Competente } \\
\text { avanzado }\end{array}$ \\
\hline 6 & 17 & Novato & 26 & $\begin{array}{l}\text { Principiante } \\
\text { avanzado }\end{array}$ \\
\hline 7 & 13 & Novato & 35 & $\begin{array}{l}\text { Principiante } \\
\text { avanzado }\end{array}$ \\
\hline 8 & 17 & Novato & 32 & $\begin{array}{l}\text { Principiante } \\
\text { avanzado }\end{array}$ \\
\hline 9 & 18 & Novato & 35 & $\begin{array}{l}\text { Principiante } \\
\text { avanzado }\end{array}$ \\
\hline 10 & 16 & Novato & 33 & $\begin{array}{l}\text { Principiante } \\
\text { avanzado }\end{array}$ \\
\hline & & & & \\
\hline
\end{tabular}

Nota: Los rangos de competencia son: 0-11 (no competente), 12-23 (novato), 24-35 (principiante avanzado), 36-47 (competente), 48-60 (competente avanzado), 61-72 (experto).

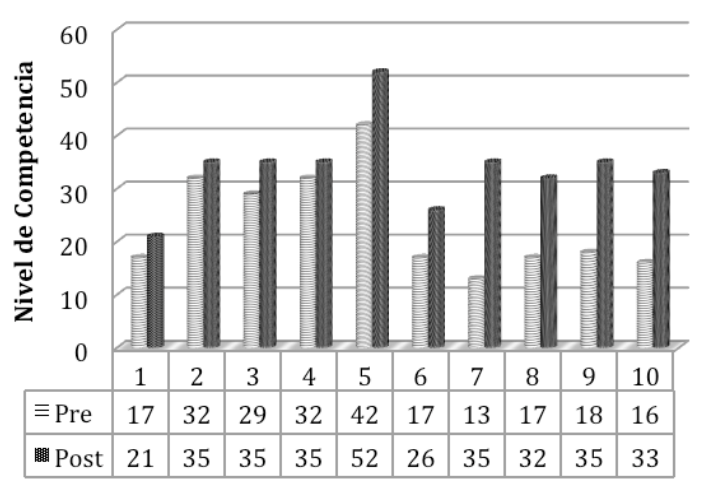

Figura 2. Nivel de competencia obtenida antes y después de la estancia de práctica.

Con la finalidad de determinar las diferencias intra-sujeto se computó la prueba estadística no paramétrica rangos de Wilcoxon para comparar el rango medio obtenido a través de la aplicación de la Escala de terapia cognitiva (ETC) antes $(M=$ $23,3, D \cdot E=9,7)$ y después $(M=34, D \cdot E .=10,6)$ de la estancia de práctica. Como se observa en la figura 3, se encontraron diferencias significativas entre las medidas para cada ejecución $(z=2,20$; $p=, 027)$.

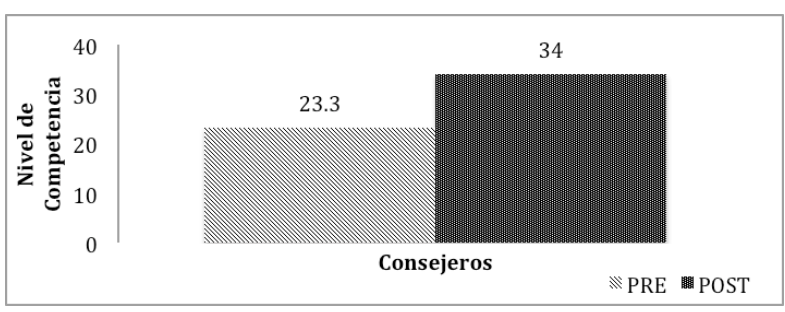

Figura 3. Media del nivel de competencia antes y después de la práctica supervisada.

Al realizar una evaluación cualitativa del desempeño, después del programa de capacitación, los estudiantes indicaron que se sentían más seguros al conducir una intervención psicológica, ya que sabían que podían consultar al supervisor en cualquier momento. El hecho de poder realizar un análisis más profundo de sus sesiones les permitió comprender mejor el fenómeno emocional del consultante y les fue más fácil formular intervenciones bajo un análisis funcional del caso clínico.

Con respecto a la evaluación de la modalidad terapéutica, como escenario de práctica para el desarrollo de las habilidades clínicas, se planteó a los estudiantes la interrogante sobre si las instrucciones y requisitos para el uso de los sistemas, los objetivos y las condiciones de trabajo eran claros. Consideraron que la modalidad de consejería emocional y el tiempo dedicado a la terapia fueron adecuados. Los practicantes consideraron que fue fácil establecer contacto con el usuario y que la modalidad era sencilla de aplicar, generaba interés y favorecía la consejería. En relación con la evaluación del escenario del programa de entrenamiento, los estudiantes consideraron que el uso de tecnologías para proporcionar consejería a través de Internet los motivó y les hizo ganar mayor seguridad para iniciar sus primeras experiencias clínicas. El sistema de evaluación e intervención facilitó la comunicación con los usuarios meta, al promover la colaboración con el usuario y permitirles adaptar el programa de consejería a las necesidades de tiempo y distancia física. También consideraron que los usuarios podían expresar emociones fácilmente. 


\section{Discusión y Conclusiones}

El propósito del estudio fue conocer la eficacia de un programa de práctica supervisada, mediada por tecnología, para el desarrollo de competencias clínicas en estudiantes de psicología a distancia. Los datos preliminares nos muestran resultados positivos al incorporar nuevas tecnologías a la enseñanza de competencias clínicas en estudiantes universitarios a distancia y proponer una alternativa prometedora ante la carencia de escenarios de práctica profesional para lograr que los estudiantes puedan involucrarse en escenarios reales relacionados con sus intereses o a la propia estructura curricular. En este sentido, nuevas perspectivas de investigación y desarrollo tecnológico se abren para el desarrollo de escenarios virtuales para la enseñanza práctica de la atención en el ámbito de la salud, ya que integra la tecnología educativa con los desarrollos tecnológicos. El propósito es proveer un escenario alternativo a los estudiantes que les permita la flexibilidad para desarrollar las competencias que la situación de aprendizaje demande para la toma de decisiones en el contexto profesional en ambientes virtuales.

Coincidentemente con lo mencionado por Cárdenas (2012) y Tirado (2008), las técnicas de formación y práctica supervisada proporcionan una oportunidad para mejorar el funcionamiento del sistema de formación y son una clave importante para reducir los errores en la asistencia psicológica. La investigación en enseñanza virtual ha mostrado que las mejoras en la formación práctica de los alumnos pueden reducir las tasas de error y mejorar la calidad de la asistencia.

La consejería psicológica en modalidad a distancia, como escenario innovador para la formación de habilidades clínicas para los estudiantes de Psicología, brinda ventajas principalmente al estudiante-terapeuta en esta etapa de formación o actualización profesional. El empleo de aplicaciones de comunicación virtuales sincrónicas y asincrónicas a través de Internet facilita la posibilidad de contar con registros de la comunicación mantenida entre el psicólogo y el paciente que, con previo consentimiento del usuario, pueden ser empleados como material de supervisión clínica, que permite que el terapeuta y supervisor realizar un análisis más cuidadoso de la conducción del problema o fenómeno psicológico. La finalidad es diseñar un tratamiento más eficaz y llevar a cabo una búsqueda más precisa para evaluar la eficacia del tratamiento. Otra ventaja para los terapeutas es que en cualquier momento el supervisor puede asesorarlo y guiarlo con respecto a las decisiones a tomar en beneficio de los usuarios meta.

La modalidad de consejería emocional a distancia incide en dos vías, como un entorno formativo de habilidades clínicas para el psicólogo. Permite a los terapeutas en el proceso de formación tener un primer contacto con usuarios "reales", sin representar un evento altamente estresante para ellos; además, representa una buena alternativa para el entrenamiento, al contar con práctica supervisada que permite el desarrollo de habilidades clínicas.

Las extraordinarias posibilidades técnicas de las nuevas tecnologías permiten la evaluación y el tratamiento de un gran número de personas de muchos lugares a través de modalidades de bajo costo.

Los indicadores de cambio permitieron probar la eficacia de la propuesta actual; sin embargo, se continuará en futuros estudios con la medición de los efectos del programa de práctica supervisa para el desarrollo de habilidades clínicas, declaraciones cognitivas, formulaciones de tratamiento, adherencia a protocolos de tratamiento, así como la relación entre el nivel de competencia del terapeuta y la eficacia de tratamientos cognitivo-conductuales. Otra limitación de este estudio piloto es el tamaño de la muestra, que puede no ser suficiente para probar realmente la eficacia de nuestro programa de entrenamiento. Por tanto, es necesario probar la eficacia de este programa de entrenamiento en muestras más grandes y usando diseños de grupo, incluyendo grupos de control y otros grupos de entrenamiento.

Es importante ser cauteloso con respecto a la confidencialidad de los datos cuando se utilizan sistemas virtuales, por lo cual se emplearon contraseñas protegidas y personalizadas. En este sentido, Wilson, Davies y Weatherhead (2016) destacan la necesidad de contar con métodos seguros para proteger la confidencialidad. Por ejemplo, eliminando de las bases de datos la información 
biográfica de los participantes. Se actuó bajo protocolos de seguridad adecuados para el resguardo de la información durante el programa de capacitación e intervención; se protegió la confidencialidad de los usuarios; se pidió el consentimiento informado para la participación voluntaria tanto de practicantes como usuarios meta, así como se contó con un servidor institucional exclusivo para el programa de intervención que permitió cifrar y encriptar la información.

Las características que distinguen al programa de formación lo hacen viable para el desarrollo de competencias profesionales en el tratamiento de diversos trastornos psicológicos. Además, es un escenario alternativo para la práctica de habilidades clínicas a través de una modalidad de psicoterapia innovadora que les permite entrenarse. Adicionalmente, la principal ventaja del programa consiste en brindar apoyo emocional a un mayor número de personas, lo que también podría reflejarse en el alcance que los psicólogos puedan tener y coadyuvar a que los estudiantes en modalidad a distancia no abandonen sus estudios por problemas emocionales.

La disponibilidad de programas formativos de servicio que refuercen la formación integral de los estudiantes universitarios, en particular la vinculación entre los conocimientos teóricos y la práctica, representa una gran contribución al campo de la psicología. La capacitación de los estudiantes en esta modalidad innovadora y su incipiente aplicación en México permite al educador dotar al estudiante de conocimientos especializados que fortalecen su nivel de competencia y lo colocan a la vanguardia como profesional en estas especialidades de reciente desarrollo.

\section{AGRADECIMIENTO}

Al Programa de Apoyo a Proyectos para la Innovación y Mejoramiento de la Enseñanza UNAM-DGAPA-PAPIME <<PE300916>> $<<$ Consejería emocional y orientación educativa a distancia: Creación de un escenario de práctica virtual para la enseñanza de competencias clínicas y psico-educativas para estudiantes de Psicología a distancia $>>$

\section{Referencias Bibliográficas}

Adlaf, E., Gliksman, L., Demers, A. \& Newton, B. (2001). The prevalence of elevated psychological distress among Canadian undergraduates: Findings from the 1998 Canadian Campus Survey. Journal of American College Health, 50, 67-72. Recuperado de: https://doi. org/10.1080/07448480109596009

Al-Qaisy, L. (2011). The relation of depression and anxiety in academic achievement among group of university students. International Journal of Psychology Counseling, 3 (5), 96-100.

Álvarez, L. \& Cáceres, L. (2010). Resiliencia, rendimiento académico y variables sociodemográficas en estudiantes universitarios de Bucaramanga. Psicología Iberoamericana, 18 (2), 37-46.

Aragón, L. (2011). Perfil de personalidad de estudiantes universitarios de la carrera de Psicología. El caso de la Facultad de Estudios Superiores Iztacala. Perfiles Educativos, 33 (133), 68-87.

Araujo, F., Larreal, B. y Alonso, J. (2014). Comunidades de prácticas virtuales para el desarrollo de competencias investigativas. Opción, 30 (75), 75-91.

Beck, A. \& Young, J. (1980). Cognitive Therapy Scale: Rating Manual. Psychotherapy Research Unit. University of Pennsylvania.

Blackburn, I., James, D., Milne \& Reichelt, F. (2000). Cognitive therapy scale - revised (CTS-R). Newcastle upon Tyne, UK.

Cárdenas, G., De la Rosa, A. y Jurado, S. (2012). Evaluación de Simuladores Virtuales para la Enseńanza de Habilidades de Entrevista y Diagnóstico con Estudiantes de Psicología Clínica. Memorias del 1er. Simposio en Psicopedagogía en la Educación a Distancia: Investigación y práctica. Facultad de Psicología. UNAM.

Castells, M. (2000). La sociedad Red. (Carmen Martínez Gimeno y Jesús Alborés, trad.). Madrid, Editorial Alianza (Obra original publicada en 1997).

Castells, M. (2012). El impacto de Internet en la sociedad. Una perspectiva global. Madrid: Editorial Alianza.

De la Rosa, A. (2016). Manual de entrenamiento para asesores psicológicos a distancia. Programa de Apoyo a Proyectos para la Innovación y Mejoramiento de la Enseñanza UNAM-DGAPA- PAPIME <PE300916>.

Filippi, J., Pérez, D. y Aguirre, S. (2011). Nuevo escenario educativo. El aula virtual. Multiciencias, 11, (4), 353-361.

Francisco, J. (2012). Calidad en entornos virtuales de aprendizaje. Compendium, 15 (29), 97-107.

González, M. (2014). Propuesta de servicio de apoyo psicológico al SUAyED, Iztacala (SAPS). Coordinación de Educación a Distancia. Abril, manuscrito no publicado.

Haddock, G., Devane, S., Bradshaw, T., McGovern, J., Tarrier, N., Kinderman, P., Baguley, I., Lancashire, S. \& Harris, N. (2001). An investigation into the psychome- 
tric properties of the Cognitive Therapy Scale for Psychosis (CTSPsy). Behaviour and Cognitive Psychotherapy, 29, 2, 221-233. Recuperado de: https://doi.org/10.1017/ S1352465801002089

Hernández, R., Fernández, C. y Baptista, M. (2010). Metodología de la Investigación ( $5^{a}$ Ed.). México: McGraw Hill Educación.

Murdock, J, Williams, A., Becker, K., Bruce, M.A. \& Young, S. (2012). The Journal of Human Resource and Adult Learning, 8 (1), 105-118.

Montero, I. y León, O. (2007). A guide for naming research studies in Psychology. International Journal of Clinical and Health Psychology, 7 (3), 847-862.

Osornio, L. y Palomino, L. (2009). Depresión en estudiantes universitarios. Archivos en Medicina Familiar, 11 (1), $1-2$.

Rodríguez, J. (2007). Comunidades virtuales, práctica y aprendizaje: elemento para una problemática. Teoría de la Educación. Educación y Cultura en la Sociedad de la Información, 8 (3), 6-22.

Rodríguez, J. y Leyva, M. (2007). La deserción escolar universitaria. La experiencia de la UAM. Entre el déficit de la oferta educativa superior y las dificultades de la retención escolar. El Cotidiano, 22 (142), 98-111.

Romero, C. y Yurén, M. (2007). Ethos profesional, dispositivo universitario y conformación. Reencuentro, México, 49, 22-29.

Rousmaniere, T. \& Renfro-Michel, E. (eds). (2016). Clinical Supervision in an Online Group Format, in Using Technology to Enhance Clinical Supervision, American Counseling Association., Alexandria, USA. Recuperado de: https:// doi.org/10.1002/9781119268499.ch11

Sangrà, A. (2001). Enseñar y aprender en la virtualidad. Educar, 28, 117-131. Recuperado de: https://doi.org/10.5565/ rev/educar.394

Silva (2005). Plan de estudios de la licenciatura en Psicología para el Sistema de Universidad Abierta y Educación a Distancia. Facultad de Estudios Superiores Iztacala, UNAM.

Tirado, R., Marín, I. y Lojo, B. (2008). Creando comunidades virtuales de aprendizaje en las prácticas curriculares. Factores para su desarrollo, 33, 133-153.

Voelker, R. (2003). Mounting student depression taxing campus mental health services. JAMA, 289, 2055-2056. Recuperado de: https://doi.org/10.1001/jama.289.16.2055

Wayne, C. (2012). Constructing Professional Identity in an Online Graduate Clinical Training Program: Possibilities for Online Supervision. Journal of Systemic Therapies, 31 (3), 53-67. Recuperado de: https://doi.org/10.1521/ jsyt.2012.31.3.53

Wilson, H., Davies, J. \& Weatherhead, S. (2016). Trainee Therapists' Experiences of Supervision During Training: A Meta-synthesis. Clinical Psychology Psychotheraphy, 23, 340-351. Recuperado de: https://doi.org/10.1002/ cpp. 1957 


\title{
Los recursos tecnológicos como soporte para la enseñanza de las ciencias naturales \\ Technological resources as support in natural sciences teaching
}

\author{
Milagros Esperanza Rojas Salgado ${ }^{1}$ \\ Universidad Nacional Mayor de San Marcos, Perú
}

Recibido: $14-02-2017$

Aceptado: 23-05-2017

\section{Cita Recomendada}

Rojas, M. (2017) Los recursos tecnológicos como soporte para la enseńanza de las ciencias naturales. Hamut'ay, 4 (1), 85-95. Recuperado de: http://doi.org/10.21503/hamu.v4i1.1403

\section{RESUMEN}

En este artículo se presenta un estudio etnográfico de la situación actual de la enseñanza de las ciencias naturales en nuestro país, desde la perspectiva de los lineamientos educativos a nivel nacional. Asimismo, se sustenta la necesidad de la integración de los recursos tecnológicos en esta área. El objetivo fue documentar las formas en las que se podría innovar teniendo en cuenta que las Tecnologías de la Información y la Comunicación (TIC) son un medio para alcanzar los resultados de aprendizajes planteados y no un fin en sí mismo, pues permiten aprovechar las competencias que nuestros estudiantes están desarrollando en su día a día para lograr y/o empoderar sus aprendizajes. A partir del estudio se puede concluir que la integración de las TIC en la enseñanza de las Ciencias Naturales es necesaria y pertinente, dado que contribuyen al logro de los resultados de aprendizaje esperados en los estudiantes, generando competencias no solo a nivel cognitivo sino también a nivel actitudinal.

Palabras Clave: Enseñanza de las Ciencias Naturales, recursos tecnológicos, aprendizajes.

\section{Abstract}

This article presents an ethnographic study of the current situation of Natural Sciences teaching in our country, from the perspective of the national education guidelines. It also highlights the need to integrate technological resources in this area. The objective was to document the ways in which innovations could be made, taking into account that Information and Communication Technologies (ICTs) are a means to achieve the desirable learning outcomes and not an end in itself; since they allow us to benefit from the competences that our students develop in their daily basis to achieve and / or empower their learning. From the study it can be concluded that the integration of ICTs in Natural Sciences teaching is necessary and relevant, since they contribute to the achievement of

\footnotetext{
1 Licenciada en Educación Secundaria de la Universidad Nacional Mayor de San Marcos, especialidad de Biología y Química, Licenciada en Psicología Humana de la Universidad Alas Peruanas. Candidata a magister en Gestión de la Educación y Doctorando en Educación por la Universidad Inca Garcilaso de la Vega. Con estudios de Post grado en Neuropedagogía. E-mail: milagrosrojassalgado@ gmail.com
} 
the expected learning outcomes in the students, generating competences not only at the cognitive but also at attitudinal level.

Keywords: Natural Sciences teaching, technological resources, learning.

\section{INTRODUCCIÓN}

A menudo se habla de la implementación de las TIC como una necesidad primordial en las escuelas. El hecho que el servicio educativo que se brinda esté en completa consonancia con los estudiantes que lo reciben, considerando la sociedad en la que estos se desenvuelven, se ha destacado como una de esas prioridades que se deben de atender desde las políticas y normativas que brinda nuestro sistema educativo nacional, hasta su consecuente implementación, seguimiento, análisis de resultados e innovaciones respectivas. Sin embargo, la escuela actual en Perú todavía se encuentra en estado incipiente respecto a los espacios que brinda para que los estudiantes cuenten con las posibilidades de usar recursos tecnológicos de forma simultánea. Por el contrario, la participación en clases, en la fase de recuperación de aprendizajes previos, aún se realiza en actividades plenarias durante los diez o quince minutos iniciales, para que cinco de los más de veinte estudiantes brinden su punto de vista sobre un tema. ¿Y los demás?, ¿quedarán para la próxima clase? Es más: todos los estudiantes deben de participar sobre la misma "situación significativa". Cabe preguntarse entonces: ¿cómo podrían gestionar sus aprendizajes si aún no pueden ser autónomos en lo que les genera interés? ¿cómo podrán los docentes identificar las necesidades de aprendizaje de sus estudiantes si estos no han tenido la oportunidad de poner en evidencia sus concepciones alternativas sobre las cuales se tendría que trabajar? Puede ser que también valga la pena preguntarse ¿por qué necesariamente se debe cambiar el modelo de escuela del siglo XX para este siglo. ¿Funcionaba mal la escuela del siglo pasado? La respuesta es rotunda; evidencias sobran para sustentar el desfase entre lo que se hace en la escuela y lo que requiere la sociedad, donde todo gira básicamente en torno a habilidades como la resolución de problemas, el trabajo en equipo y la gestión del tiempo (Hampson, Patton \& Shanks, 2011). En estas tres habilidades está la tecnología como elemento inherente; es así que cabe señalar que existe una fuerte tendencia a implementar las tecnologías en el proceso de aprendizaje-enseñanza por ello a nivel nacional se produce un proceso de transición en la implementación tecnológica, específicamente en lo que se refiere a TIC en Educación, con un diseño curricular establecido en el 2016 y las modificaciones en el 2017, que incluye a la alfabetización tecnológica como una de las competencias transversales a desarrollar en los estudiantes y que se encuentra descrita en mapas de progreso y estándares de aprendizaje a alcanzar en cada uno de sus niveles de la escolaridad.

En este contexto resulta complicado y hasta soñador poder emprender planes de implementación de la TIC integradas a la enseńanza de las áreas del currículo, pues la gran concentración de esfuerzos está en garantizar mínimamente la disponibilidad de dichos recursos en las escuelas, entre otros niveles, siendo uno de los más avanzados la capacidad del docente para planificar unidades de aprendizaje con integración de las TIC. Se sabe que es necesario innovar en la educación peruana, en cuyo contexto se realiza esta investigación, pues las innovaciones son un fuerte potencial para mejorar los resultados en educación y, conscientemente, se sabe que hay mucho por hacer en este sector.

En las nuevas tendencias, la integración de las TIC con fines educativos desempeña un rol fundamental para poder brindar una enseñanza personalizada e individualizada. Adicionalmente a lo anterior, la educación es percibida en muchos países como uno de los medios principales para lograr la equidad, de manera que las innovaciones puedan ayudar a alcanzar este objetivo por lo menos en el acceso a la educación. Ser más eficientes económicamente hablando, es decir, minimizar 
costos y maximizar recursos, también cuenta y cuenta mucho. Este artículo se propuso determinar cuál es la situación actual con respecto a la enseñanza de las Ciencias Naturales a los nativos digitales, como definió Prensky a los estudiantes de este siglo. Se trató también de establecer los niveles de implementación que requeriría la integración de las TIC en la enseñanza y los retos que supone hacerlo, como también algunas propuestas para hacer esto realidad.

\section{MÉTodo}

El presente artículo se realizó a través de la revisión, lectura y análisis de libros, tesis, conferencias virtuales y artículos académicos, haciéndose una búsqueda mediante los descriptores siguientes: Enseñanza de las Ciencias Naturales, integración de los recursos tecnológicos, innovaciones educativas y nuevas Tecnologías de la Información y Comunicación. La búsqueda se realizó en la base de datos de SciELO, Redalyc, Revistas Electrónicas de Investigación Educativa; de Investigación y Experiencias Didácticas; Iberoamericana de Educación en Tecnología y Tecnología en Educación; Actualidades Investigativas en Educación; Revista Cubana de Ciencias Informáticas; de Medios y Educación; The Education Digest y en redes como Flipped Learning Network y Innosight Institute, International Society for Technology in Education (ISTE) y Google Books. Dada la temática del artículo, la información revisada comprende desde 2014 hasta el presente 2017, debido a que abarcan las innovaciones en Educación en materia de integración de las TIC con la enseñanza de las Ciencias Naturales. El estudio examina el impacto generado por algunos de los recursos tecnológicos cuando estos se aplican como un medio para lograr los resultados de aprendizaje esperados en el área curricular de Ciencias Naturales.

\section{La escuela para los estudiantes del siglo XXI}

La escuela del siglo XXI ha pasado de estar centrada en la cobertura del contenido, a la formación en competencias, principalmente. También es posible identificar el cambio de paradigma en que se sustenta, pasando de un paradigma con- ductual hacia la construcción del conocimiento $y$, actualmente, se habla de un paradigma sociocontructivista.

Es en este paradigma que el desarrollo de las competencias cobra real importancia. La competencia, definida como "la capacidad de movilizar varios recursos cognitivos para enfrentarse a una situación” (Perrenoud, 2004), es trabajada en las aulas del siglo XXI a través de situaciones de aprendizaje que, como su definición, exigen en el estudiante procesos de alta demanda cognitiva que integran capacidades y otros recursos con los que cuenta el estudiante, de tal manera que va construyendo su propio aprendizaje en un entorno social del que se nutre y donde, a su vez, aplica lo aprendido. Para que los estudiantes sean competentes se debe trabajar elementos esenciales, entre ellos la articulación sistémica y en tejido de las actitudes, los conocimientos y las habilidades procedimentales dentro de las cuales estarían el manejo de los recursos tecnológicos, el desempeño tanto ante actividades, como en respecto al análisis y resolución de problemas y la idoneidad en el actuar (Tobón et al., 2008).

Los cambios generados a nivel mundial a finales del siglo XIX, con el auge que tuvieron las TIC en todas las esferas y ámbitos, por ejemplo el educativo y el económico, hicieron que el mundo en sí tuviera que cambiar. Esto ocasionó que en las instituciones educativas y otros espacios de aprendizaje coexistan comunidades generacionales diferentes, una de jóvenes y nińos y otra de adultos, que aunque tienen la oportunidad de acceder a los mismos recursos tecnológicos como medio para desarrollar estas habilidades, se diferencien en la funcionalidad que le dan a estos recursos (Cassany, 2008). Entonces se puede hablar también de estas dos generaciones como las denominó Prensky en su momento: los nativos y los inmigrantes digitales.

En la sociedad peruana, los nativos digitales no solo tienen el adicional de la disponibilidad de TIC, sino que además cuentan con un contexto diferente. Y no es que uno sea mejor que el otro, se trata de una cuestión de pertinencia según el contexto. En ese sentido, es necesario considerar que, si los estudiantes están expuestos a diversas 
experiencias, es evidente que sus conexiones neuronales debido a la plasticidad cerebral también serán diferentes, pues dadas las oportunidades de aprendizaje en ellos se establecerán nuevas conexiones que permitirán a las personas desempeñarse en otras habilidades cada más diversas (Garcés y Suárez, 2014). Es por ello importante brindar a los estudiantes diversas oportunidades de aprendizaje para así aprovechar al máximo el tipo de plasticidad que poseen y que depende de la experiencia. Esto cobra aún mayor importancia en estudiantes que tienen trastornos del desarrollo o enfermedades neurodegenerativas (Coll, 2011).

\section{Rol del docente en este siglo XXI}

En la actualidad, los docentes intentan reducir la brecha entre lo que los estudiantes quieren aprender, la forma en cómo quieren aprender y lo que ellos pueden hacer desde su experticia profesional. Así le hacen frente al problema ya documentado por Prensky, quien claramente precisaba que, como educadores de inmigrantes digitales, los docentes hablan una lengua que no es la de los estudiantes. Los docentes pretenden enseñarles un idioma completamente nuevo con el que ellos ya están familiarizados. Es decir, los docentes pretenden enseñar a los estudiantes algo que estos podrían enseñarles mejor a ellos (Prensky, 2001). Por esta razón existe todavía una gran resistencia a la integración de las TIC en la enseñanza por parte de los docentes cuya educación se realizó de forma diferente y no se encuentran familiarizados con las TIC (Sunkel, s/f). Pero también se debe destacar que hay docentes que han comprendido que su rol ha cambiado y se han visto en la necesidad de innovar el proceso de enseñanza utilizando recursos tecnológicos idóneos para apoyar a sus estudiantes; aprovechan las características de plataformas y aulas virtuales de uso libre que permiten la interactividad, la simultaneidad, la retroalimentación entre pares, la generación del inter-aprendizaje. Estas plataformas permiten brindar una diversidad de experiencias educativas y están disponibles y accesibles desde distintos dispositivos, lugares y momentos; constituyen un factor principal para el compromiso que los docentes deben tener para integrar la tecnología en sus unidades de aprendizaje, dado que esa es la forma cómo aprenden los estudian- tes de este siglo (UNESCO, 2013). Conscientes de este nuevo rol, hay docentes que administran evaluaciones en línea, mediante el uso de software que permiten la retroalimentación inmediata, así como el consecuente registro de las calificaciones obtenidas por parte de los estudiantes, generándose mayor motivación en ellos y en el aprendizaje a través de este tipo de actividades.

Si realmente se quiere generar cambios en las aulas, ya se cuenta con el principal agente de cambio: "el estudiante de hoy"; sin embargo, es necesario generar cambios en los docentes. Exponerlos a procesos de formación continua es una manera intuitiva de hacerlo; constituye una estrategia compensatoria en la adquisición de competencias en TIC para aquellos cuya formación dista mucho de la actual (Sunkel, Trucco y Espejo, 2014). La actualización docente considera ahora a docentes que tiendan a trabajar en equipo por el bien de la escuela; entre otras competencias, deberían poder elegir los contenidos pertinentes, emplear la tecnología como recurso del aprendizaje y así estar preparados para un mundo globalizado sometido a cambios constantes. (UNESCO, 2015).

\section{La enseñanza de las Ciencias Naturales en Perú}

Desde el año 2014 se han ido implementando nuevos lineamientos en materia educativa en todo el país; aunque todos son perfectibles como, es normal, sobre todo cuando en materia de currículo se trata, es primordial identificar lo que supone la enseñanza de las Ciencias Naturales. En Perú se cuenta con un currículo nacional que propone tres competencias relacionadas a esta área: (i) "Indaga mediante métodos científicos para construir sus conocimientos, (ii) Explica el mundo físico basándose en conocimientos sobre los seres vivos, materia y energía, biodiversidad, Tierra y universo y (iii) Diseña y construye soluciones" (MINEDU, 2016) estas tres competencias, al igual que las demás estipuladas en las otras áreas curriculares, se deben desarrollar integrando otras dos competencias transversales y enfoques. Una de estas es la que constituye el interés central en este artículo, la referida a desenvolvimientos en entornos virtuales generados por las TIC.

La enseñanza de las Ciencias Naturales exige que 
los estudiantes sean competentes científicamente, es decir, que puedan emplear el conocimiento científico para identificar preguntas y obtener conclusiones basadas en pruebas, con el fin de comprender y poder tomar decisiones sobre el mundo natural y sobre los cambios que la actividad humana produce en este (OCDE, 2000). Lo anterior se debe alcanzar mediante el enfoque de la indagación y la alfabetización científica. Cuando un estudiante aprende ciencias naturales con el enfoque de la indagación y la alfabetización científica, plantea preguntas acerca de un hecho o fenómeno que observa; formula posibles explicaciones sobre dichas observaciones, se involucra en una investigación que previamente diseña, colecta, analiza datos y elabora conclusiones a partir de los resultados que obtiene y su contraste con las explicaciones iniciales (National Science Foundation, 2001).

Actualmente se propone desarrollar en los estudiantes estas competencias a través de las unidades de aprendizaje (MINEDU, 2016), que son secuencias de actividades organizadas en función de una situación problemática que supone que los estudiantes usen capacidades para poderla resolver y en las que la integración de las TIC solo se puede observar en momentos específicos o en proceso de implementación paulatina.

En este punto también es necesario considerar el nivel de infraestructura escolar que se tiene en nuestro país para la enseńanza tanto en el sector privado como en el público. Hay escuelas dotadas de mobiliario escolar y espacios físicos destinados al aprendizaje de las ciencias naturales, la motricidad gruesa y cómputo. Sin embargo, los estudiantes aprenden ciencias naturales y otras áreas del conocimiento de manera integrada, donde el principal soporte son las TIC para poder lograr aprendizajes, no se dispone de aulas donde ellos tengan acceso a diversos recursos incluyendo los tecnológicos como tabletas para organizar su trabajo, aplicaciones tipo simuladores, laboratorios para experimentar las hipótesis que formularon o, mejor aún, buscar información sobre si estas ya fueron comprobadas previamente por otros estudiantes en el mundo, tener la oportunidad de interactuar con otros estudiantes en función de sus dudas, generar debates, compartir puntos de vista.

\section{Las TIC en la Educación}

La integración de las TIC al campo educativo es uno de los objetivos que forma parte de lineamientos nacionales, no solo de nuestro país sino de otros programas como el realizado por Argentina, denominado "Conectar Igualdad" del Ministerio de Educación para la educación media y la formación docente, los desarrollados por el Ministerio de Educación de Colombia como el programa "Computadores para educar", dirigido a la población preescolar, básica, media y superior; el programa "Conexión Total" con el proyecto "Red Educativa Nacional" y el programa de uso de nuevas tecnologías para el desarrollo de competencias, entre otros, que pueden ser visualizadas en el siguiente enlace http://aprende. colombiaaprende.edu.co. Colombia ha tomado seis factores de éxito para integrar las TIC en las escuelas; siendo estos: a) Las infraestructuras físicas y su mantenimiento, b) los recursos educativos digitales, c) la coordinación pedagógica de las TIC, d) la formación y actualización docente para las buenas prácticas TIC del profesorado, e) la integración de las TIC al currículo, f) la integración en los procesos organizativos y de gestión (MEN, 2013).

En Chile también hay experiencias documentadas como las estrategias dirigidas por "Enlaces" Centro de Educación y Tecnología del Ministerio de Educación (http://www.enlaces.cl/) dirigido a la Educación Básica. Brasil es otro de los países que tiene como uno de sus objetivos la implementación de las TIC. Tal es así que experiencias como el programa "UCA", que tenía las bases del Proyecto One Laptop per Child (OLPC), desarrollado por el Laboratorio de Medios del Instituto de tecnología de Massachussets (MediaLab MIT), usa la tecnología móvil, la inclusión digital y social de estudiantes, educadores y comunidad escolar; al uso pedagógico de las TIC (https:// www.media.mit.edu/).

En Perú está la experiencia del proyecto Huascarán del Ministerio de Educación que tuvo un alcance de dos etapas: La primera etapa en educación primaria y la segunda en todos los niveles 
de educación básica y a los docentes. También se debe mencionar el programa "Una Laptop por Niño", en el año 2012, llevado a cabo por la Dirección General de Tecnologías Educativas (DIGETE) del Ministerio de Educación, en el que se les proporcionó laptops $\mathrm{XO}$ a los estudiantes $\mathrm{y}$ docentes de las Instituciones Educativa del nivel Primaria, en todo el país, como una herramienta pedagógica. También está el proyecto TIC para aprender a cargo de la Organización de Estados Iberoamericanos para la Educación, la Ciencia y la Cultura (OEI) en Perú y la Dirección General de Tecnologías Educativas (DIGETE) en el 2014 en Cajamarca, en el nivel primario, para incorporar las TIC y, con ello, apoyar en la mejora de la calidad del proceso de enseñanza aprendizaje (http://educaciontic.perueduca.pe/?p=65).

Los resultados de estos programas son alentadores, como el caso de Brasil, con la implementación del programa "UCA". En medio de lo favorable que eran en cuanto a aprendizajes, existían algunas reflexiones sobre aspectos de la organización curricular, indicios de innovación educativa en la escuela y de cambios en las concepciones, metodologías y prácticas docentes. Pero es importante resaltar que no solo se puede mencionar que es suficiente la incorporación de las computadoras o las TIC, sino que adicionalmente se requieren otros elementos tan necesarios como estas y que van a la par en su proceso de implementación, como los acompañantes pedagógicos o especialistas en el proceso de cambio de las prácticas de enseñanza-aprendizaje de los docentes que implementan las TIC en sus aulas (Alderete, 2016).

\section{La integración de las TIC en la enseñanza de las Ciencias Naturales}

En los diversos niveles educativos, tanto nacionales como internacionales, se hacen múltiples intentos para integrar las TIC al proceso de aprendizaje-enseńanza de las áreas curriculares. Lamentablemente, muchas veces el foco de la atención u objetivo a lograr es dotar de TIC al proceso educativo. La implementación de materiales digitales como tabletas, computadoras, software educativos sin identificar que las TIC no son un fin en sí mismo, sino un empoderador medio para poder alcanzar los resultados de aprendizaje, (UNESCO, 2013). Los modelos de formación que han de implementarse deben responder al cambio constante e imparable que caracteriza a una sociedad del conocimiento y la información en la que vivimos; es decir, no solo se trata de fijarse en una implementación técnica o que las escuelas cuenten con los recursos tecnológicos, sino que estos recursos deben aportar al desarrollo de competencias desde un enfoque pedagógico, didáctico, reflexivo y crítico (Valencia et al., 2016), hoy enunciadas en el currículo nacional y traducidas en capacidades y desempeños.

El criterio principal para integrar las TIC en la enseñanza es que estas tienen un potencial significativo para involucrar a los estudiantes en su proceso educativo, más que tan solo formar parte del repertorio de recursos educativos con los que cuenta un docente (Stone, Franz y Breit, 2005). Desde este punto de vista, y por la experiencia, se puede decir que algo en lo que los docentes muestran interés y despliegue de esfuerzos para alcanzar es en la interactividad de sus prácticas calificadas al final de cada unidad de aprendizaje, hacer repositorios de trabajo de los estudiantes, enviar los recursos didácticos utilizados en clase como las presentaciones con diapositivas, fichas de lectura, entre otros, a través de medios digitales. Por lo tanto, la integración parcial de las TIC a través de esas acciones genera motivación e interés tanto por parte de los estudiantes como del mismo docente aunque las razones de dicha motivación son bastante distantes entre uno y otro agente educativo.

Emplear recursos de realidad aumentada, siendo que esta tecnología o grupo de tecnologías permiten realizar una combinación entre la información real y la información virtual, se convierte en una posibilidad de continuar generando oportunidades de desarrollo de la competencia científica por parte de los estudiantes (Fracchia, De Armiño y Martins, 2015). Por ello, el hecho de que los estudiantes manipulen objetos virtuales, a través de marcadores, como si se tratasen de objetos reales, tales como los generados por recursos libres y al alcance de estudiantes, docentes e investigadores, como lo son: Geogebra (https://www.geogebra. org/?lang=es), Scratch (https://scratch.mit.edu/), Kodu (https://www.kodugamelab.com/), Mind- 
craft (https://minecraft.net/es-es/) y los de realidad aumentada o 3D (https://human.biodigital. com), permiten que el estudiante realice operaciones de forma natural e intuitiva, sin necesidad de un soporte técnico diferente al que usualmente tienen; esto también es un novedoso e innovador medio de enseñanza de las Ciencias Naturales y de las demás áreas curriculares. La tecnología aplicada al campo de la enseńanza de las Ciencias Naturales genera significatividad a los aprendizajes construidos por los estudiantes, cuando esta es usada como un medio. La tecnología es un medio clave para que los estudiantes trabajen en sus concepciones alternativas. Esas explicaciones intuitivas sobre el mundo que los rodea, pero que tienen que pasar por un cambio conceptual para constituirse en una forma pertinente y científica de explicar aquello que les acontece y sobre lo que reflexionan en su día a día.

Otra de las estrategias docentes mayormente usada a lo largo de los tiempos para enseñar ciencias naturales es el laboratorio. En la actualidad existe la oportunidad de llevar a acabo laboratorios virtuales y recursos que permiten realizar el procesamiento con el consecuente análisis de datos obtenidos a partir de dichas experimentaciones virtuales y que se constituye en una aproximación bastante acertada al tan ansiado cambio conceptual por parte de los estudiantes. Existe evidencia sobre la efectividad de la estrategia de los laboratorios virtuales para trabajar la propuesta didáctica referida al estudio de la termodinámica. Se aplicó un instrumento tecnológico que permitía la detección y colección de datos en tiempo real lo cual mejoro considerablemente (hasta en un $400 \%)$ la distinción entre calor y temperatura por parte de los estudiantes. Por ello es relevante enunciar aquellos simuladores gratuitos que se tienen para la enseñanza de las ciencias, como el proyecto $\mathrm{PhET}$ Interactive Simulations de la Universidad de Colorado Boulder (https://phet. colorado.edu/), el cual ofrece simulaciones interactivas gratuitas de matemáticas y ciencias que, en un ambiente intuitivo y lúdico, están orientadas a involucrar a los estudiantes en su proceso de aprendizaje a través de la exploración y el descubrimiento. El the Molecular Workbench (http://mw.concord.org/nextgen/), proporciona simuladores para enseñar y aprender ciencia. El
Jet Propulsion Laboratory California Institute of Technology (http://space.jpl.nasa.gov/) brinda a la oportunidad de colocar parámetros deseados para acceder a vistas y simulaciones sobre los cuerpos en el Universo.

Actualmente se habla de integrar estas herramientas tecnológicas en espacios virtuales donde los estudiantes tengan acceso no solo a ellas y a otras actividades que el docente puede programar como una evaluación en línea sobre los aprendizajes generados mediante el uso de un simulador, un video, participar en un debate sobre alguna cuestión socio-científica, acceder a otros recursos en formatos diferentes o llevar el control de sus propios avances y con ello gestionar su propio aprendizaje.

La diversidad de implementación de plataformas virtuales para el aprendizaje de las Ciencias $\mathrm{Na}$ turales está permitiendo también que estas sean utilizadas y apoyen el proceso de aprendizaje- enseñanza, como es el Entorno Web de Indagación en Ciencias, creado por un equipo de la Universidad de Berkeley, California, que ofrecen recursos TIC para integrar secuencias didácticas con herramientas de gestión de clase y de evaluación (Irribaren, Furman, Podestá y Luzuriaga, 2014).

El hecho de que los estudiantes accedan a estos recursos TIC como videos, animaciones, simuladores, gráficos dinámicos que generan oportunidades para que los estudiantes puedan plantear hipótesis; diseñar, realizar experimentos y justificar sus respuestas se consolida como una herramienta en conjunto, potente para generar competencia científica y actitudes favorables tanto por parte de los estudiantes como de los otros integrantes de la comunidad educativa, como los propios padres de familia, docentes, pares, líderes de la escuela.

Una de las plataformas que ha permitido ser un soporte para los materiales de clases de ciencias naturales es la implementación del Moodle (https://moodle.org/?lang=es). Este es un espacio virtual de aprendizaje para los estudiantes y de esta forma lo que plantean es la metodología Blended learning o B- Learning, es decir, espacios de aprendizaje en un aula física con otros aprendizajes que se generan por intermedio de un aula virtual. Dentro de la Educación Básica regu- 
lar encontramos también experiencias exitosas de su implementación, como en la institución educativa Los Ángeles de España (http://plataforma.ieslosangeles.es/course/category.php?id=3).

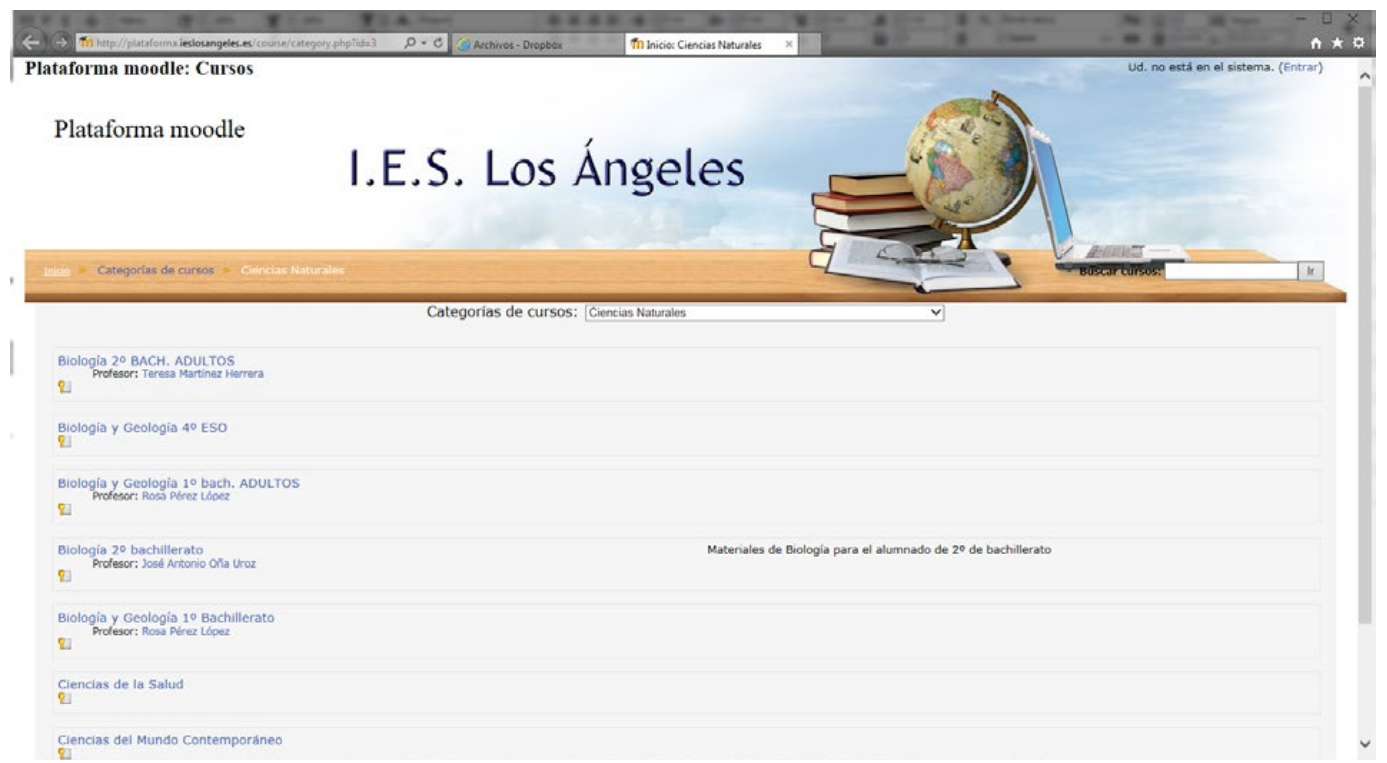

Figura 1. Plataforma Moodle de Ciencias Naturales.

Fuente: http://plataforma.ieslosangeles.es/course/category.php?id=3

Otro de estos entornos virtuales, la plataforma Edmodo, que es gratuita, permite al docente organizar sus actividades por grupos, diversificarlas, enlazarlas con otras webs, integrar aplicaciones, evaluaciones en línea, encuestas, foros y obtener los resultados para comparar y establecer planes de mejora. Edmodo funciona de un modo análogo a Facebook, pues permite que el docente pueda invitar a sus estudiantes a grupos que él previamente ha organizado; colocar fotos de actividades compartidas; dar "me gusta", comentar; participar en una temática de discusión, con el valor agregado de dar a los padres acceso para que conozcan en qué invierten el tiempo sus hijos(as), tanto a nivel de comentarios en plataforma como en el de evaluaciones calificadas, pues la plataforma proporciona un dashboard actualizado en tiempo real. Por otra parte, el docente tiene el control de los estudiantes que acceden al grupo, cómo lo hacen y la posibilidad de asignarles roles.

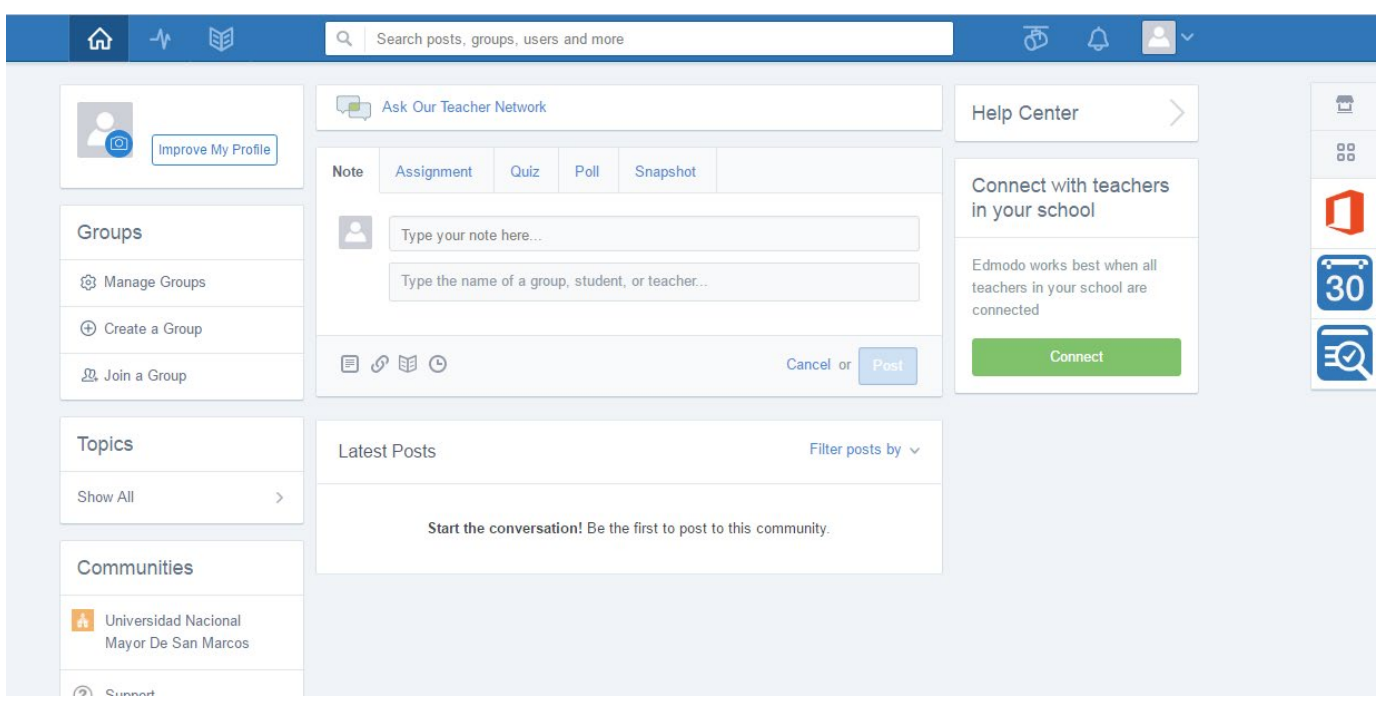

Figura 2. Inicio en la plataforma de edmodo.

Fuente: https://www.edmodo.com/?language=es 
A través de la implementación de este tipo de estrategias se ha documentado que los estudiantes pueden construir aprendizajes significativos, pues favorece la motivación hacia la participación: propicia el trabajo colaborativo e incrementa el interés de los estudiantes en situaciones de aprendizaje que se trabajan (Cuenca, 2015).

Es posible apoyar todos los contenidos curriculares usando las TIC. El éxito de esta implementación depende de la mediación pedagógica de los docentes, sus conocimientos y formas de gestionar el aprendizaje de sus estudiantes con dichos recursos (Sunkel, s.f). Estos pueden ser modelos de enseñanza que contemplen el "blended learning”, aprendizaje basado en proyectos y ambientes personalizados de aprendizaje, harán posible la incorporación educativa de juegos, redes sociales, de plataformas en línea, de videos y otros recursos tecnológicos, incluso a estudiantes de menores recursos económicos (UNESCO, 2013).

\section{CONCLUSIONES}

La integración de las TIC es un medio importante para generar aprendizajes en los estudiantes en lo que respecta a Ciencias Naturales. Existe diversidad de recursos tecnológicos, como por ejemplo los destinados a la organización y el procesamiento de datos como el uso de simuladores: recursos que desarrollan y/o refuerzan las capacidades que integran las competencias de esta área siendo una de las principales las de "Diseñar estrategias para hacer indagación" y "Generar y registrar datos o información”.

Para poder integrar las TIC a la enseñanza no solo de las Ciencias Naturales, sino de cualquier otra área curricular se puede realizar en diversos niveles considerando primordialmente la preparación de los agentes educativos (estudiantes, padres de familia, docentes y líderes de las escuelas) tanto a nivel cognitivo como actitudinal, y los recursos con los que se cuentan para acceder a la tecnología que se desea implementar siendo el objetivo, la mejora de la calidad de los aprendizajes en el área en el que se están implementando y, mejor aún, si se busca esta mejora de manera inter-áreas, en proyectos que integren las diversas áreas curriculares. Estos niveles de implementación pueden ser paulatinos, a través del uso de recursos que potencien secciones específicas de las unidades de aprendizaje o utilizando metodología como el Blended Learning o Flipped the Class, metodologías en los que la inclusión de la tecnología goza de un espacio privilegiado en tanto que hace que el momento de enseńanza de una determinada área vaya más allá del aula y en espacios gestionados por el estudiante y guiados por el docente sin que ambos estén físicamente presentes.

Se debe considerar que dentro de los retos que demanda la integración de las TIC a la enseñanza de las Ciencias Naturales, está el que los estudiantes no estén dispuestos a realizar la inversión de esfuerzo que conlleve un modo de aprender distinto al que generalmente están acostumbrados. Sin embargo se debe de tener como norte que la integración de las TIC es uno de los medios necesarios para alcanzar los resultados de aprendizaje que se espera en los estudiantes.

Además, en los entornos virtuales atractivos pero inestables, los estudiantes están comprometidos y poseen estrategias de aprendizaje en las que las plataformas virtuales se constituyen como medios privilegiados para proponer tareas que involucran participación entre pares, como por ejemplo los foros y debates tienen mayores tasas de cumplimiento que aquellas que requieren de trabajo individual. Sin embargo, la participación de los estudiantes se aleja de los criterios de calidad que el docente espera por más que estos sean establecidos como reglas de juegos, desde el inicio de la actividad. Pero evidentemente es un proceso continuo de formación, por ello la solución no está en dejar de lado la integración de las TIC al proceso de aprendizaje-enseńanza, sino que se debe ir aprendiendo en el camino, generando estrategias innovadoras.

La integración exitosa de las TIC tiene como componente central luego del actuar de los estudiantes, el de los docentes, que necesitan condiciones propicias para desempeñarse en dicha integración y capacitaciones organizadas de la misma forma, en cómo se espera que ellos se apropien de estas herramientas tecnológicas en el aula de clases. 
Otro agente sumamente importante son los padres de familia, quienes demandan la integración de las TIC, pero necesitan mayor información de lo que esto significa o significará de su parte, pues para que la integración de las TIC en la enseñanza de las ciencias naturales y, en general, de toda área, es necesario que los padres de familia estén involucrados, ya sea guiando y/o monitoreando el desempeño académico de sus hijos.

Se debe tener en cuenta que, si bien es cierto, existen materiales gratuitos, sin mayores requerimientos de software; estos no siempre están alineados al desarrollo de competencias, por lo que se deben de producir en "in house", adaptarse también es una buena opción.

\section{REFERENCIAS BIBLIOGRÁFICAS}

Alderete, M., y Formichella., M. (2016). Efecto de las tic en el rendimiento educativo: el Programa Conectar Igualdad en la Argentina. Revista Cpal. Recuperado de: https://doi. org/10.18356/c7045fd1-es.

Bergmann, J., y Sams, A. (2012). Flipped yor classroom: Reach every student in every classevery day. EEUU: International Society for Technology in Education.

Bruni, J., Aguirre, L., Díaz, H., Fernandez, A. y Barrios. M. (2008). Una mejor educación para una mejor sociedad. Propuestas para el diálogo y la transformación educativa en en América Latina y el Caribe. Federación Internacional de Fe y Alegría.

Cajiao, F. (2001). La sociedad educadora. 26. Organización de los Estados Iberoamericanos.

Cassany, D (2008). Nativos e inmigrantes digitales en la escuela. Educativa, Ed. Barcelona: Estudios e Investigaciones.

Coll, A. (2011). XII Congreso Internacional de Teoría de la Educación. Plasticidad cerebral y experiencia:fundamentos neurobiológicos de la educación. Barcelona: Dept. Psicobiologia i Metodologia de les Ciències de la Salut. Institut de Neurociències. Universitat Autònoma de Barcelona.

Coll, C. (s.f). Los desafíos de las TIC para el cambio educativo. Aprender y enseñar con las TIC:expectativas, realidad y potencialidades. Espańa: Organización de Estados Iberoamericanos para la Educación.

Cuenca, C. (2015). El foro virtual como estrategia de enseñanza en la educación superior. Hamut'ay, 2 (1) 23-31. Recuperado de: https://doi.org/10.21503/hamu.v2i1.827

Fernández, A. (2016). Modelo educativo emergente en las buenas practicas TIC. 1(18), 33-47. Recuperado de: https:// doi.org/10.12795/revistafuentes.2016.18.1.02
Fracchia, C., De armińo, A., y Martins, A. (2015). Realidad Aumentada aplicada a la enseńanza de las Ciencias Naturales. Revista Iberoamericana de Educación en Tecnología y Tecnología en Educación (16), 7-15.

Fulton, K. (2012). Upside Down and Inside Out: Flip Your Classroom to Improve Student Learning. Learning \& Leading with Technology. International Society for Technology in Education.

Garcés, M., y Suárez, J. (2014). Neuroplasticidad: aspectos bioquímicos y neurofisiológicos. Revista Ces medicina, 28(1).

Hampson M., Patton A. \& Shanks L. (2011). 10 schools for the 21 st century. Innovation Unit.

Irribaren, R., Furman, M., Podestá, M. y Luzuriaga, M. (2014). Diseño e implementación de la plataforma virtual de aprendizaje WISE en el aprendizaje de las Ciencias $\mathrm{Na}$ turales. Congreso Iberoamericano de Ciencia, Tecnología e Innovación en Educación.Argentina.

Marticorena, B. (Agosto de 2006). Tecnología y Educación. 7(2). Perú: Editorial Norma.

Ministerio de Educación Nacional de Colombia. (2013). Competencias TIC para el Desarrollo Profesional Docente. Obtenido de http://www.colombiaaprende.edu.co/html/ micrositios/1752/articles-318264_recurso_tic.pdf

Ministerio de Educación del Perú. (2016). Currículo Nacional de la Educación Básica.Obtenido de http://www.minedu.gob.pe/curriculo/pdf/curriculo-nacional-2016-2.pdf.

National Science Foundation. (2001). A Monograph for Professionals in Science, Mathematics, and Technology Education: Professional Development that Supports School Mathematics Reform. 3.

Organización para la Cooperación y el Desarrollo Económicos. (2000). Measuring Student Knowledge and Skills: A new Framework for Assessment. Paris.

Prensky, M. (diciembre de 2001). Nativos Digitales, Inmigrantes Digitales. MCB University Press, 9(6).

Proyecto the flipped classroom. (2012). Un infográfico sobre Flipped Classroom. España.

Revista Electrónica de Investigación Educativa. Recuperado de: http://redie.uabc.mx/redie/issue/archive

Revista de Investigación y Experiencias Didácticas. Recuperado de: http://ensciencias.uab.es/index

Revista Iberoamericana de Educación en Tecnología y Tecnología en Educación. Recuperado de: http://teyet-revista. info.unlp.edu.ar/

Revista Electrónica Actualidades Investigativas en Educación. Recuperado de: http://revistas.ucr.ac.cr/index.php/aie Revista Cubana de Ciencias Informáticas. Recuperado de: http://rcci.uci.cu/?journal=rcci\&page=issue\&op=archive

Revista de Medios y Educación. Recuperado de: http://acdc. sav.us.es

Sams, A., y Bergmann, J. (2012). Flip your Classroom Reach every student in every class every day. EEUU: International Society for Technology in Education. 
Schalk, Q. (2010). El impacto de las TIC en la educación. Brasil: Organización de las Naciones Unidas para el desarrollo de la Educación, la Ciencia y la Cultura.

Staker, H., y Horn, M. (2012). Classifying K-12 Blended Learning. Innosight Institute.

Stavert, B. (2013). Bring Your Own Device (BYOD) in Schools: Literature Review. (D. o. Communities, Ed.) Technology for Learning Program - Information Technology Directorate.

Stone, W., Franz, R. y Breit, L. (2005). Teaching for understanding eith technology. EEUU: Jossey Bass.

Sunkel, G. (s.f). Las nuevas tecnologías de la comunicación y la información (TIC) en la Educación. Desafíos para las políticas públicas en América Latina. Comisión Económica para América Latina y el Caribe.

Sunkel, G., Trucco, D., y Espejo, A.(2014). La integración de las tecnologías digitales en las escuelas de América Latina y el Caribe: Una mirada multidimensional. Chile : Comisión Económica para América Latina y el Caribe (CEPAL).

Thomas, R. \& Tighe, J. (2003). Backward Desing for Forward Action. 60(5).

Tobón, T., García, F., Rodriguez, S., y Lopez, R. (2008). Gestión del Currículo por Competencias: Una aproximación desde el modelo sistémico complejo. Perú: AB Representaciones Generales S.R.L.

Organización de las Naciones Unidas para la Educación, la Ciencia y la Cultura. (2013). Enfoques estratégicos sobre las TIC en Educación en América Latina y el Caribe. Chile: Organización de las Naciones Unidas para la Educación, la Ciencia y la Cultura.

Organización de las Naciones Unidas para la Educación, la Ciencia y la Cultura. (2015). Replantear la Educación ¿Hacia un bien común mundial? Francia : Organización de las Naciones Unidas para la Educación, la Ciencia y la Cultura.

Perrenoud, P. (2004). Diez nuevas competencias clave para enseñar. Barcelona: Graó.

Upside Down and Inside Out: Flip Your Classroom to Improve Student Learning. (s.f.). Learning \& Leading with Technology. International Society for Technology in Education.

Valencia, T., Serna, A., Ochoa, S., Caicedo, A., Montés, J., y Chávez, J. (2016). ICT Standards competences from the pedagogical dimension: A perspective from levels of ICT adoption in teachers' education practice. Colombia: Pontifica Universidad Javeriana. 


\section{PARES REVISORES}

Hamut'ay 4(1). Enero-junio 2017

\section{Dr. José Bernardo Peña Arcila}

Prof. Titular, Universidad Politécnica Territorial del estado Aragua. Venezuela. Integrante del Grupo internacional de investigación TEIS, Universidad de Granada,

España. Miembro Categoría B, Programa de Estímulo al

Investigador PEII y PPI 9206, Venezuela.

\section{Dr. Víctor M. Hernández Rivero}

Docente e investigador. Laboratorio de educación y nuevas tecnologías (EDULLAB). Dpto. Didáctica e Investigación

Educativa, Universidad de La Laguna. España.

\section{Dr. Walfredo Gonzales Hernández}

Docente investigador, Universidad de Matanzas, Cuba

\section{Dr. Javier Fombona Cadavieco}

Facultad de Formación del Profesorado y Educación.

Docente investigador. Universidad de Oviedo, Espańa.

\section{Dr. Jorge Norberto Cornejo}

Director de proyectos de investigación y extensión.

Gabinete de Desarrollo de Metodologías de la Enseñanza.

Facultad de Ingeniería, Universidad de Buenos Aires, Argentina

\section{Dr. Rafael Andrés Nieto Göller}

Docente investigador. Centro Universitario Internacional,

México. Universidad Simón Bolívar, México.

\section{M. en CTE. Silvia Leticia Fernández Quiroz}

Coordinadora de Proyectos Especiales. Unidad Politécnica para la Educación Virtual. Instituto Politécnico Nacional, México.

\section{Magister María de Jesús Diaz Quintero}

Docente investigador. Centro de Investigación, Desarrollo e Innovación en las TICs - CIDITIC. Universidad Tecnológica de Panamá.

\section{PhD. Héctor Mazurkiewicz}

Profesor ordinario de la Universidad del Zulia (LUZ), Venezuela. Núcleo COL, Licenciado en Educación Mención Industrial (LUZ), Magister en Informática Educativa (Universidad Rafael Belloso Chacín), Doctor en Procesos de Formación en Espacios Virtuales (Universidad de Salamanca - España) e Investigador del Consejo de

Desarrollo Científico y Humanístico (CONDES).
Dr. Ing. Jayguer Vásquez T. Msc. PhD. Coordinador del Grupo de Investigación en Digital Media. Investigador Centro de Investigación, Desarrollo e Innovación en las TICs - CIDITIC, Universidad Tecnológica de Panamá.

\section{Dr. Néstor Fernández}

Docente investigador. Editor en jefe de la Revista de Educación Abierta y a Distancia en México (READ.MX), Universidad Nacional Autónoma de México.

\section{Dra. Melba Stanziola}

Docente investigadora. Facultad de Psicología. Departamento de Psicología Clínica y de la Salud, Universidad de Panamá.

\section{M.Sc. Magda Julissa Rojas Bahamón} Magíster en Ciencias de la Educación. Especialista en Pedagogía. Ingeniera de Sistemas. Docente investigadora Grupo de investigación Lenguajes, representaciones y Educación, Universidad de la Amazonia. Miembro Comité Editorial Revista Amazonia Investiga Universidad de la Amazonia. Docente Titular IE Antonio Ricaurte. Colombia.

\section{Dra. Mercedes Leticia Sánchez Ambriz}

Coordinadora académica del módulo de Educación a distancia, Instituto Latinoamericano de la Comunicación Educativa (ILCE). Miembro del Consejo Editorial de la Revista de la Academia de Educación abierta y a distancia. México. 


\section{INSTRUCCIONES PARA AUTORES}

La revista HAMUT'AY es una publicación semestral de la División de Investigación y Extensión Científica Tecnológica de la Dirección Universitaria de Educación a Distancia de la Universidad Alas Peruanas cuyo objetivo es divulgar artículos científicos a texto completo sobre tecnologías y virtualidad y se dirige a la comunidad universitaria nacional e internacional.

Todos los artículos son sometidos a un arbitraje por parte de pares evaluadores nacionales e internacionales de amplia trayectoria en la línea temática de la revista. Los pares no son miembros del Comité Editorial ni de la institución editora.

Los artículos que se remiten a la revista deben ser originales e inéditos, no se enviaron a otra revista para su publicación y no han sido publicados.

\section{TIPOS DE ARTÍCULOS A PUBLICAR}

La revista acepta tres categorías de artículos.

Artículos de investigación científica y tecnológica (López, 2013, Publindex, 2010). Son investigaciones originales que presentan resultados de uno o varios proyectos de investigación académico-tecnológica concluidos o en proceso.

Artículos de revisión (Fernández-Ríos y Buela-Casal 2009). Son síntesis de estudios bibliográficos de un tema determinado, en el que se analiza, sintetiza y discute la información publicada de una manera integrada.

Reportes de Casos (Publindex, 2010). Son presentaciones de resultados de un estudio de caso sobre una situación específica, que da a conocer las experiencias técnicas y metodológicas consideradas en el caso.

\section{ESTRUCTURA DE LOS TIPOS DE ARTÍCULOS}

Todos los artículos deberán ser redactados con el programa Microsoft Word, usando las siguientes normas de estilo de la revista digital: tamaño pa- pel A4 con márgen izquierdo de $3 \mathrm{~cm}$. y $2.5 \mathrm{~cm}$. en los demás márgenes; fuente Times New Román, tamaño 12 e interlineado a doble espacio.

En el encabezado deberá ir el título del artículo y los nombres completos de los autores, según el orden de participación. Cada una de las páginas del artículo debe estar numerada consecutivamente.

\section{Composición de los tipos de artículos}

Los artículos de investigación científica y tecnológica (López, 2013; Bobenrieth, 2002). Se componen del título, autor(es), resumen (abstract), palabras claves (keywords), introducción (objetivos), materiales y método (participantes, instrumento, diseño, procedimiento), resultados (interpretación tablas y figuras), discusión y conclusiones, referencias bibliográficas y agradecimientos y anexos (opcional). EFACYT.

Los artículos de revisión (Fernández-Ríos y Buela-Casal 2009, p.332). Están compuestos del título, autor(es), resumen (abstract), palabras claves (keywords), introducción, método (criterios de selección de la literatura), revisión de la literatura (marco teórico del tema de revisión), conclusiones (aspectos relevantes de la revisión de la literatura y sugerencias o recomendaciones a futuro) y referencias bibliográficas. EFAR

Tablas: El título será claro, conciso y descriptivo del contenido de la tabla. Solo la palabra inicial lleva mayúsculas y no se coloca punto al final del título. Veáse modelo siguiente:

Tabla 1

Tiempo transcurrido de arranque y consumo de CPU de las herramientas de virtualización

\begin{tabular}{lcc}
\hline $\begin{array}{l}\text { Herramientas de } \\
\text { virtualización }\end{array}$ & Tiempo (s) & CPU (\%) \\
\hline Xen & $109^{*}$ & 35.14 \\
VirtualBox & 87 & 0.88 \\
\hline
\end{tabular}

Nota: Tomada de García (2010)

* Las variables de control incluyeron tipo y modelo de fuente de poder 
En el contenido de la tabla las fracciones decimales se expresarán con una coma, excepto en el Abstract donde se usará el punto. Las cifras en miles y millones se separarán con un espacio simple, en vez de comas.

Figuras: Son gráficas, fotografías, diagramas y dibujos en formato JPG de calidad alta. El título será breve y conciso. Veáse el siguiente ejemplo.

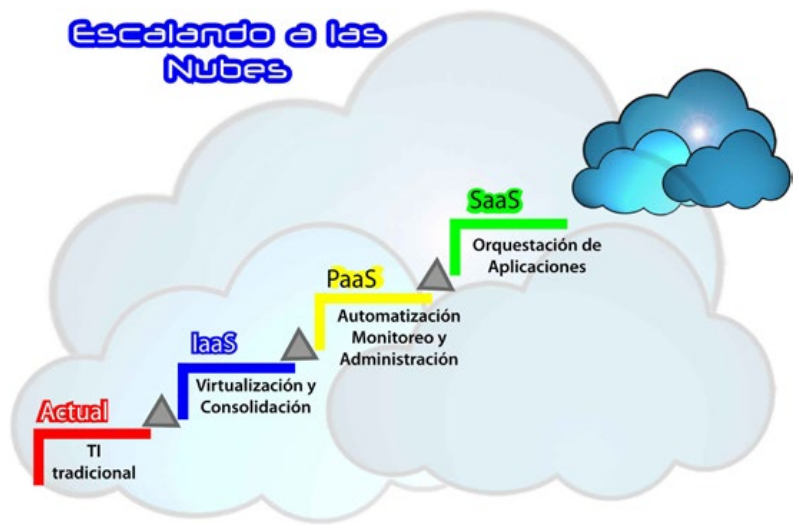

Figura 1. Escalando a las nubes.

Fuente: http://www.eikonix.mx/?page_id=113

Referencias bibliográficas. Las referencias y citas bibliográficas deberán considerar las Normas APA, Sexta Edición. Veáse los siguientes ejemplos:

\section{Artículos publicados en revistas:}

Alcalde-Alvites, M. (2016) Software libre enfocados en diversos campos de las ciencias biológicas. Revista Hamut'ay, 3 (1) 59-70.

DOI: http://dx.doi.org/10.21503/hamu.v3i1.1000

Cabero, J. (2010). Los retos de la integración de las TICs en los procesos educativos: Limites y pósibilidades, Rev Perspectiva Educacional, 49 (1), 36-61

\section{Libros:}

Cabello, R. y Levis, D. (2007), Medios informáticos en la educación a principios del siglo XXI, (p.107) 1era. Edición. Argentina: Publicaciones Prometeo Libros

\section{Capitulos de libros:}

García, A., Cocero, D., Velázquez, J., Blanco, E., Grande, M., Núñez, M.V. y Tejera, R. Aplicación de la teledetección a la gestión silvopastoral (2006). En Camacho Olmedo, M., Cañete, J. y Lara, J. El acceso a la información espacial y las tecnologías geográficas. (pp.831-842). España Granada: Editorial universidad de Granada
Tesis:

Carmona, J. (2012) Aplicaciones de la simulación tridimensional para la detección precoz de consumo de sustancias y violencia escolar en ámbitos educativos entre los años 2011 y 2012. Tesis doctoral, Universidad de Almería, Almería, España

\section{Páginas electrónicas:}

Fernandez-Rios \& Buela-Casal, G. (2009) Standars for the preparation and writing of psichology, Internacional Journal of Clinical and Health Psychology (citado el 15 de febrero del 2014), 9 (2), 329-344. Recuperado de http://www.aepc.es/ ijchp/ref-es-326.pdf

\section{ENVÍO DE ARTÍCULOS}

Los autores enviarán el artículo científico acompañado de la declaración jurada de autoría y autorización (DEJA) al Editor jefe de la revista (Dra. Cleofé Genoveva Alvites Huamaní < revistahamutay@uap.edu.pe>. Los autores recibirán confirmación de la fecha de recepción de su trabajo.

\section{PROCESO DE EVALUACIÓN DE ARTÍCULOS}

La evaluación de los artículos tiene dos fases:

Primera fase: El grupo editorial verifica el cumplimiento de los aspectos estructurales y de forma según las indicaciones para autores, en los formatos establecidos, y de acuerdo al tipo de artículo.

Segunda fase: Los árbitros (pares revisores) determinan el valor del contenido del artículo y sus aspectos metodológicos, evaluando la calidad científica del artículo. Los pares evaluadores emiten uno de los siguientes criterios: No publica, Publica con condición (levantará observaciones previa a la publicación) y publica, considerando para ello los criterios estipulados en el PEAR o PEAO o PEEC, según sea el caso. Si se da el criterio de Publica con condición se remitirá al autor para que levante las observaciones, luego éste devolverá al editor para que lo envíe al par revisor nuevamente para su decision final. En el caso de que un artículo tenga la aceptacion de un par evaluador y del otro no, para dirimir se remitirá a un tercer evaluador. 


\section{REFERENCIAS BIBLIOGRÁFICAS}

Asociación Americana de Psicología. (2010). Manual de Publicaciones. México: El Manual Moderno S.A.

Bobenrieth, M. (2002) Normas para revisión de artículos originales en Ciencias de la Salud. Revista Internacional de Psicología Clínica y de la Salud, 2 (4) 509-523.

Fernandez-Ríos, L. y Buela-Casal, G. (2009) Standards for the preparation and writin of Psychology review articles. Revista International Journal of Clinical and Health Psychology, 9 (2) 329-344.

López, S. (2013) El proceso de escritura y publicación de un artículo científico. Revista Electrónica Educare, 17 (1), 5-27. Recuperado de http://www.revistas.una.ac.cr/index. php/EDUCARE/issue/current.

Romani, F. (2010) Reporte de caso y serie de casos: una aproximación para el pregrado. Revista CIMEL 15 (1), 46-51 recuperado de http://www.redalyc.org/articulo. oa?id=71720941013.

Publindex (2010) Documento Guía, servicio permanente de indexación de Revistas de Ciencia, Tecnología e innovación Colombianas, Base Bibliográfica Nacional-BBN, Índice bibliográfico nacional Publindex-IBN. 